\title{
Overview of the donation register of the Confraternity of St Anne of the Iceland Merchants, Hamburg
}

This document belongs as additional material to the publication Bart Holterman, The Fish Lands. German trade with Iceland, Shetland, and the Faroe Islands in the late 15th and 16th century.

The donation register of the Hamburg Confraternity of St Anne of the Iceland Merchants consists of two volumes, one for the years 1533-1628 (Staatsarchiv der freien Hansestadt Hamburg, 612-2/5, 2, Bd. 1), the other for 1629-1657. (Bd. 2). Both contain lists of donations from ships returning from the North Atlantic islands to Hamburg, and from the late 1590s onwards also of single donations. Every row in the following table corresponds to a distinct list in the register. A full transcript of the first volume can be found in the online source database HANSdoc, https://hansdoc.dsm.museum/Docs/15330000HAM00.html.

Explanation of the columns:

Destination: The harbour or region from which the ship returned to Hamburg. Sometimes these are indicated; often they can be reconstructed with other evidence such as licences, or by analogy with other years, if the same group of merchants appears year after year in the same harbour.

Name: Usually, the donations are mentioned as being from someone's ship (e.g. "up Jurgen vam Hagen sinen schepe"). This is the skipper, the leading merchant or the shipowner.

Skipper: The skipper of the ship, who does not have to be the same person as the one listed under "name". Not always mentioned.

Merchants: Only the most important merchants on board. As these are not always explicitly mentioned, persons have been included here who donated significantly more than others on board (in Hafnarfjörður also usually the ones who donated kerckenfisch, i.e. the donations for maintenance of the church in Hafnarfjörður), or who appear in other sources, e.g. licences, as important persons in the trading companies.

$\mathrm{N}$ : Total number of donations.

M: Number of merchants on board. Note that often no distinction is made between merchants, servants, and crew members.

S: Number of servants on board (if not indicated, these are usually listed among the merchants). 
2 Overview of the donation register of the Confraternity

C: Number of crew members.

D: Type of donations (f: fish; h: herring; m: money; s: sulphur).

K: Donations for the church in Hafnarfjörður (kerckenfisch).

Data in square brackets have been reconstructed from other sources. Names displayed in italics refer to licence holders. 


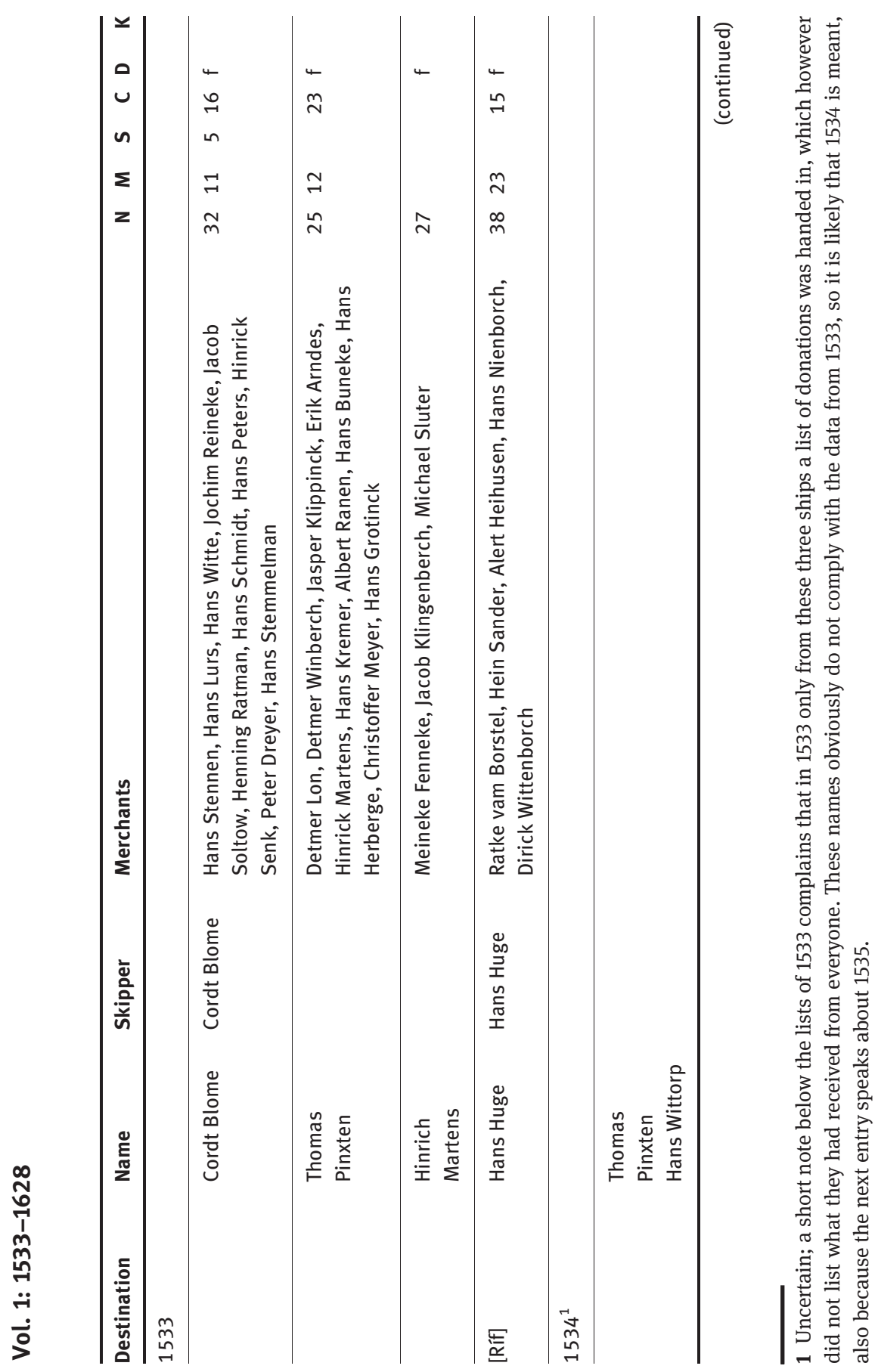


4 Overview of the donation register of the Confraternity

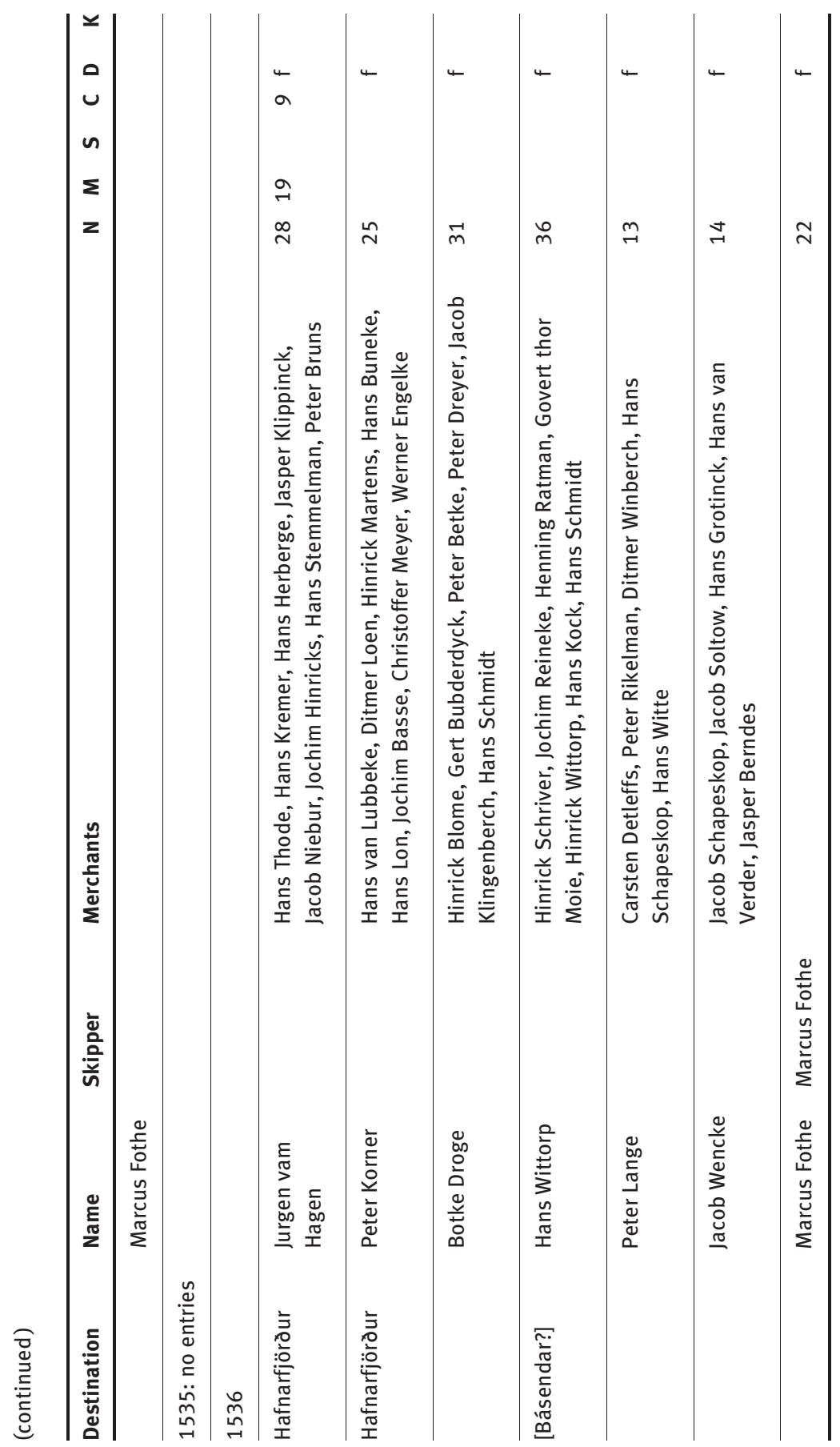




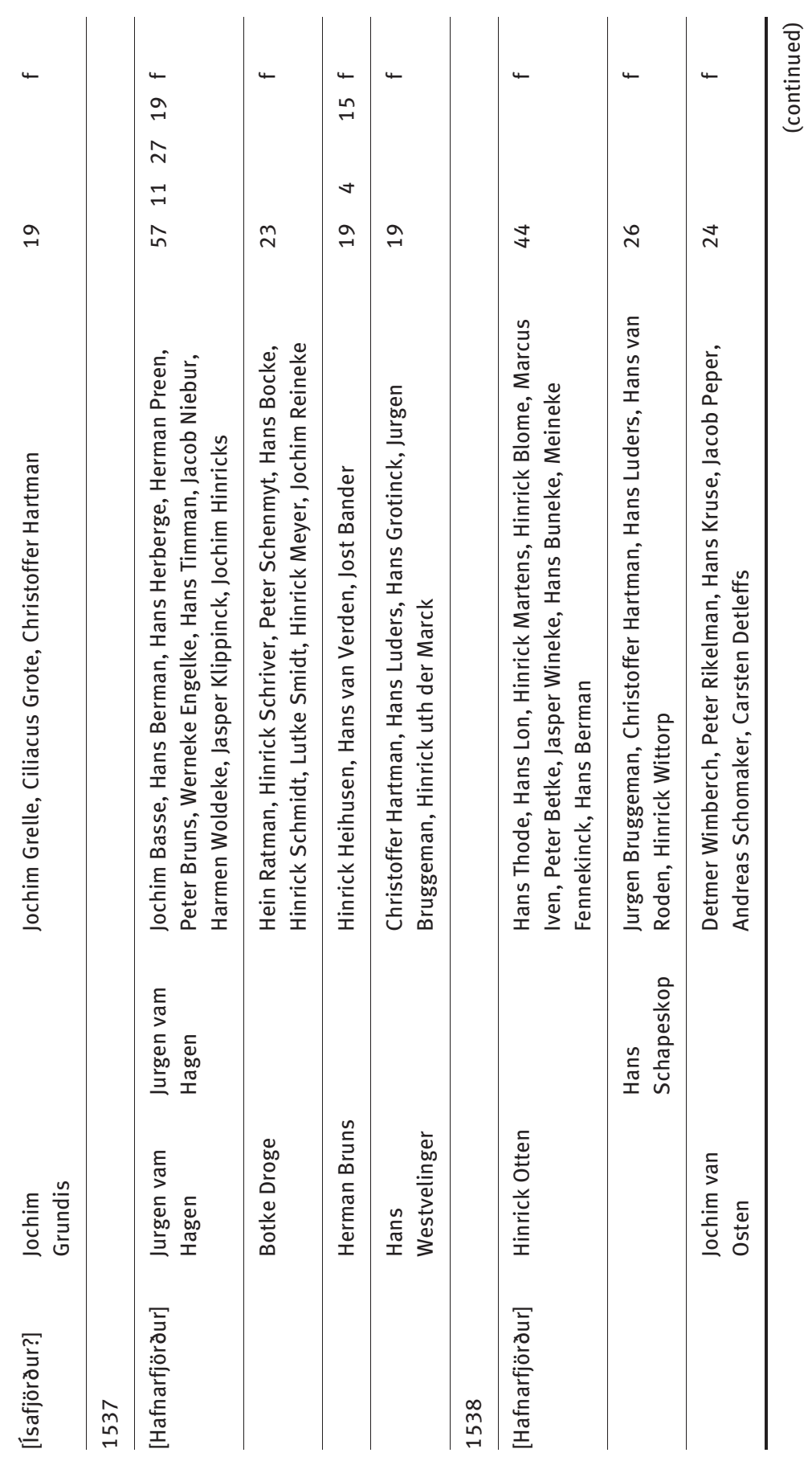




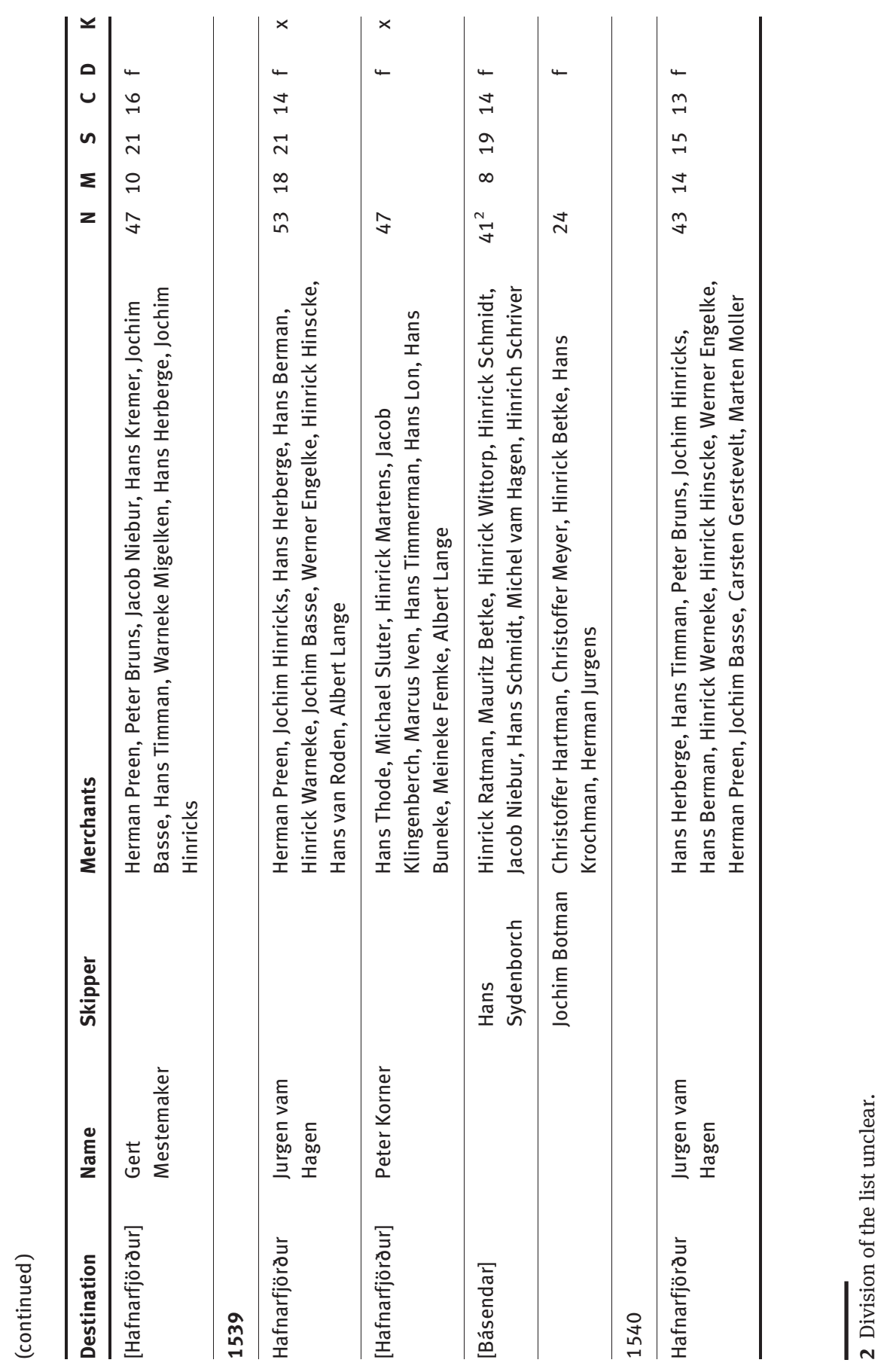




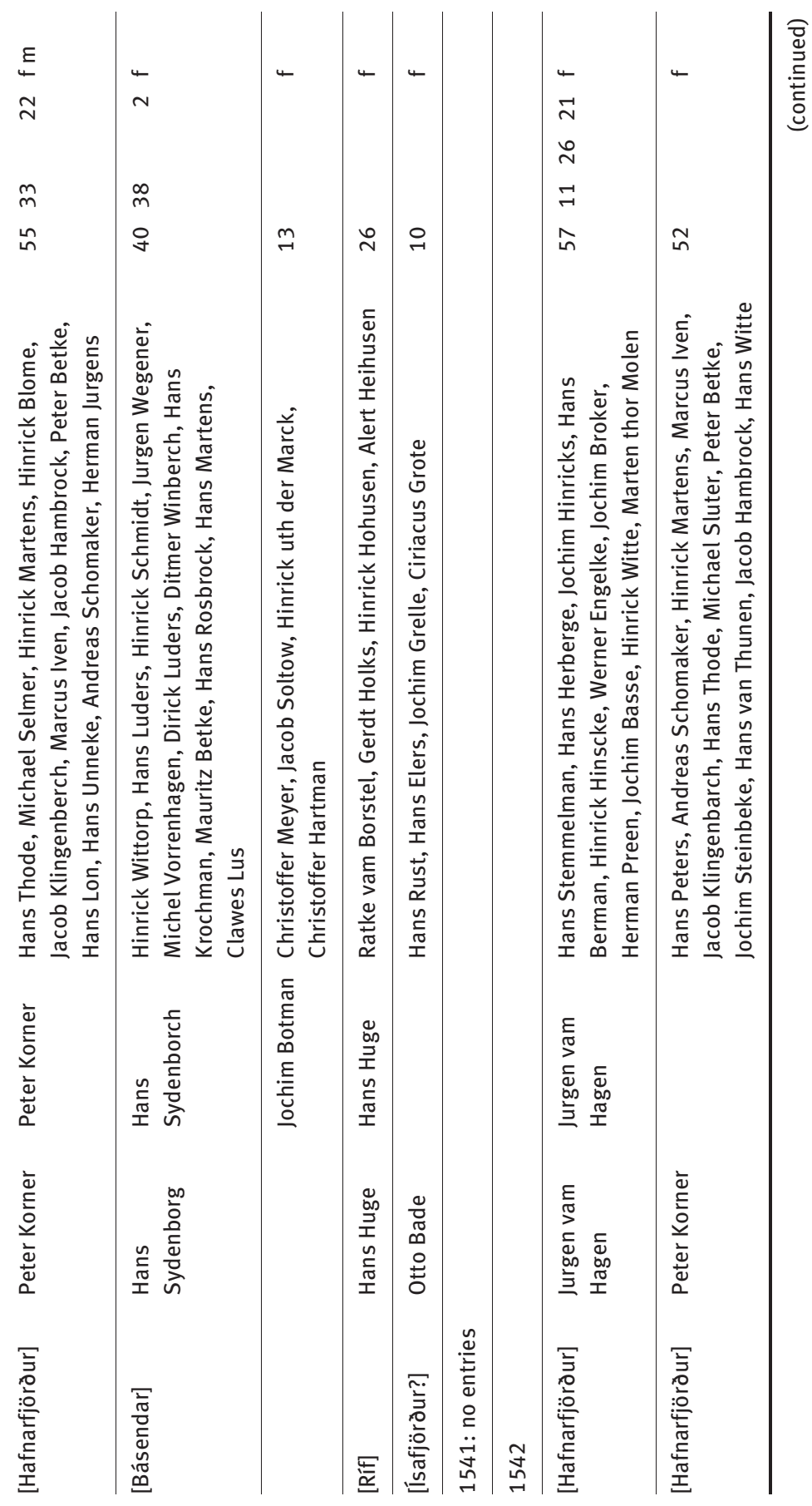




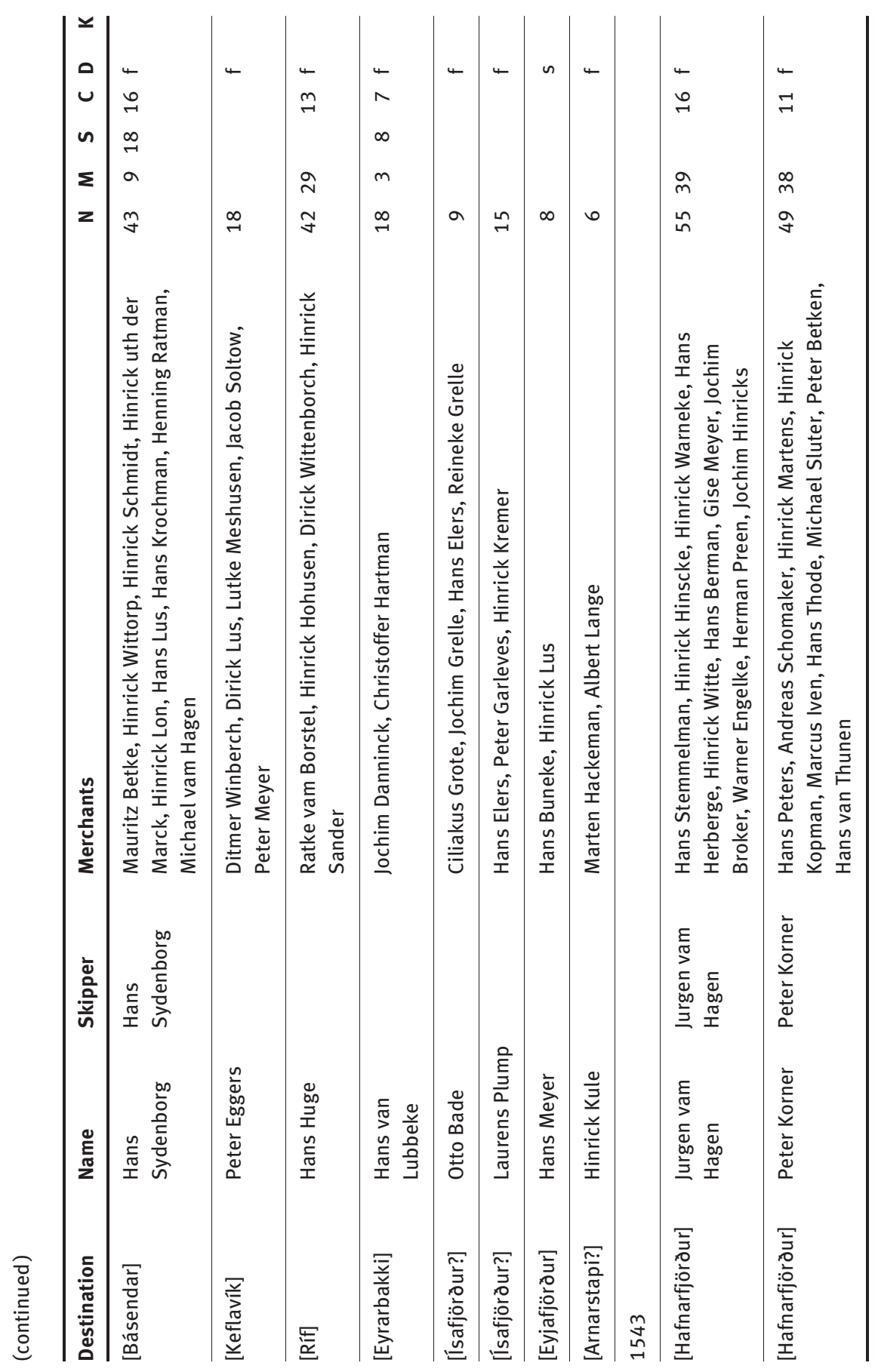



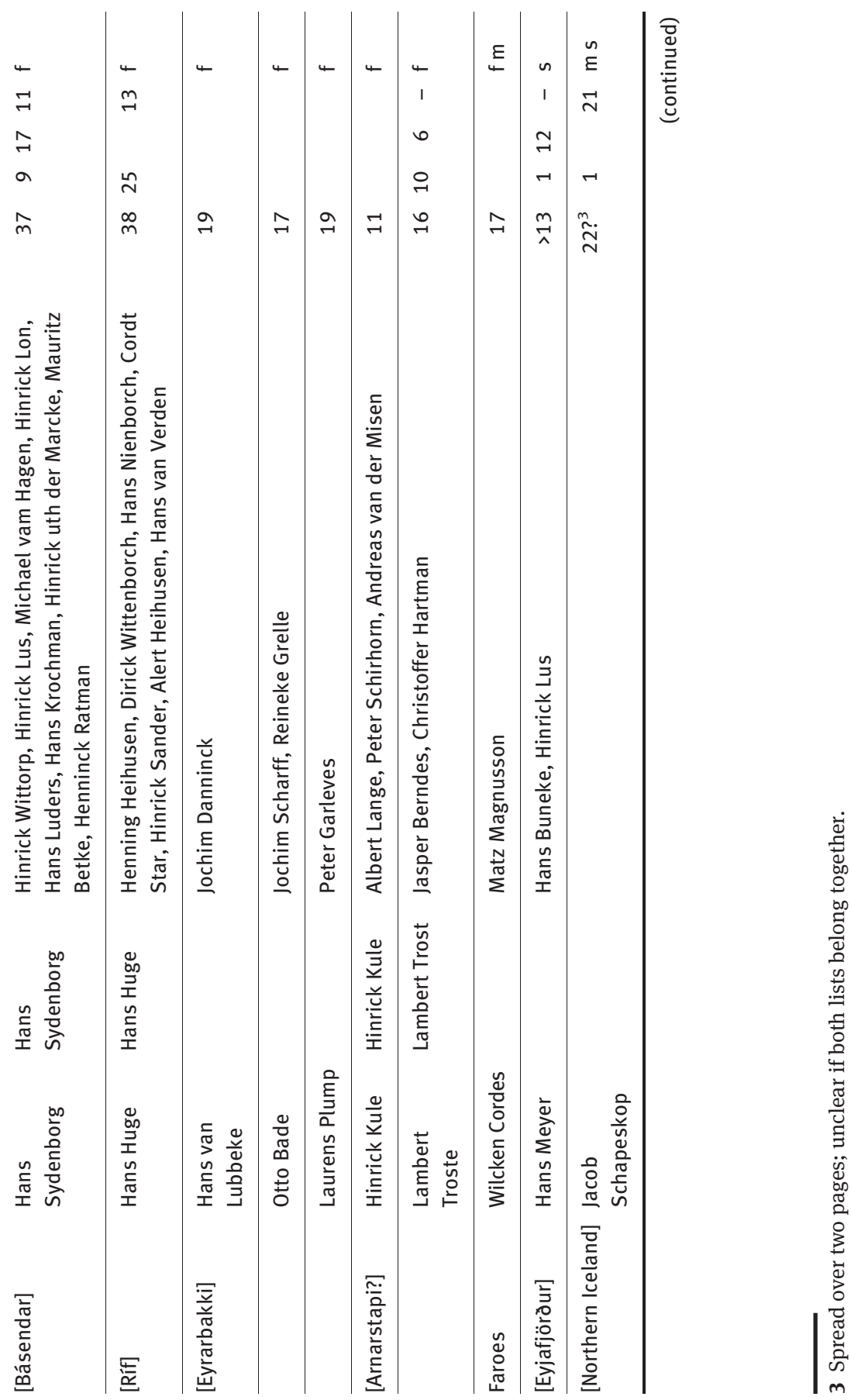


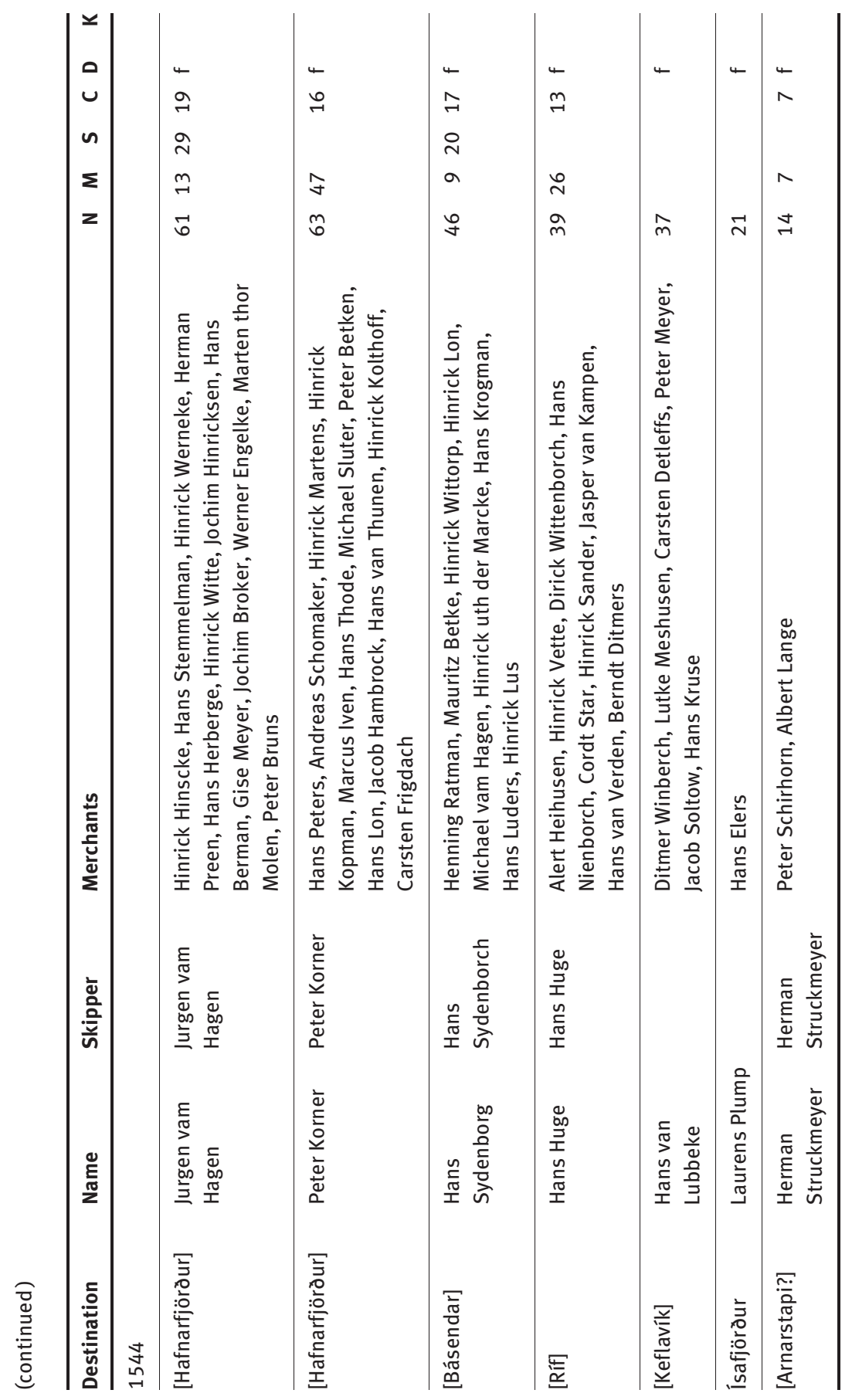




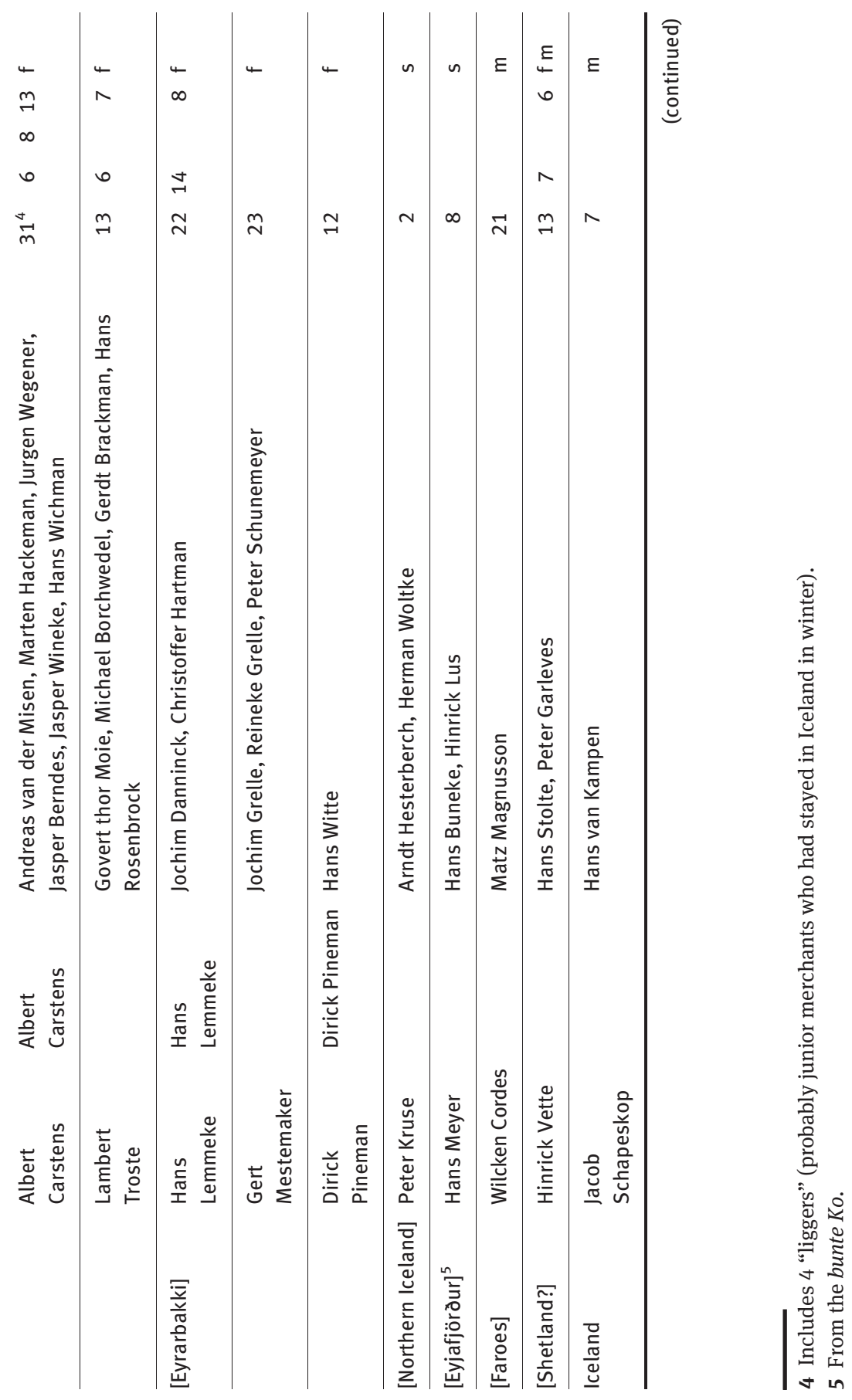




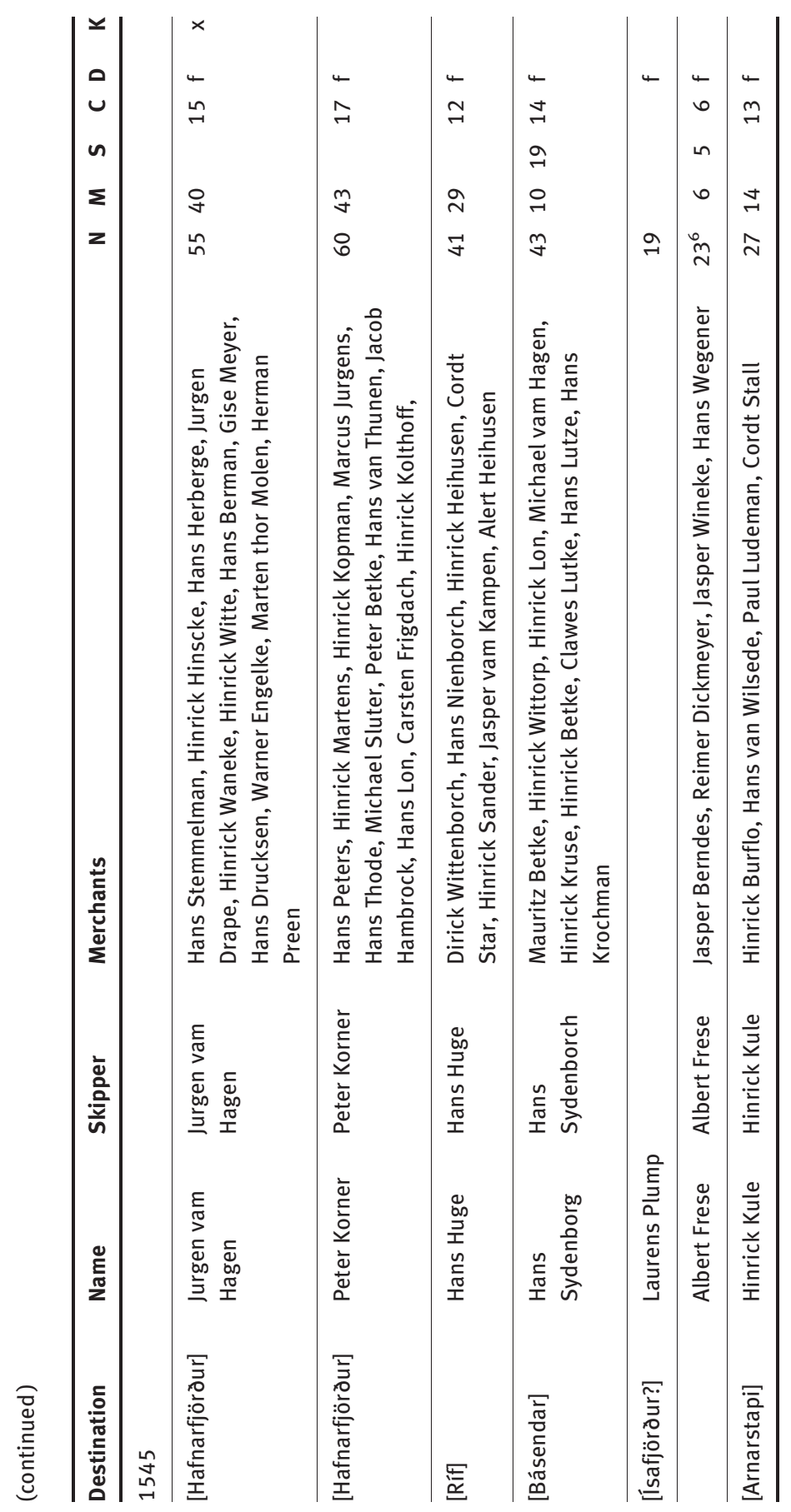

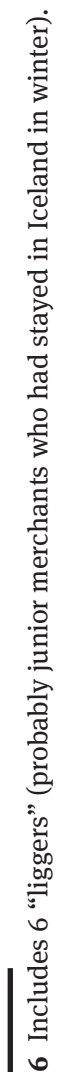




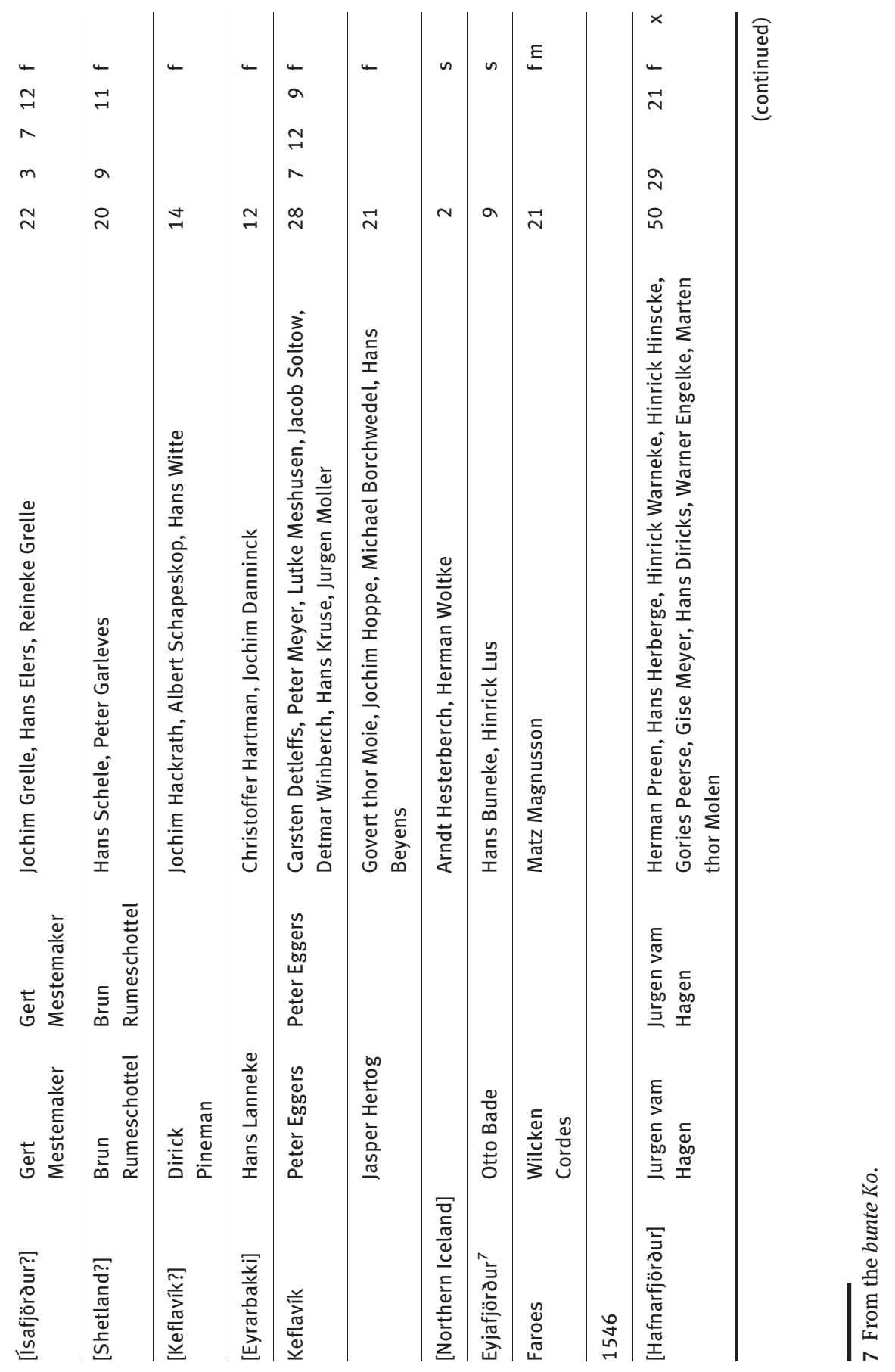




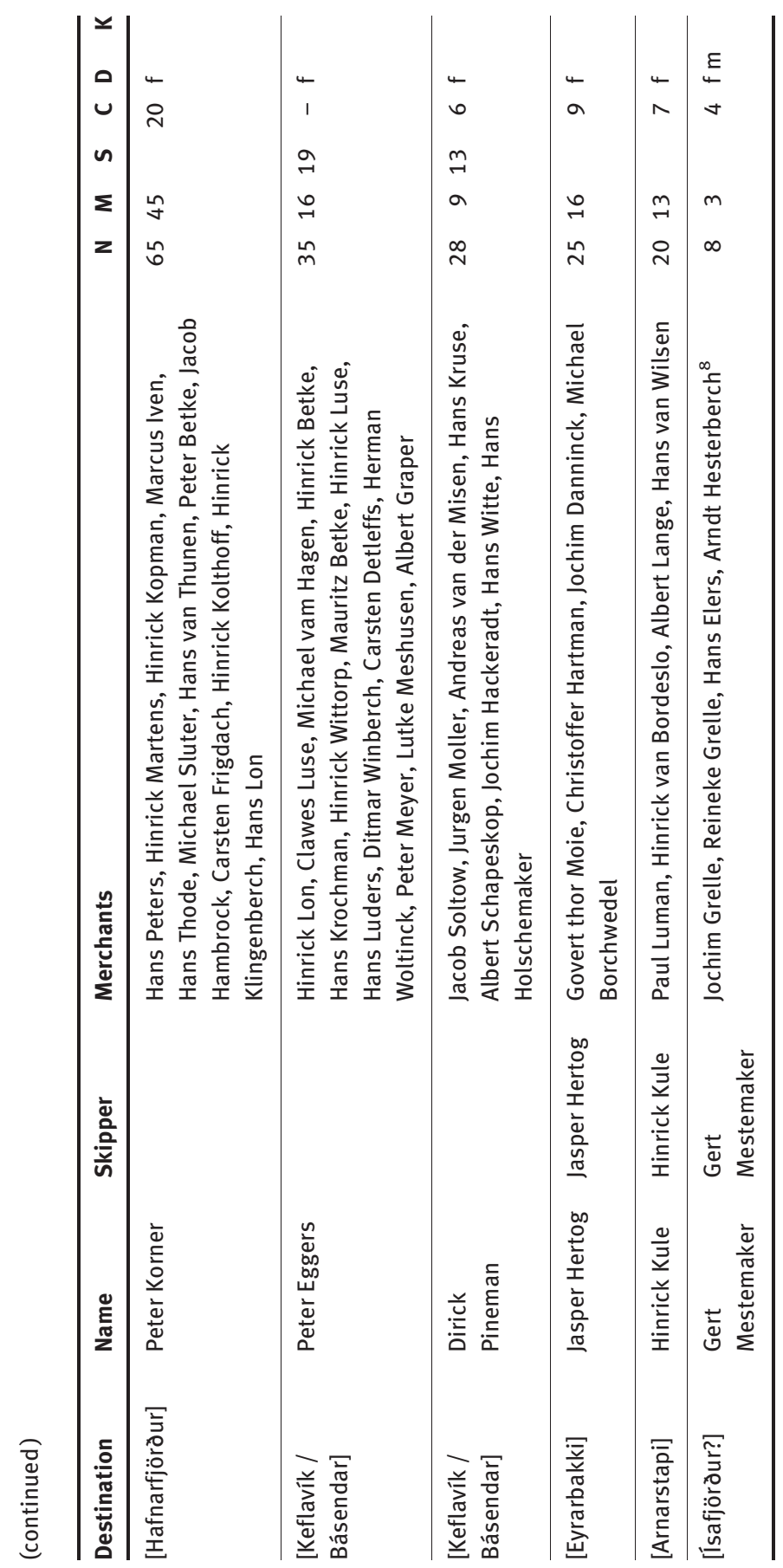

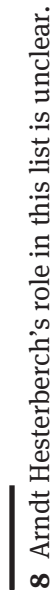




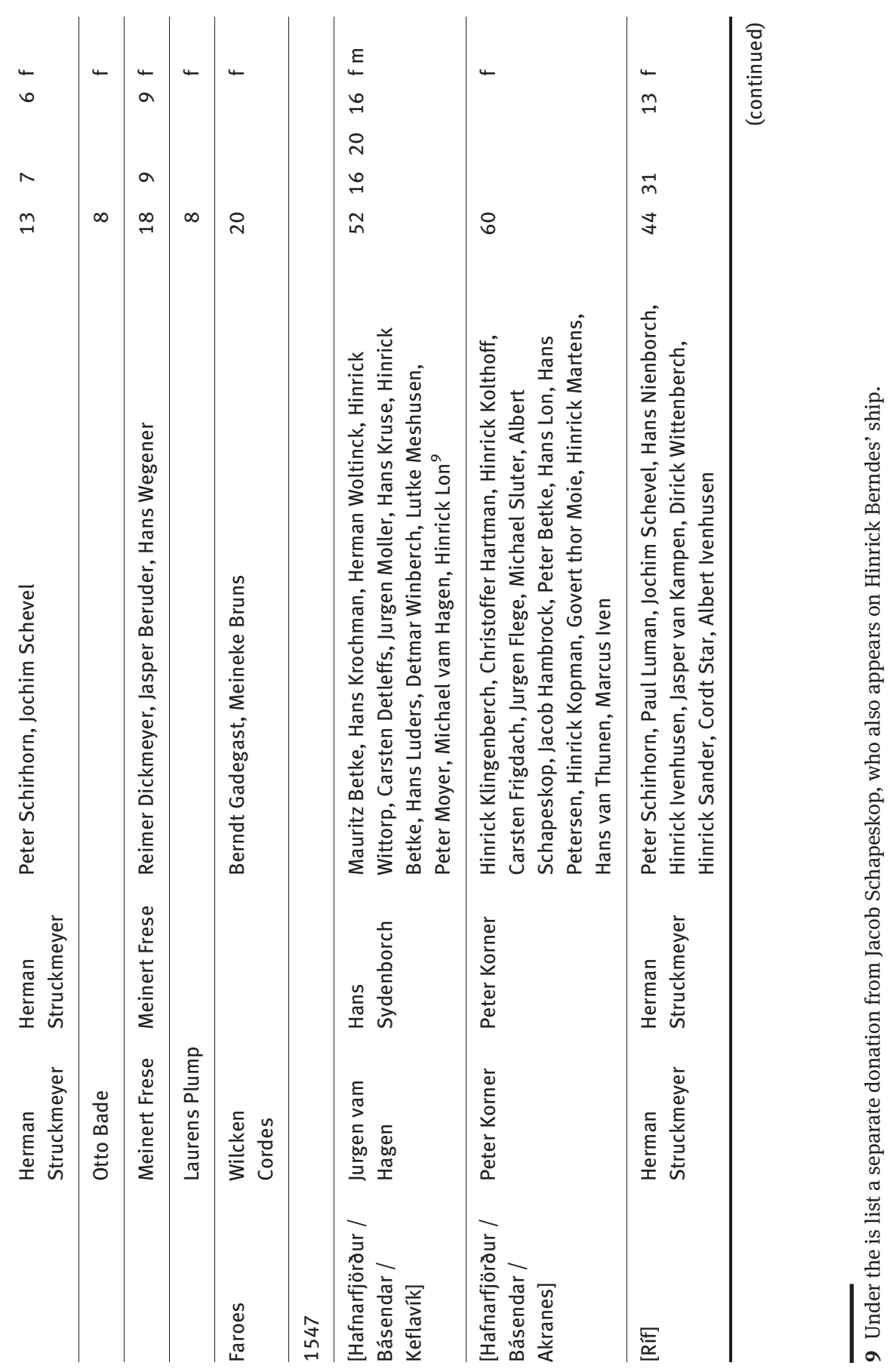




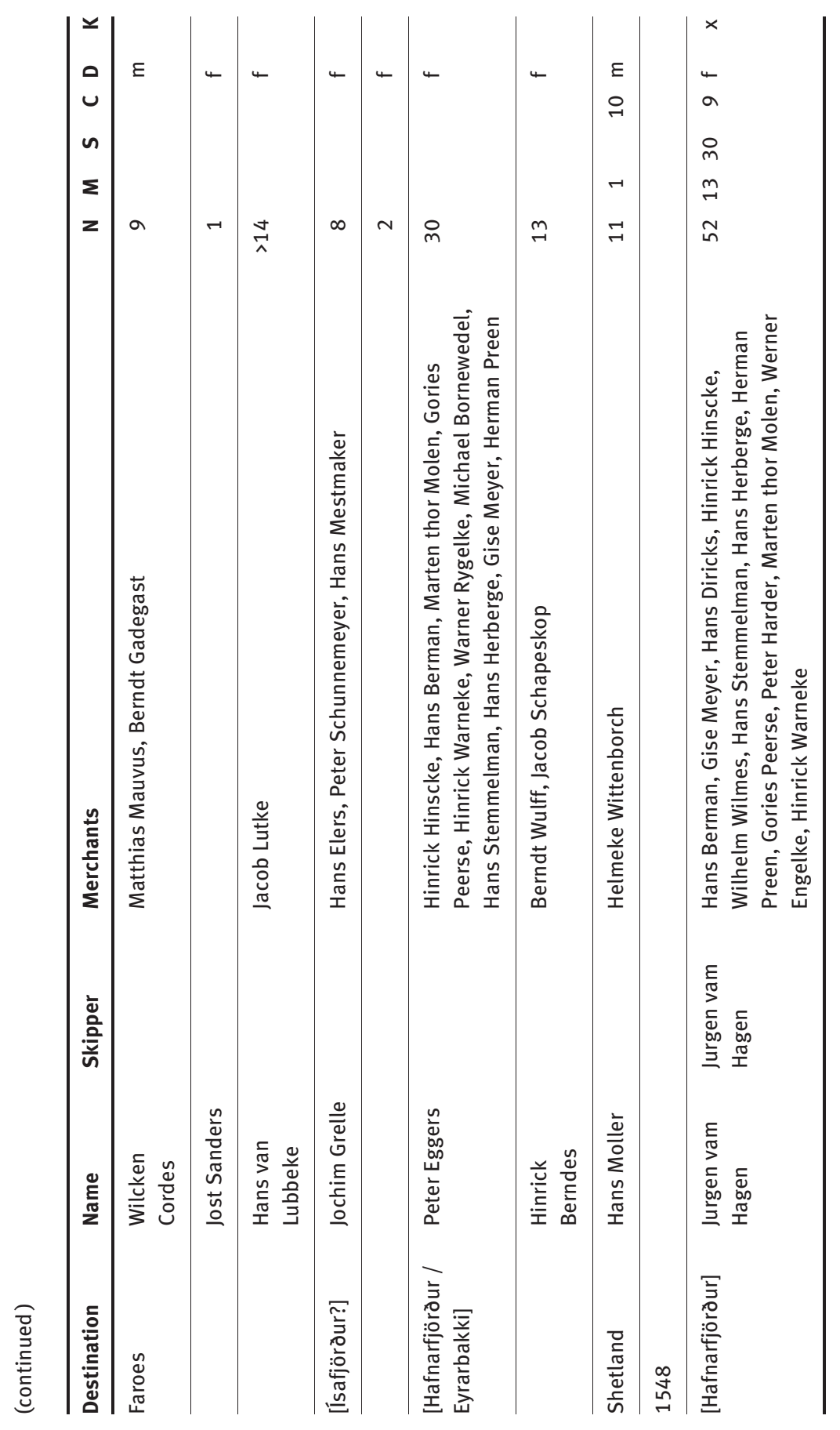




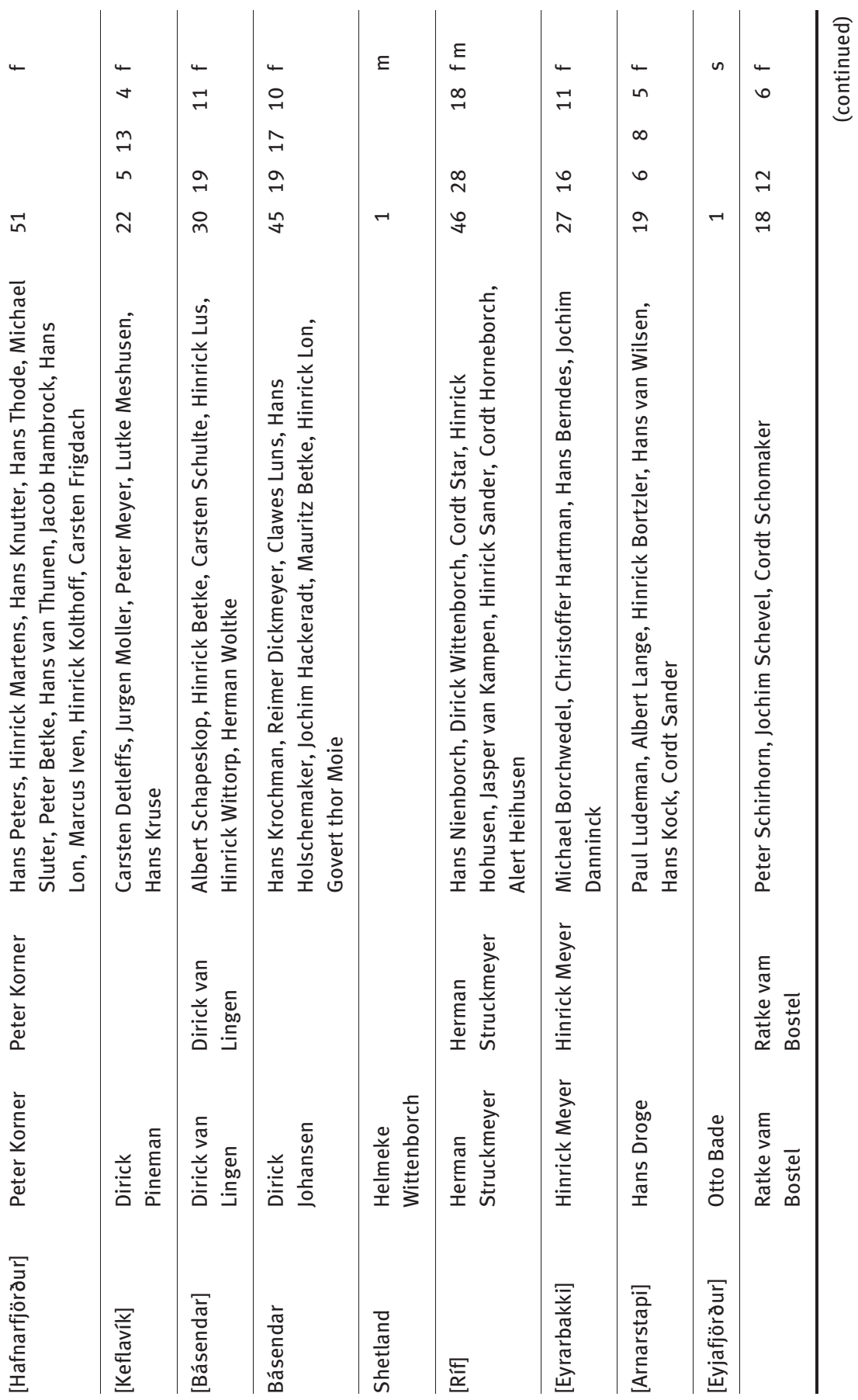




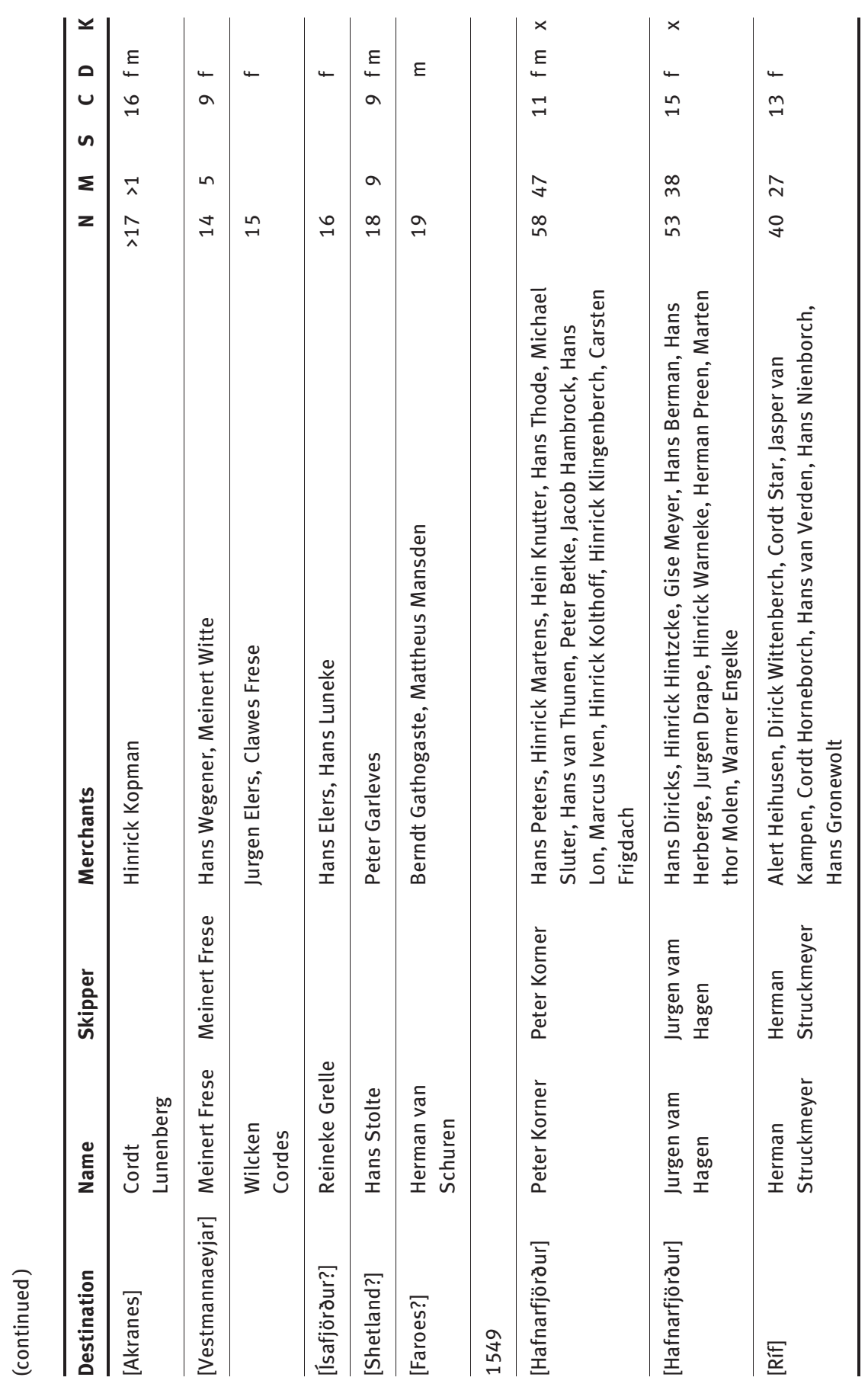




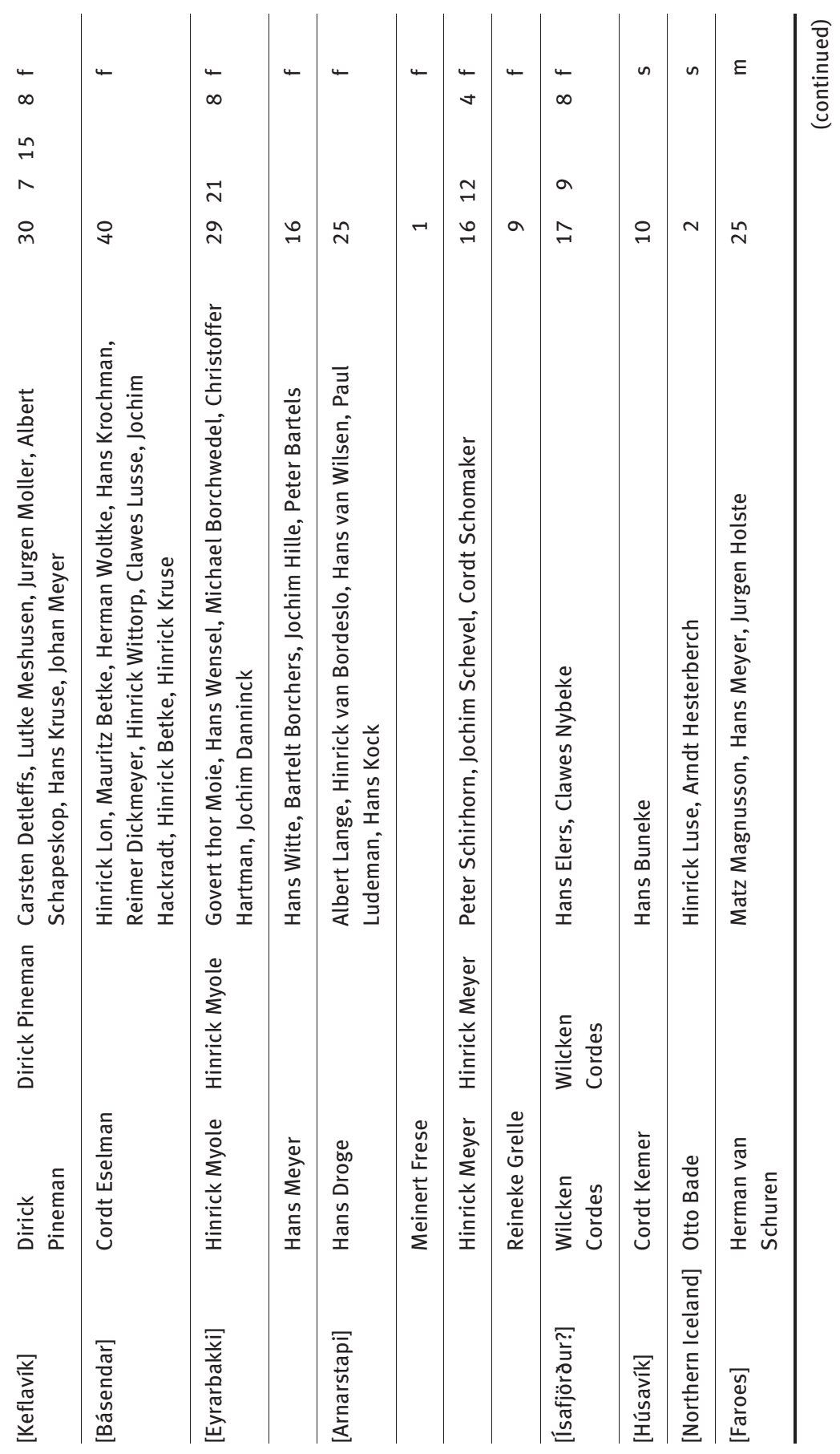




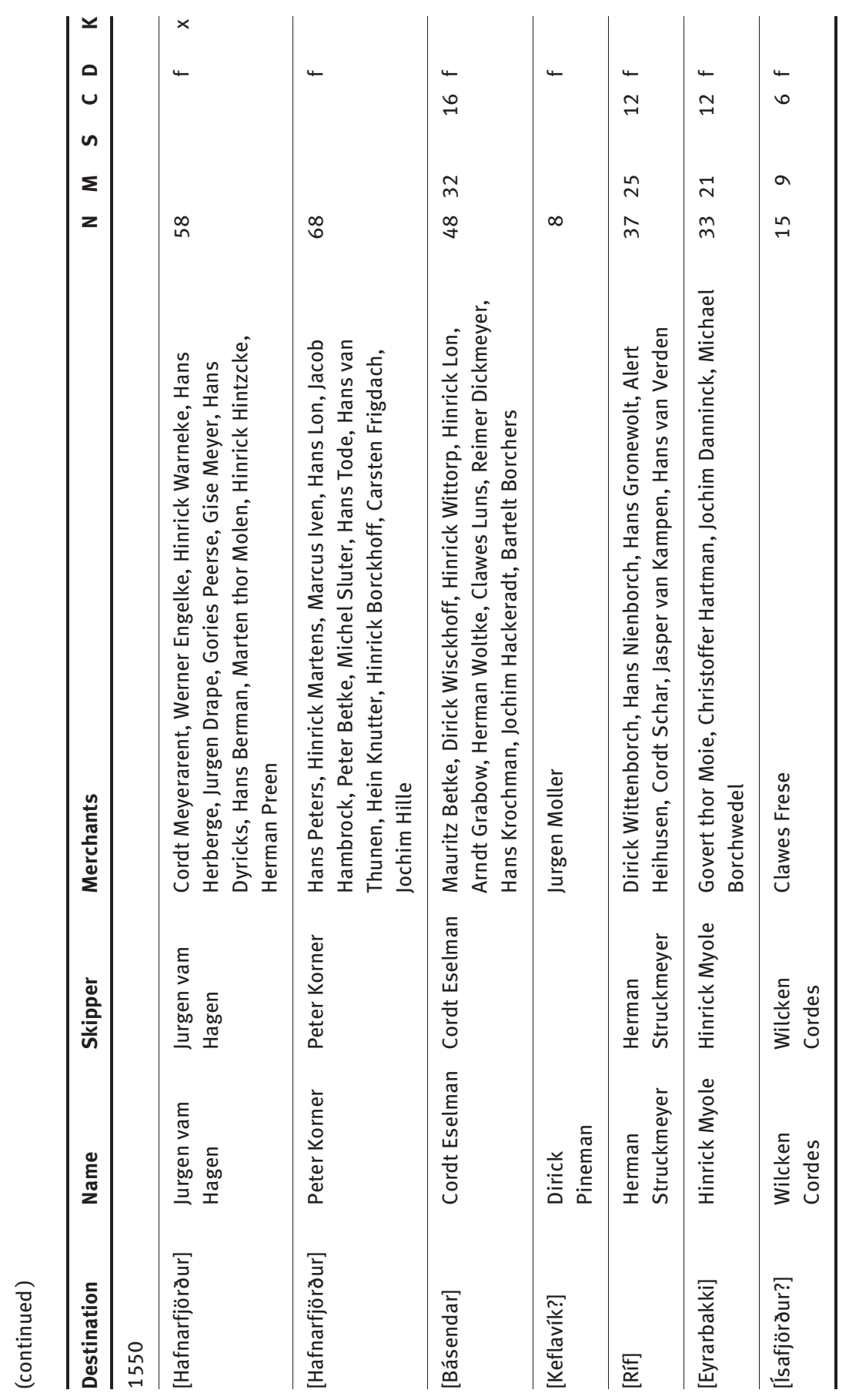




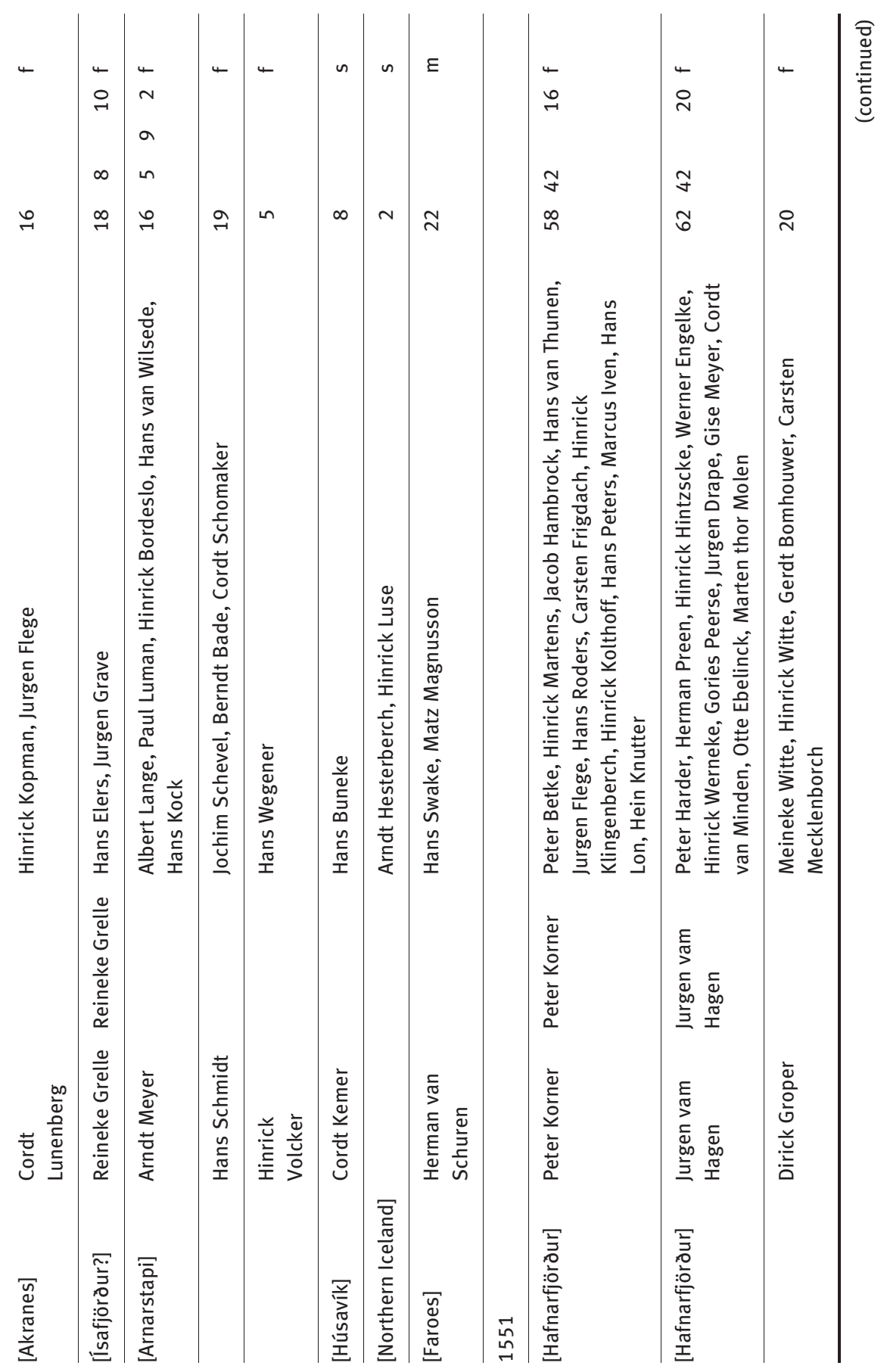




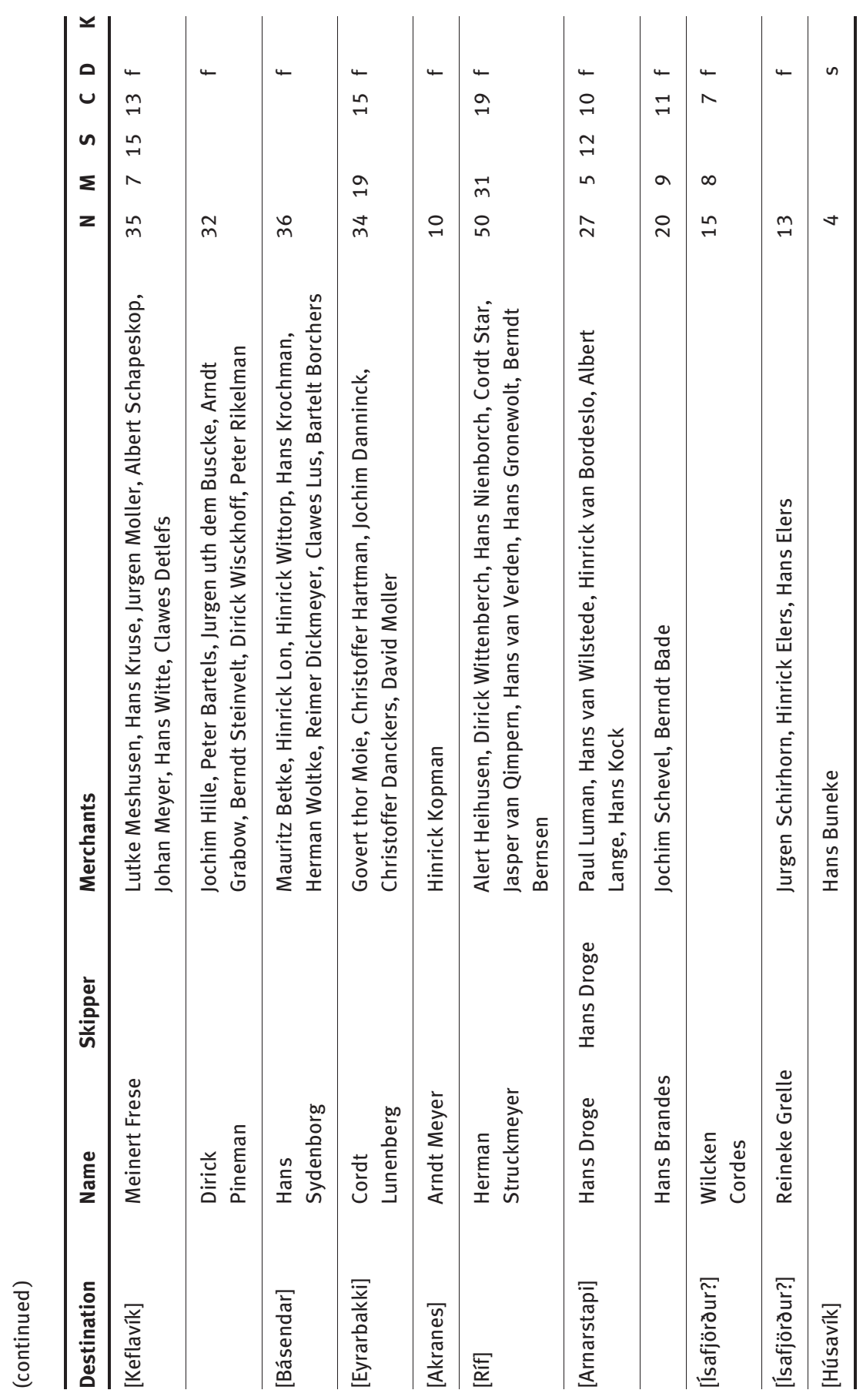




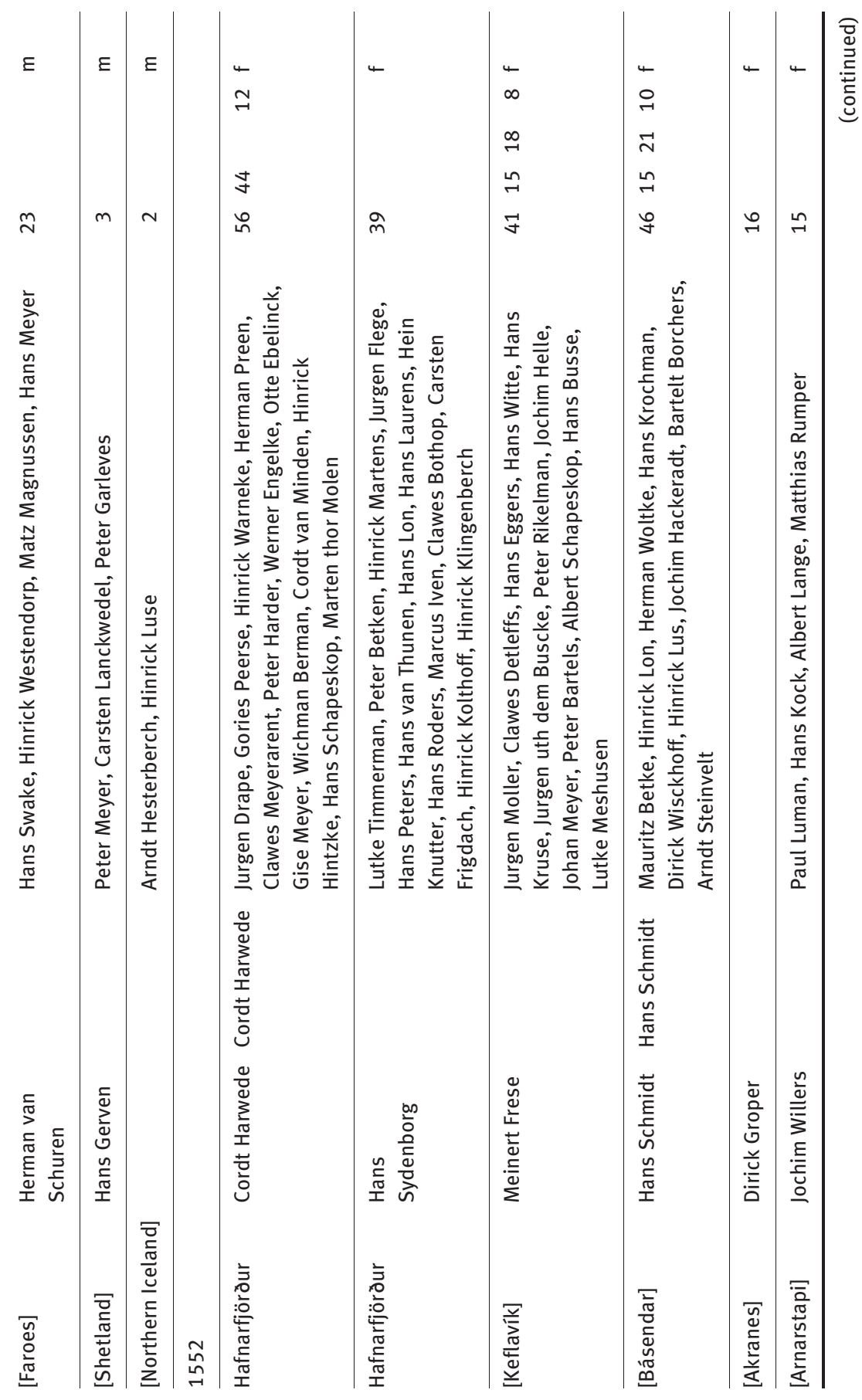




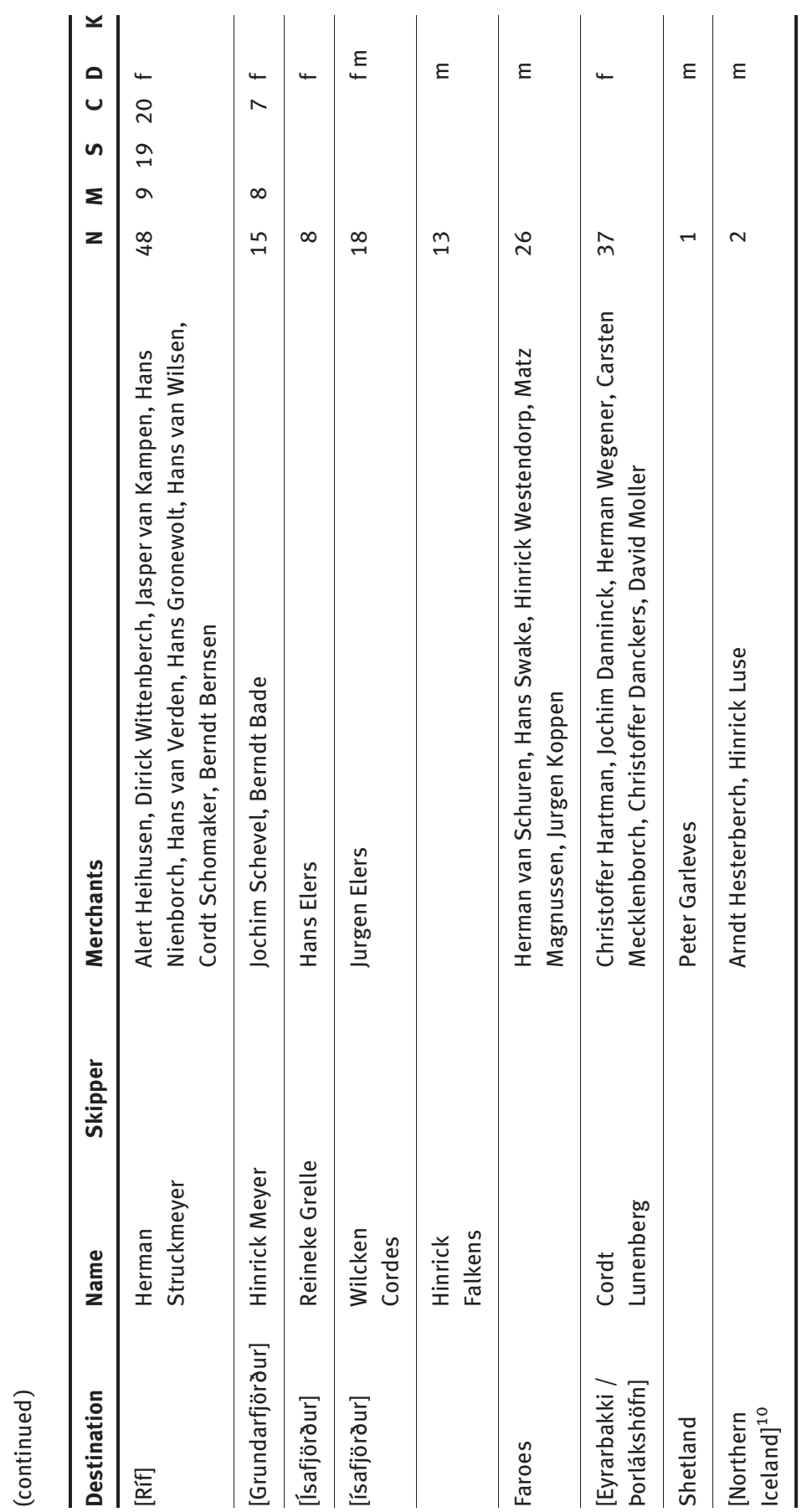

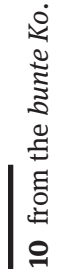




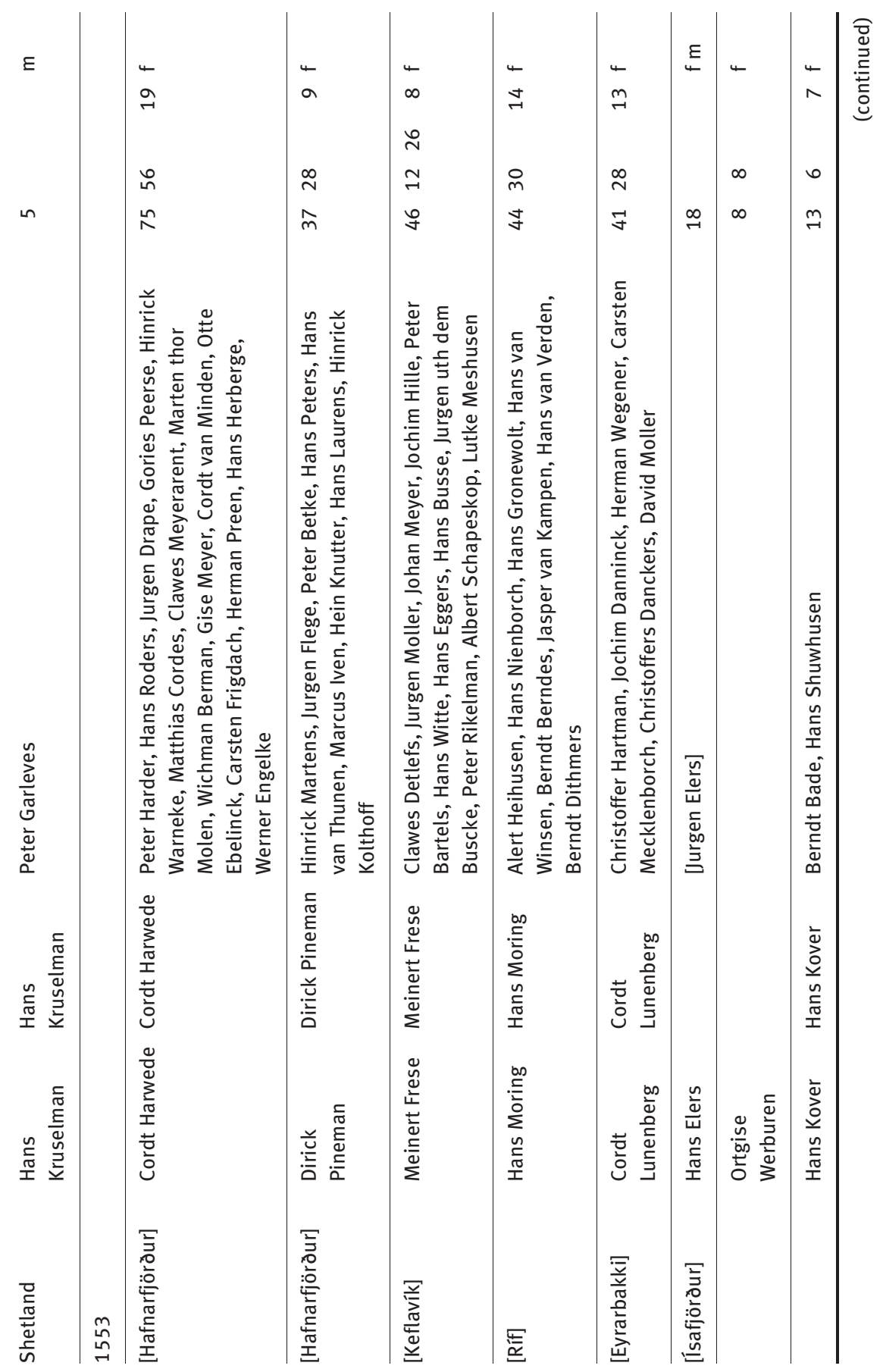




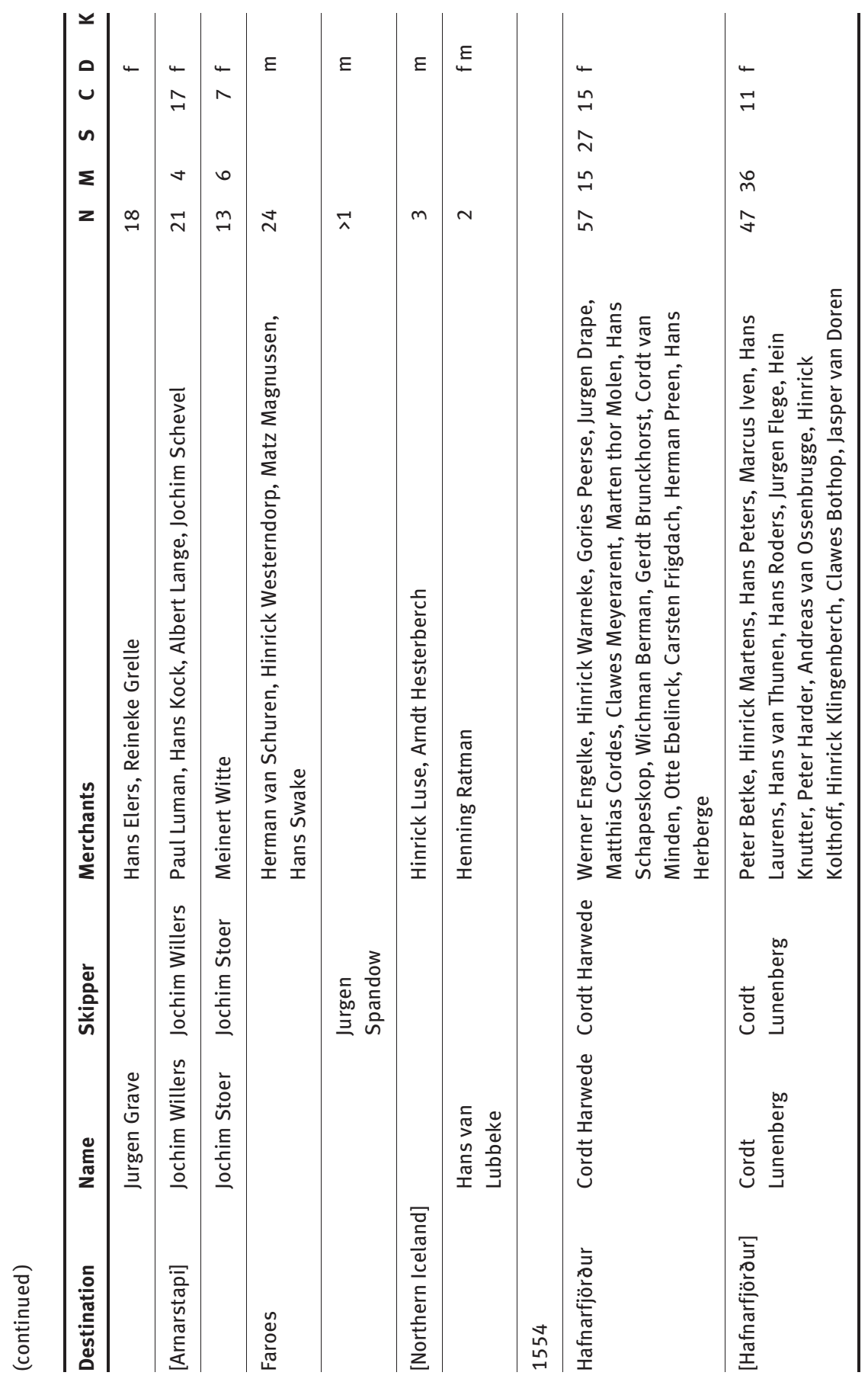




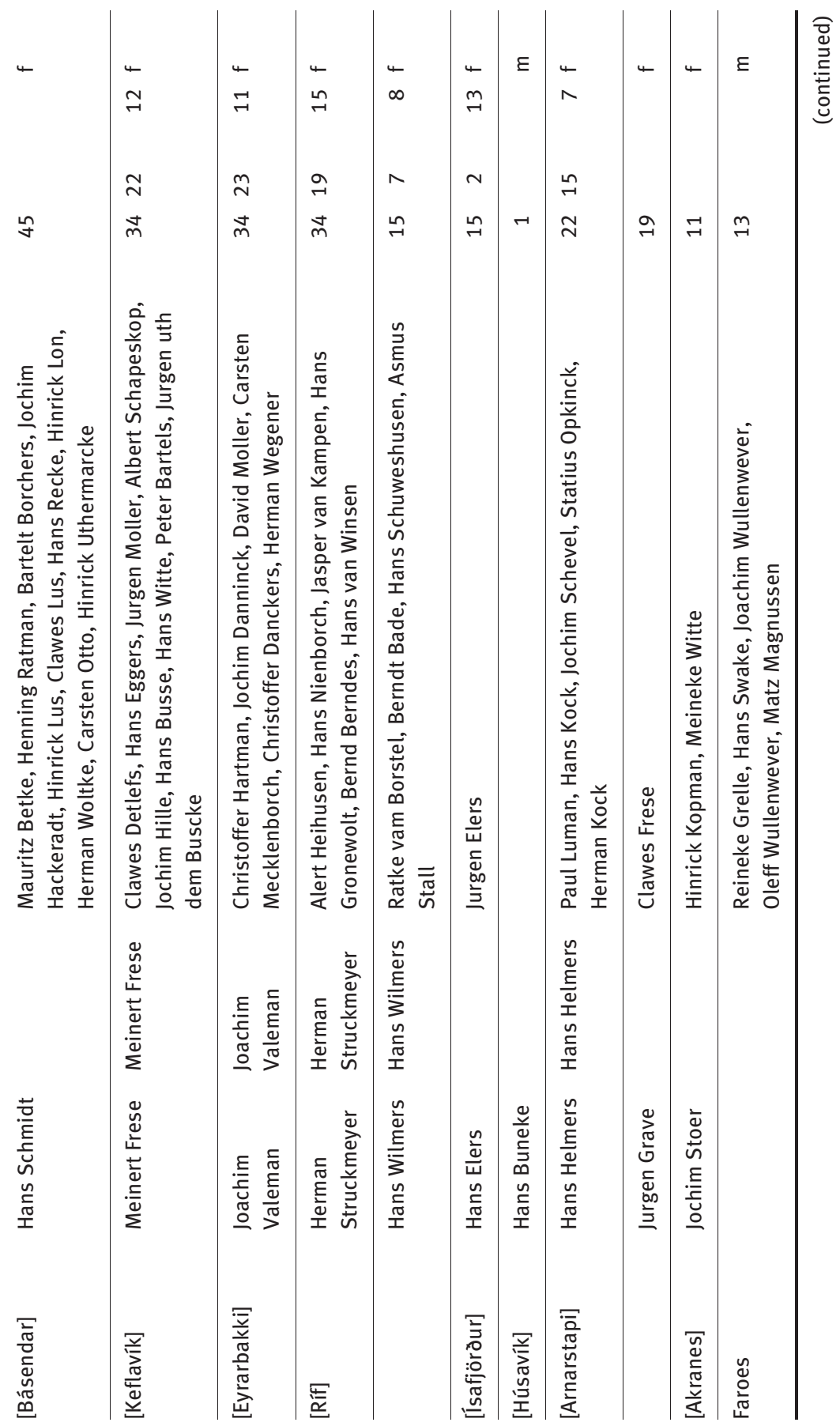




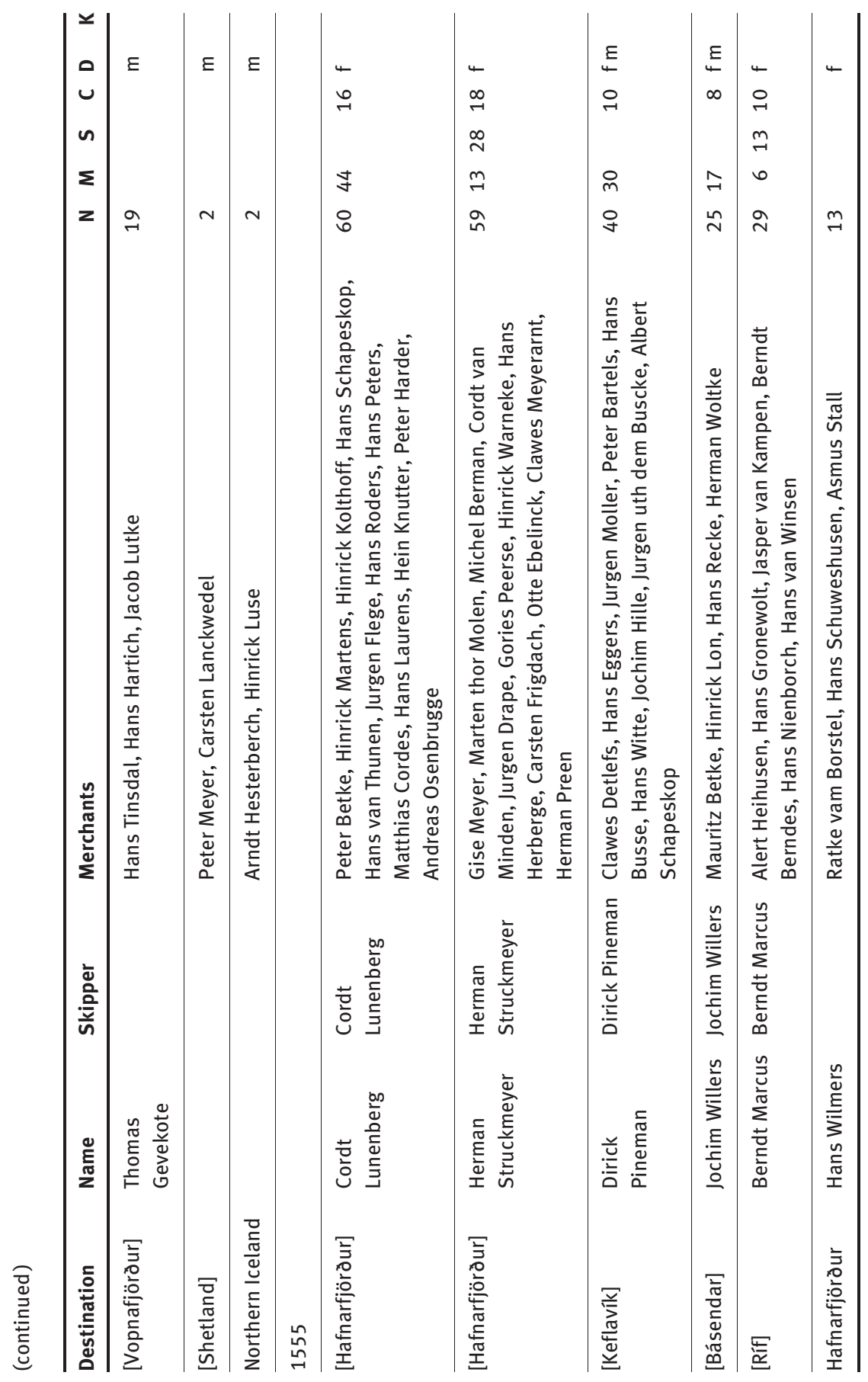




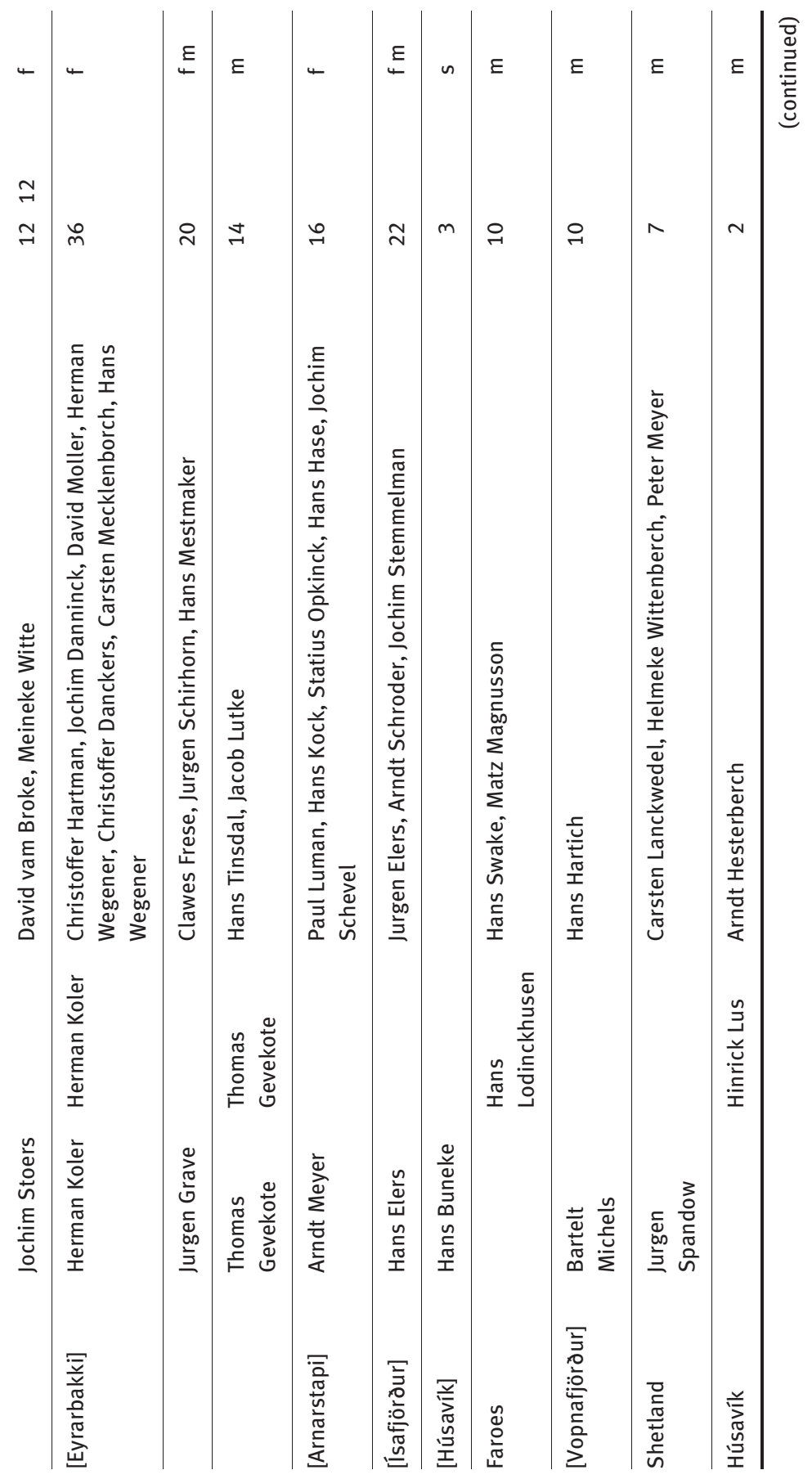




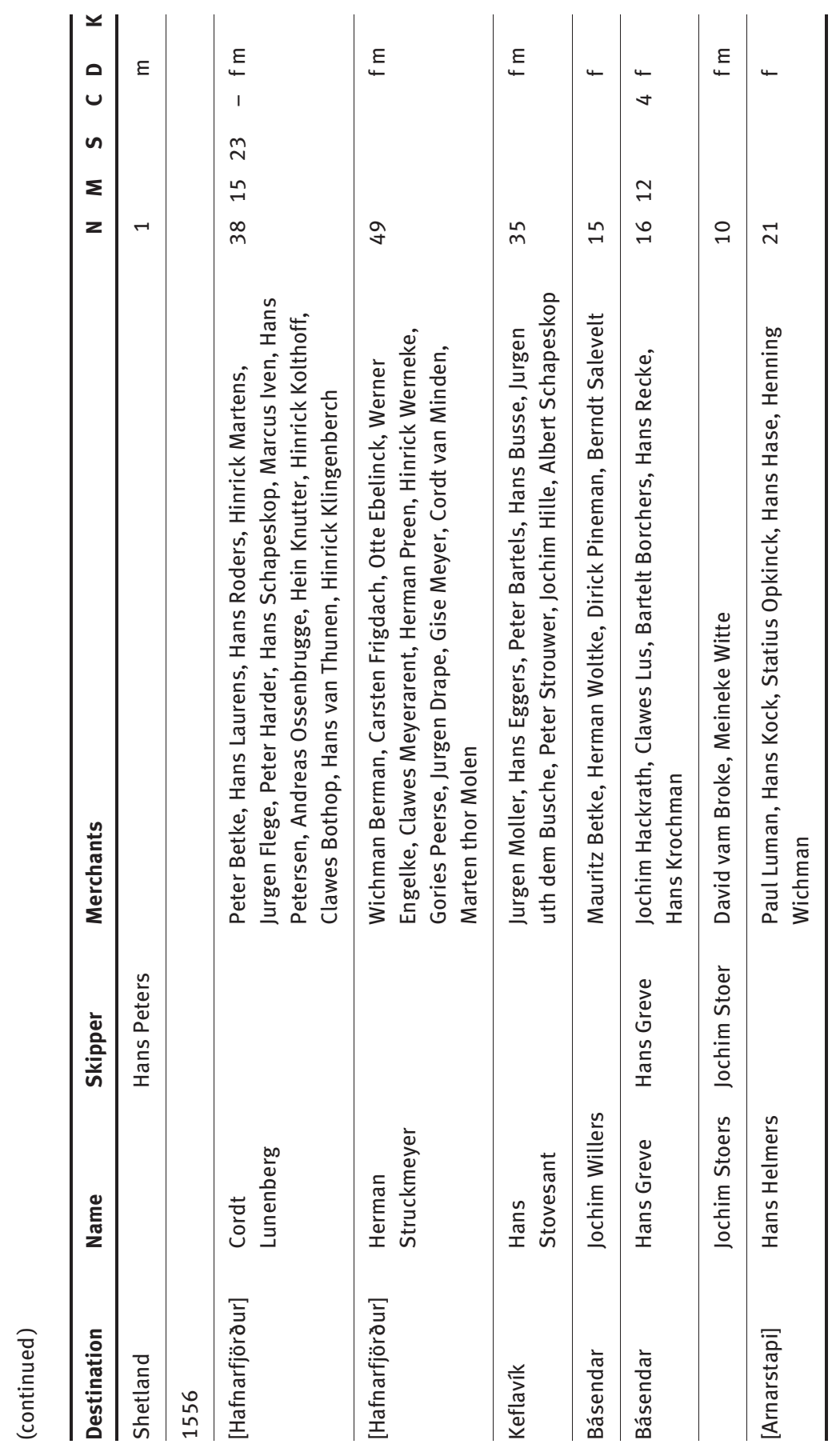




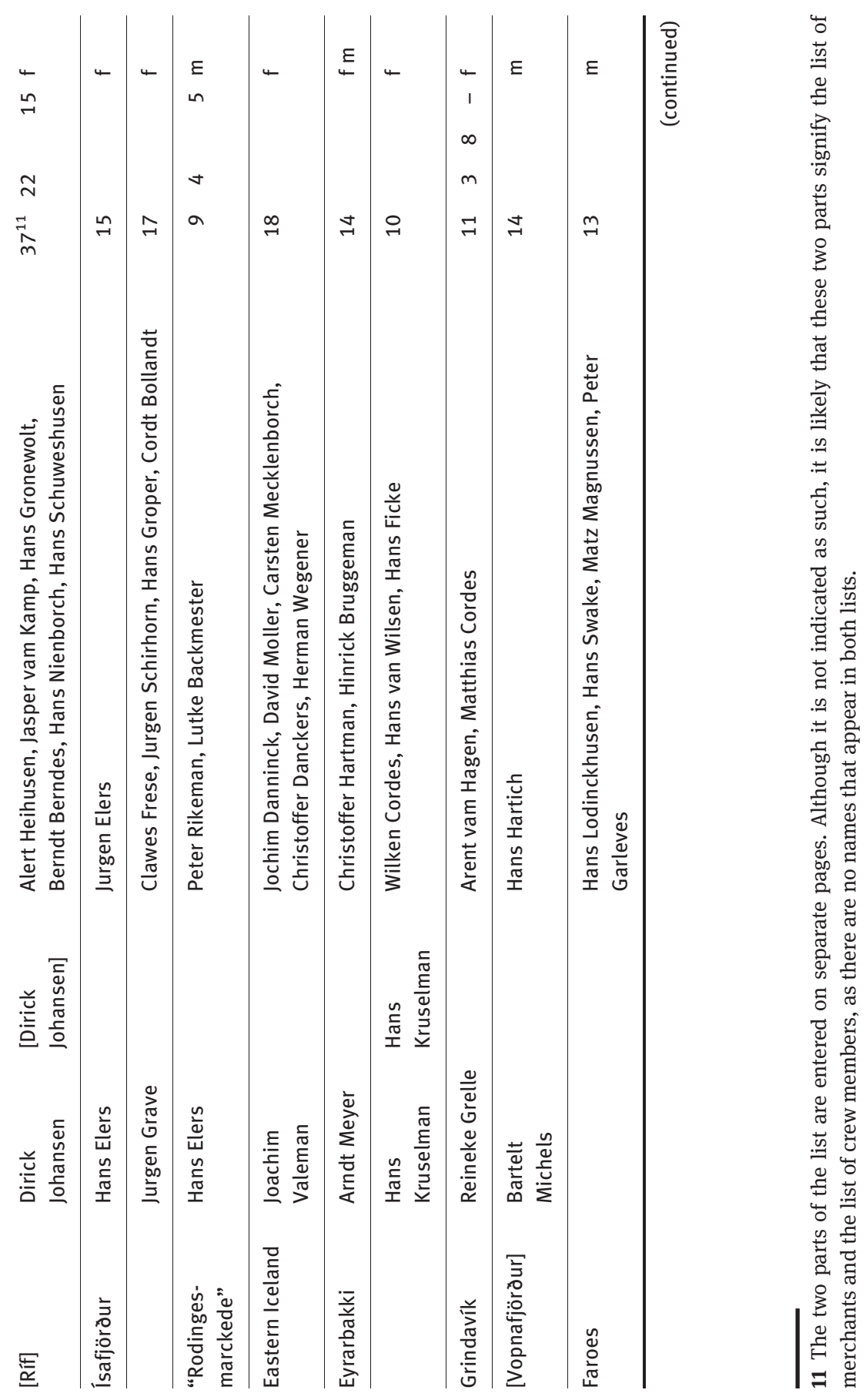




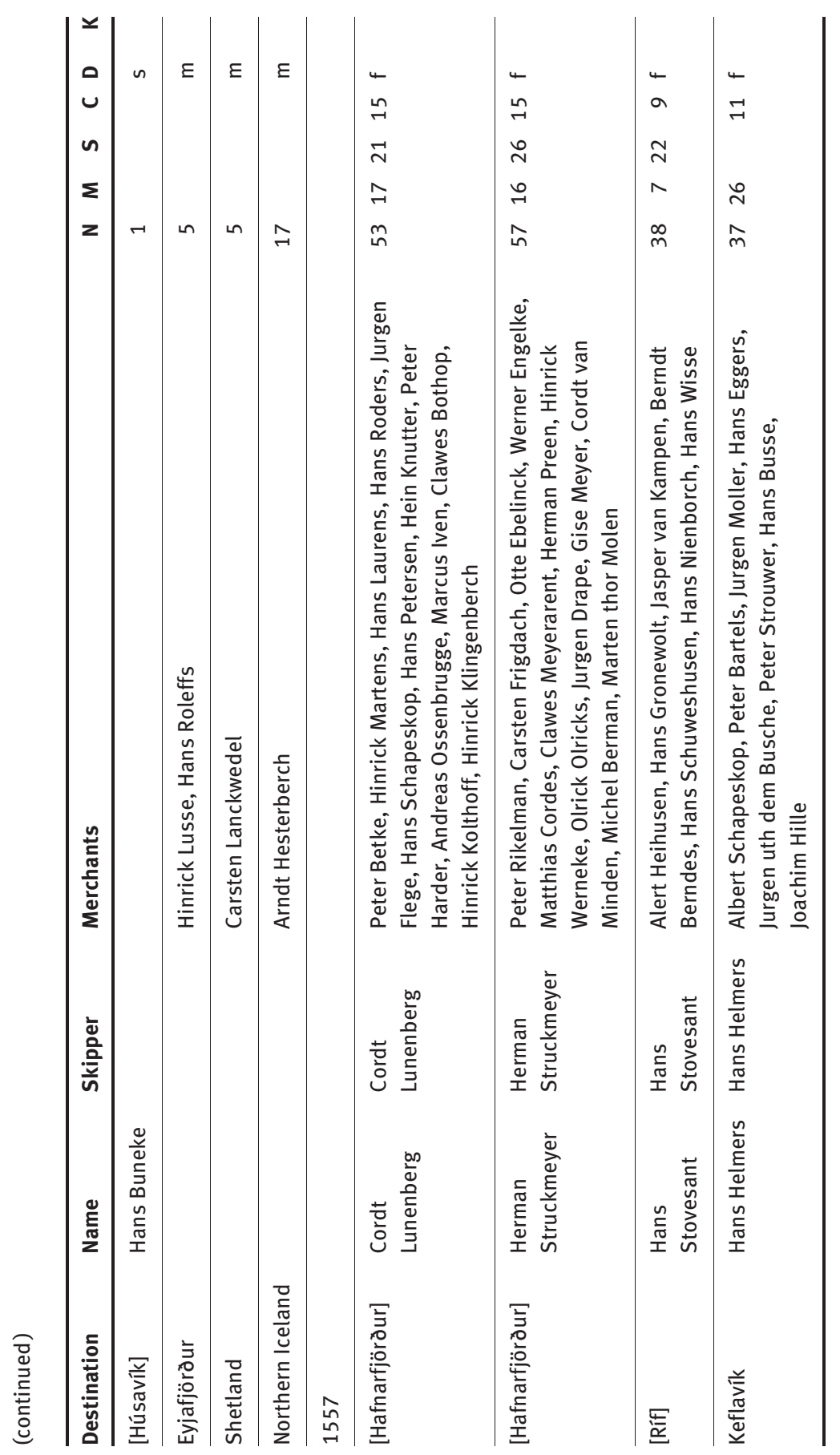




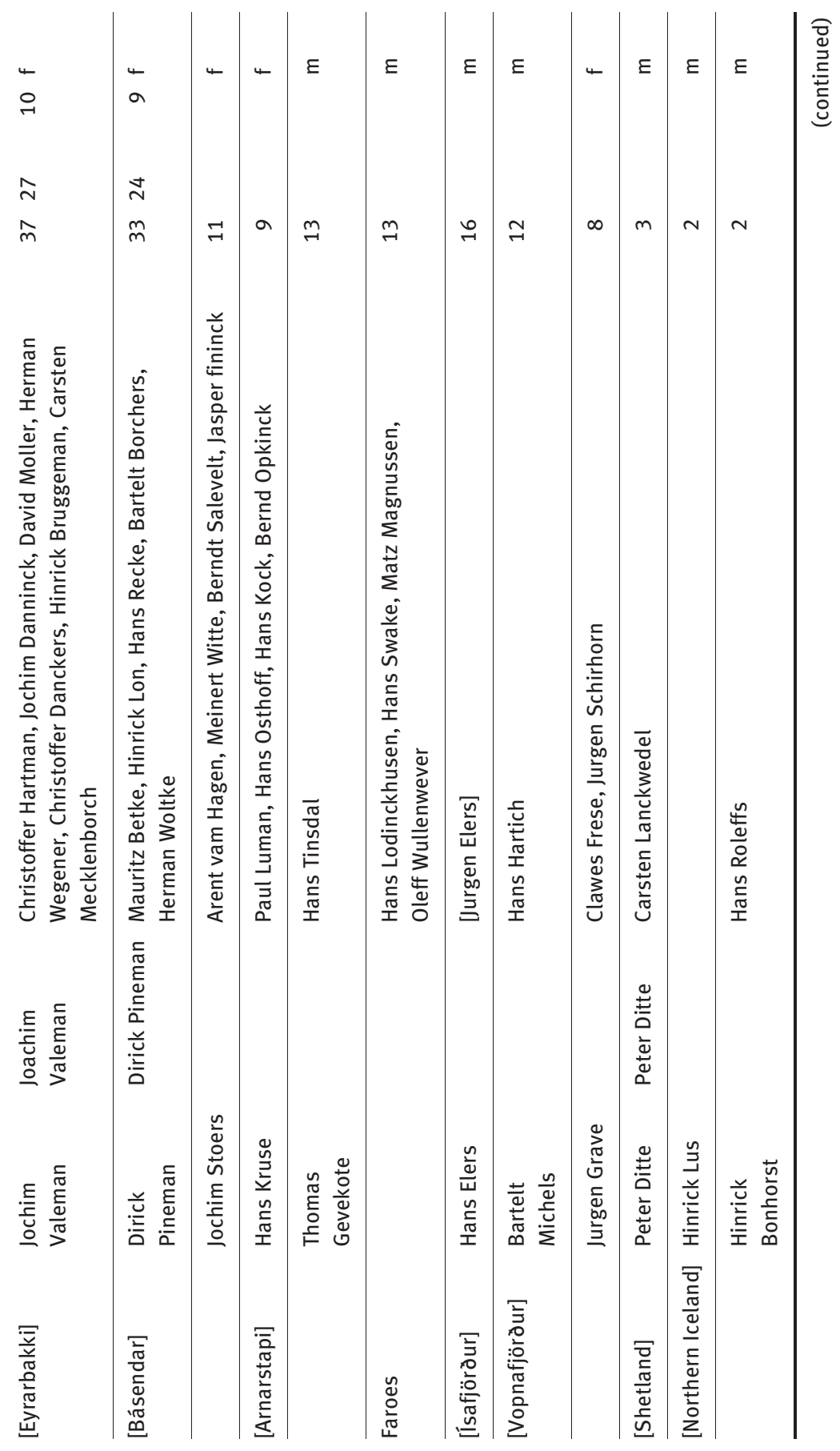




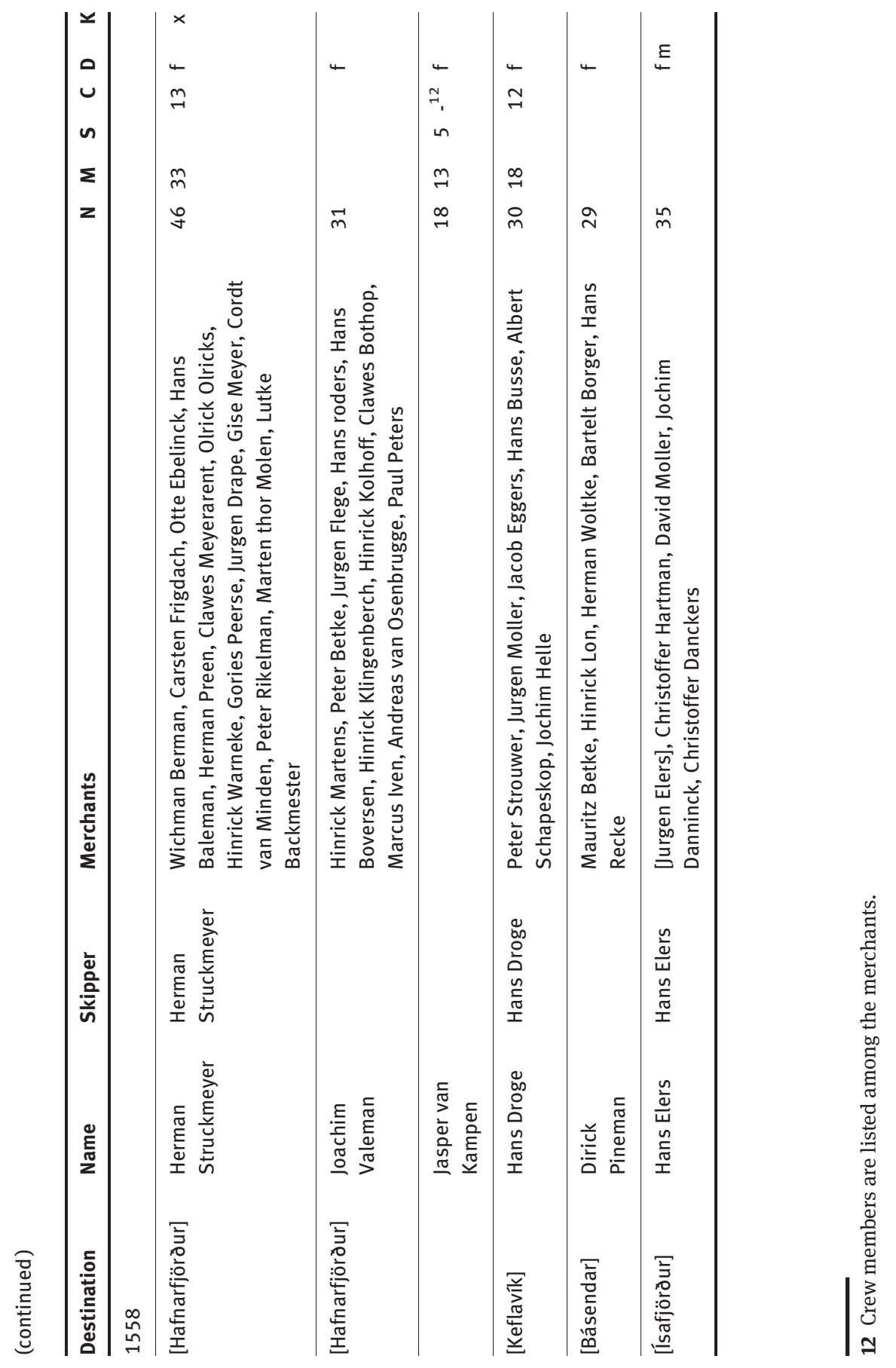




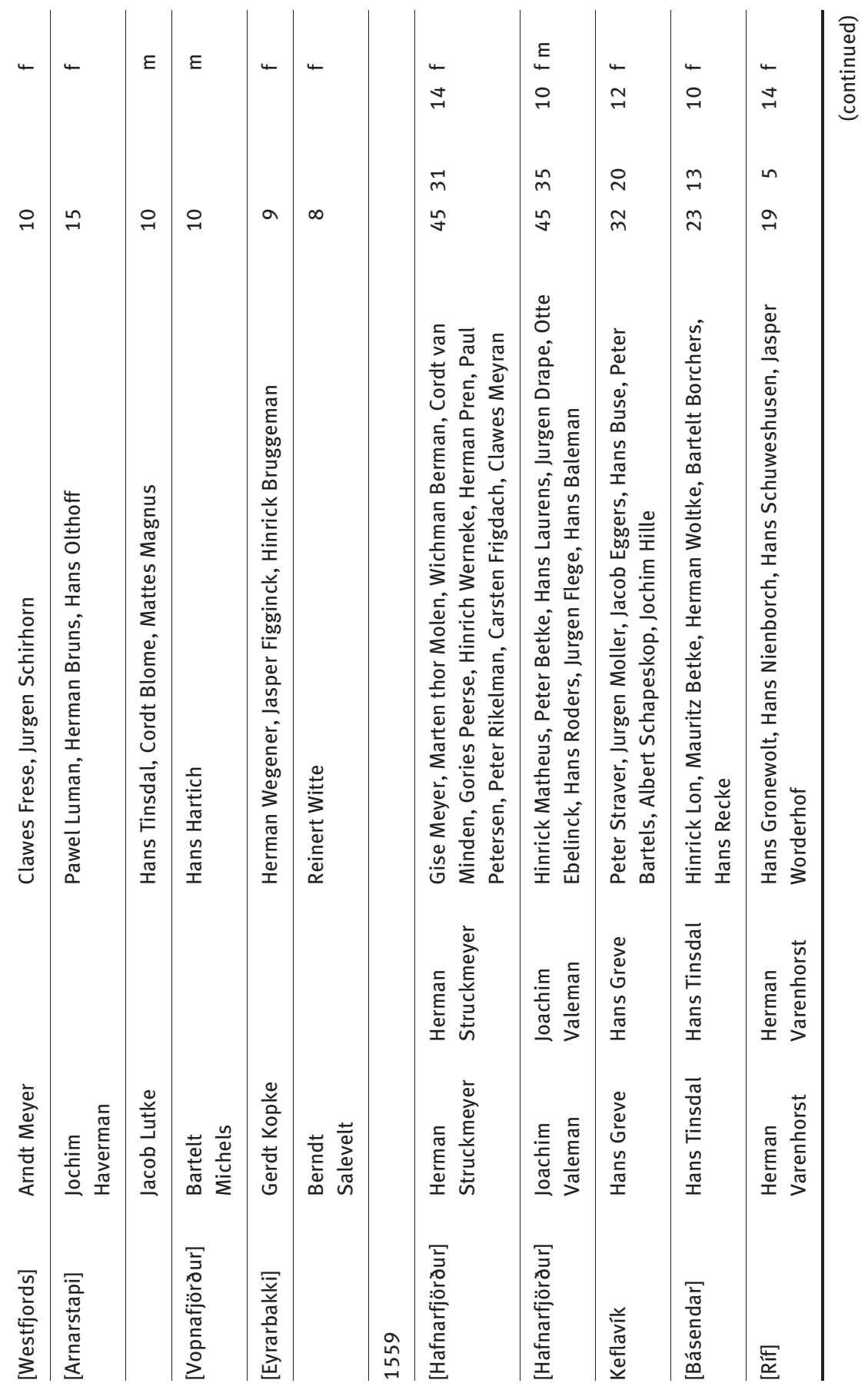




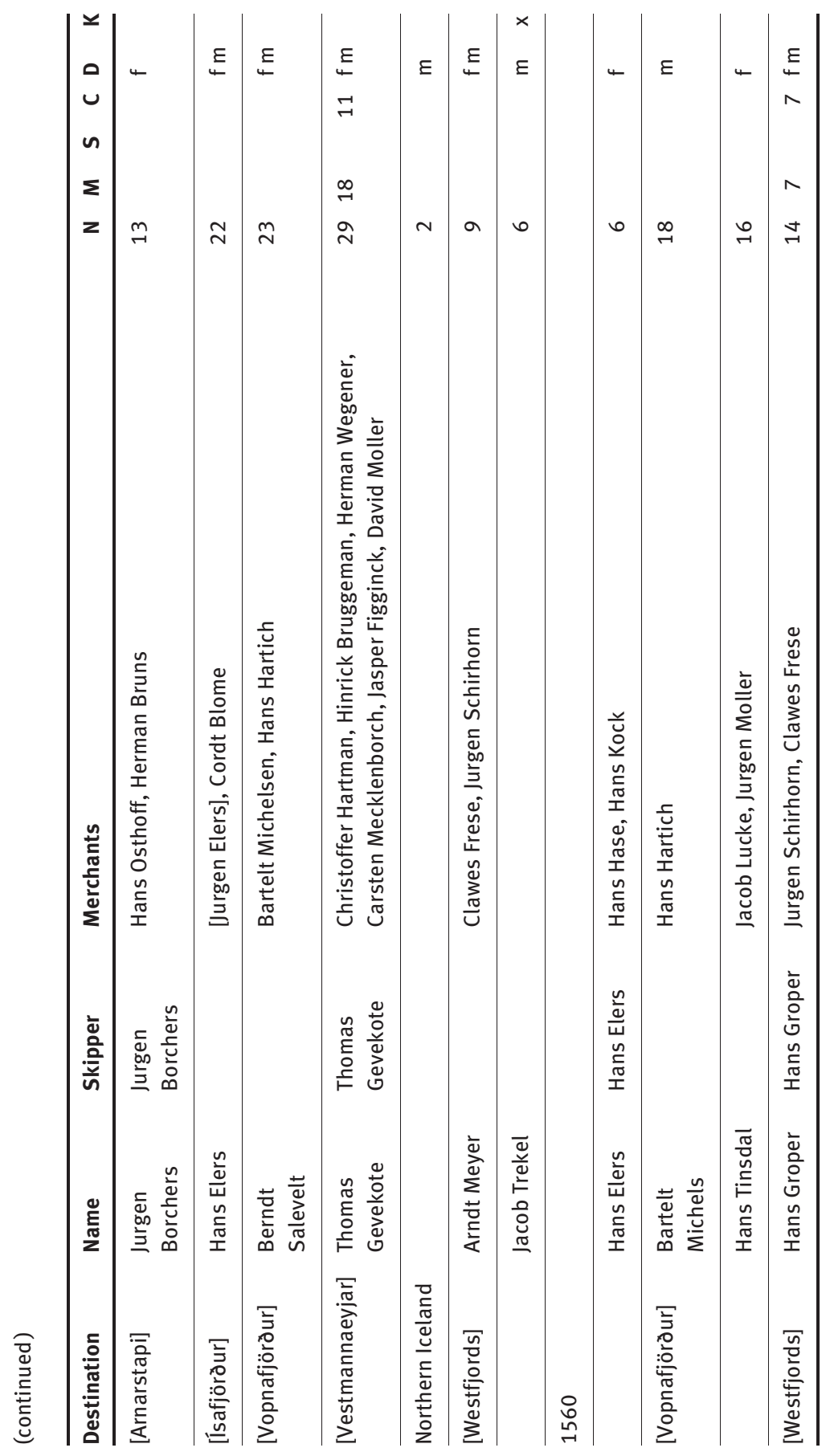




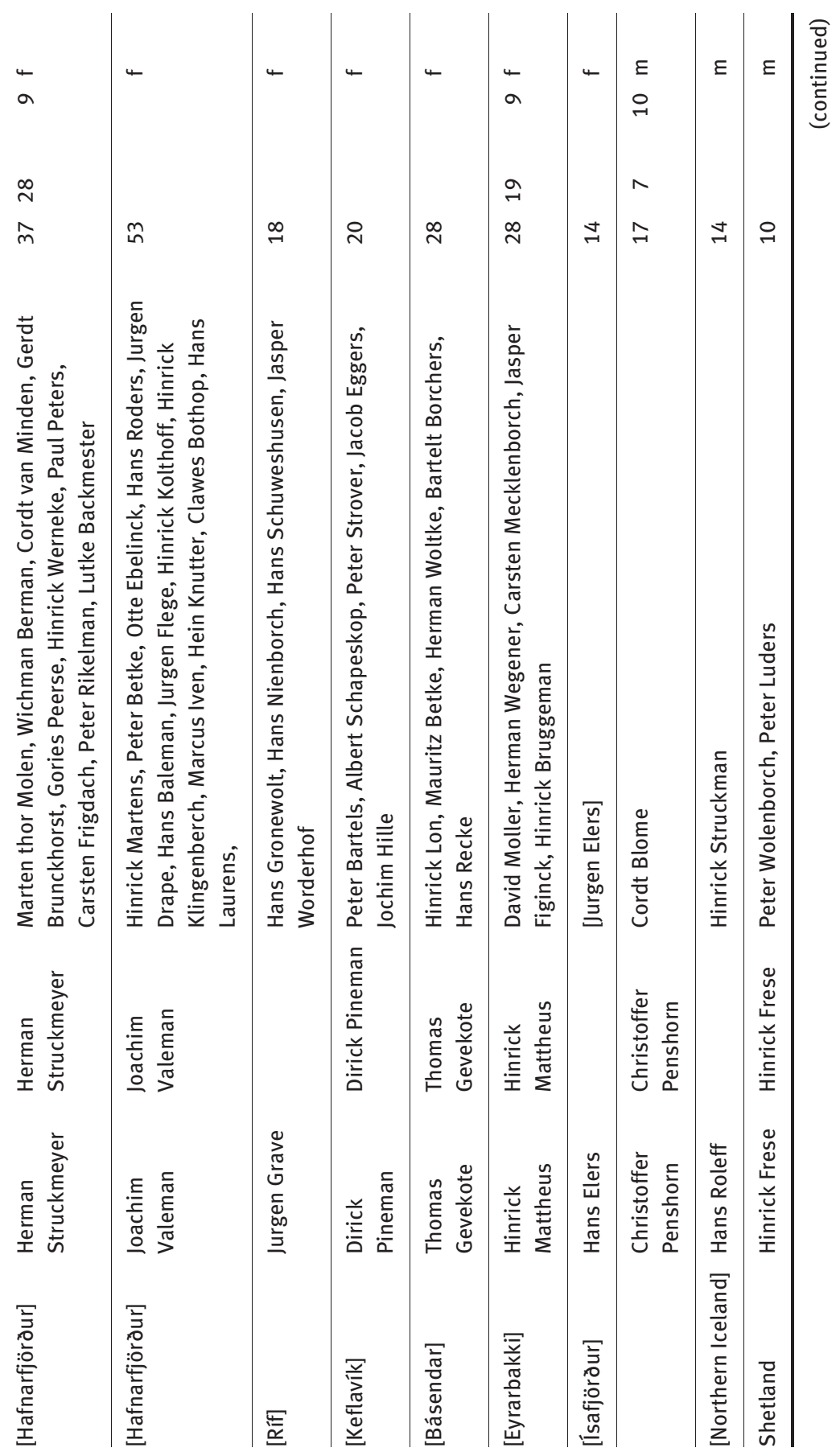



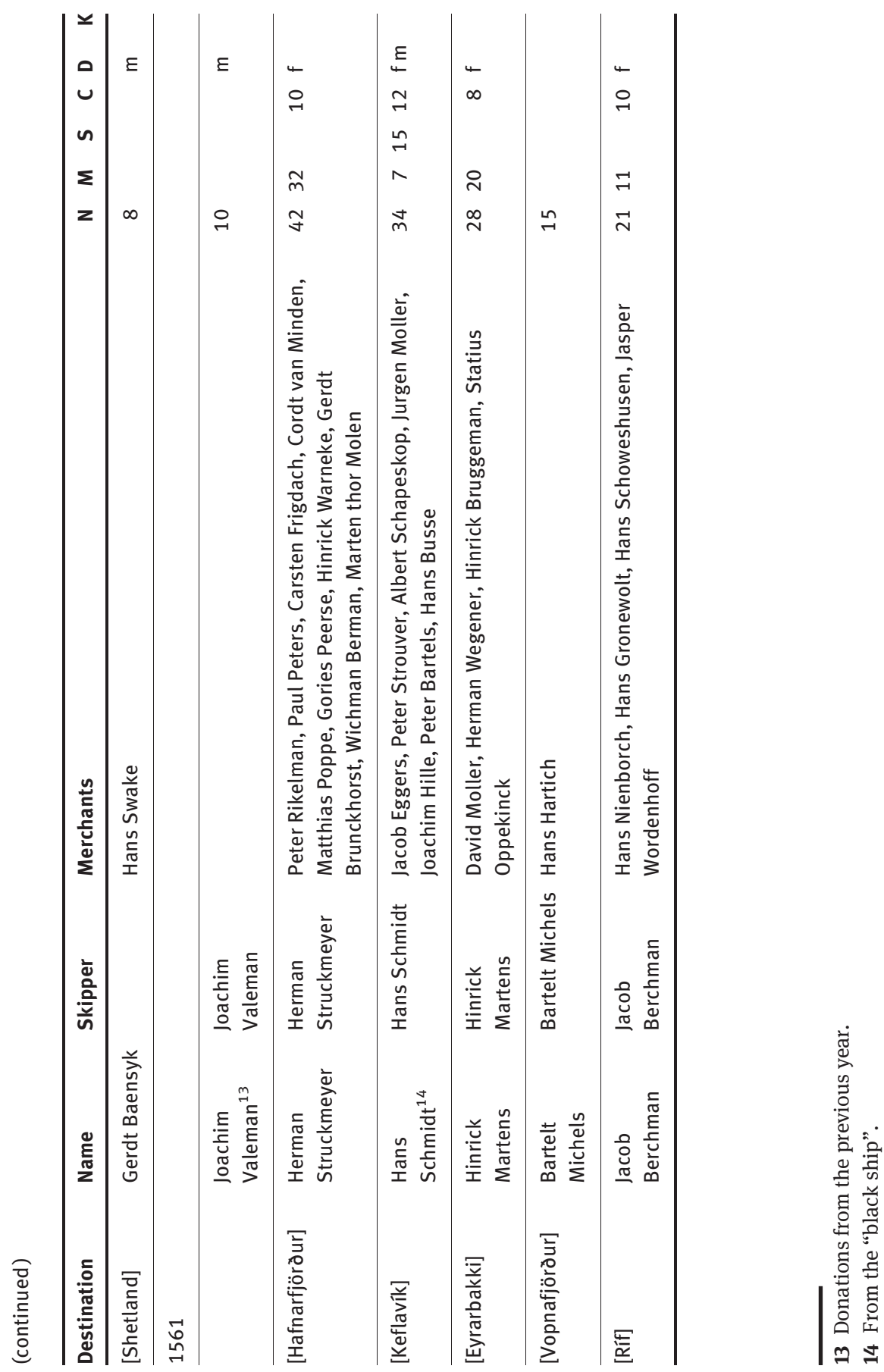


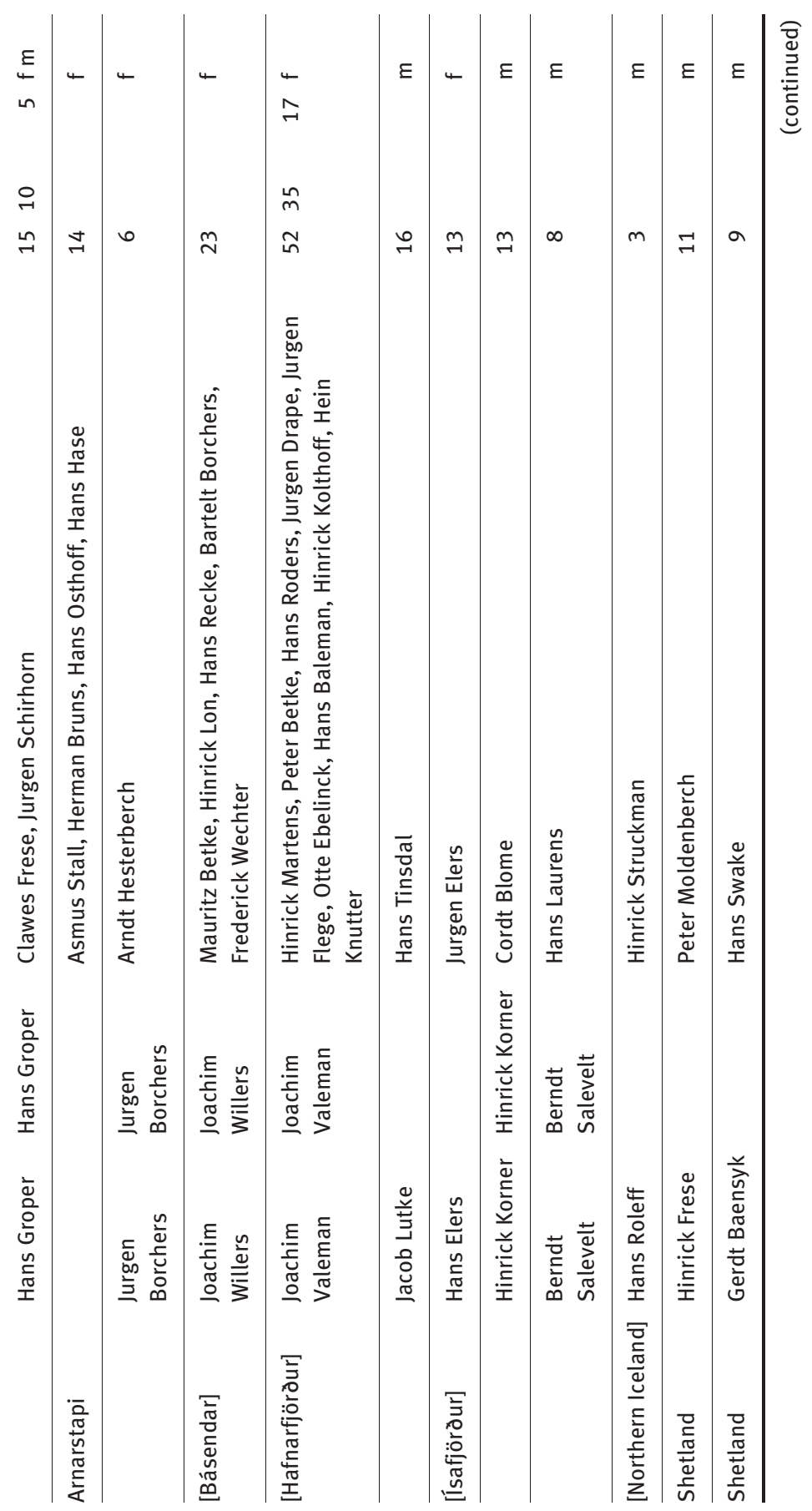




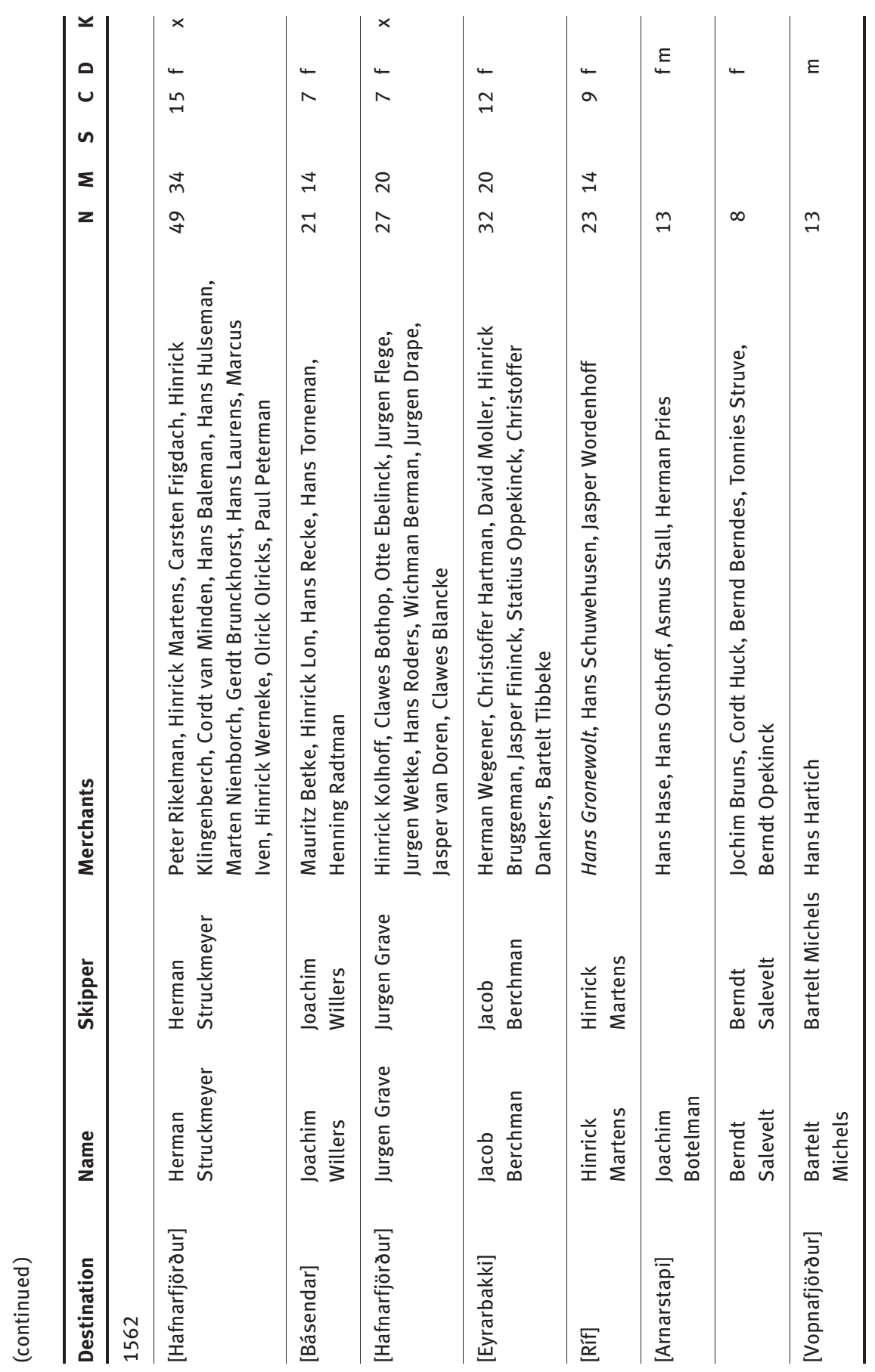




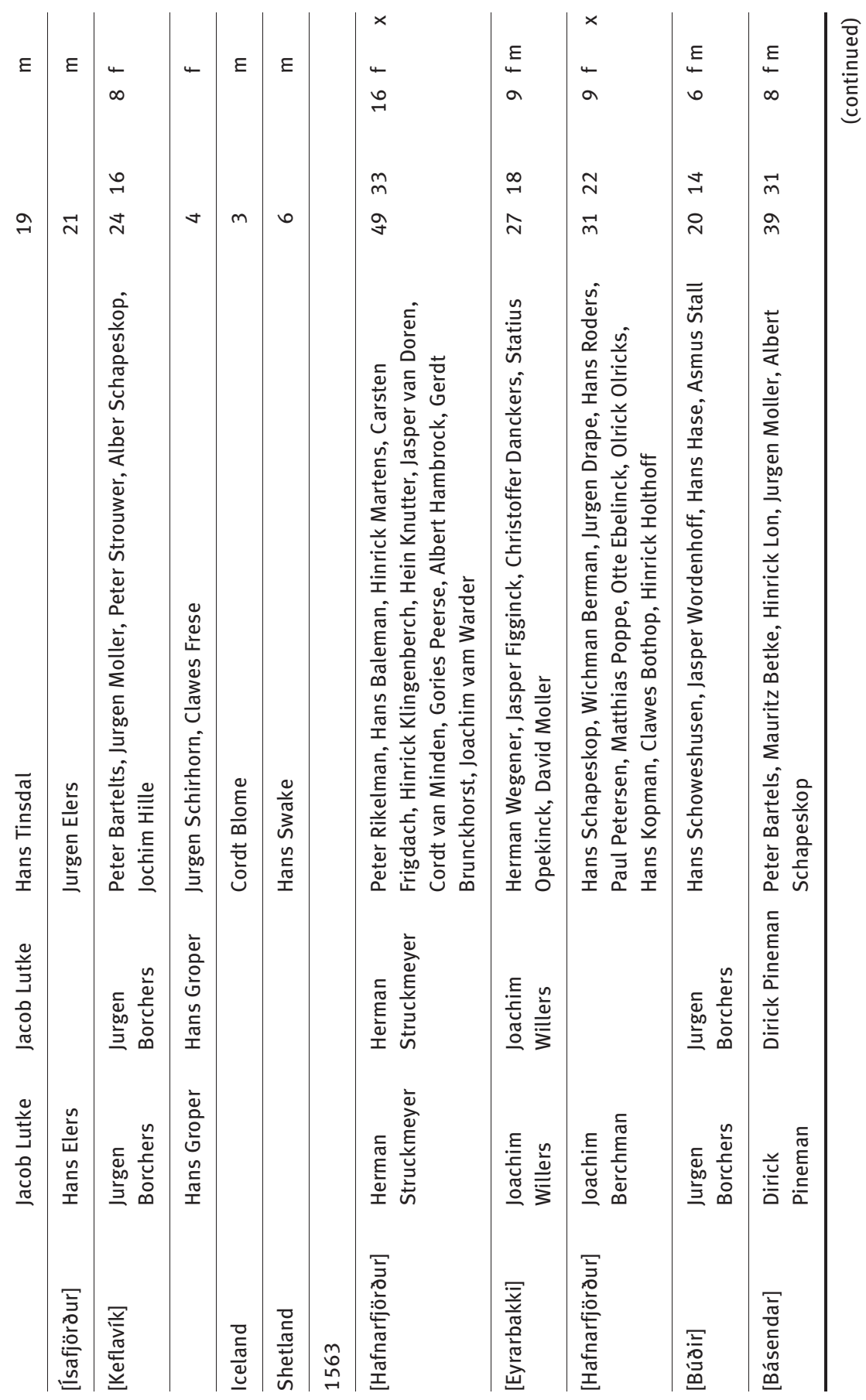




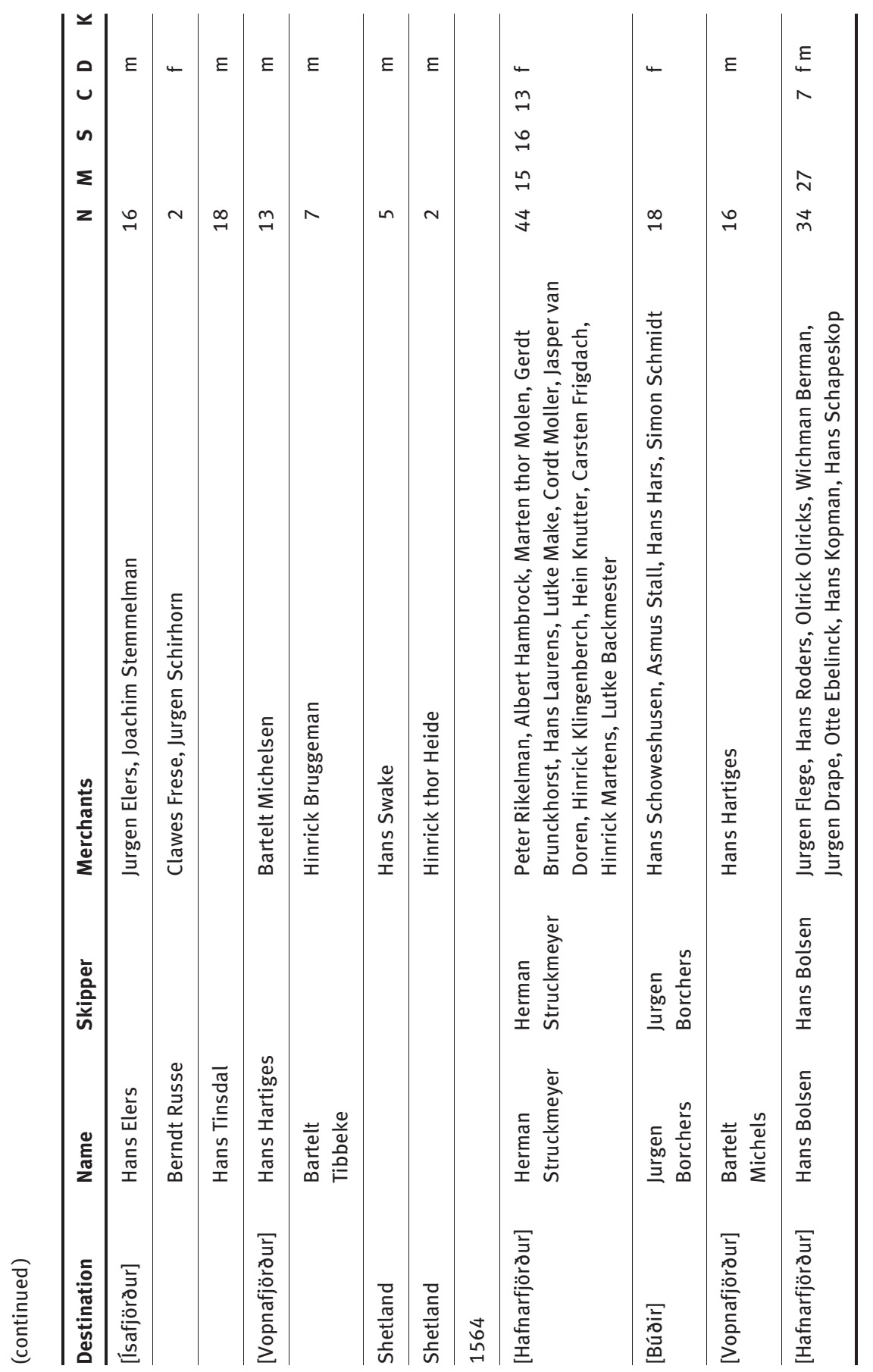




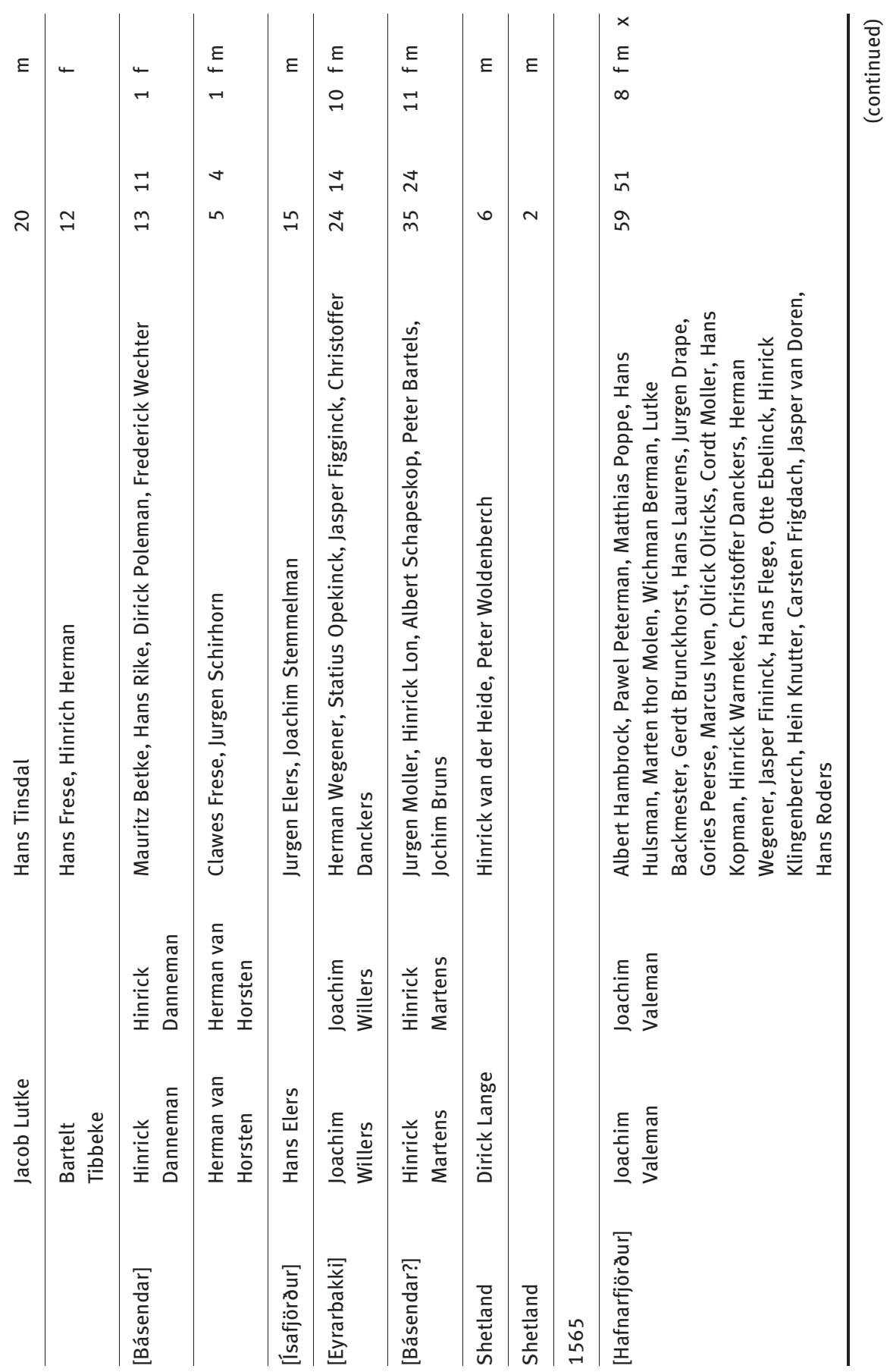




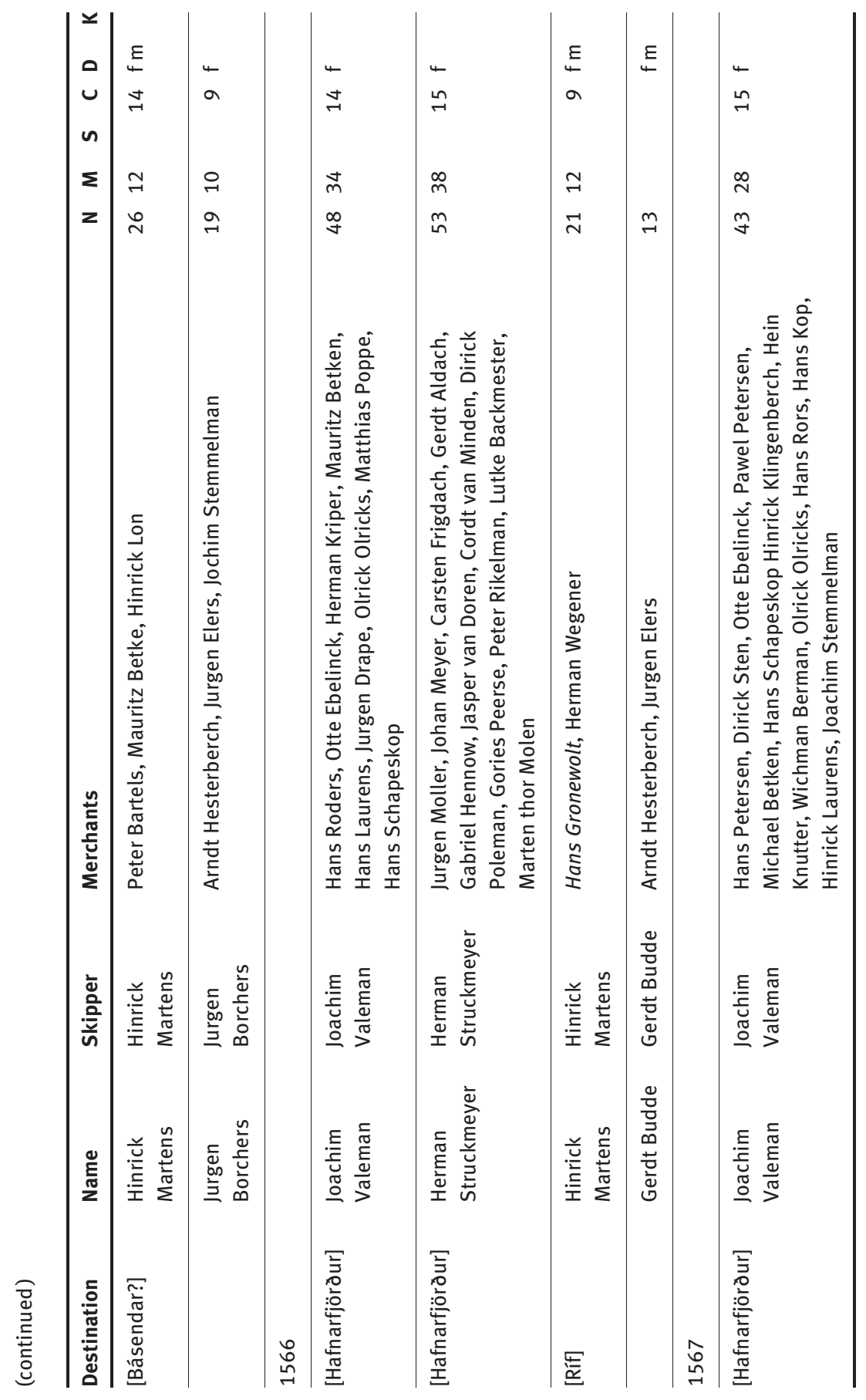




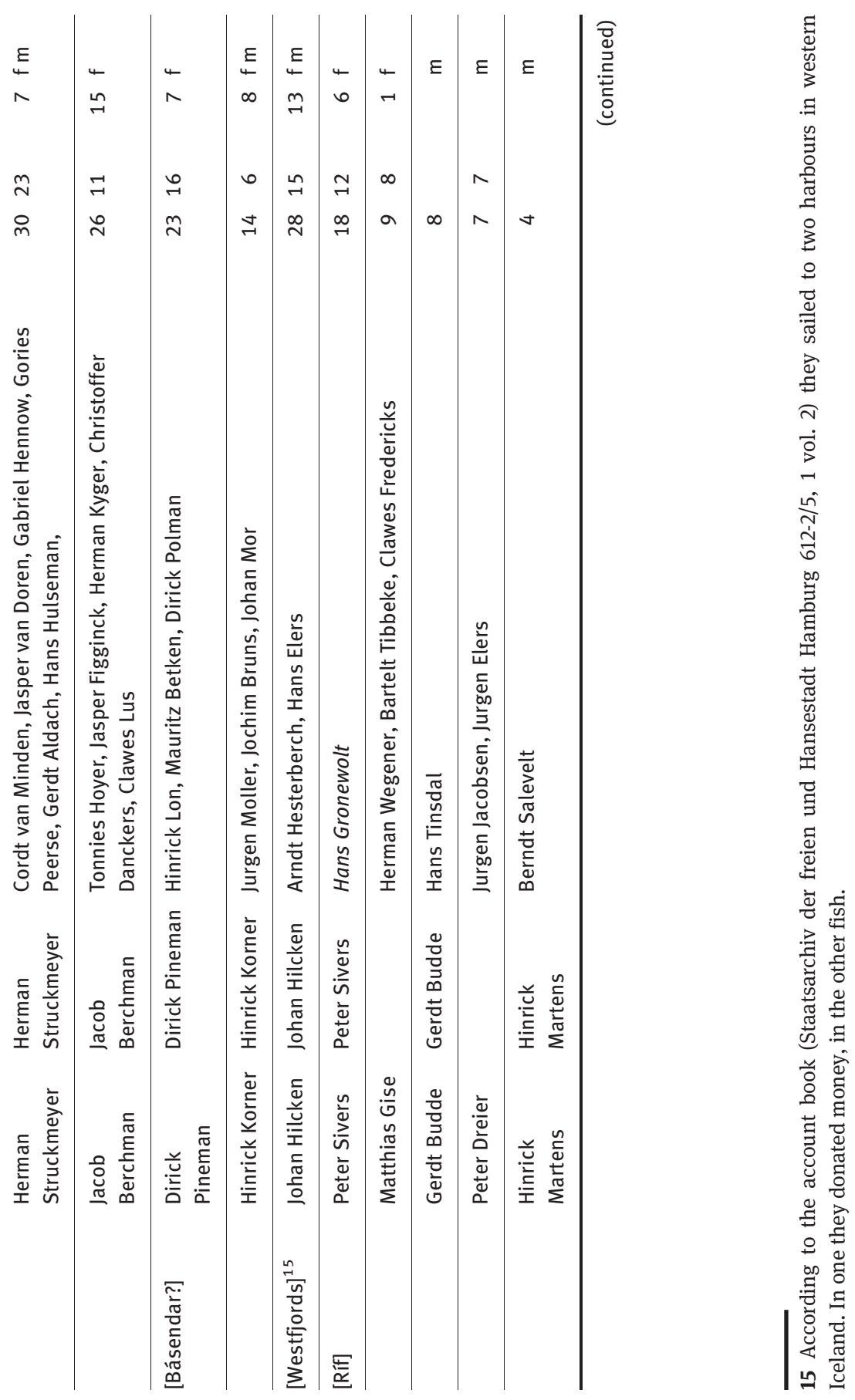




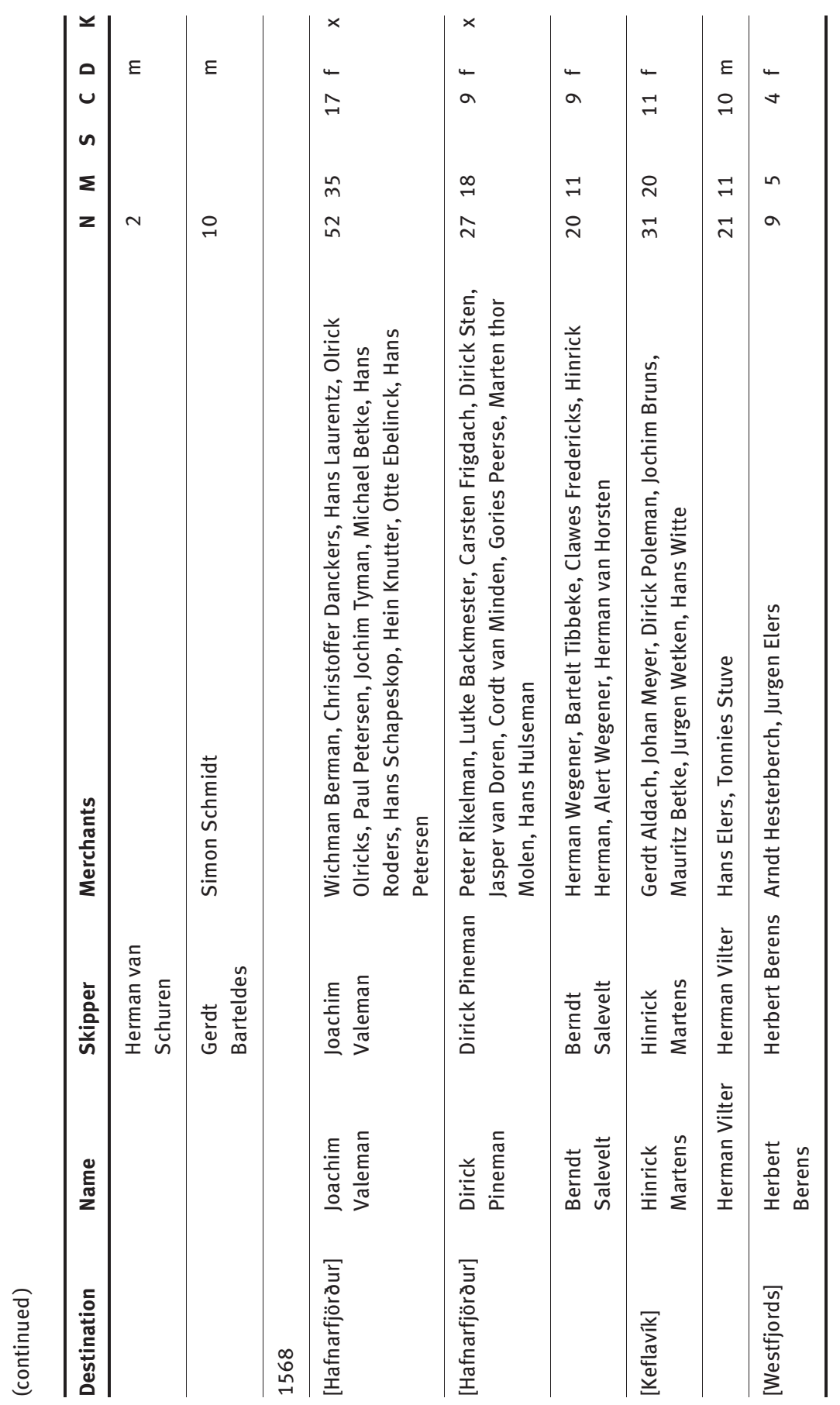




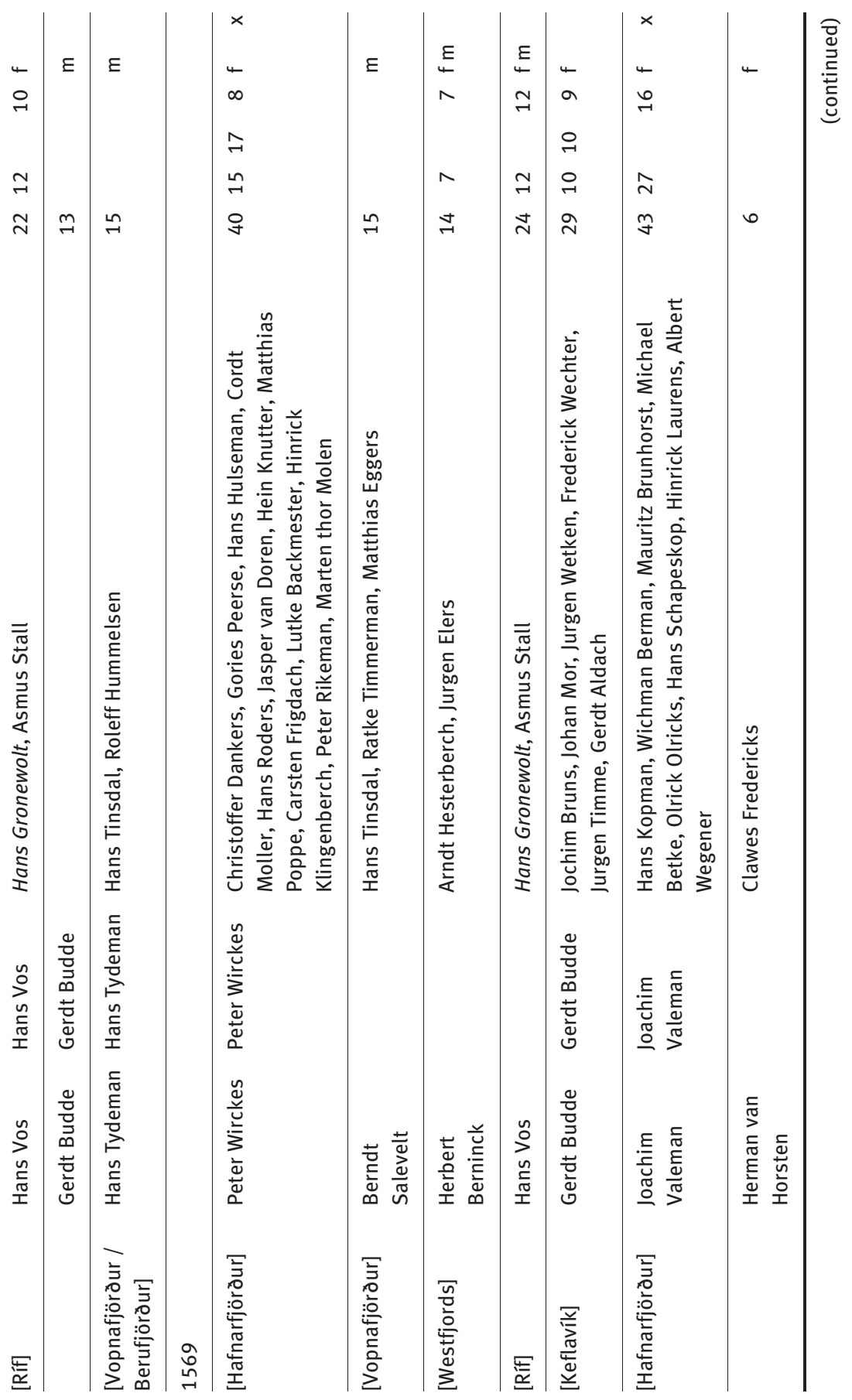




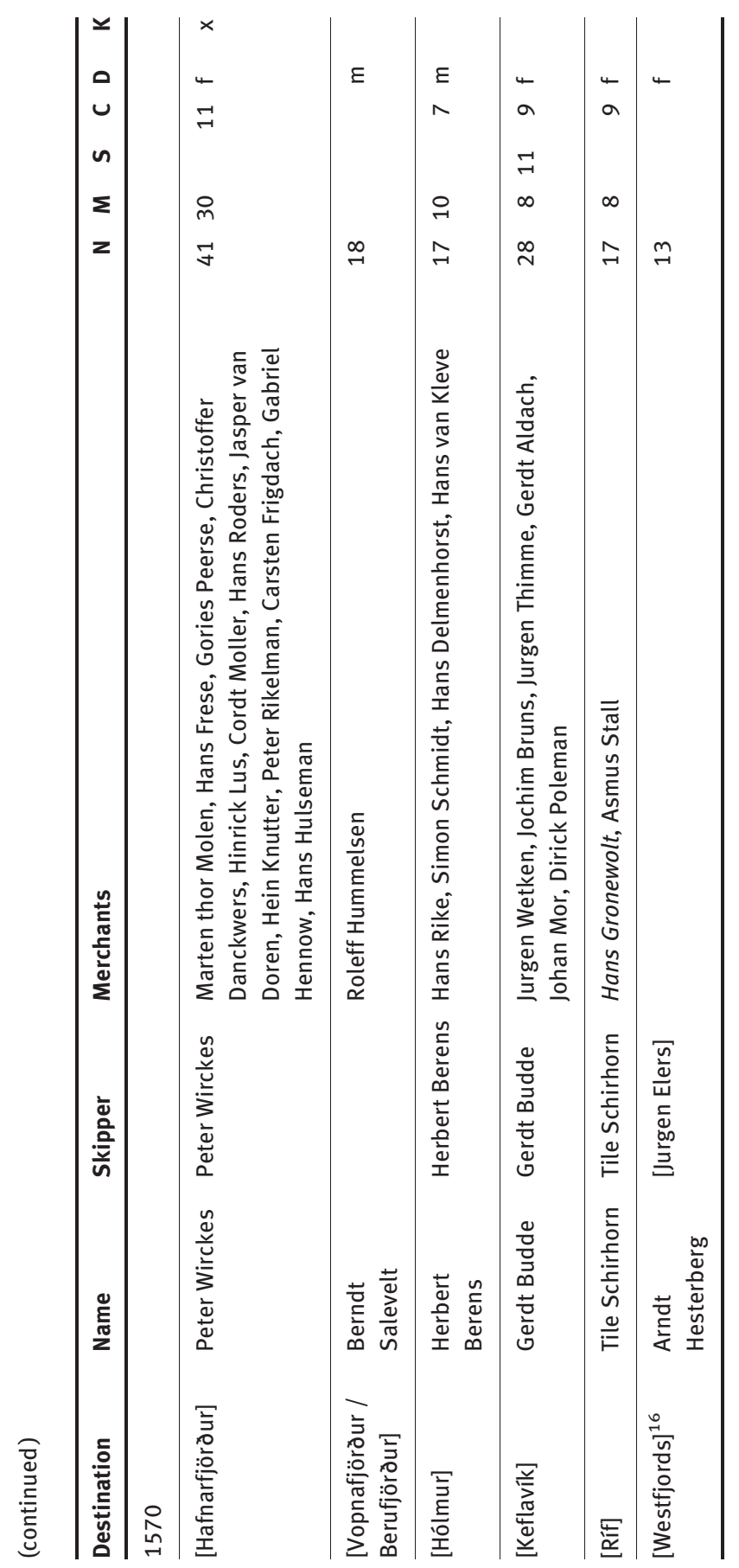

ซี

言导

: :

究

营

당

ఖ

त

. 嗮

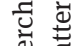

을

离

焉

흘

远

䒕

ปัँ

ยี

도

क ซี

क्ष

ปี

$\exists$ క

ธี

放

항

常

호

륨

$\stackrel{0}{\varrho}$

응

ธี प्ّ

w

코ำ

폭

충

का

되 피

岂

可

மัँ

合高

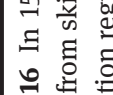




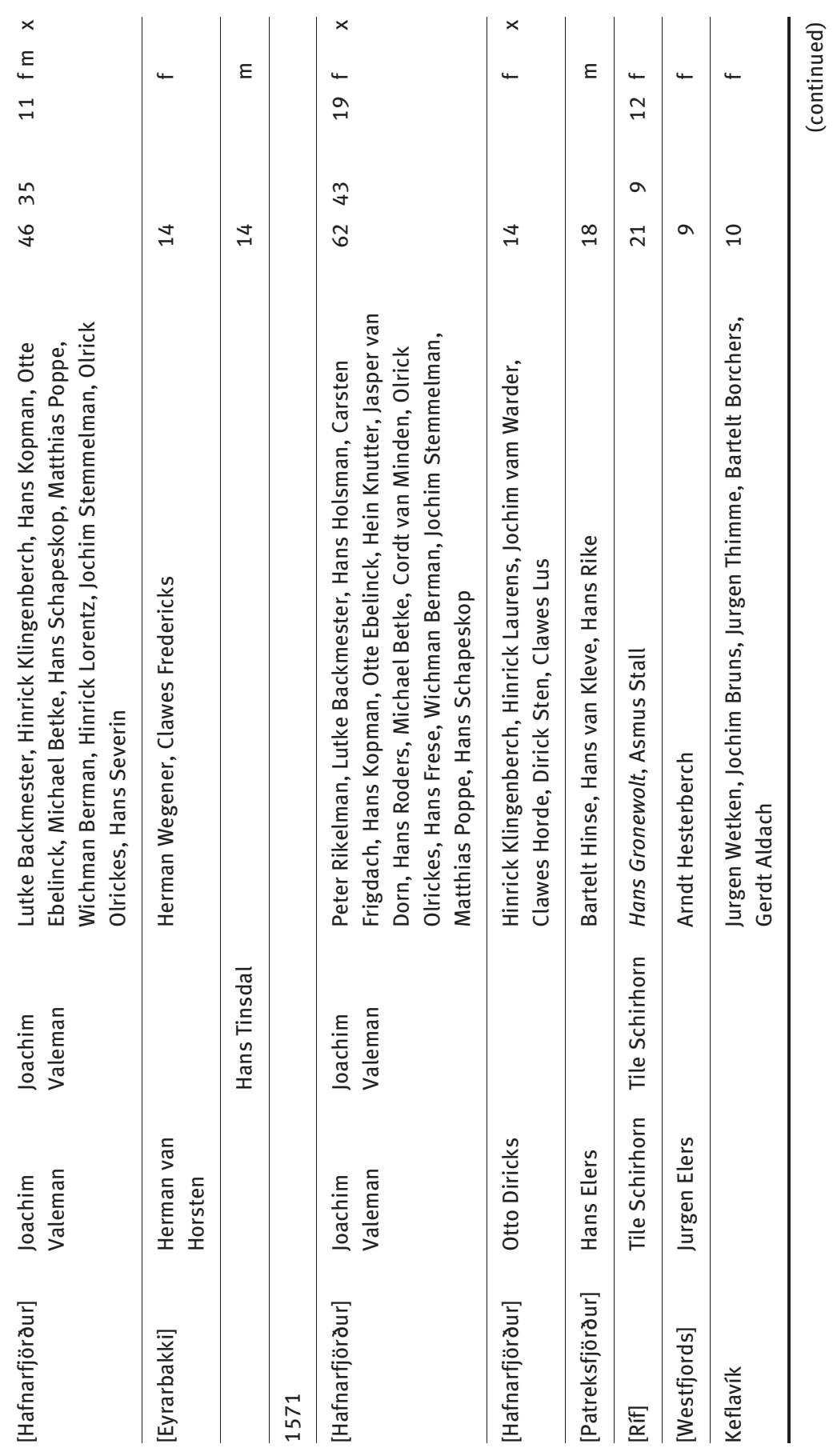




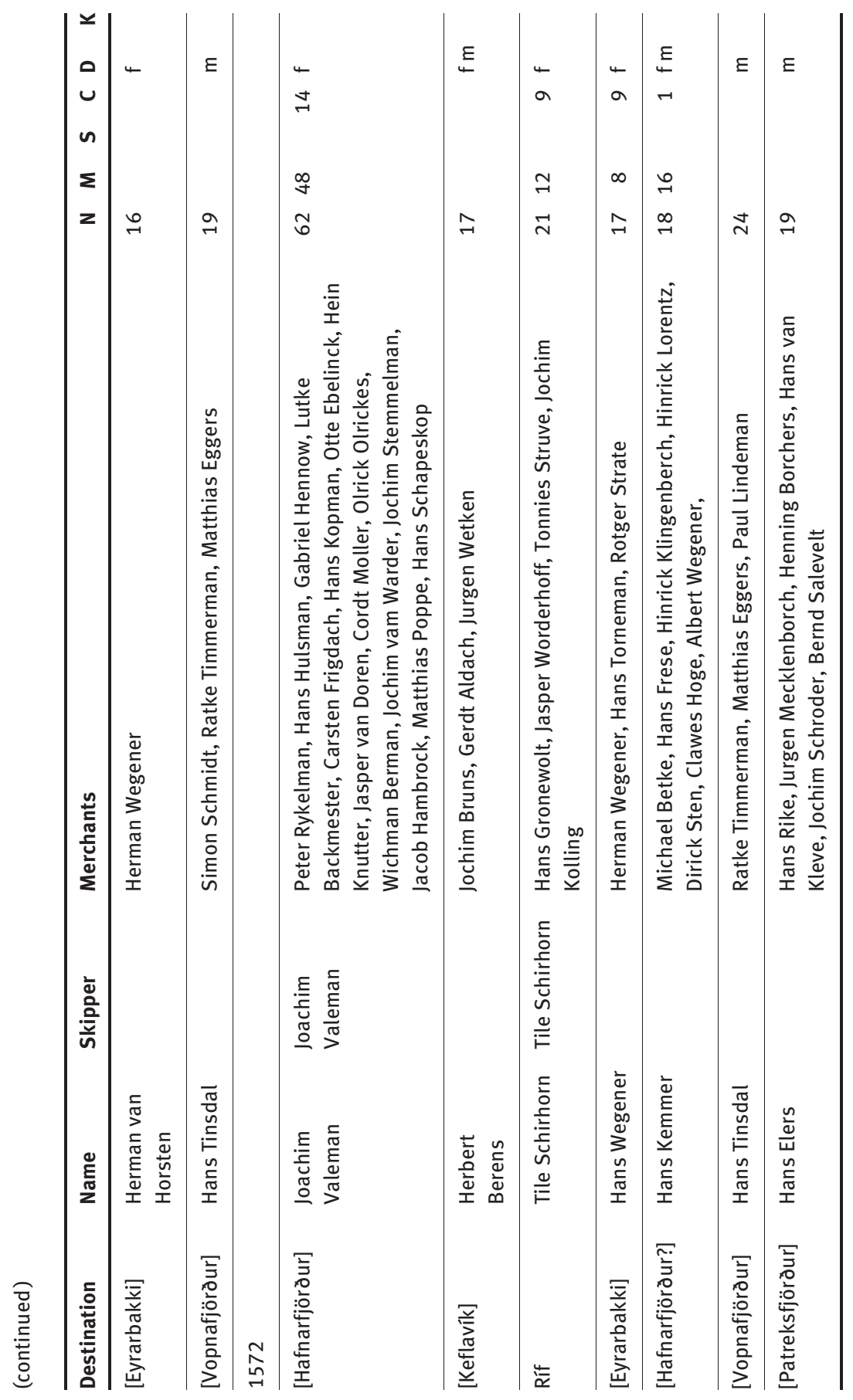




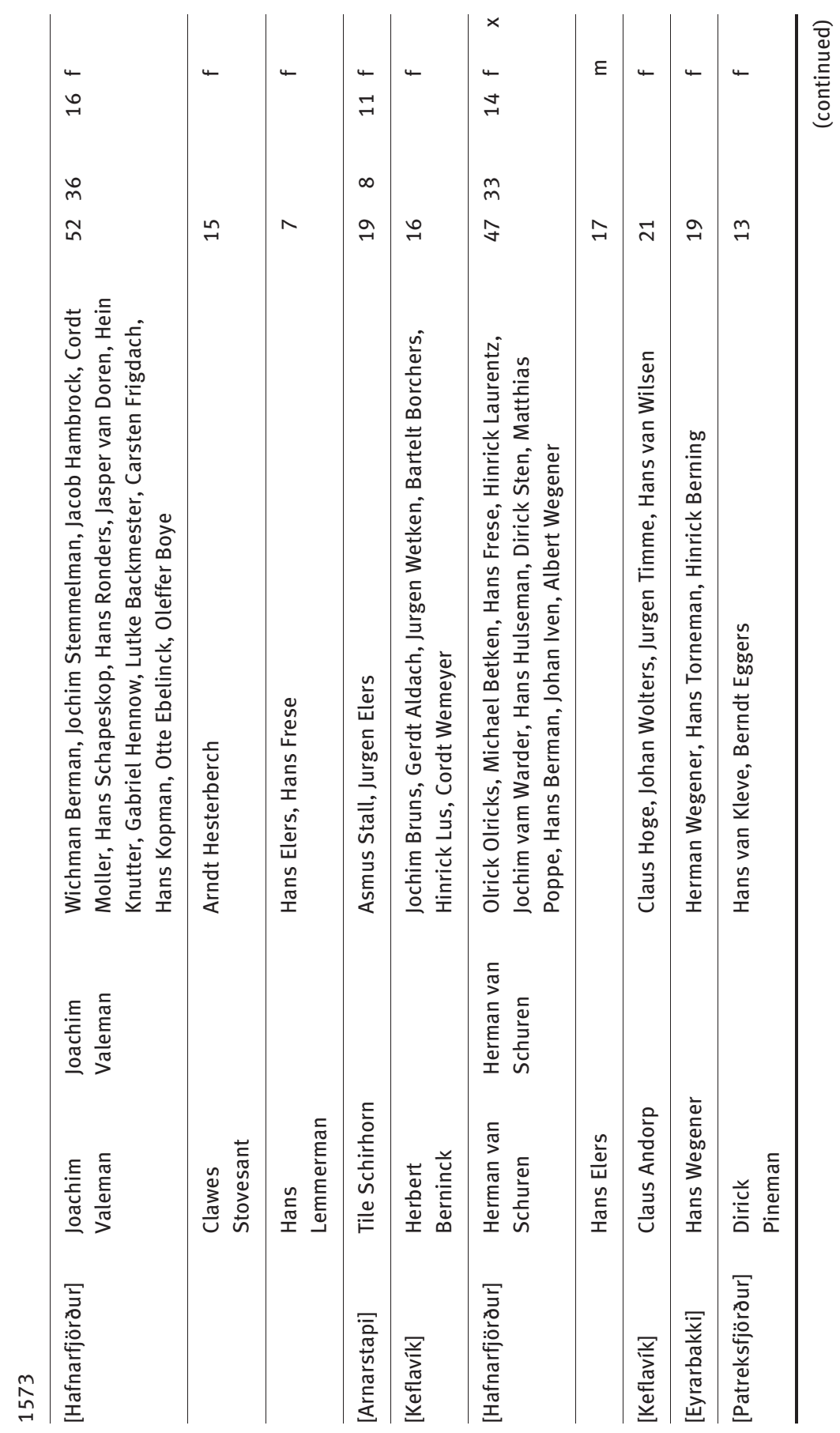




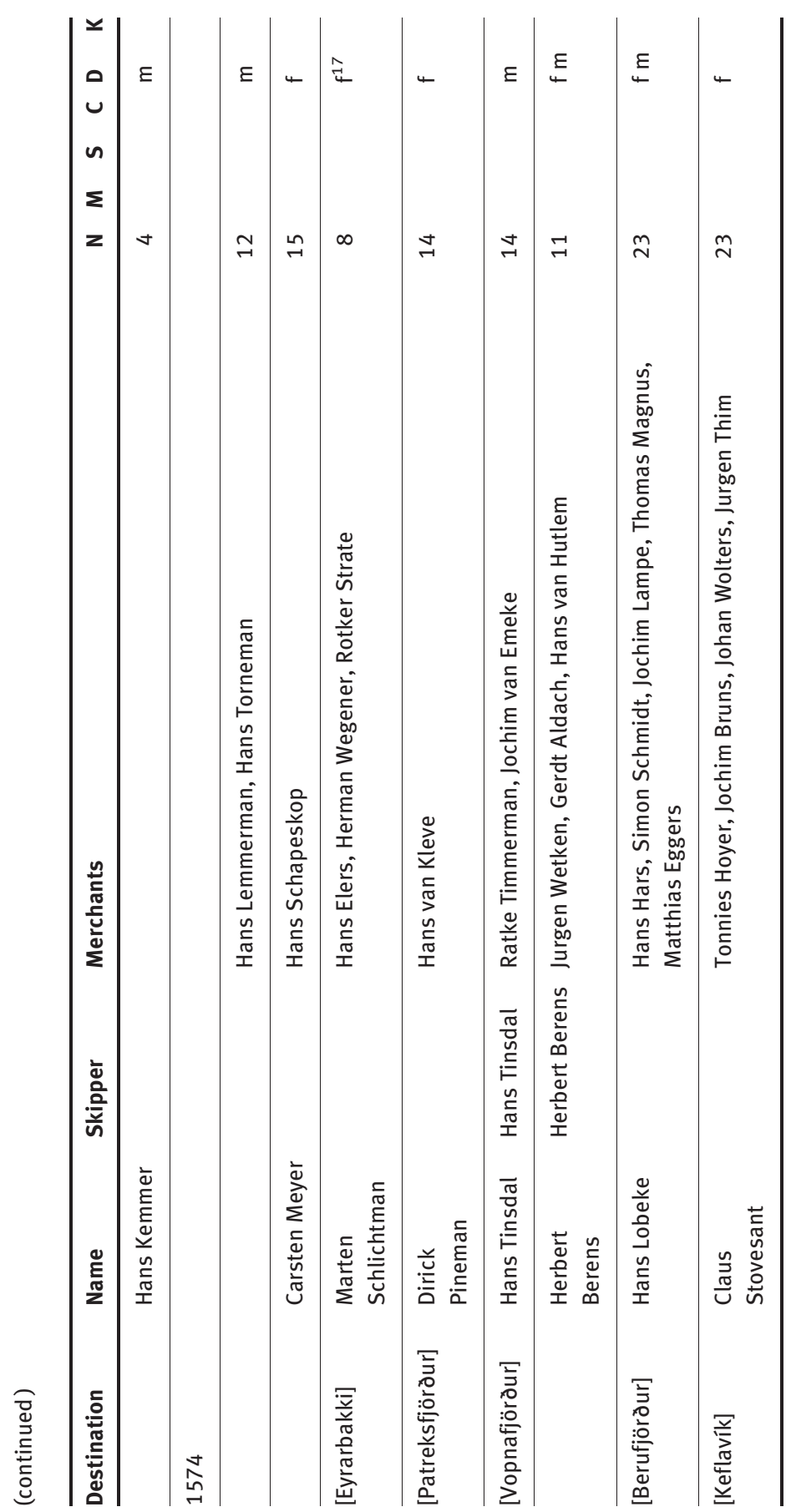

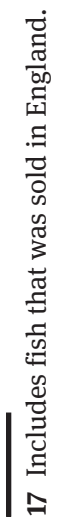




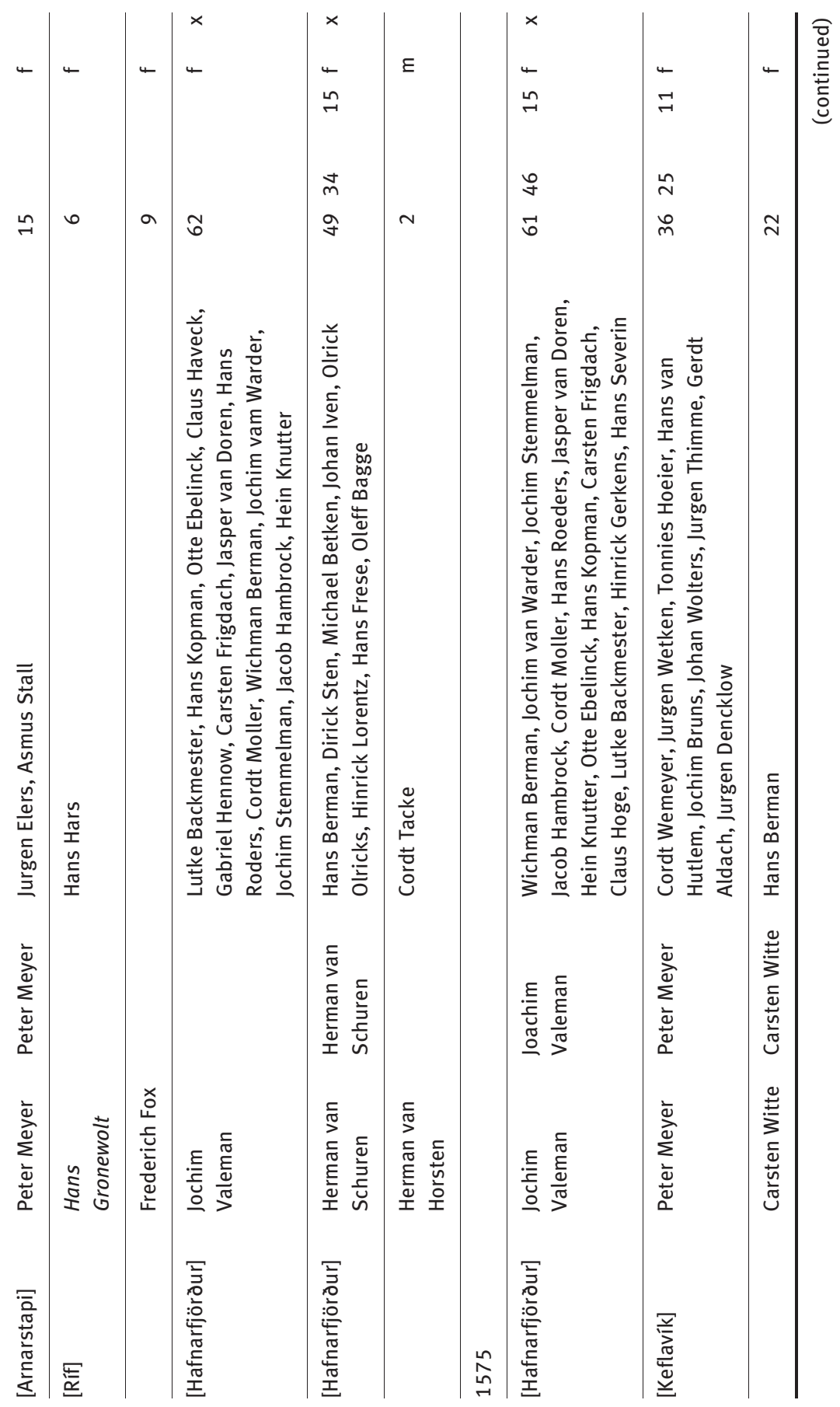




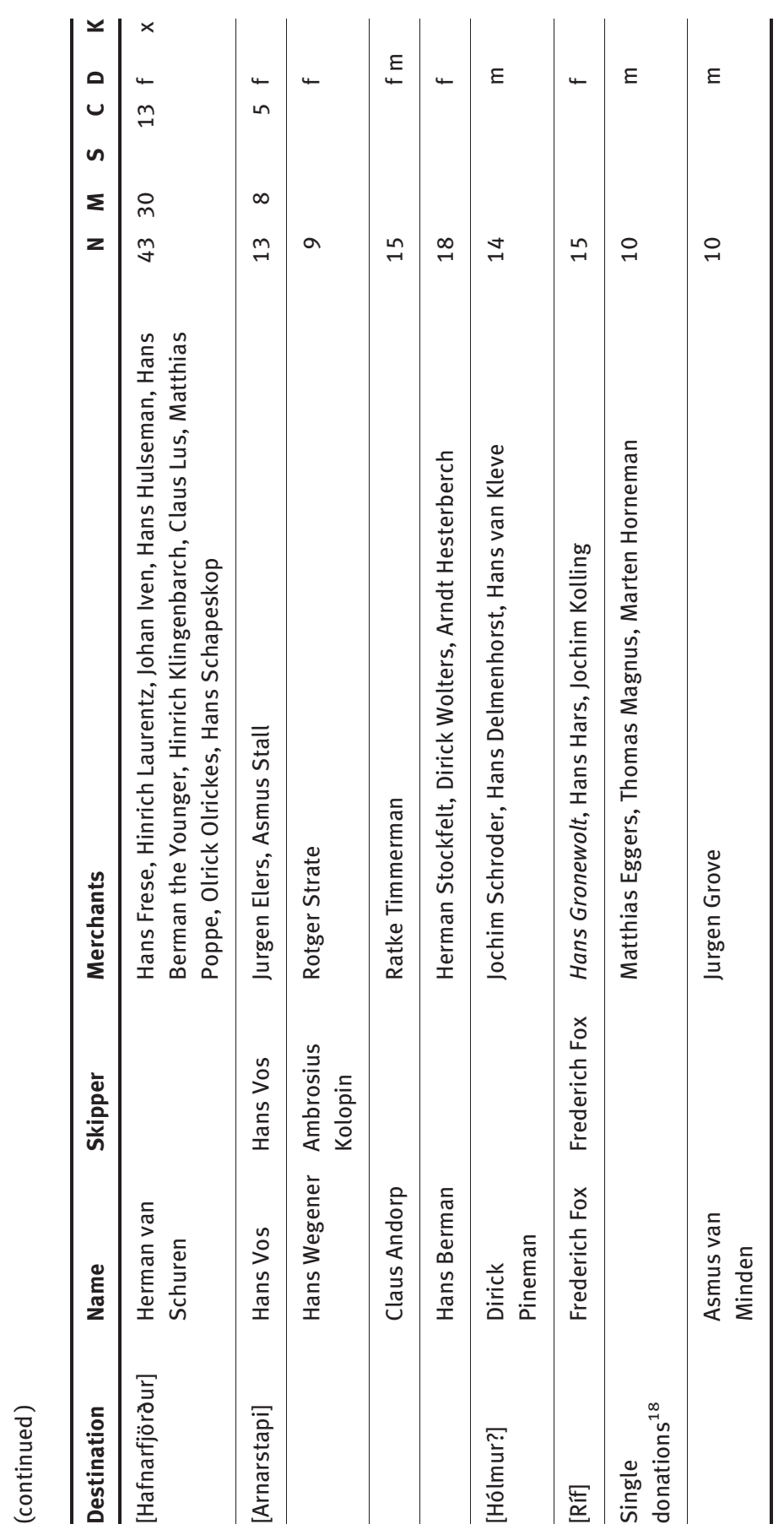

| 


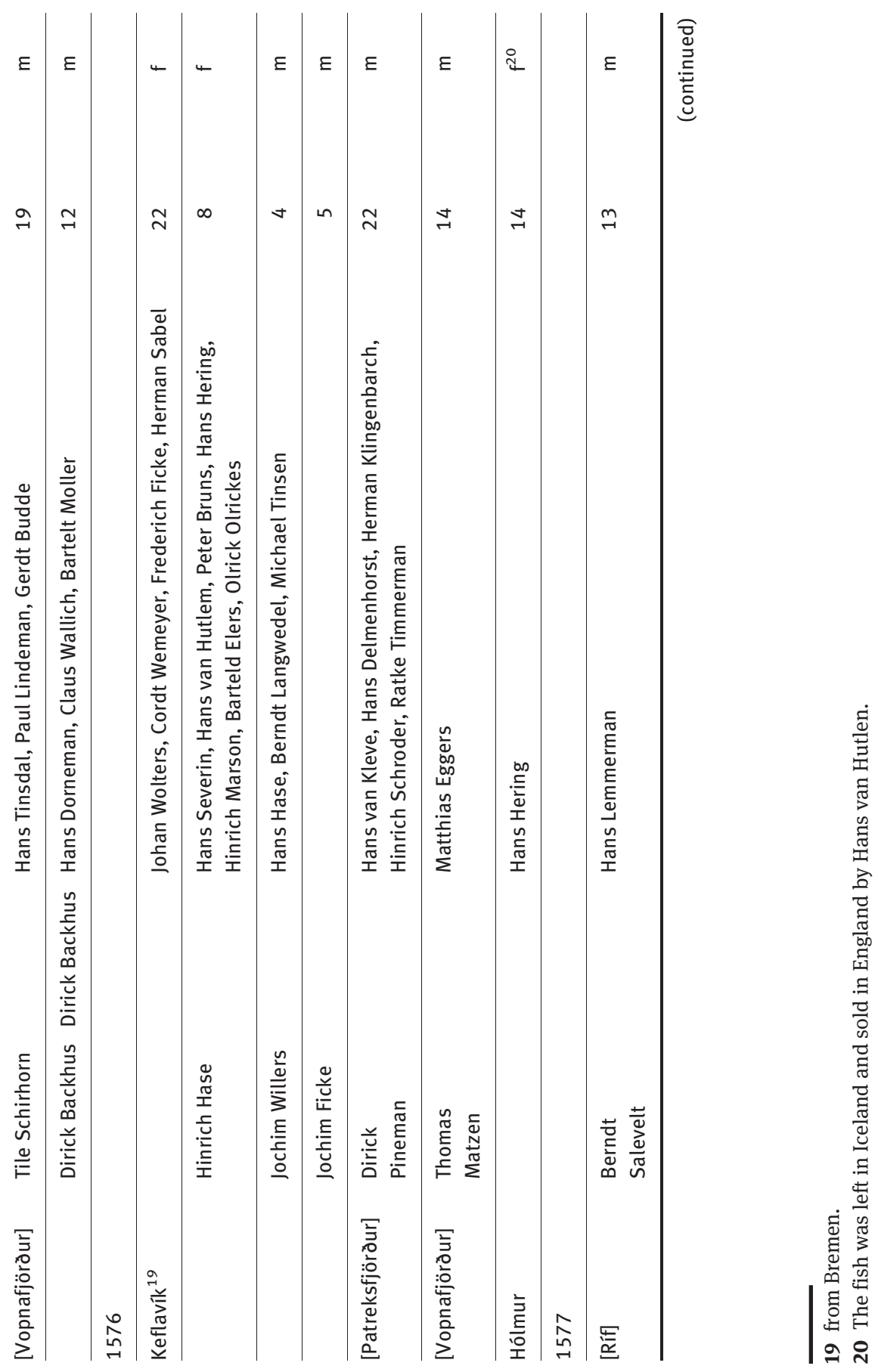




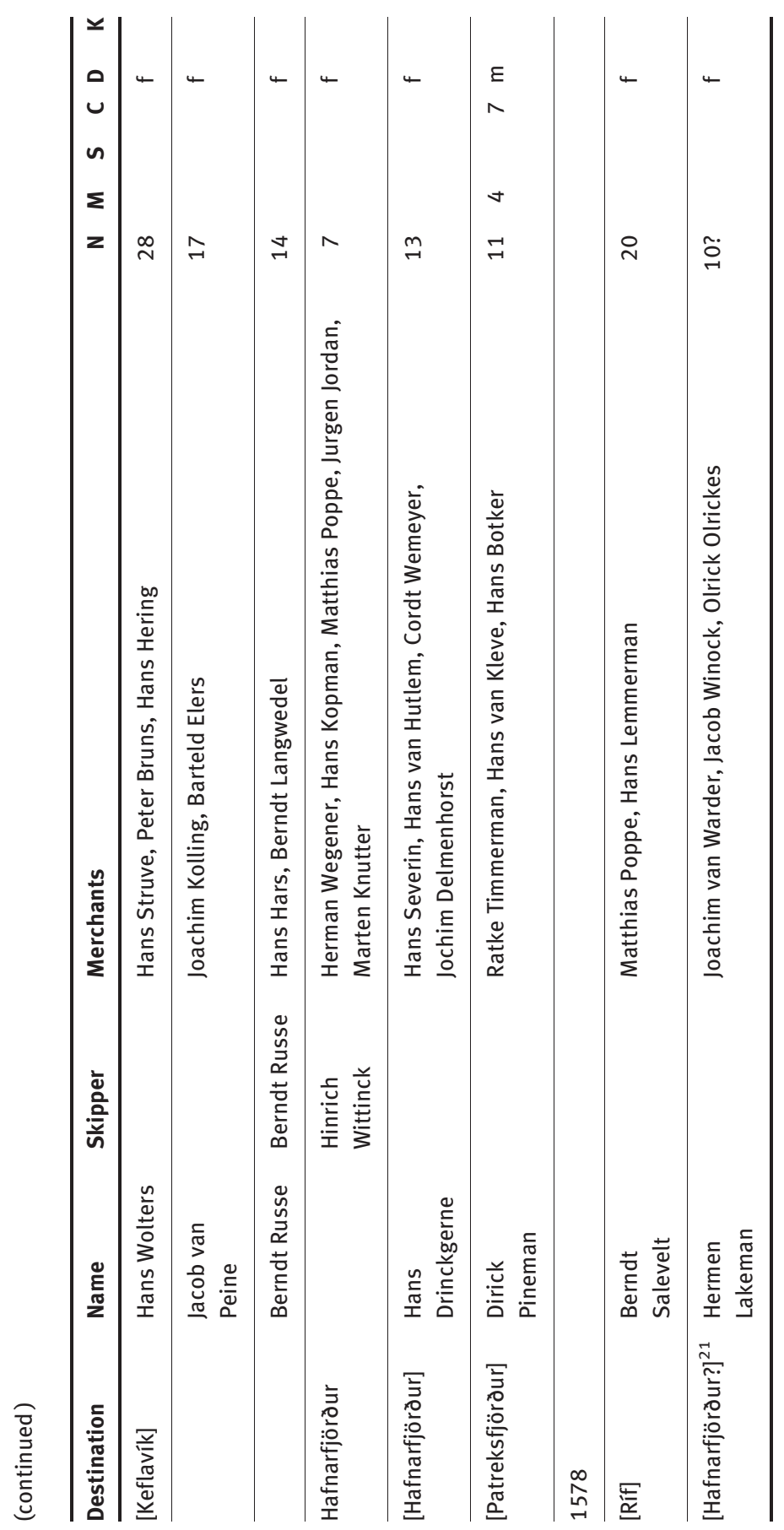

| 


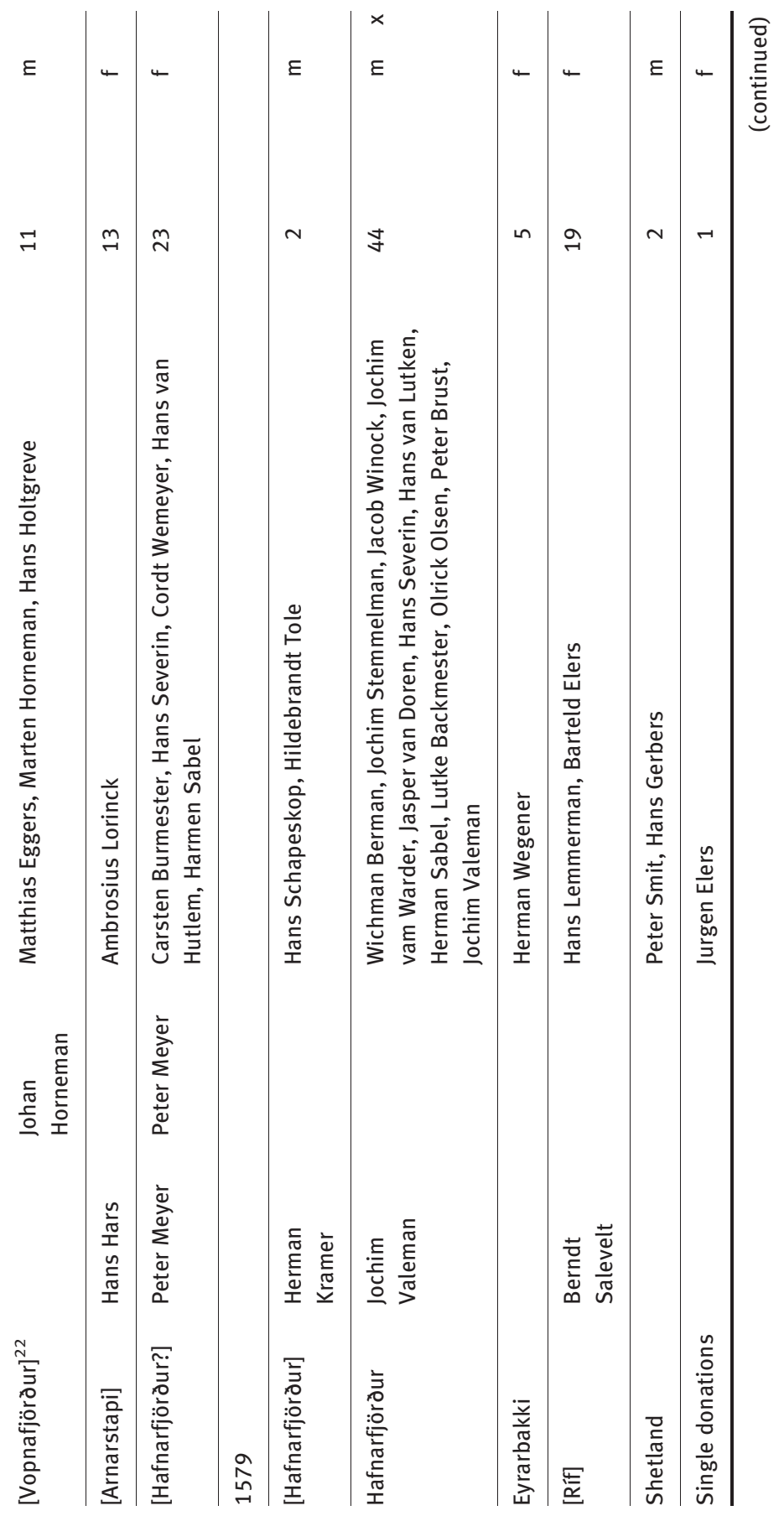

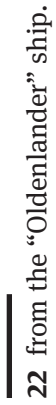




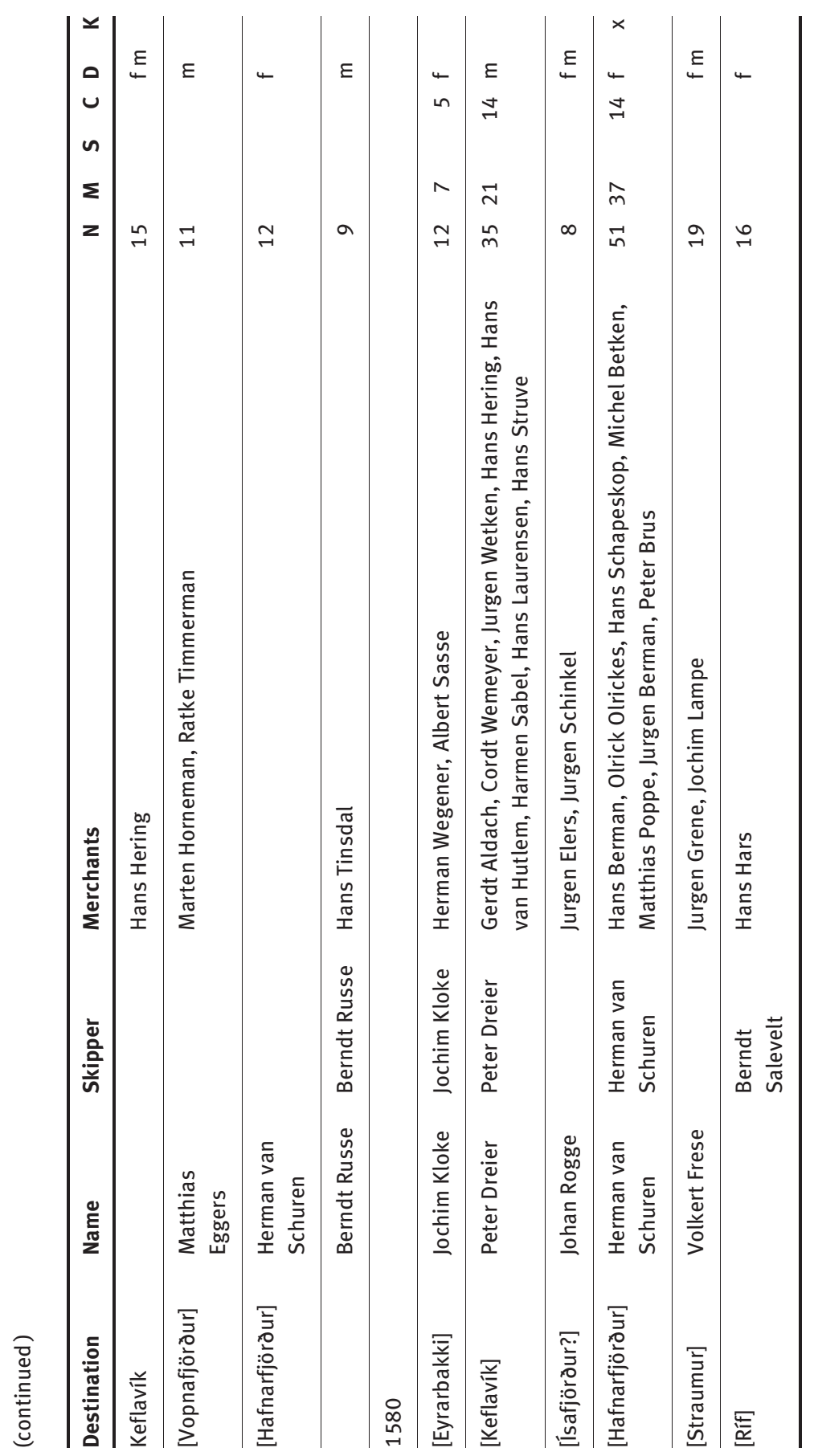




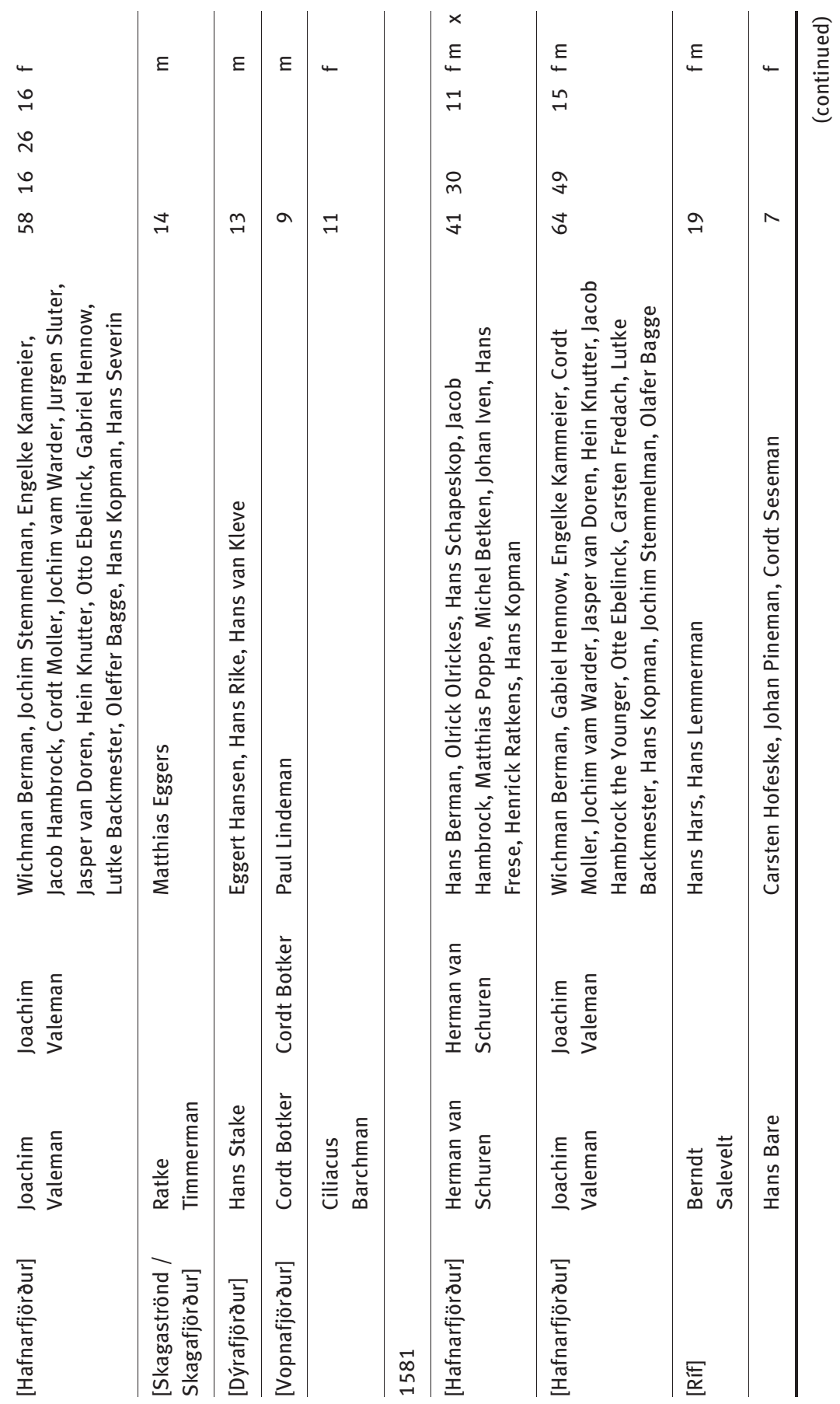




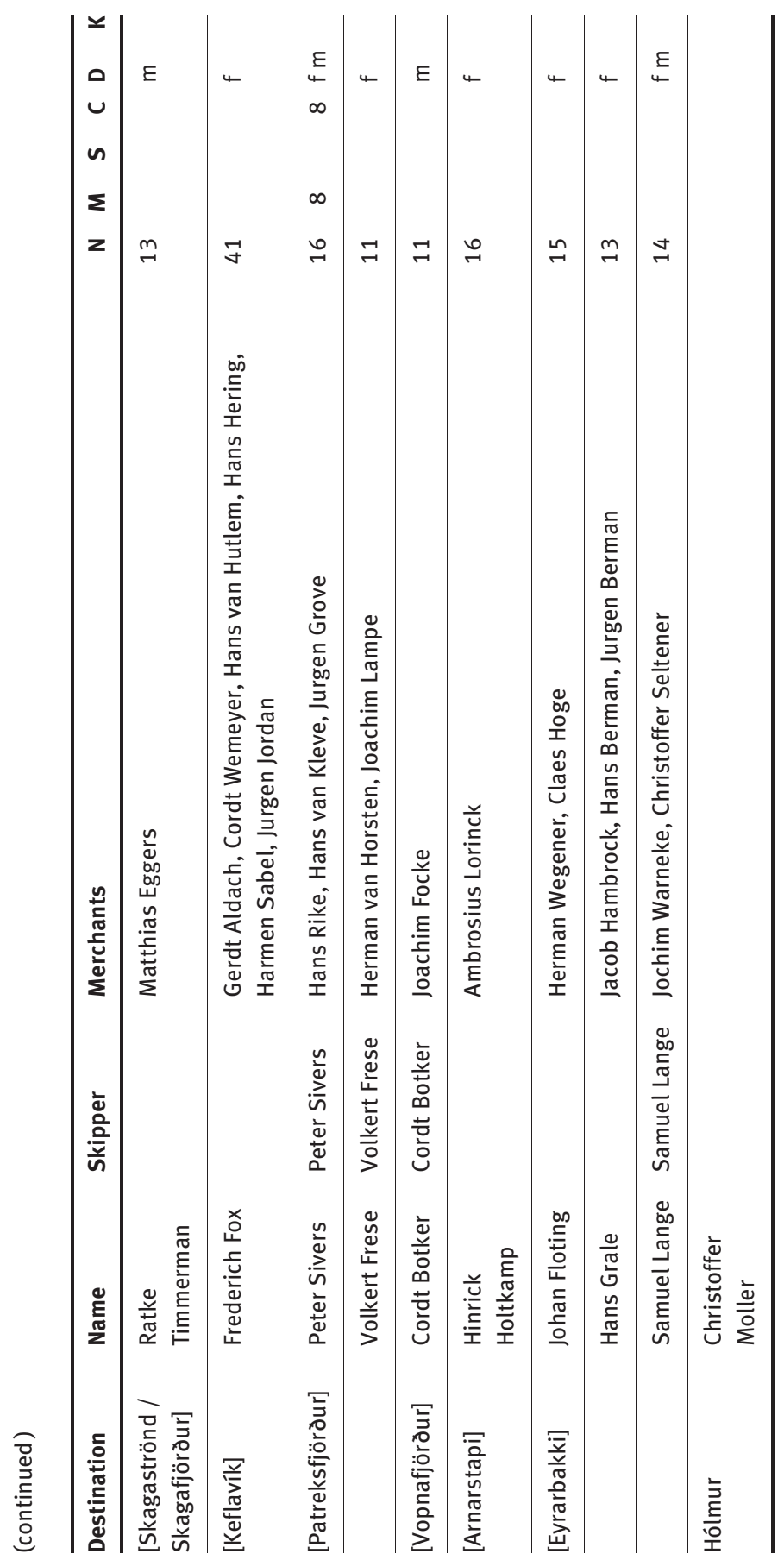




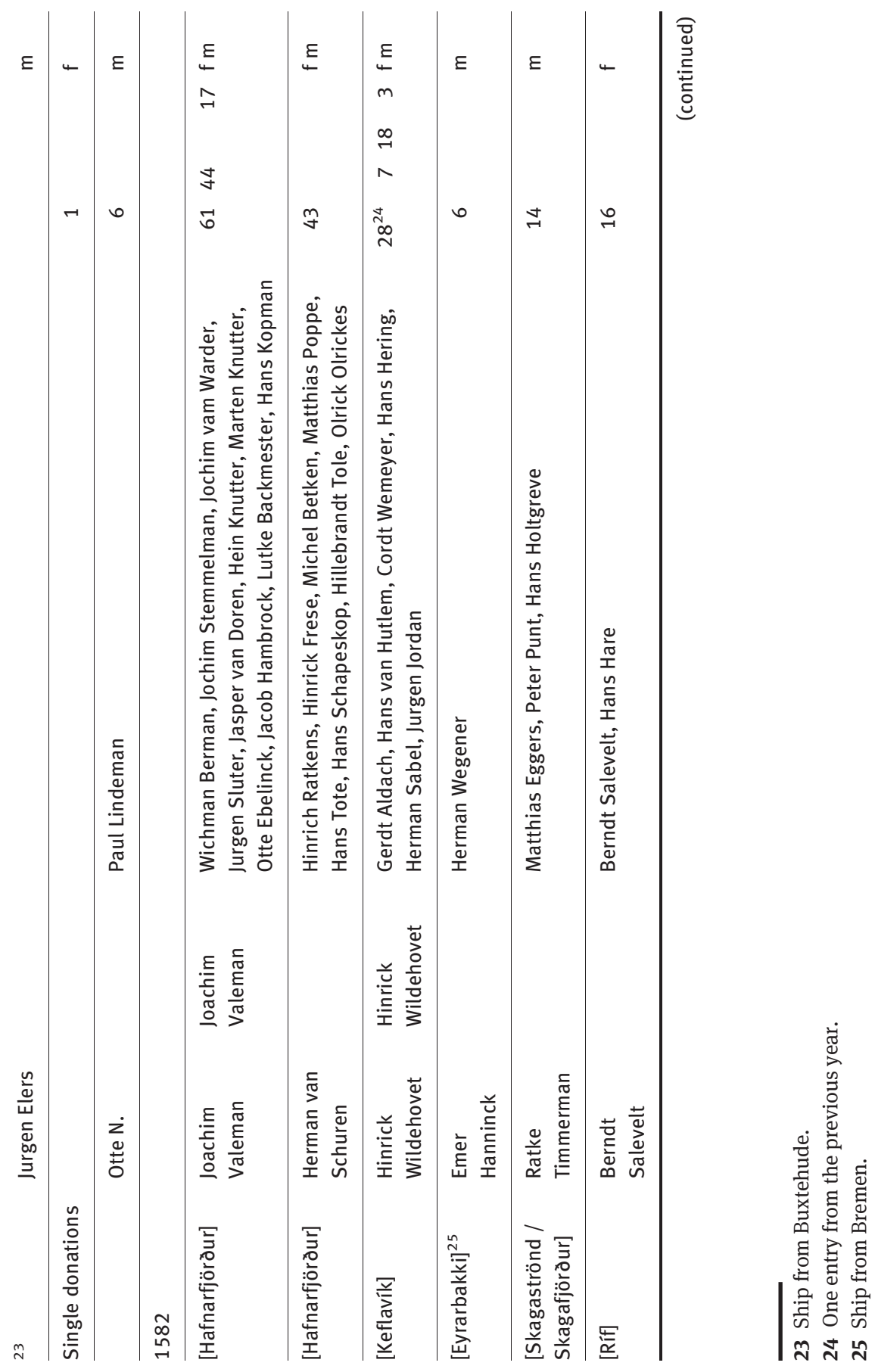




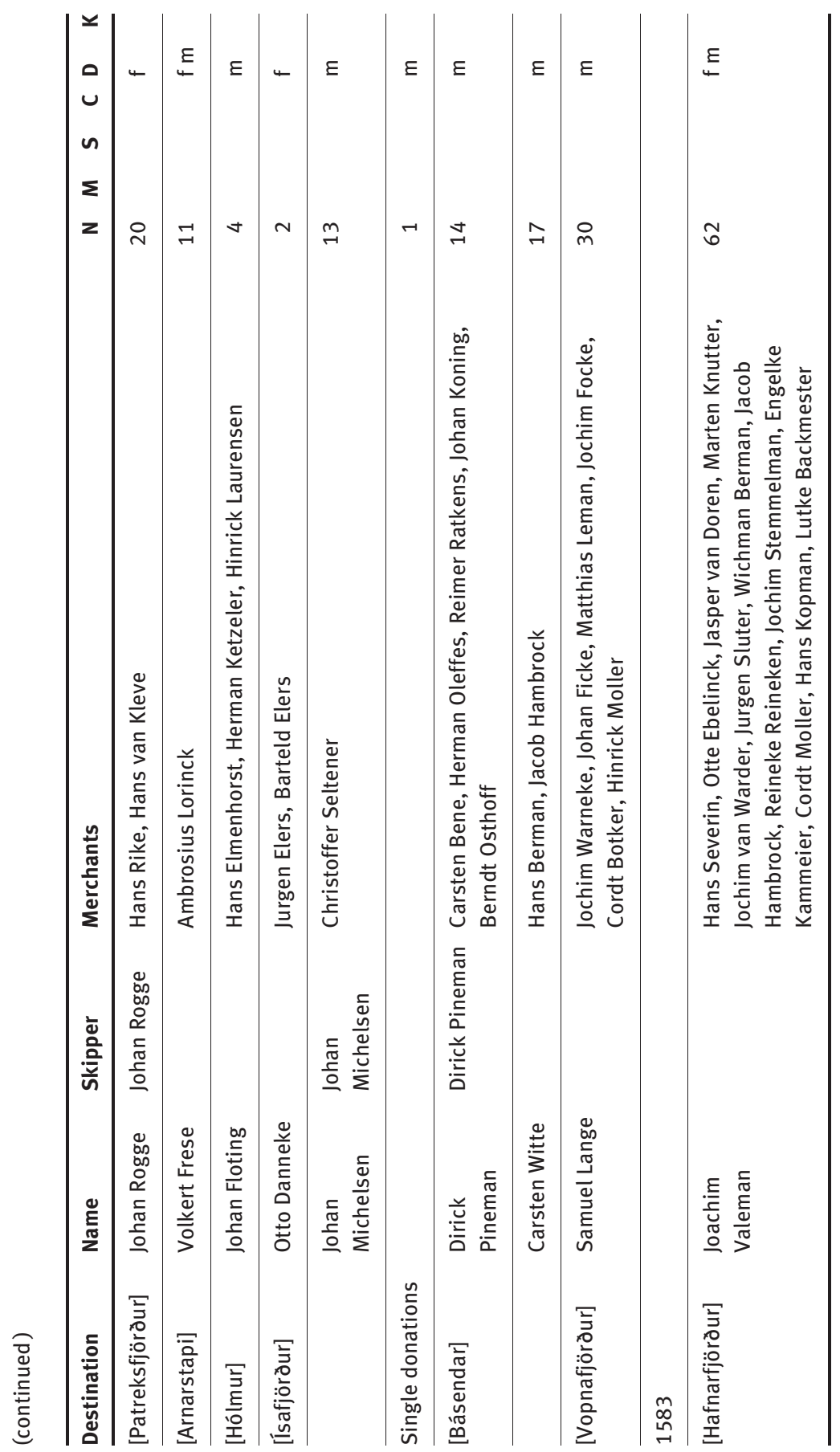




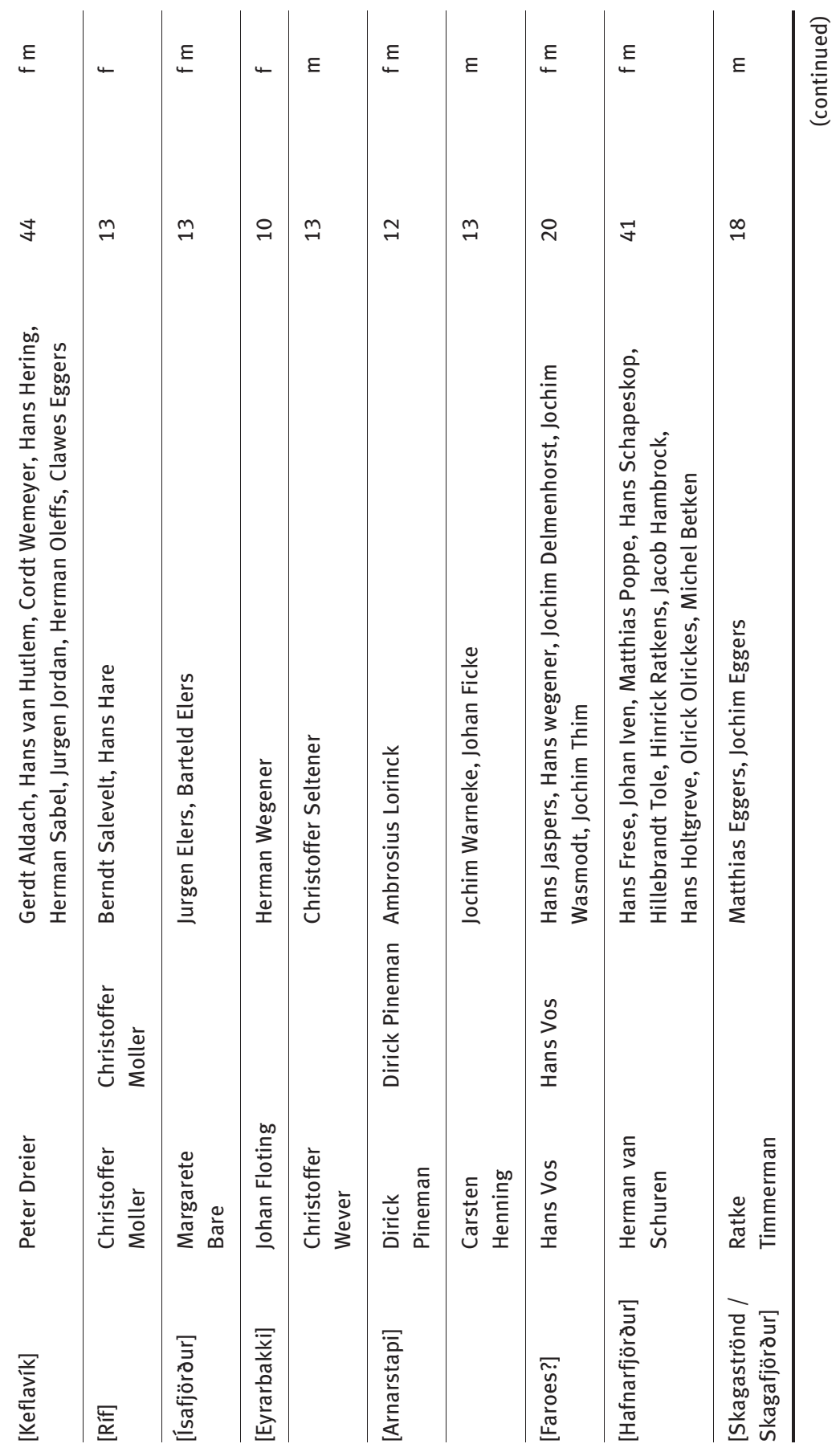




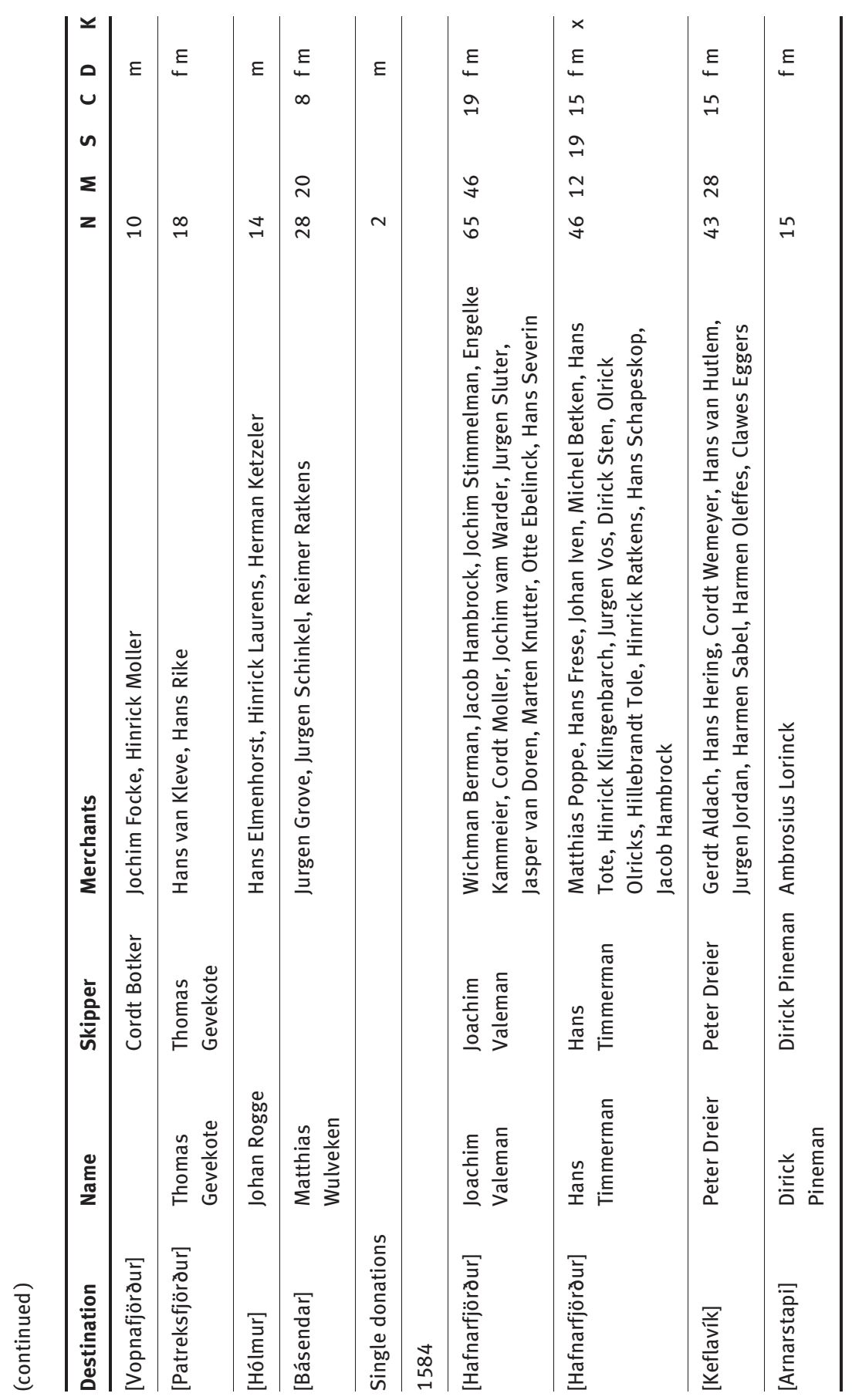




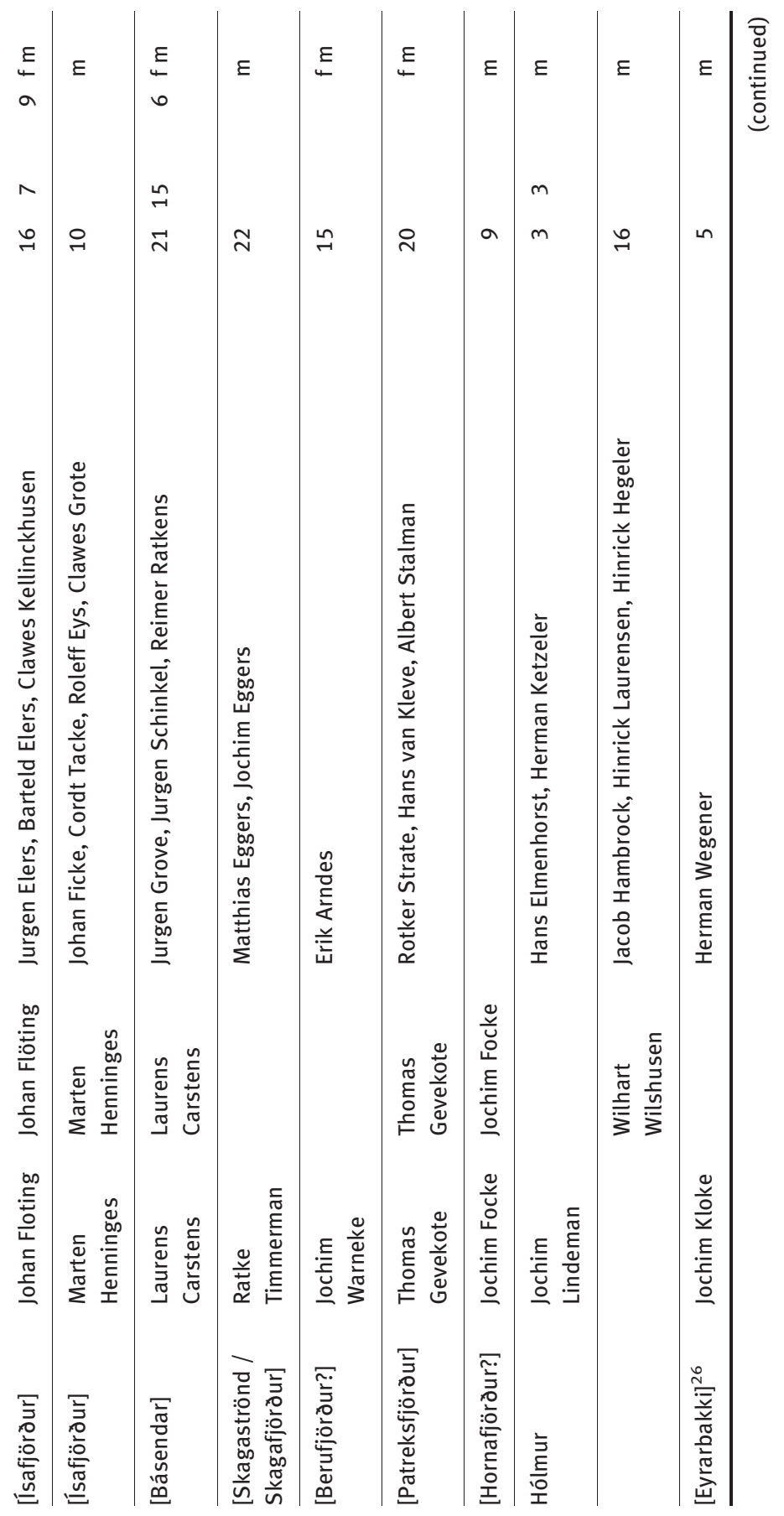

| 


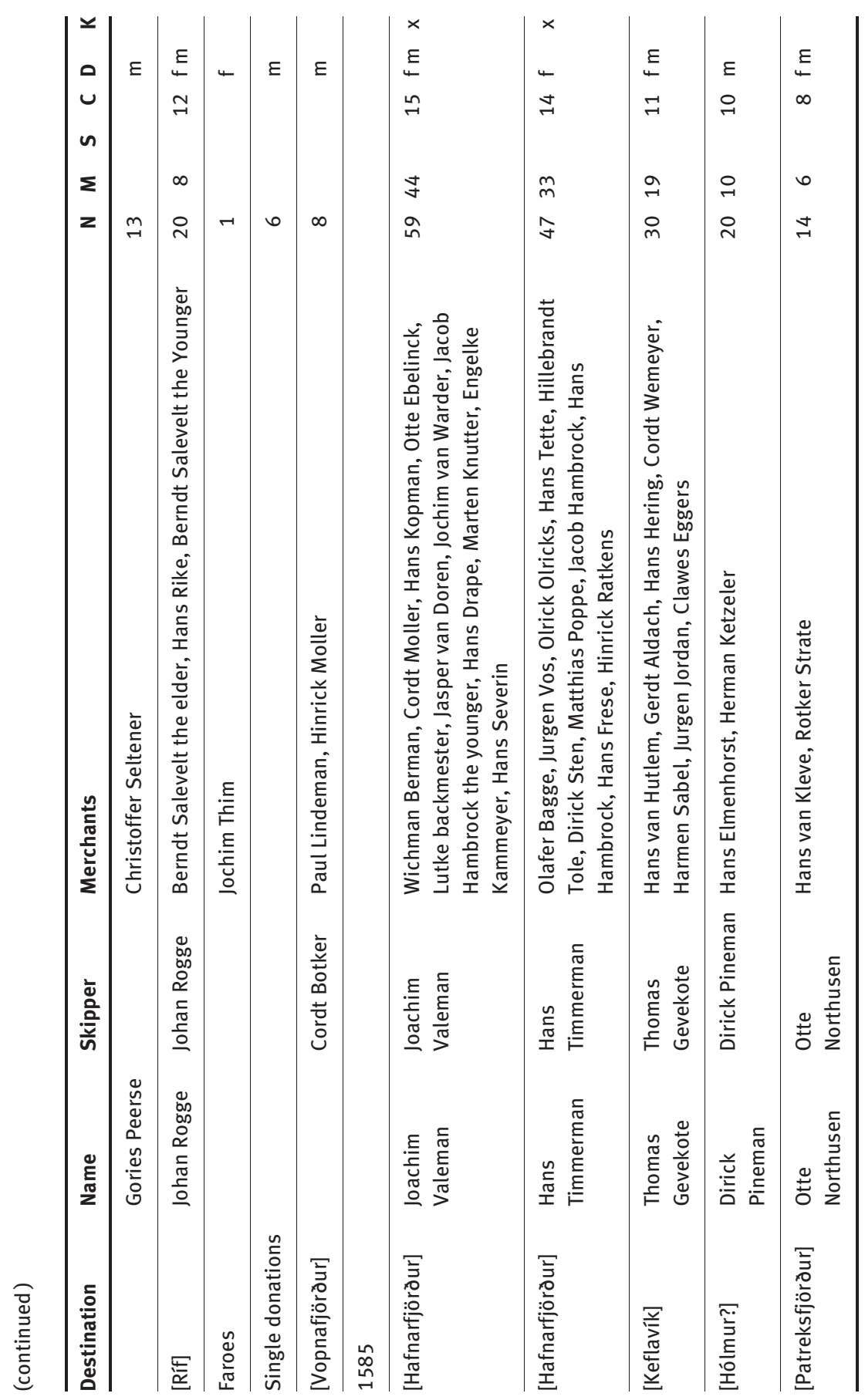




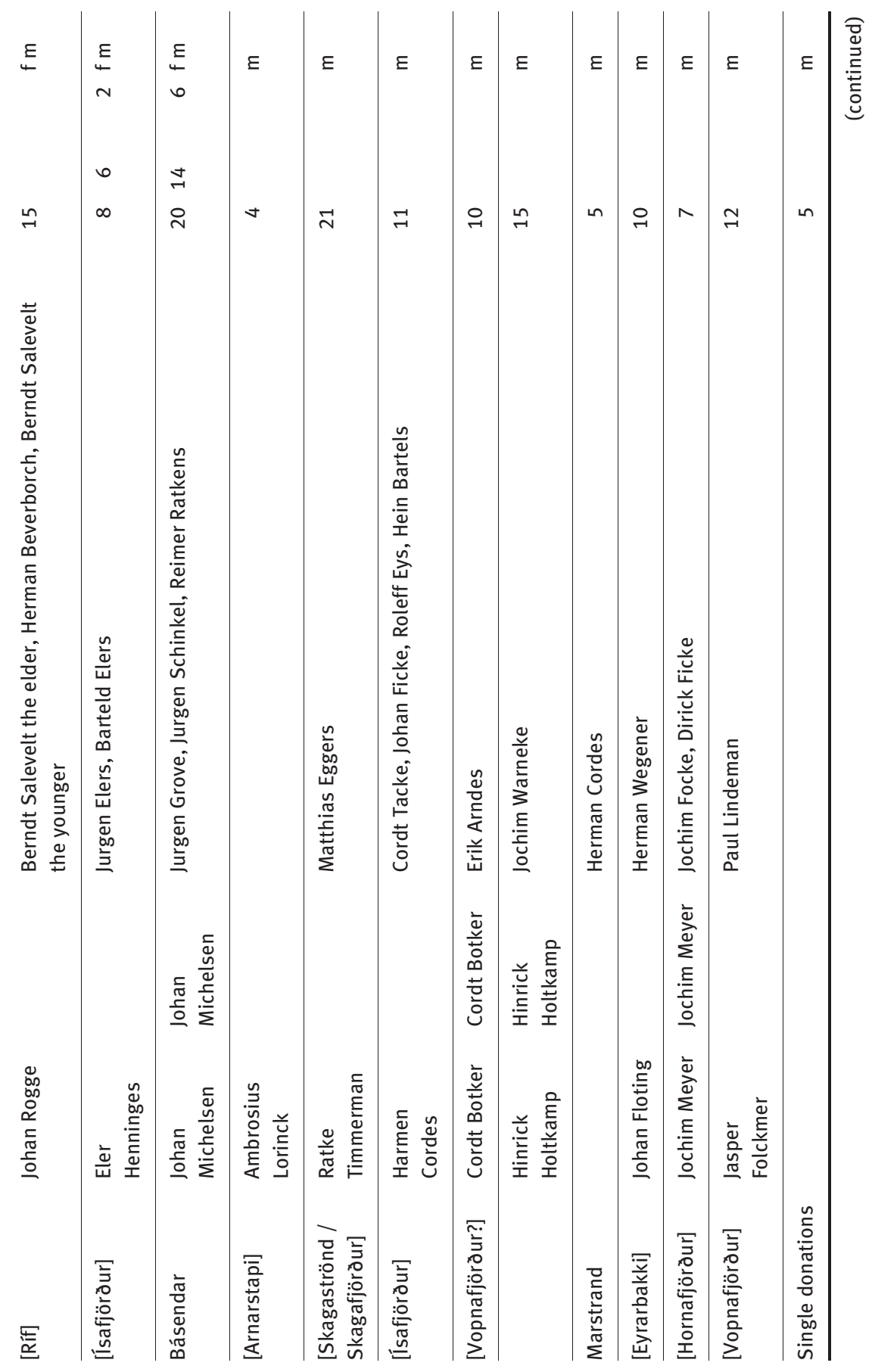




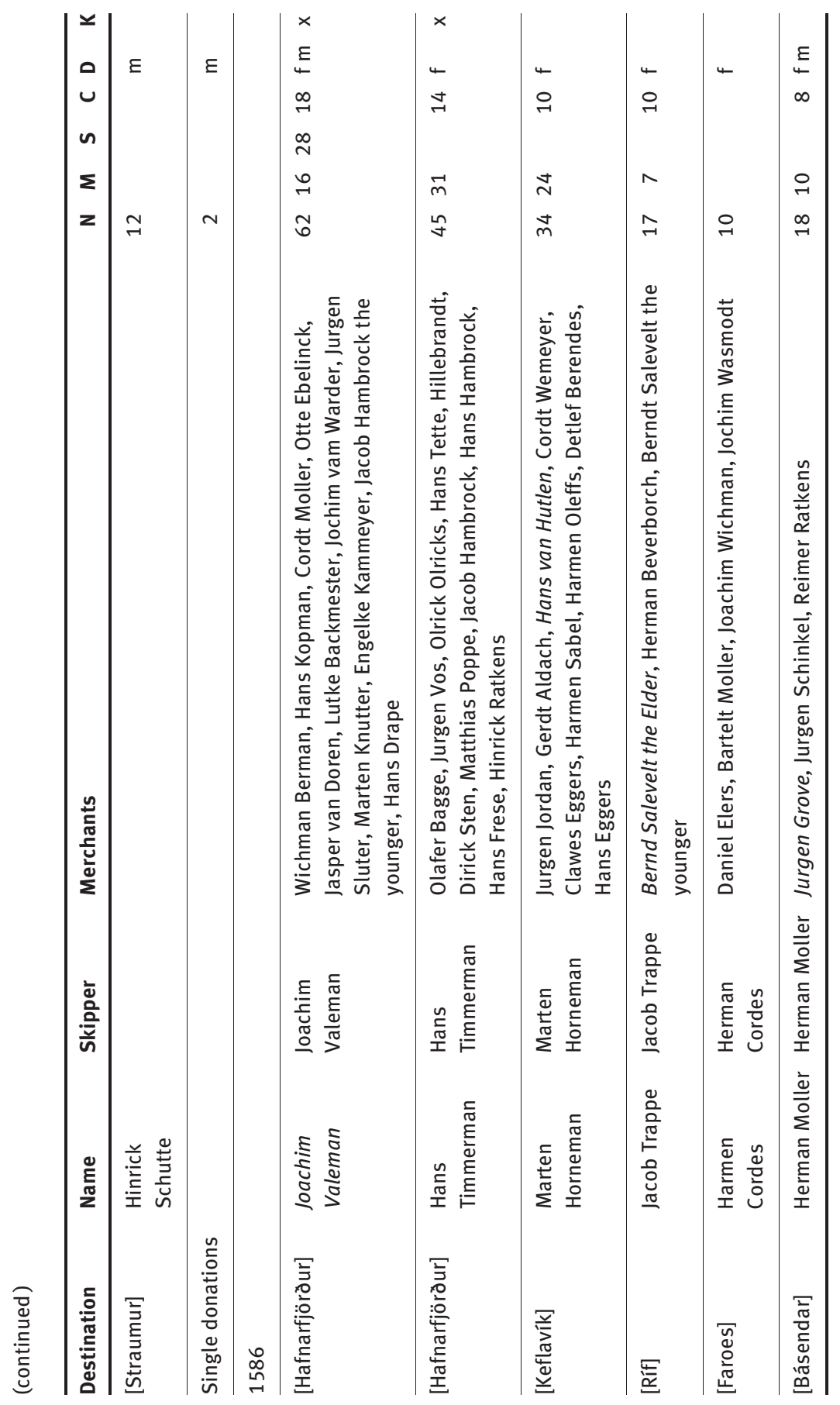




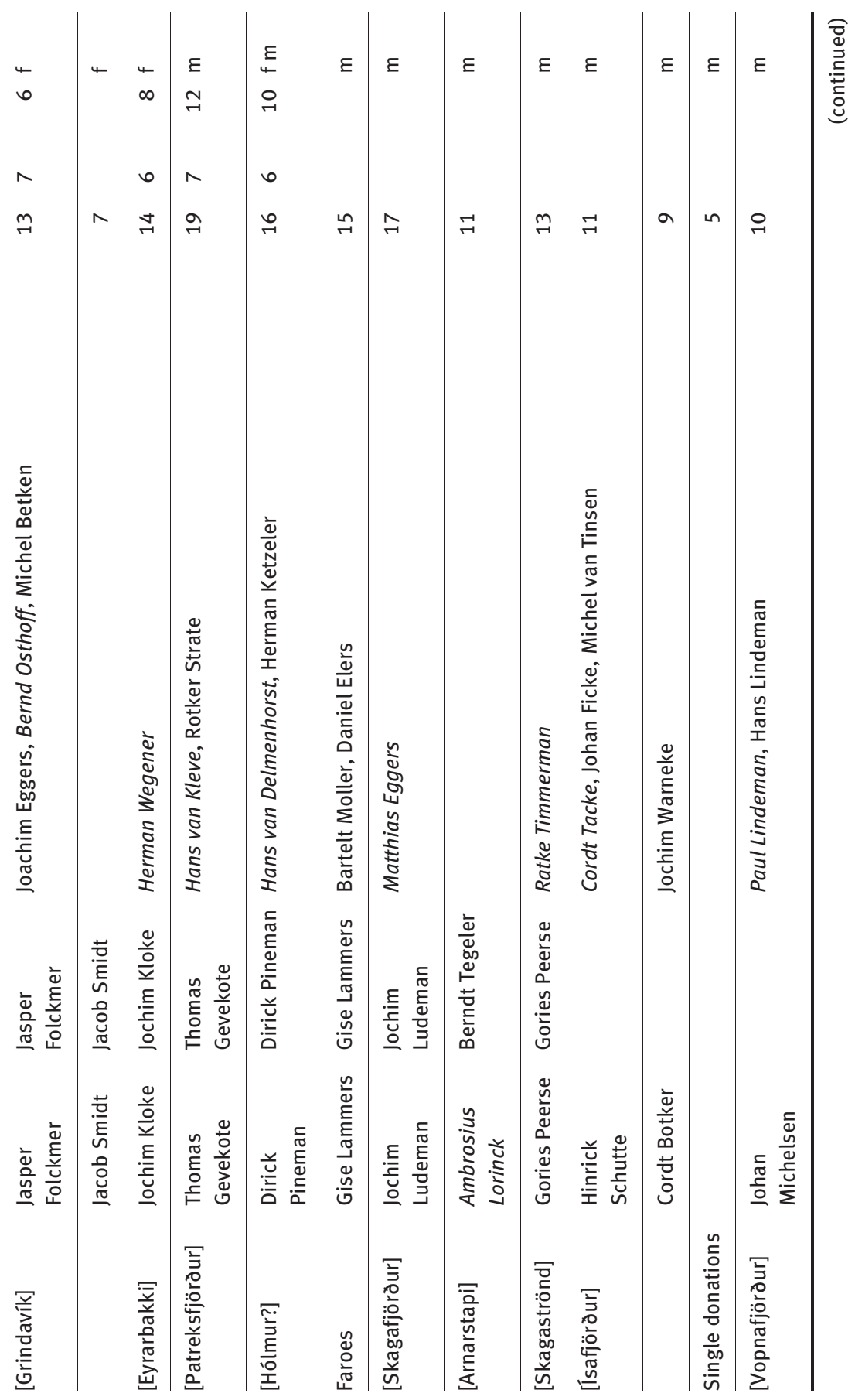



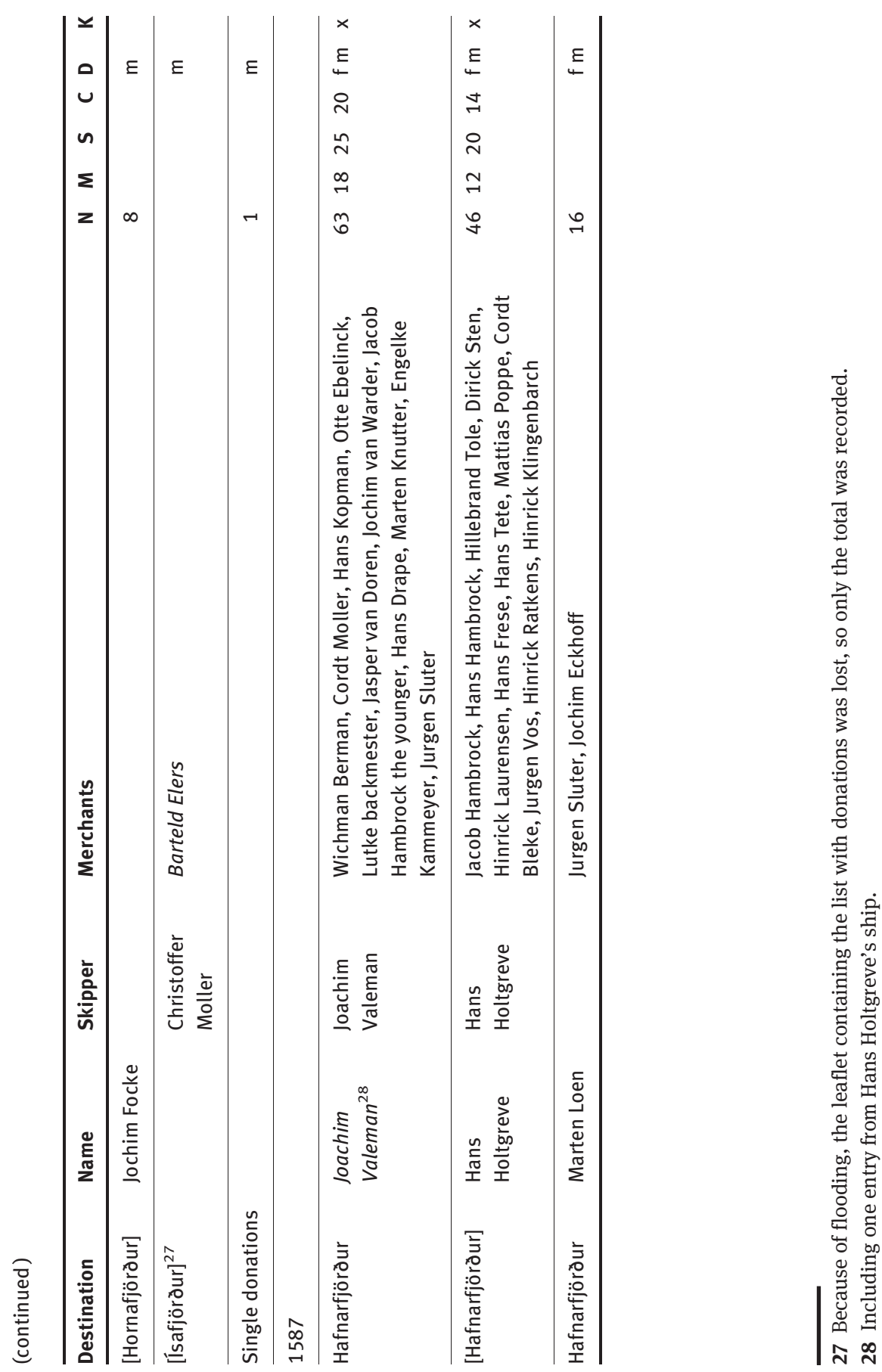


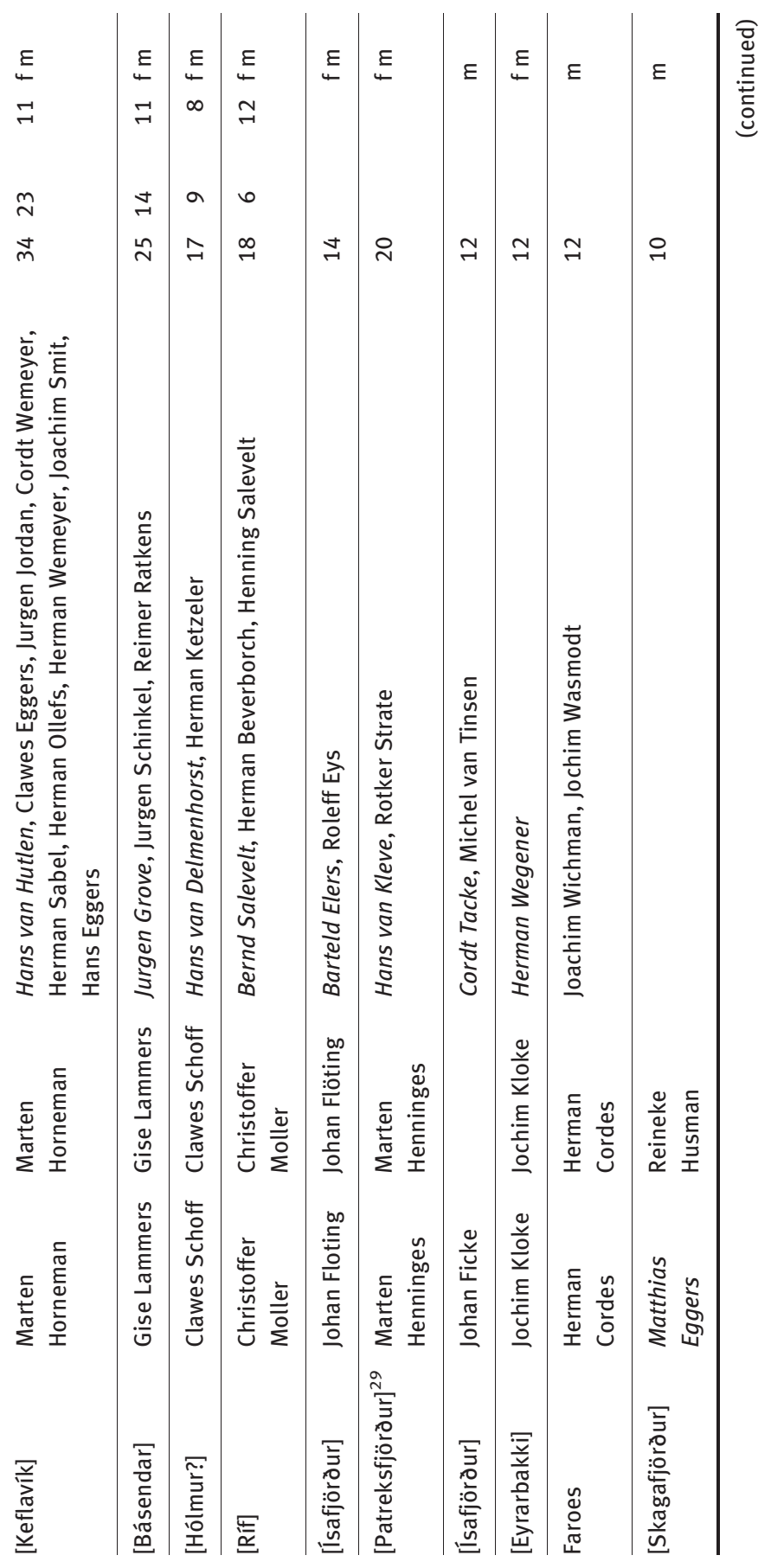

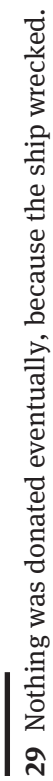




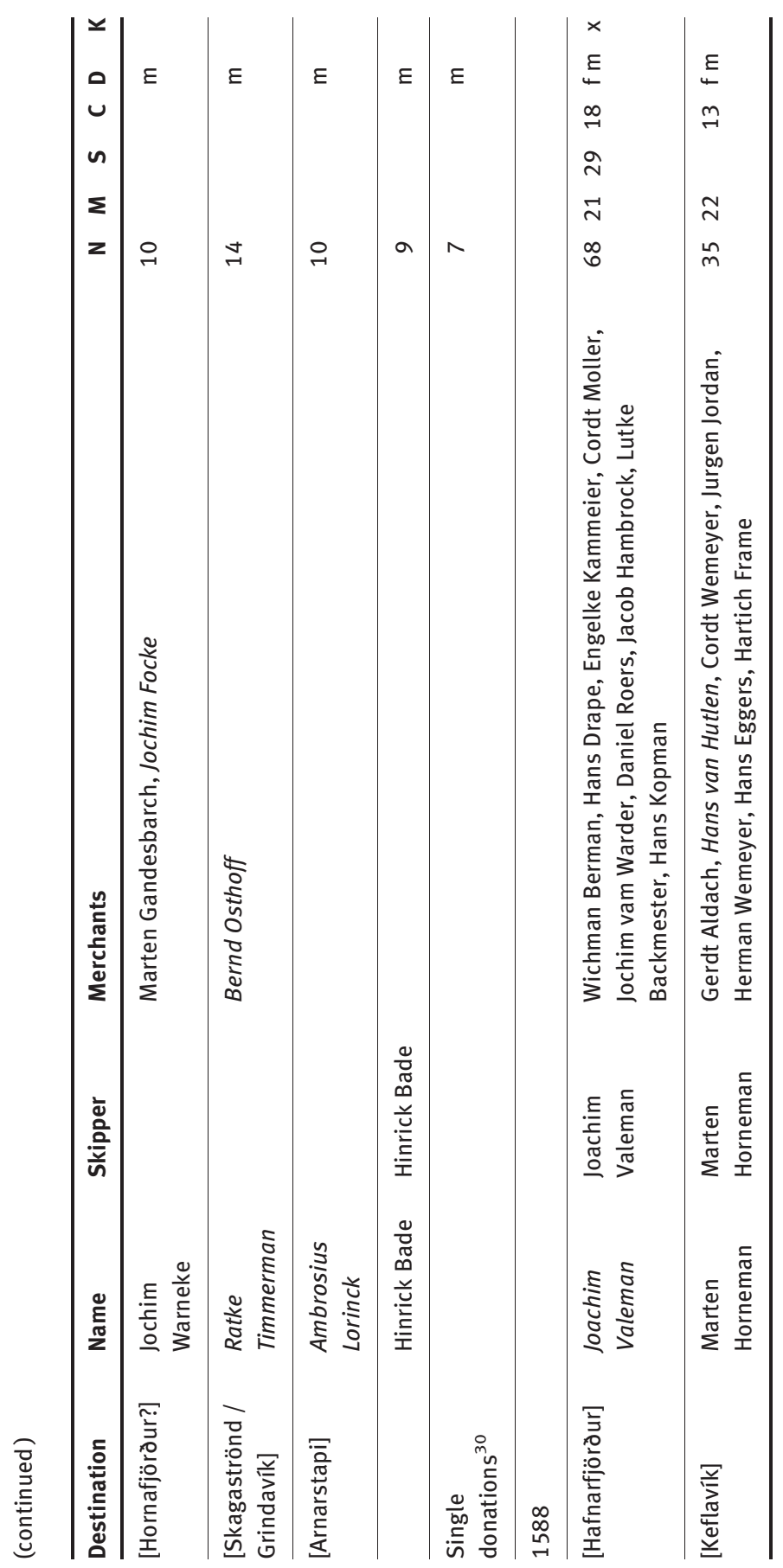




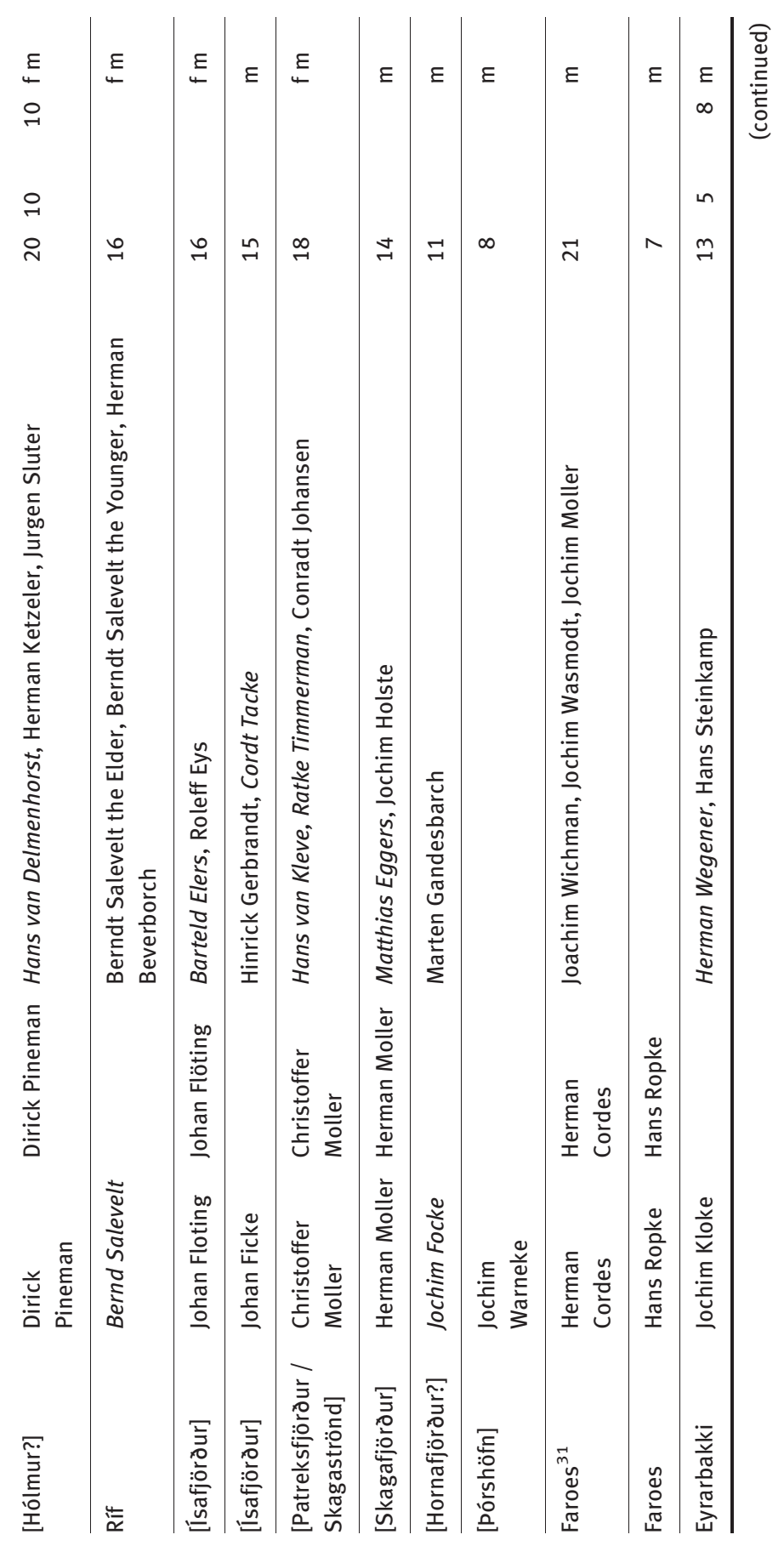

| 


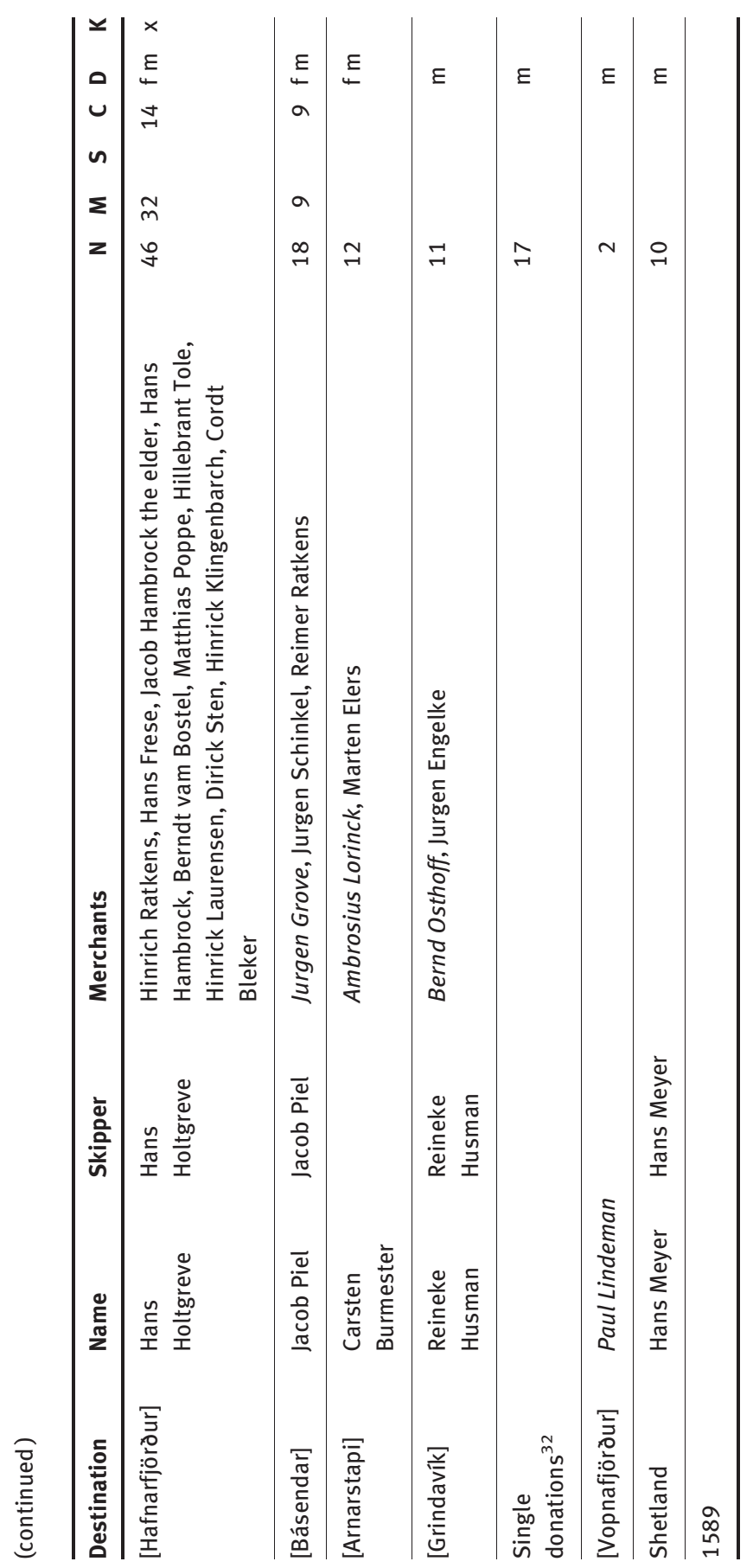

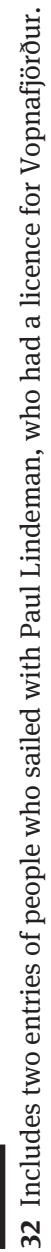




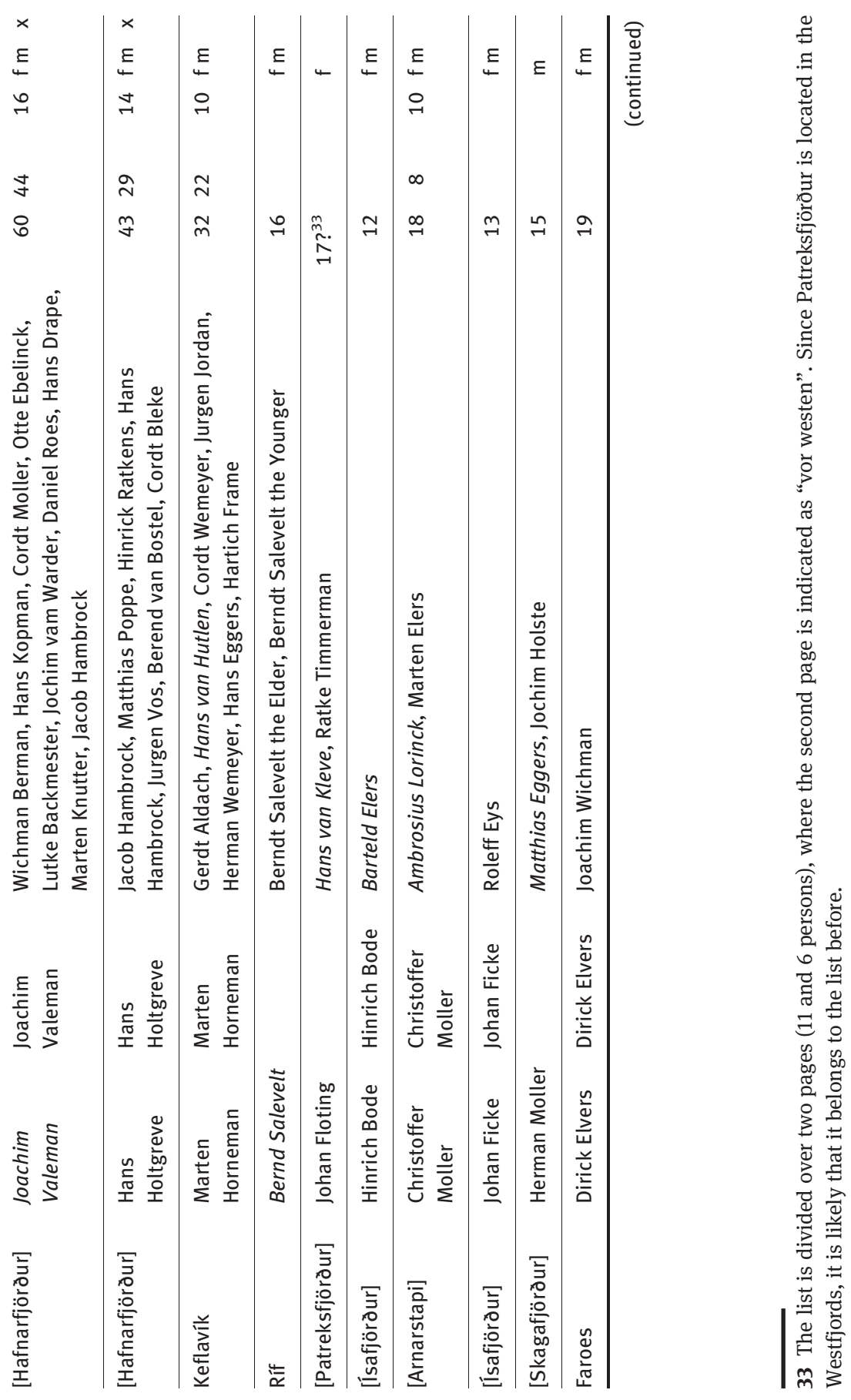




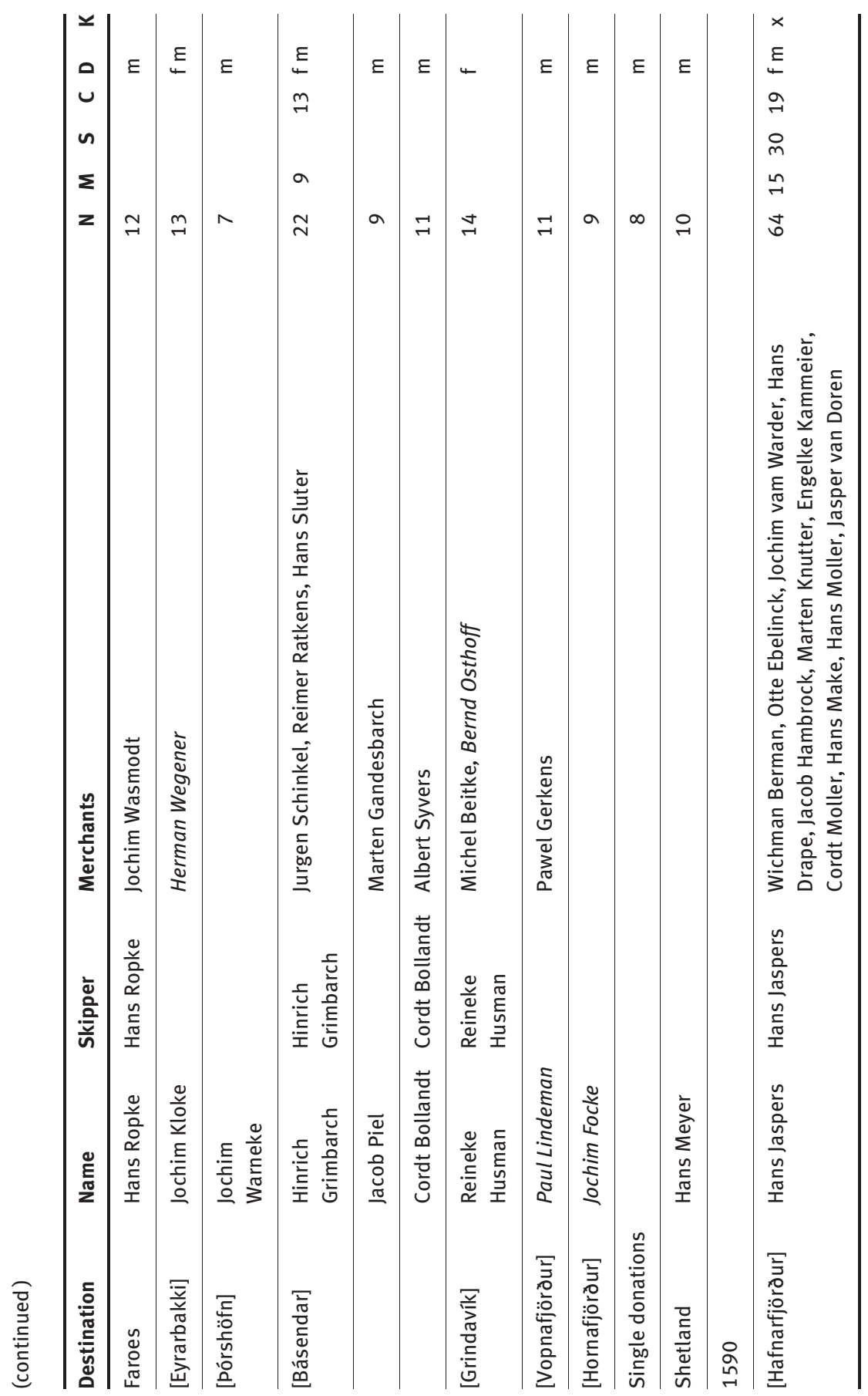




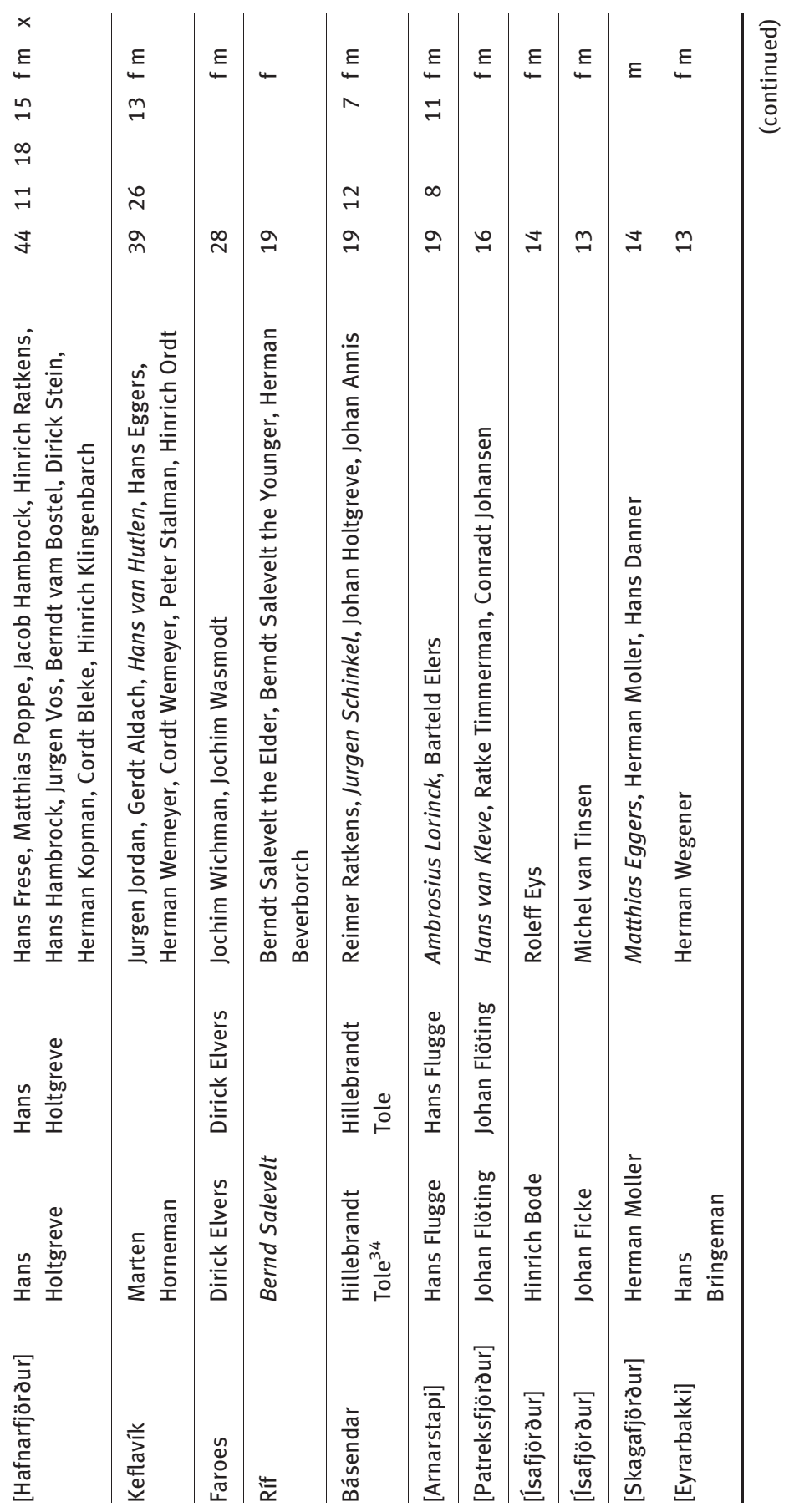




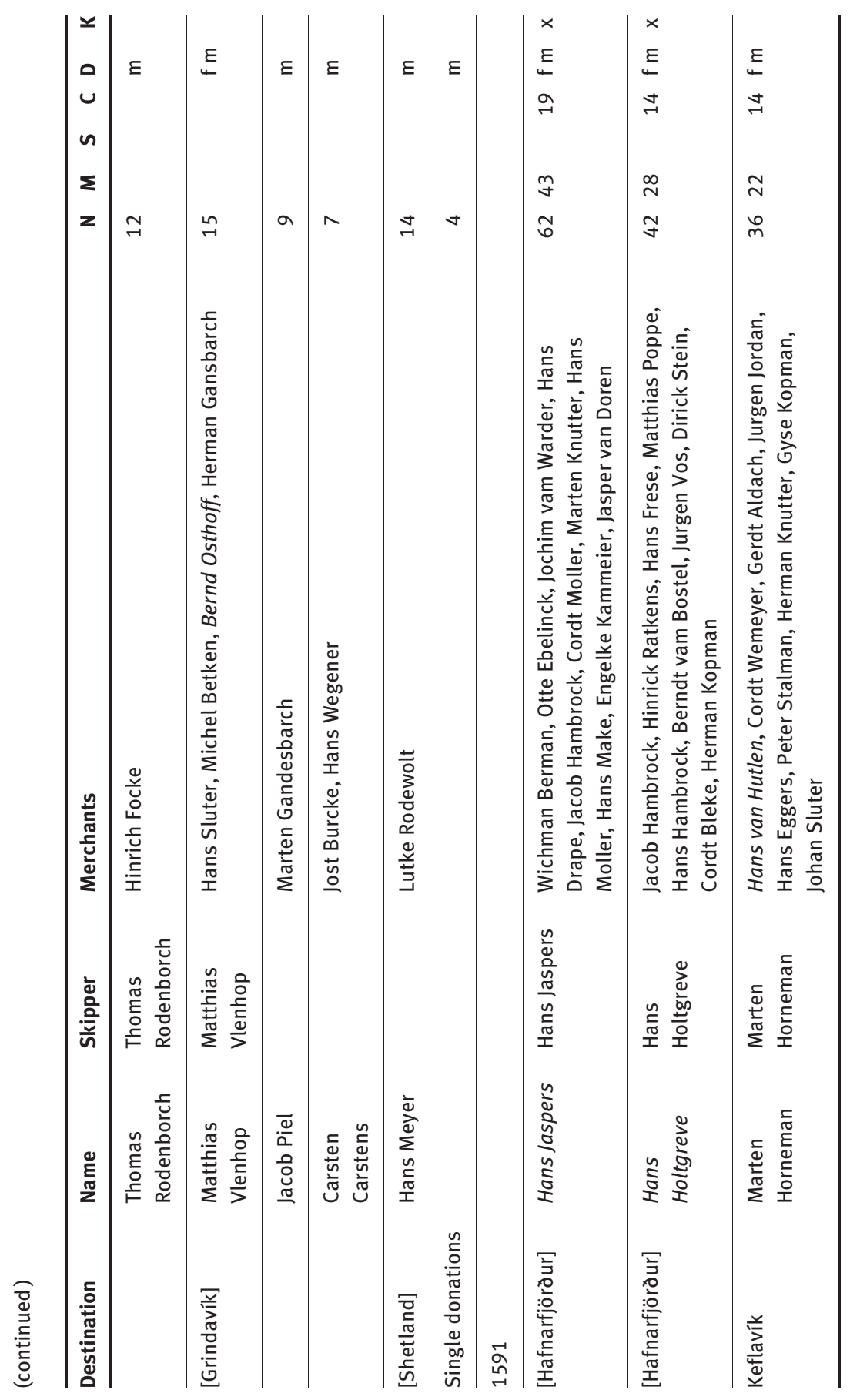




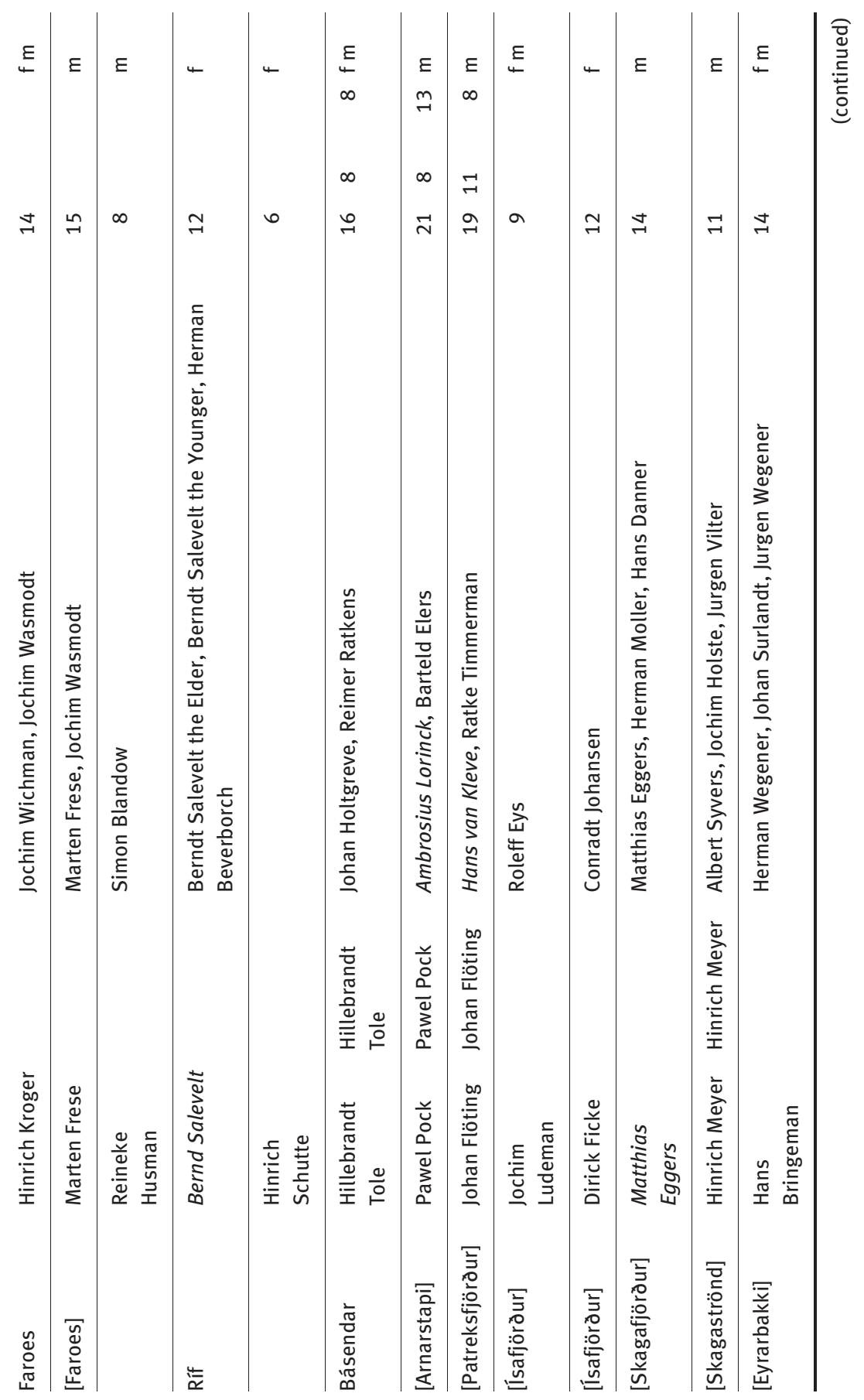




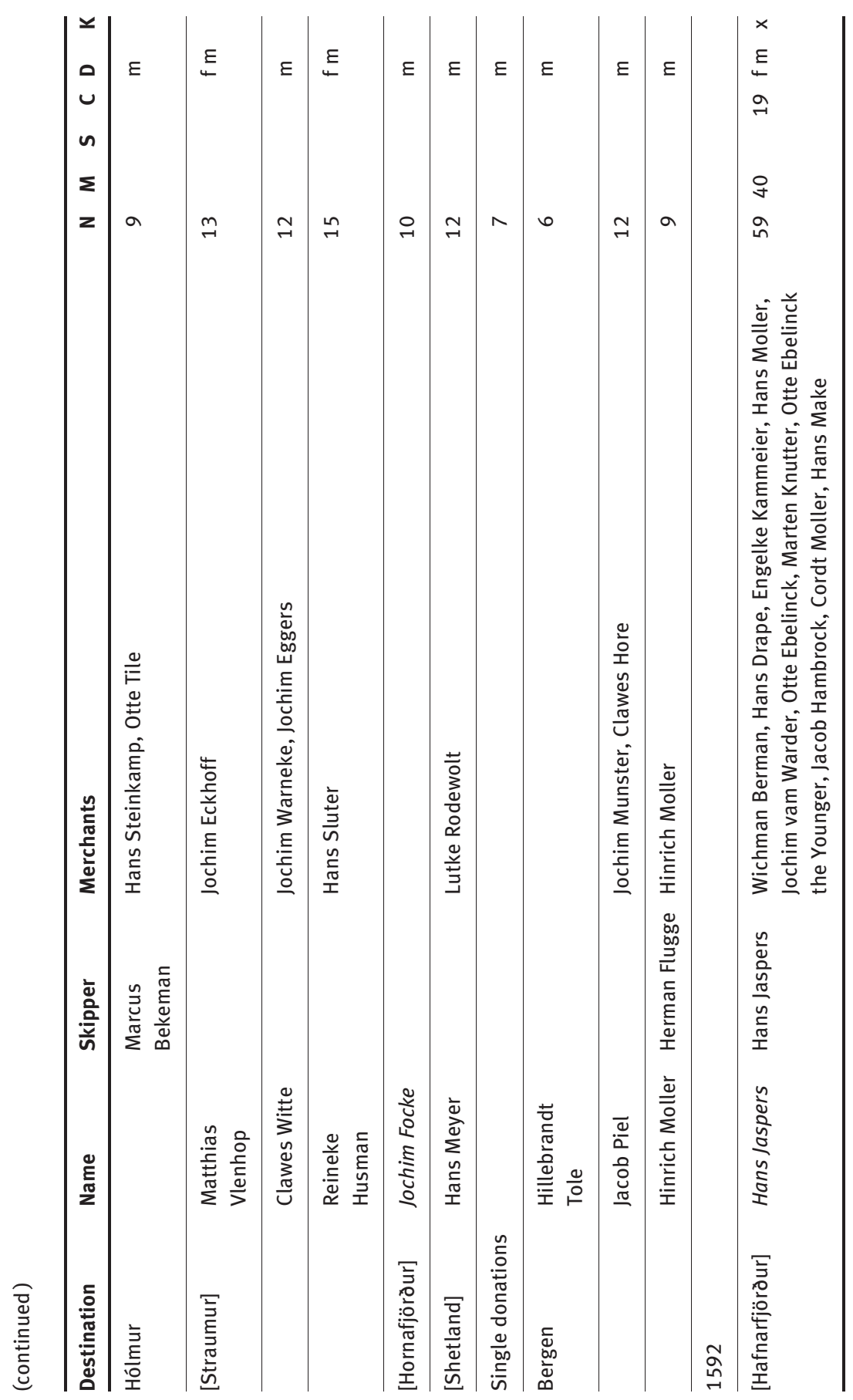




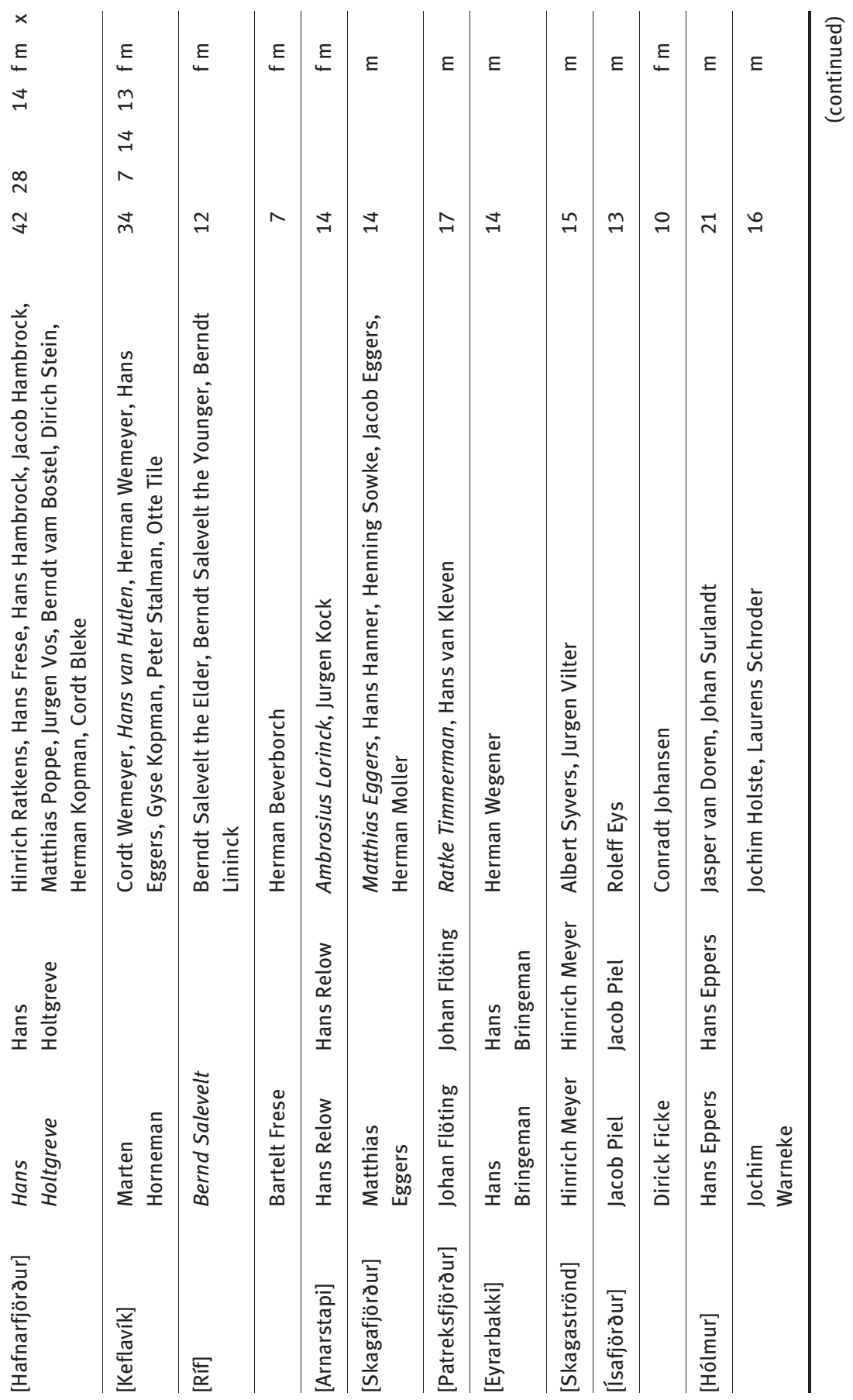




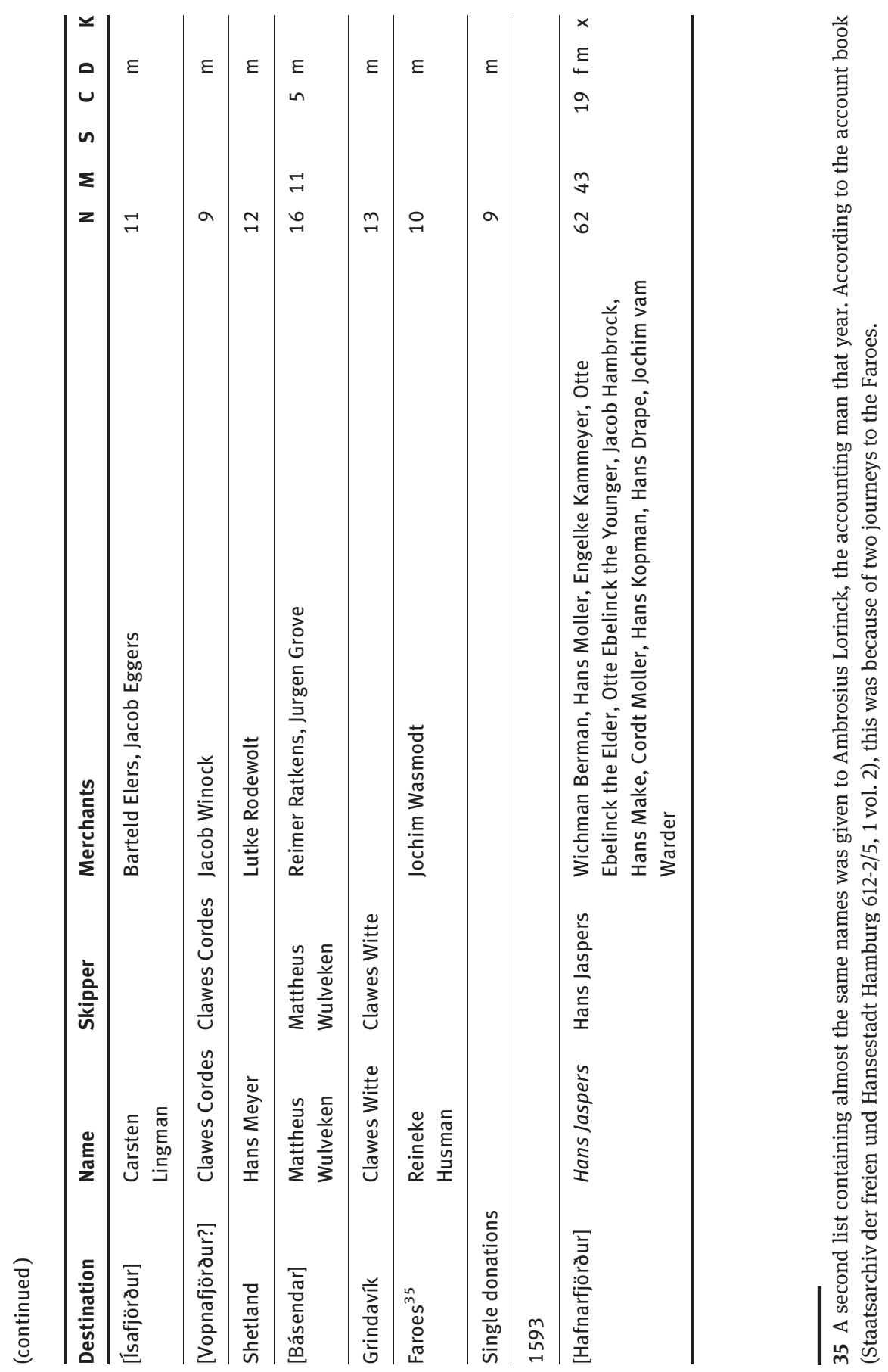




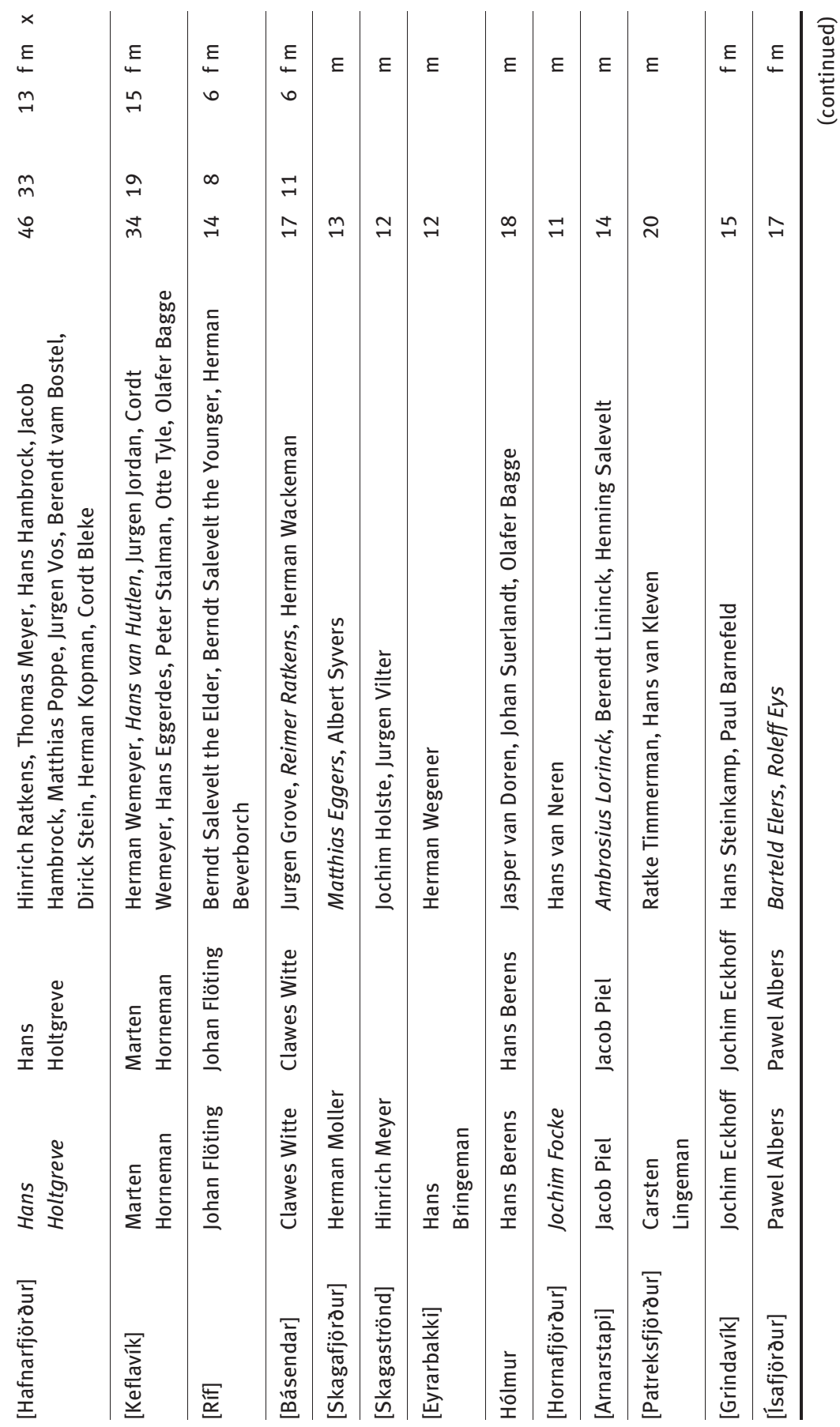




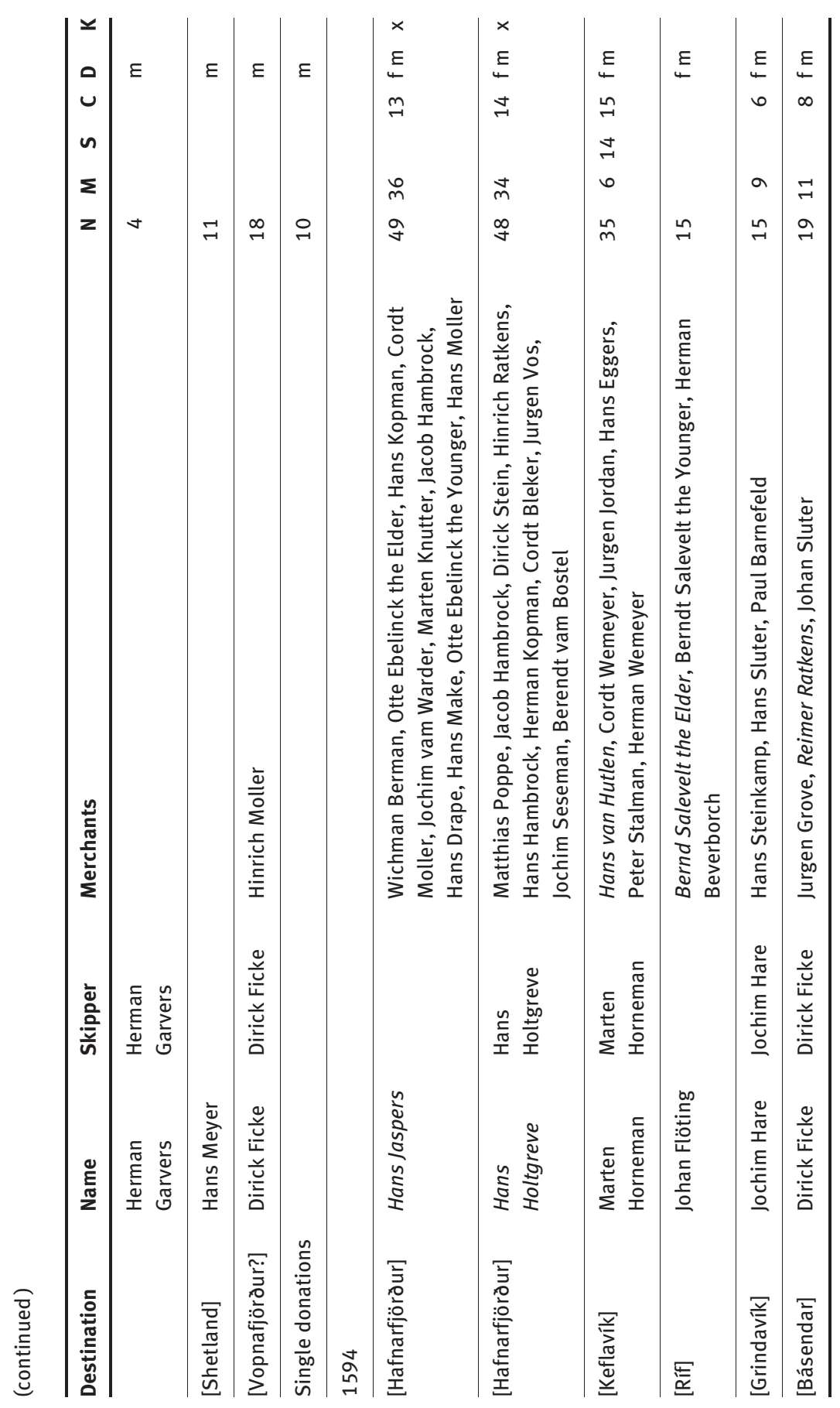




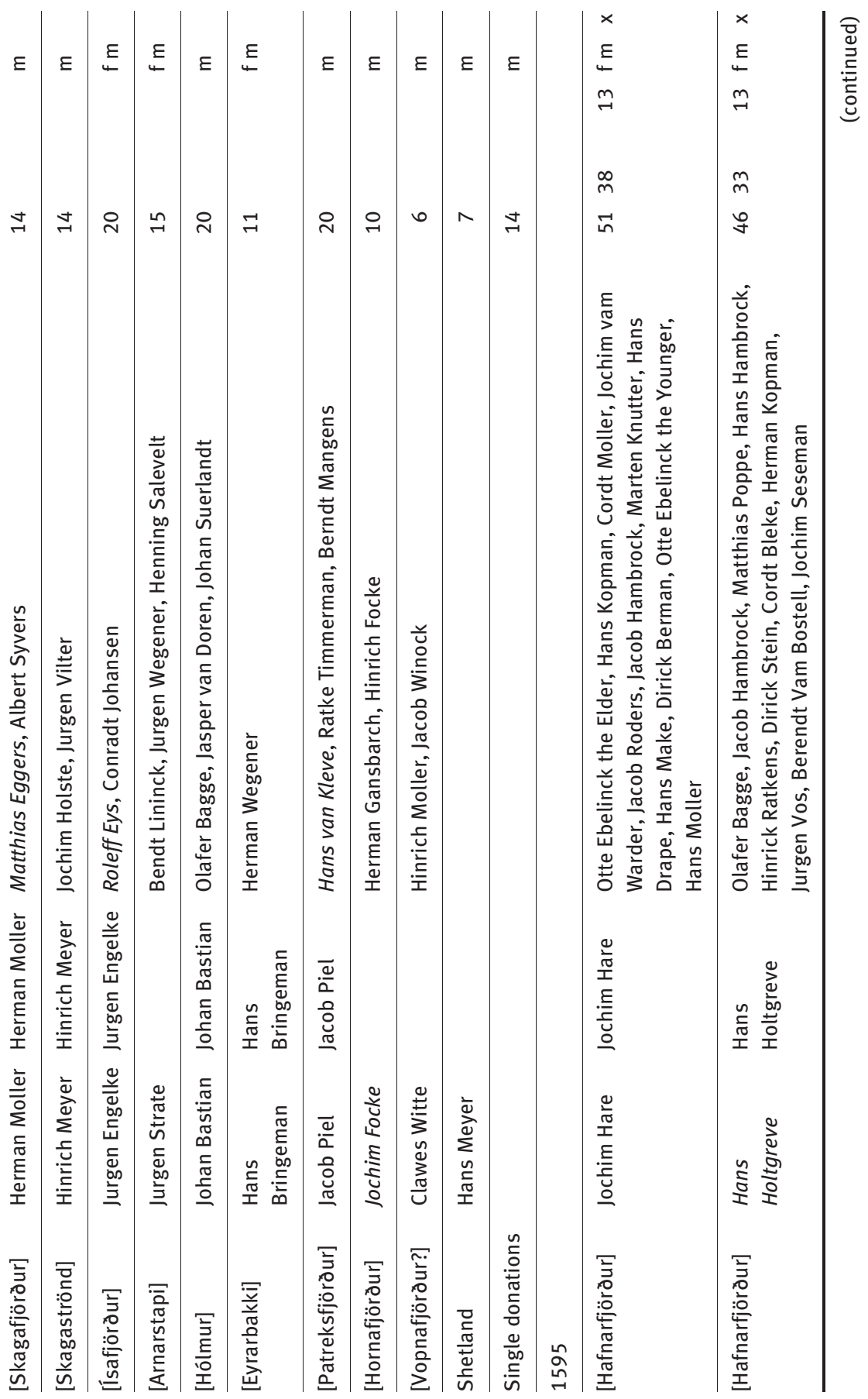




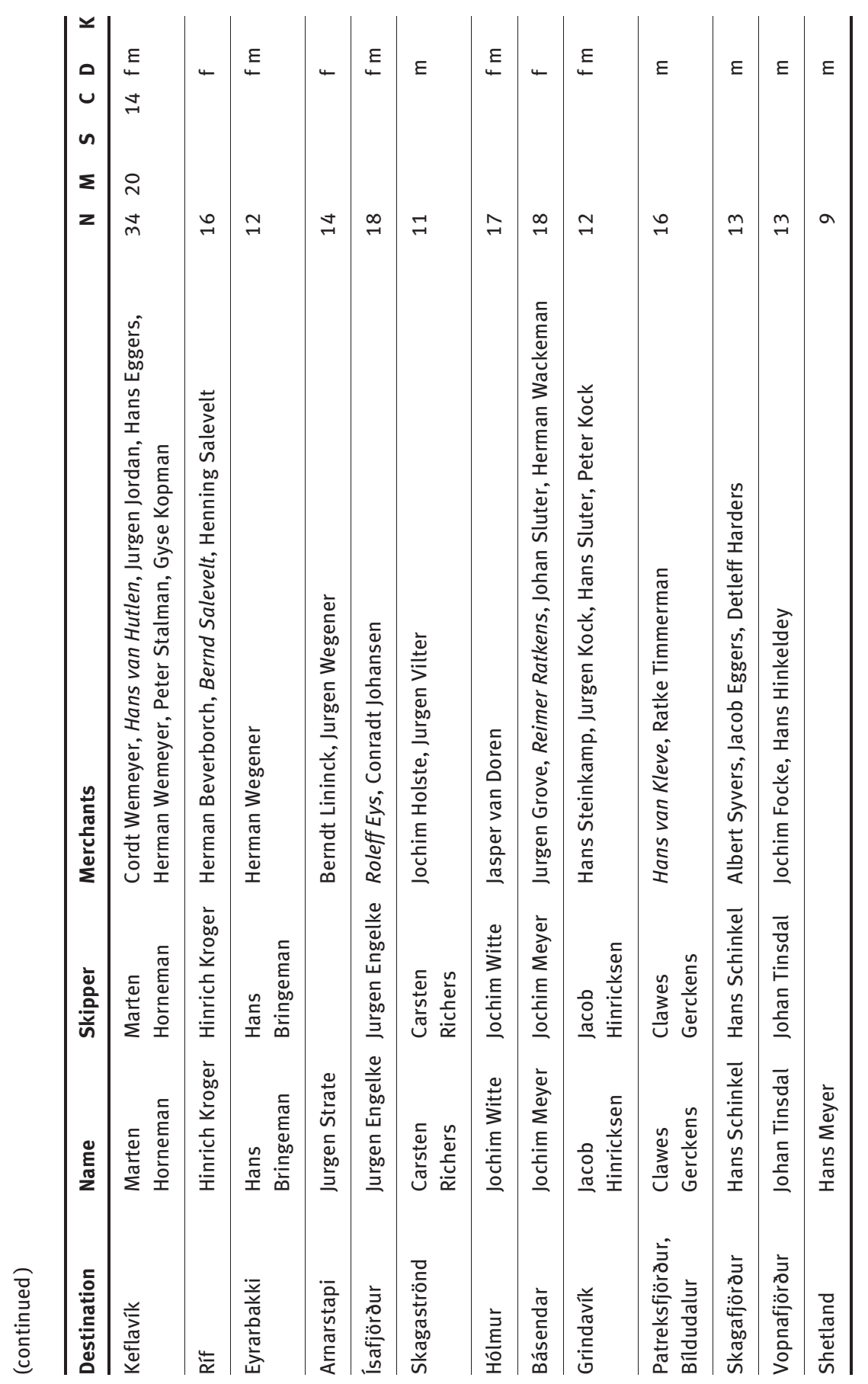




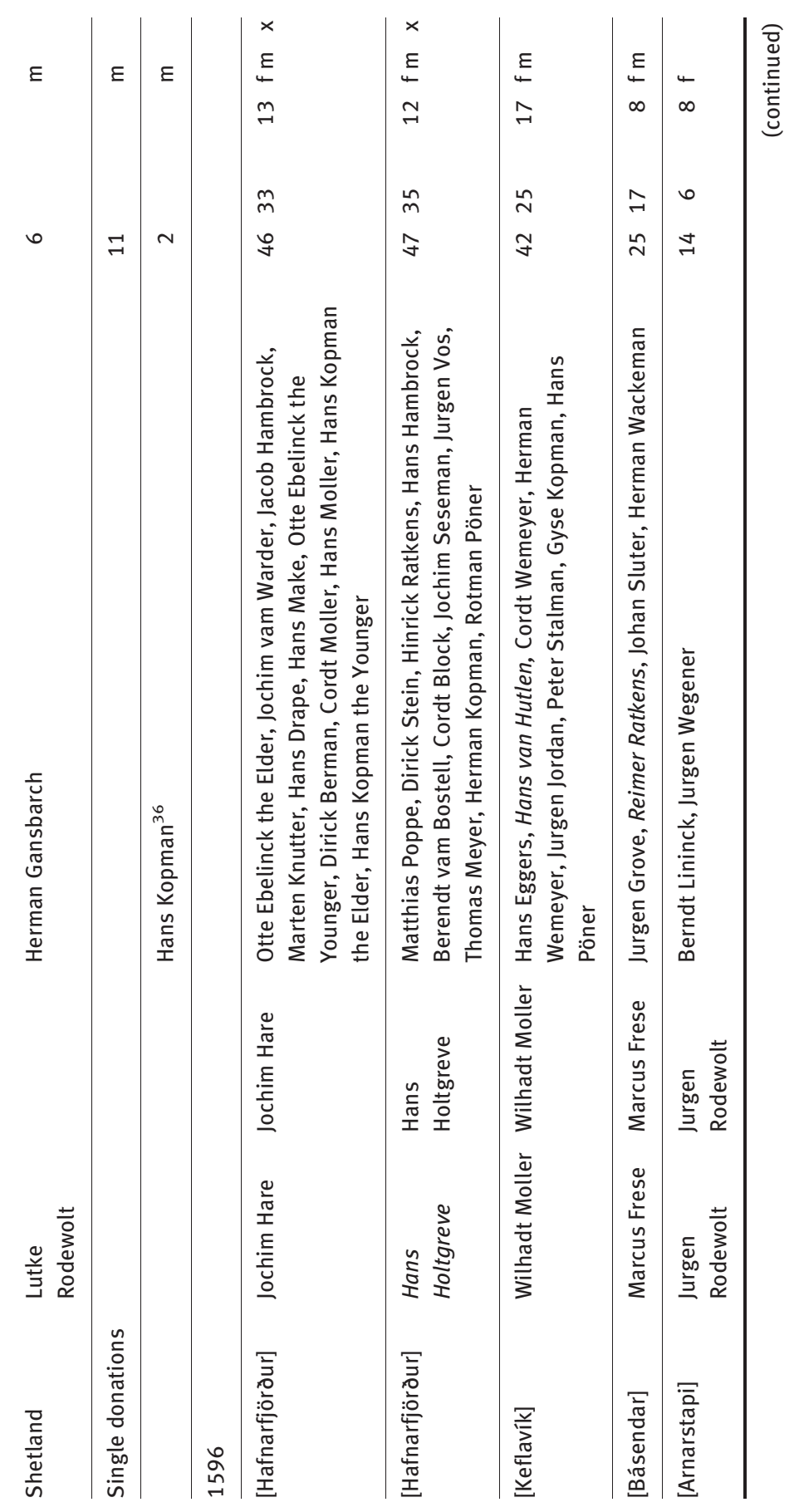

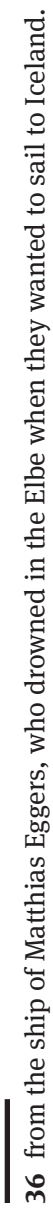




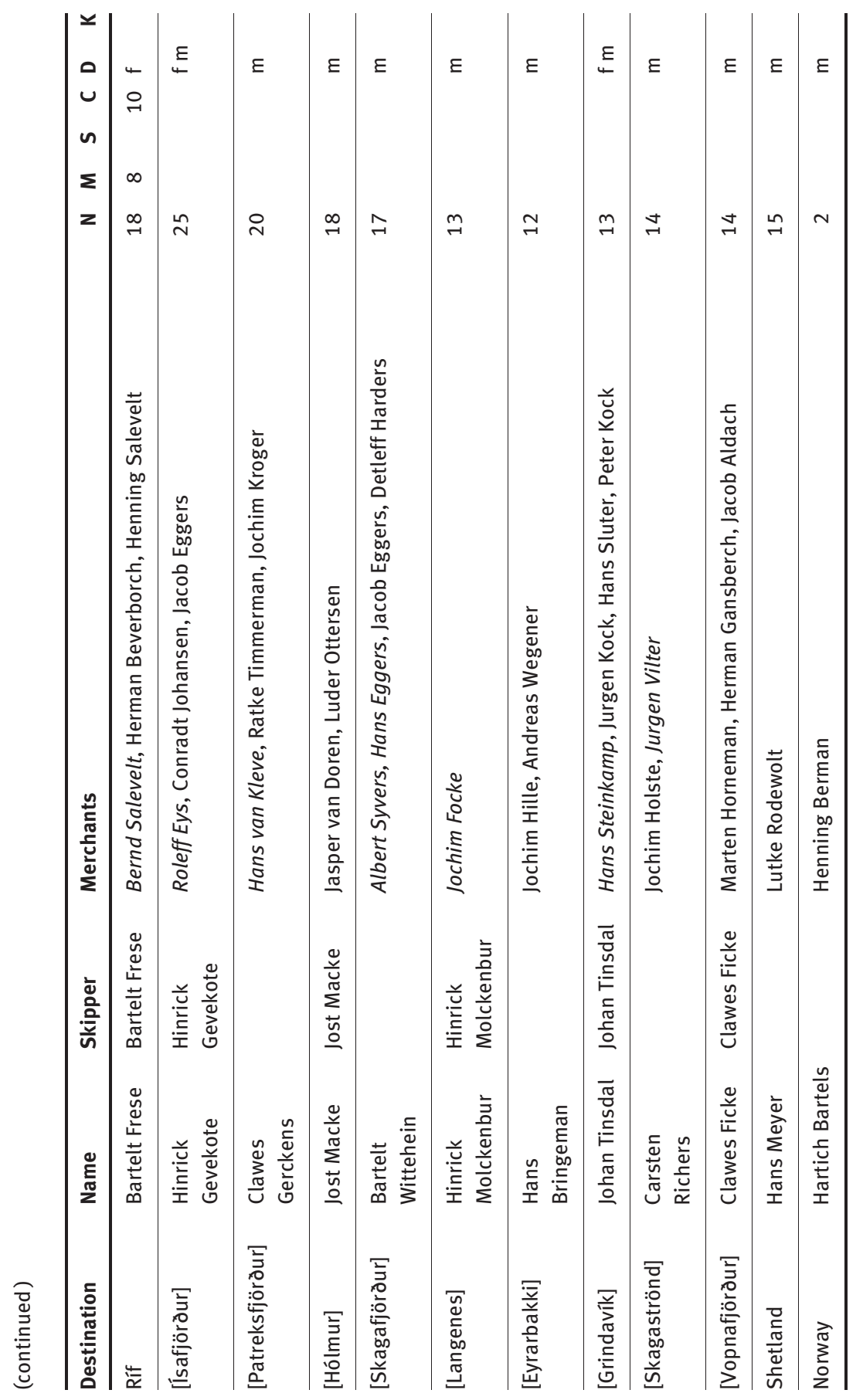



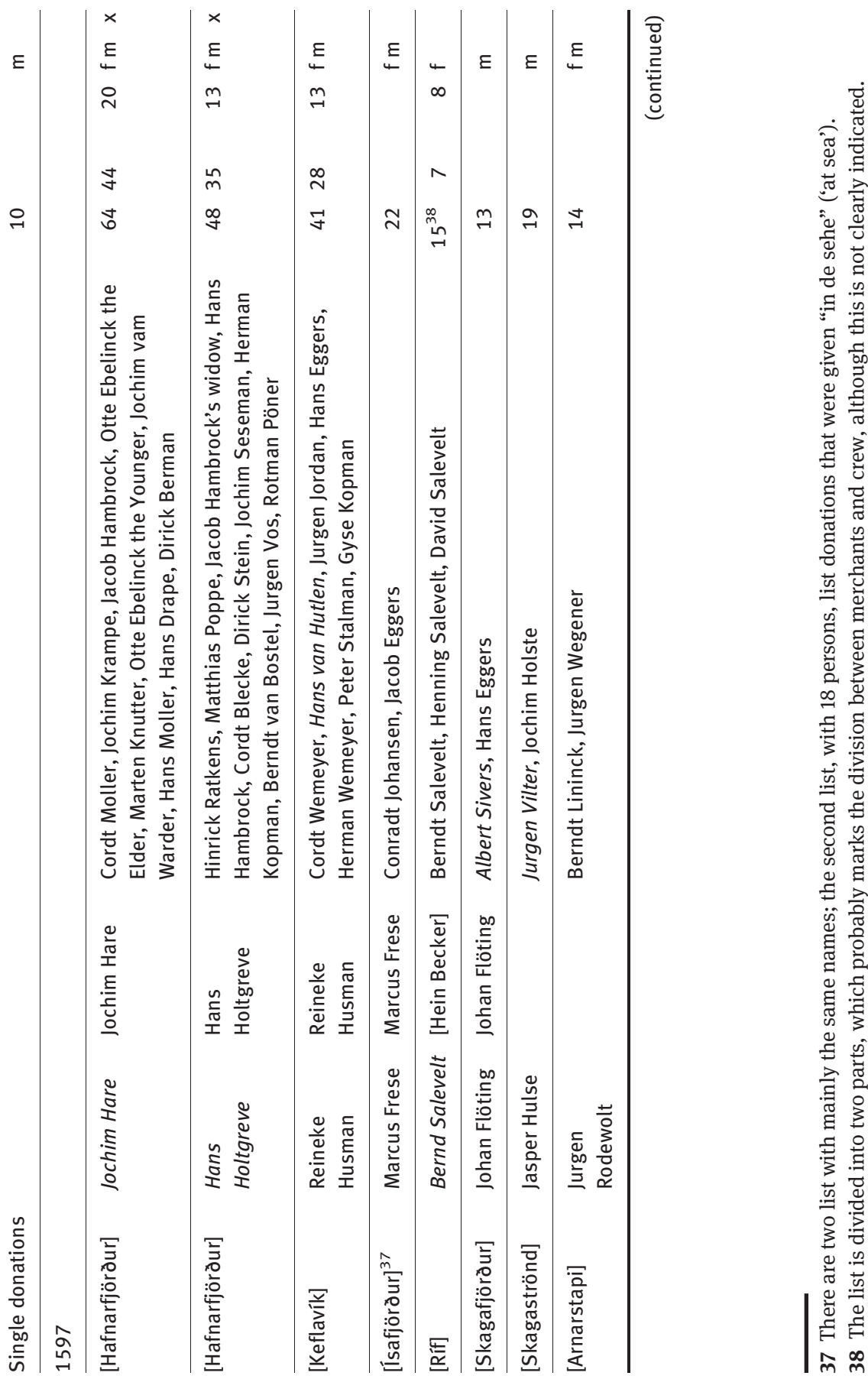


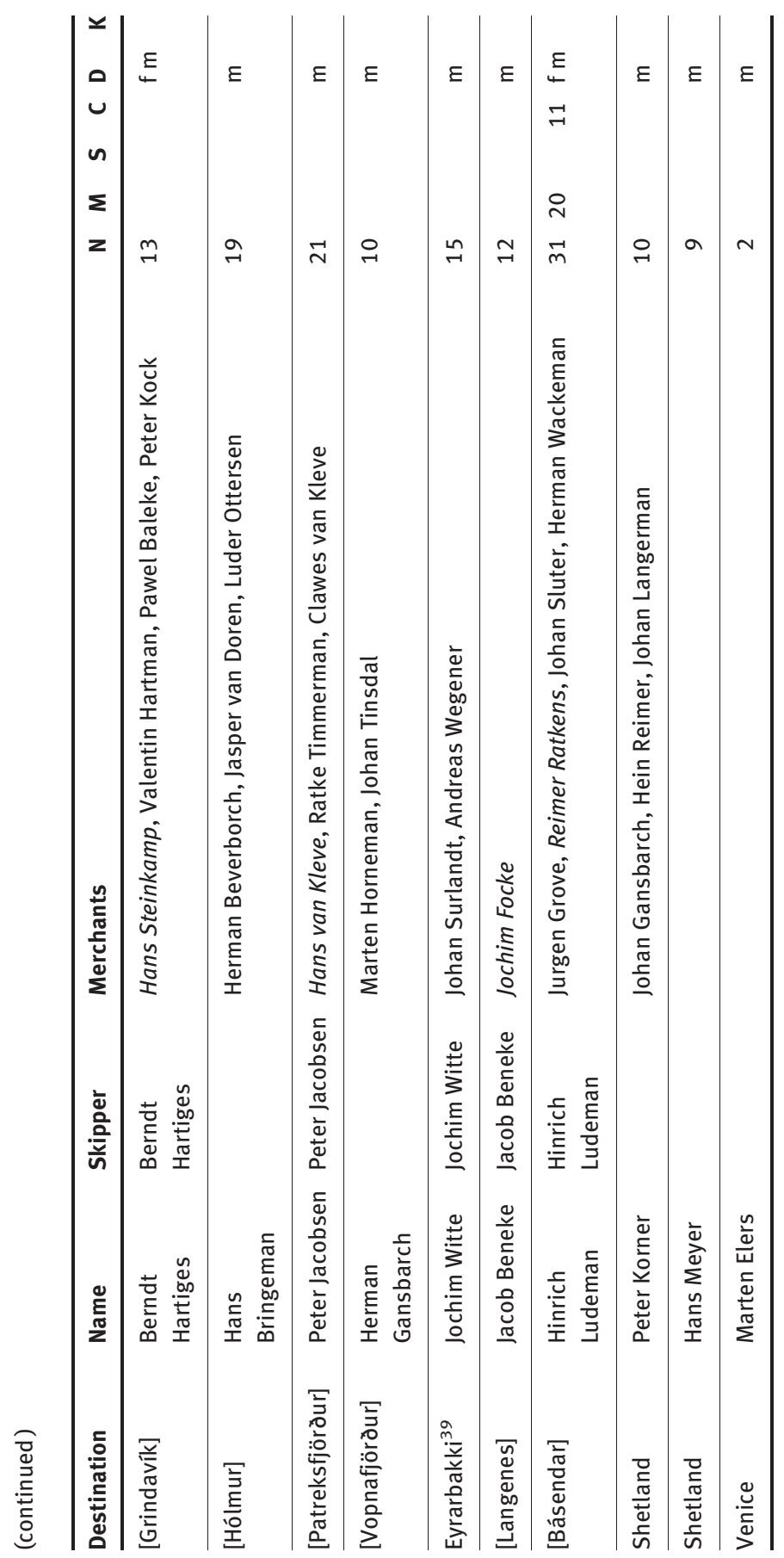




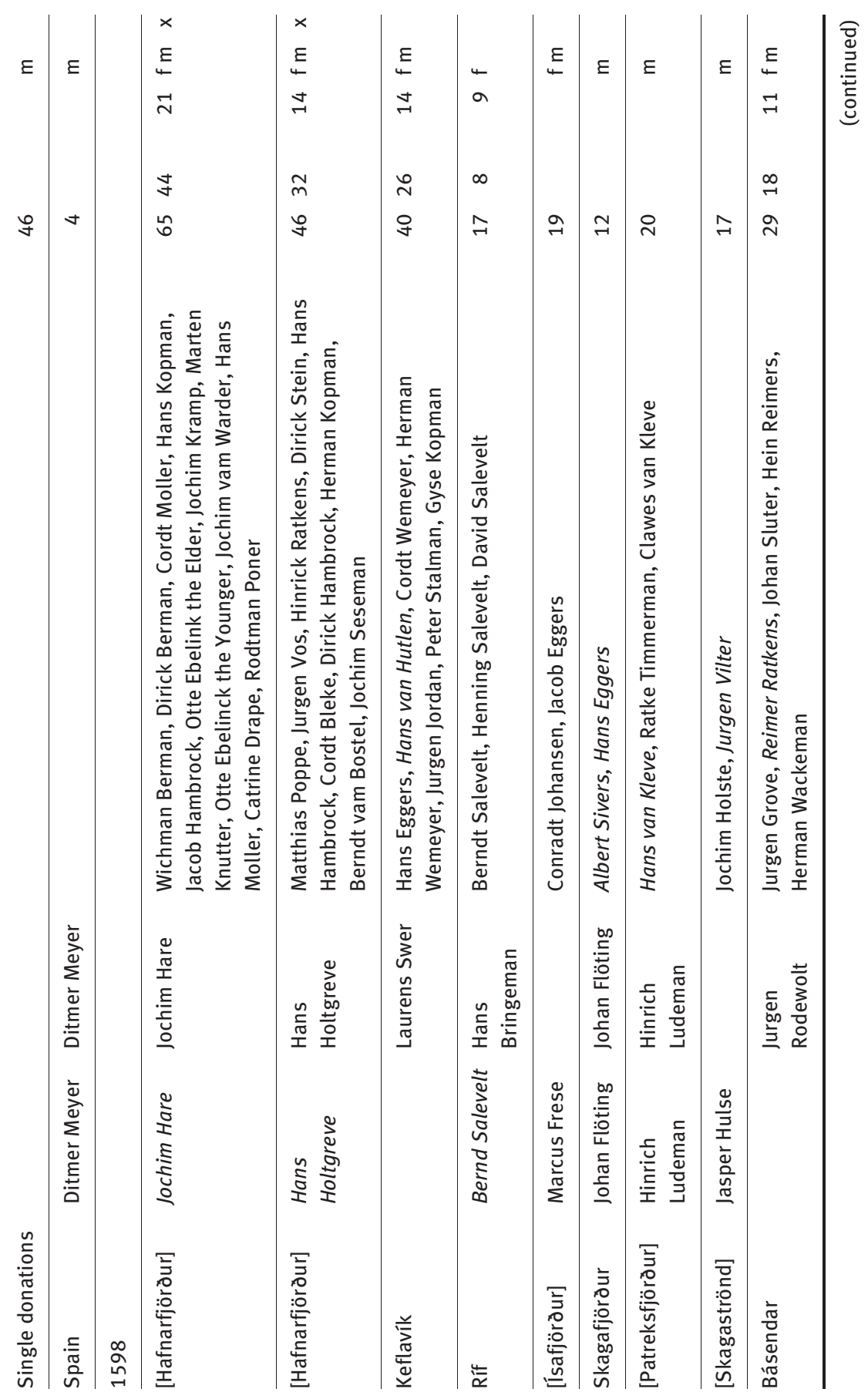




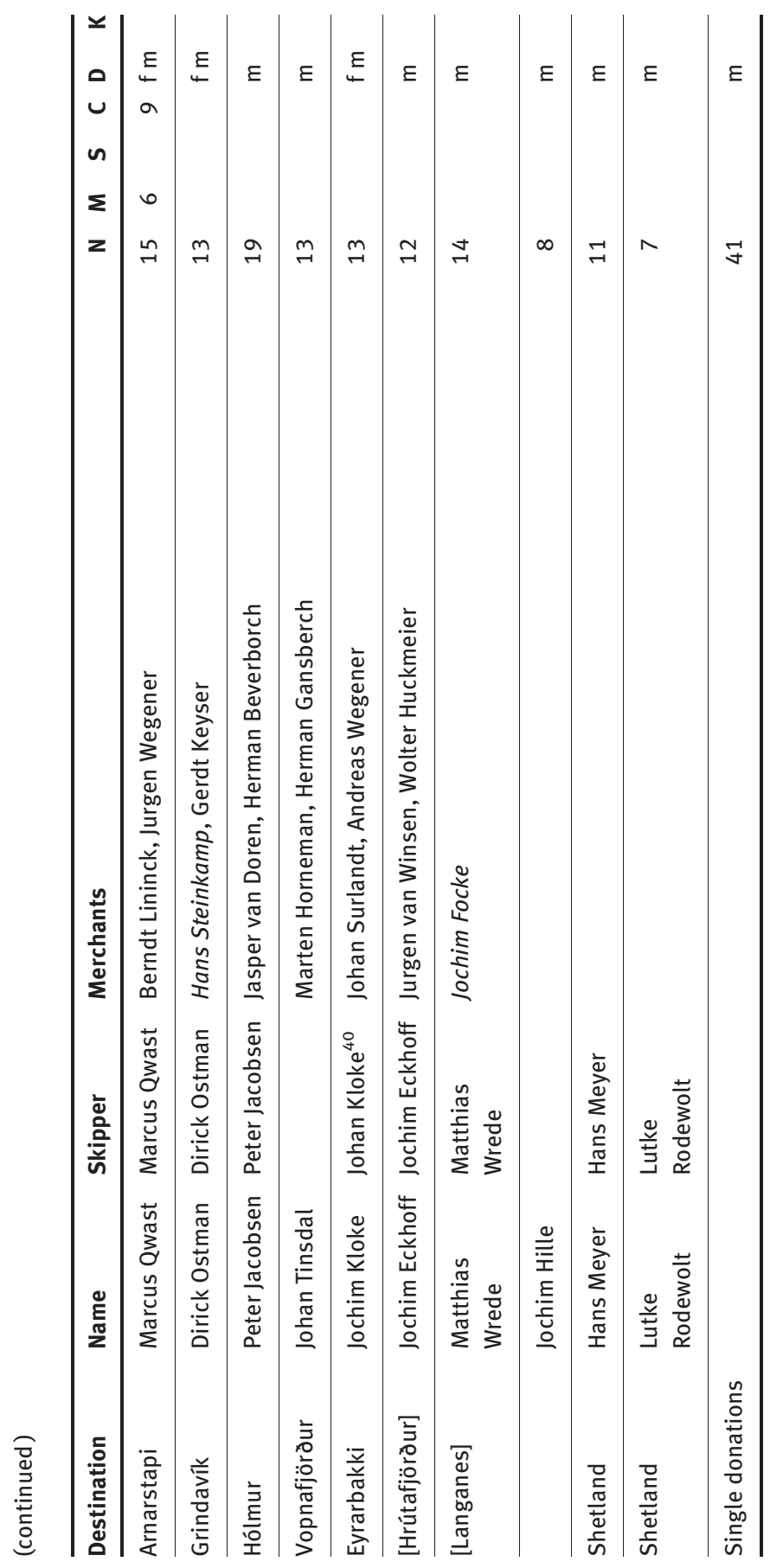

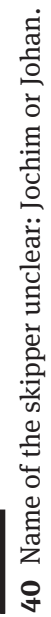




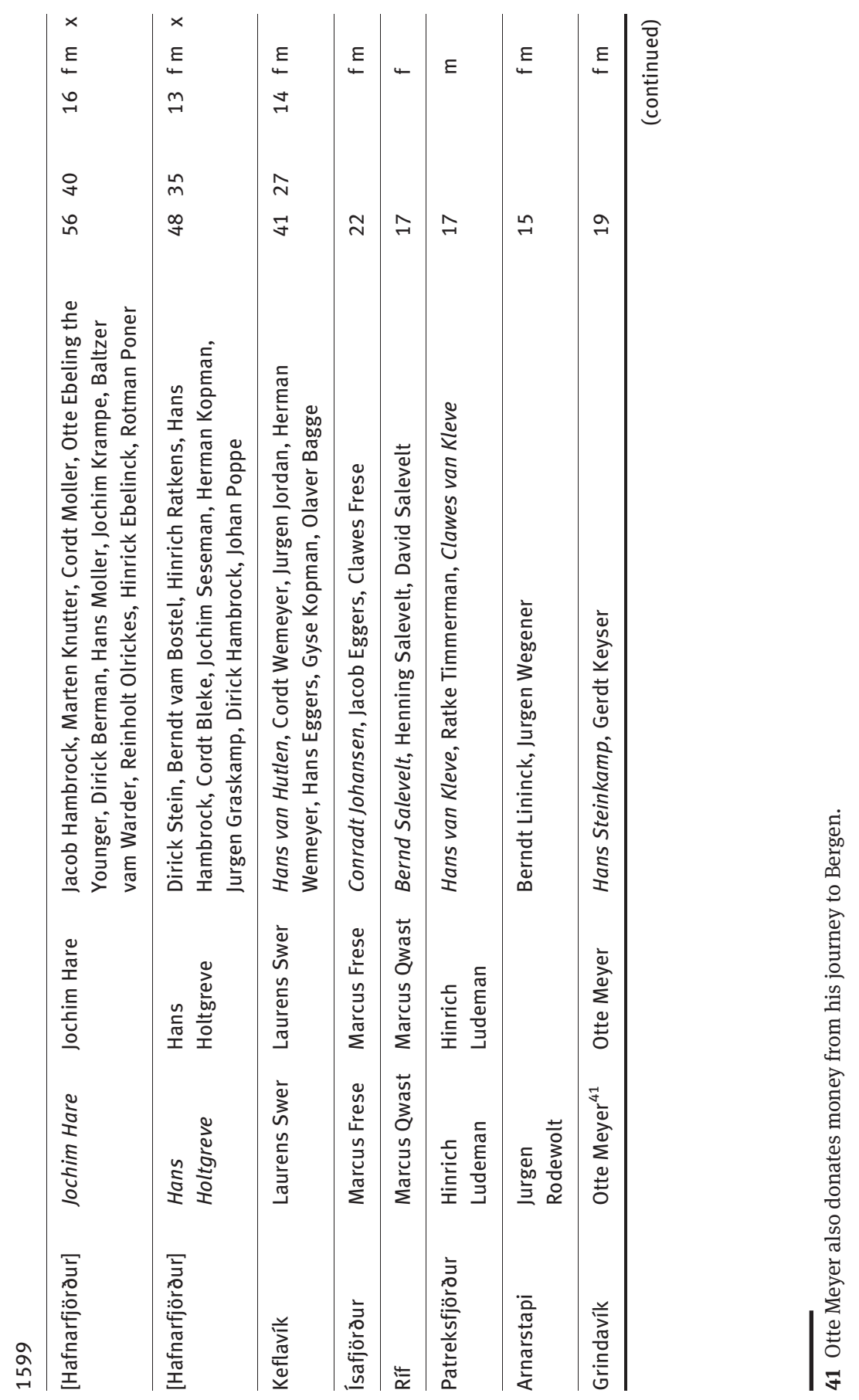




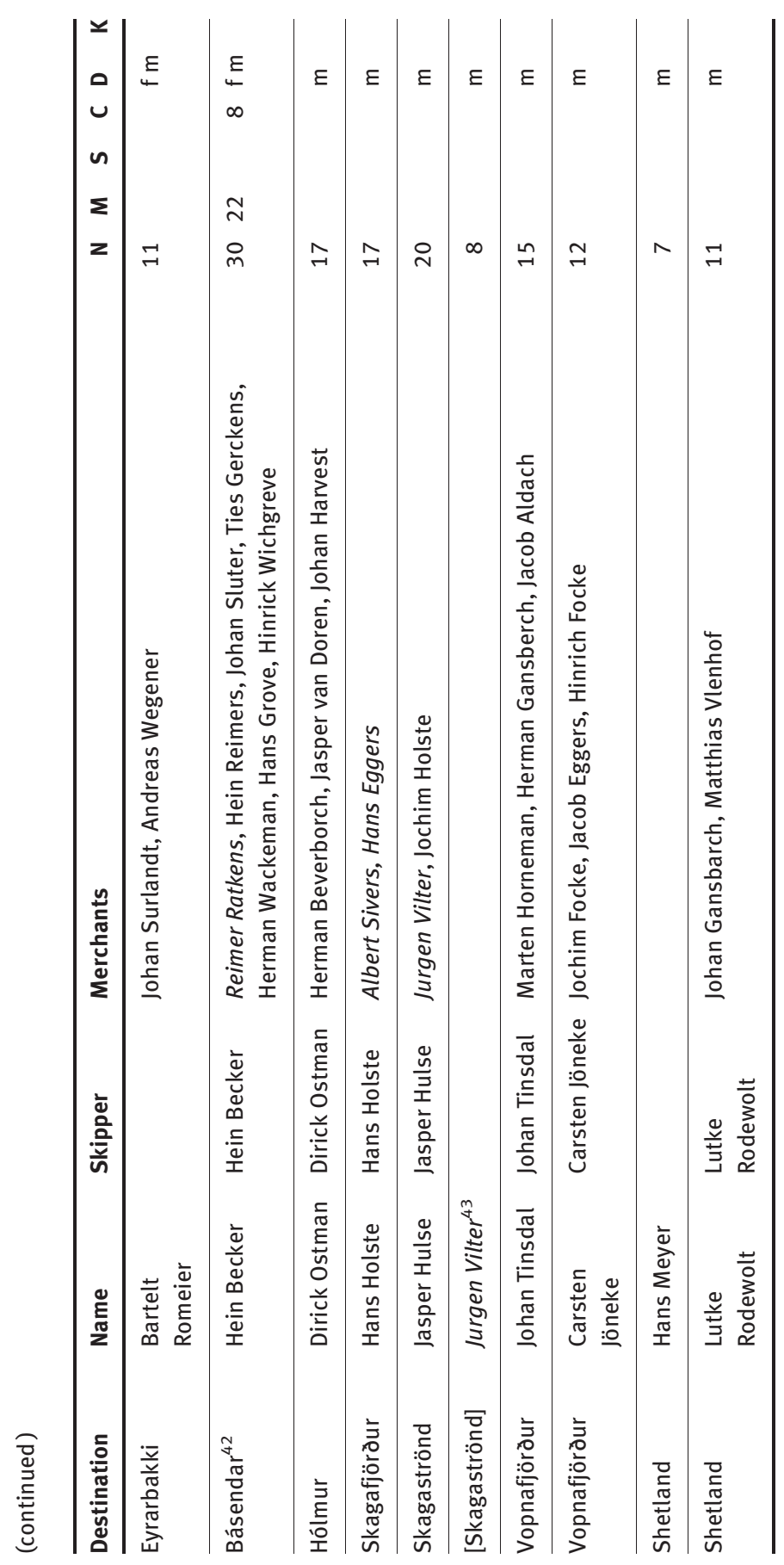

충

를

कํํำ

छี

里

:ृี

要

$\frac{\pi}{\sqrt{n}}$

$\Xi$

禺

के

फ़

㝴解

Ф ฐ

요

氖

으. 흠

离苞

롱 क्ष

$\stackrel{9}{2}$

离

䒕

듬

요

की

है के

ฮี

3.

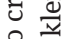

¿ क

를

एँ छ

햃.

คี สี

商敦 


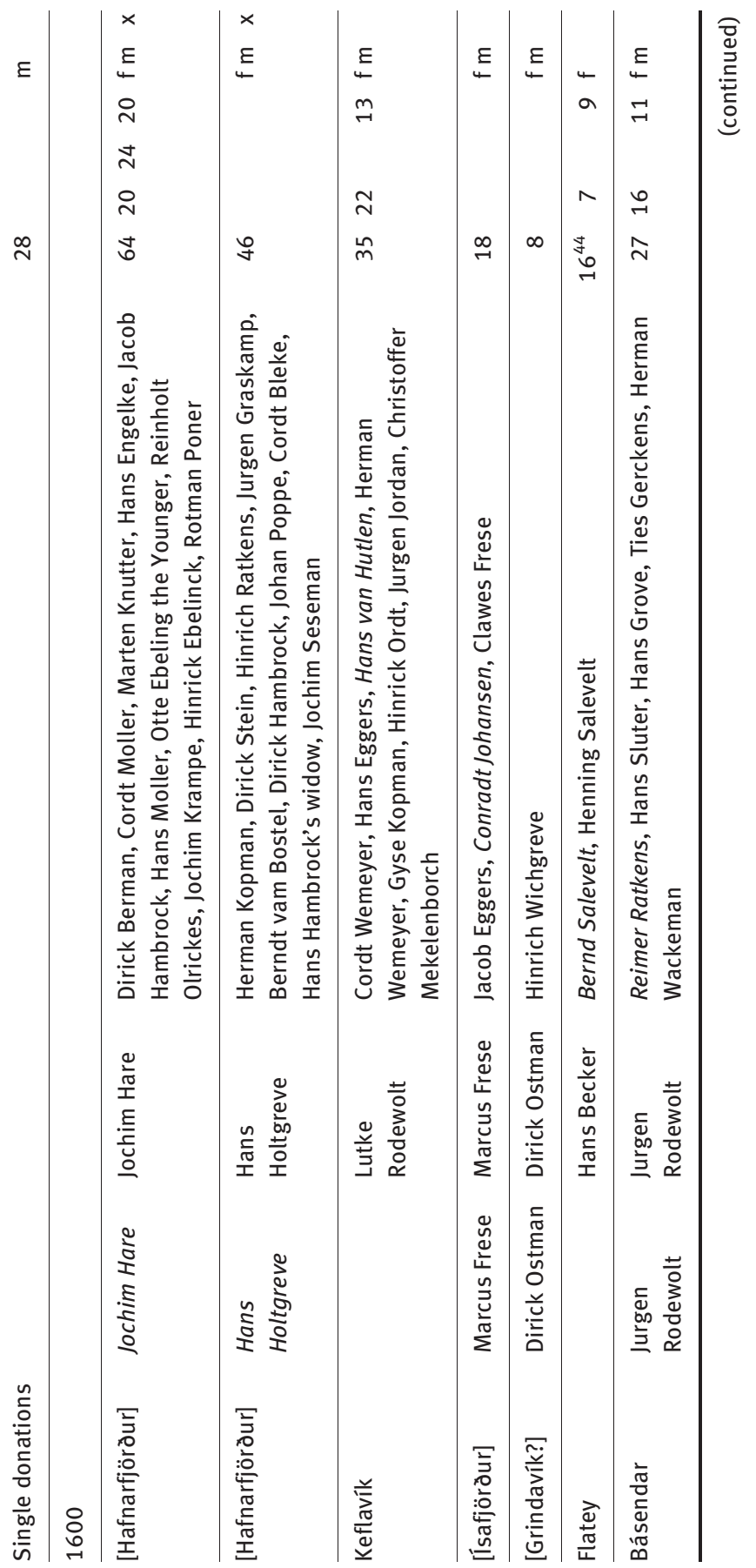

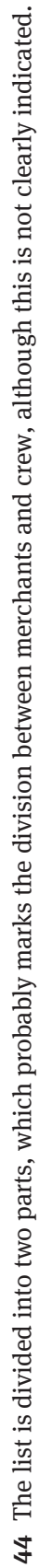




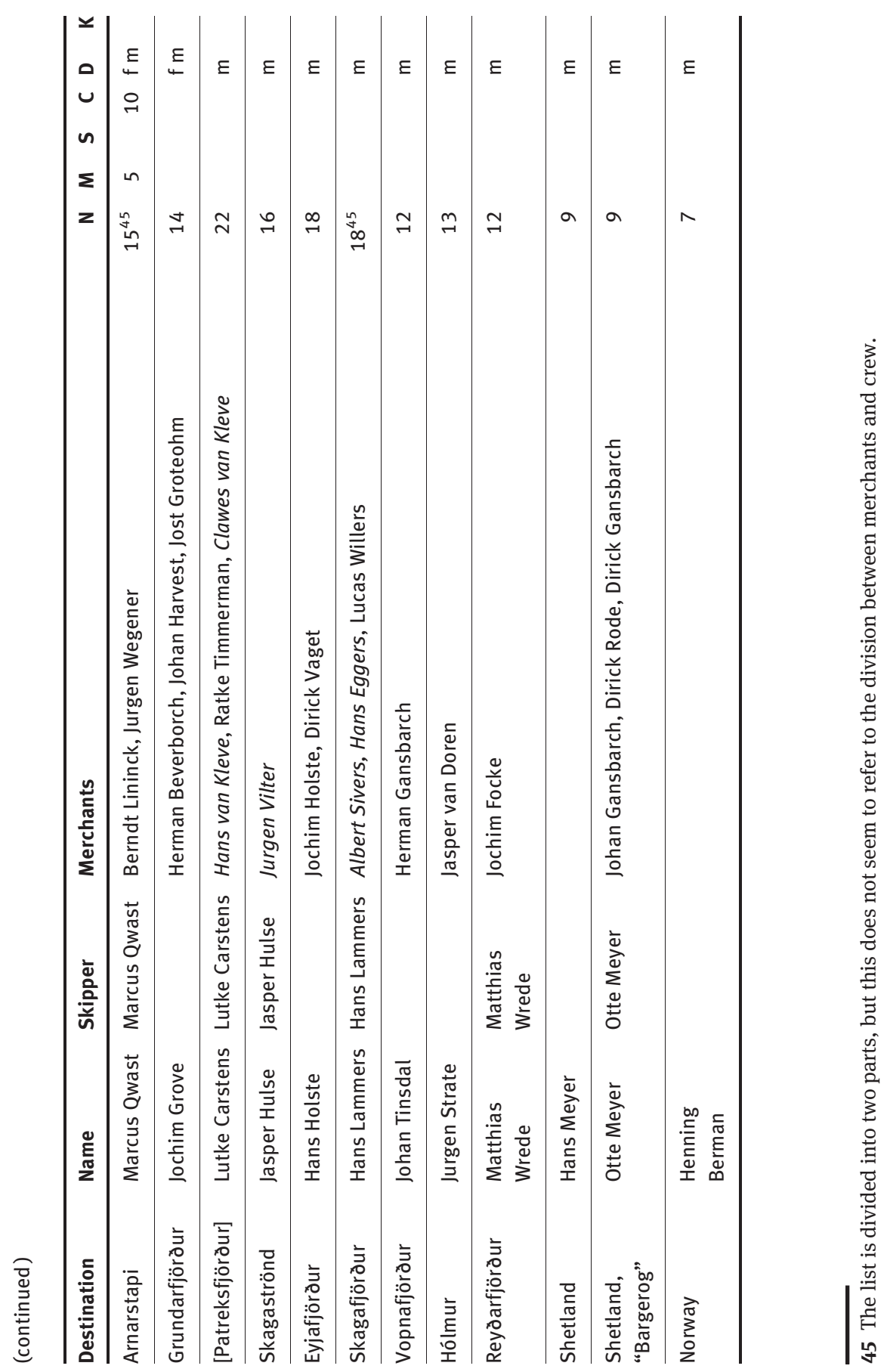




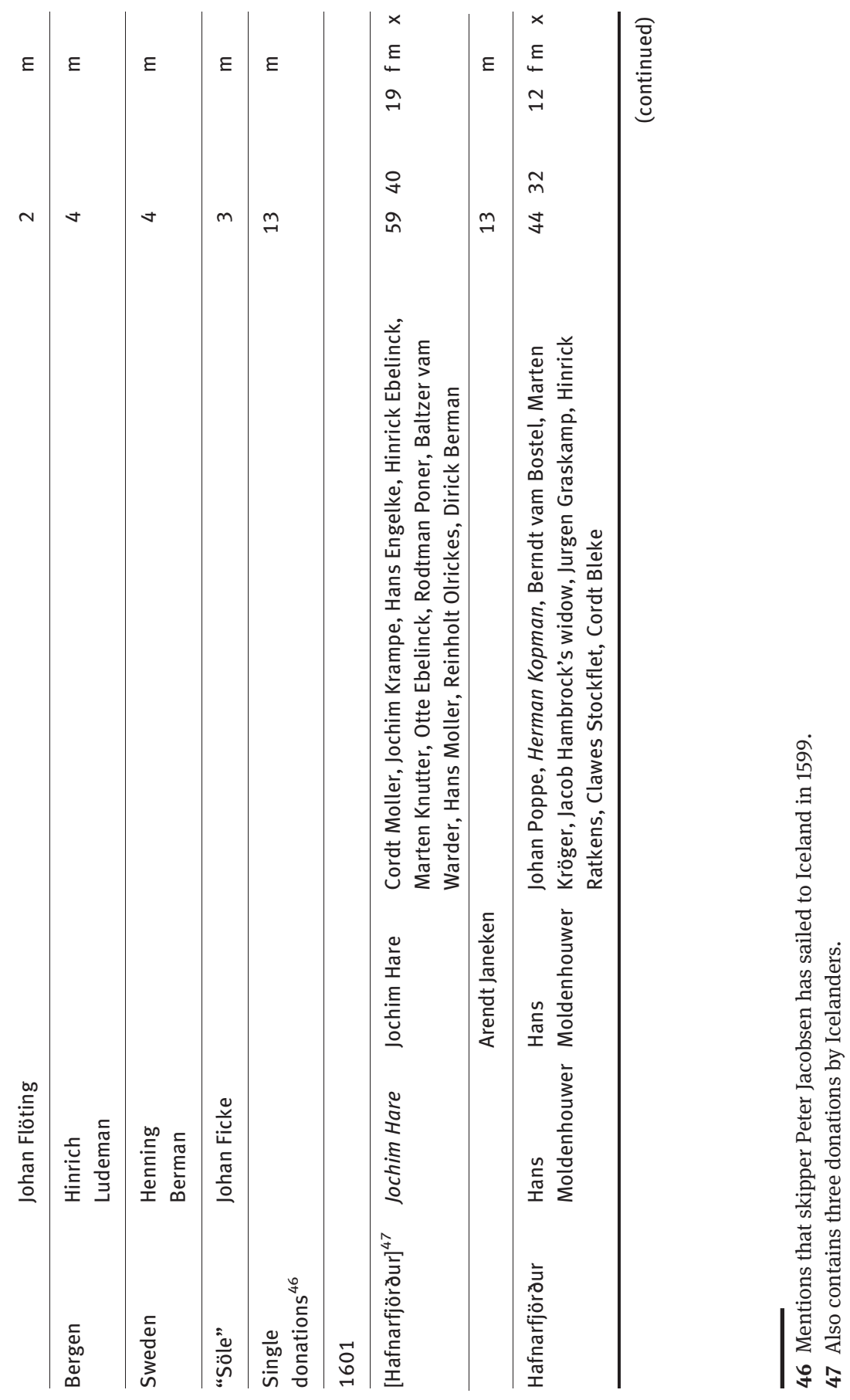



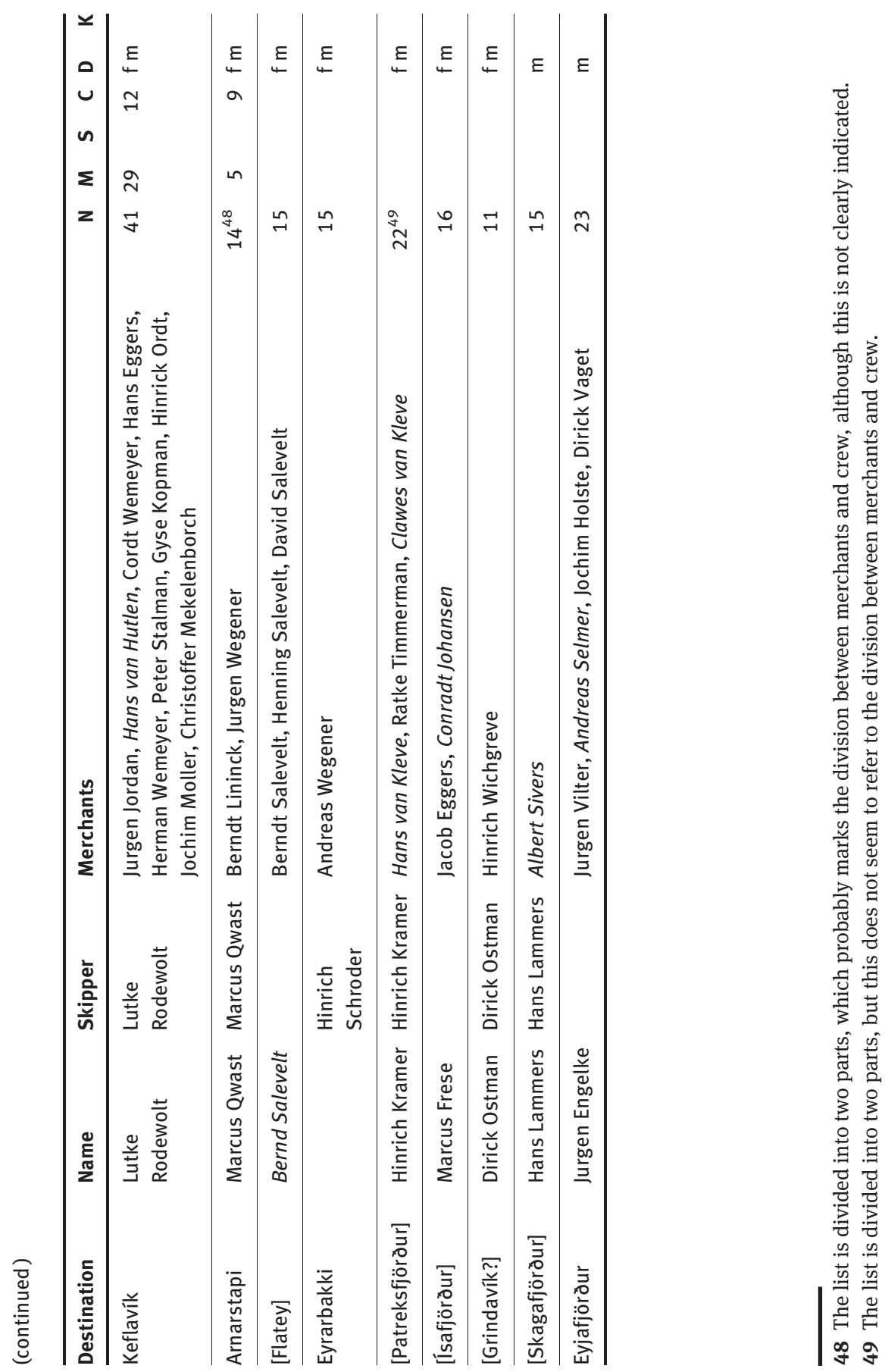


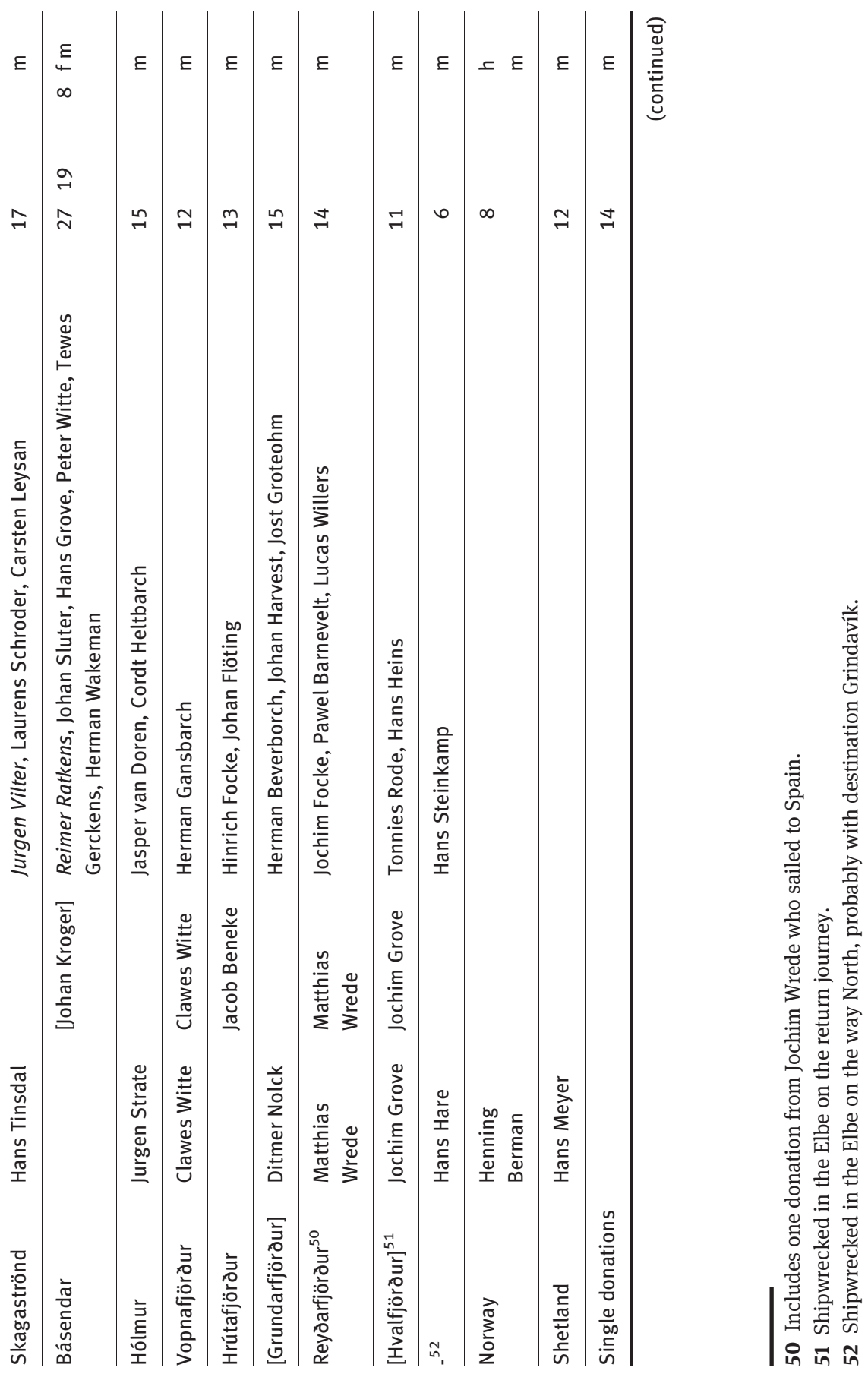




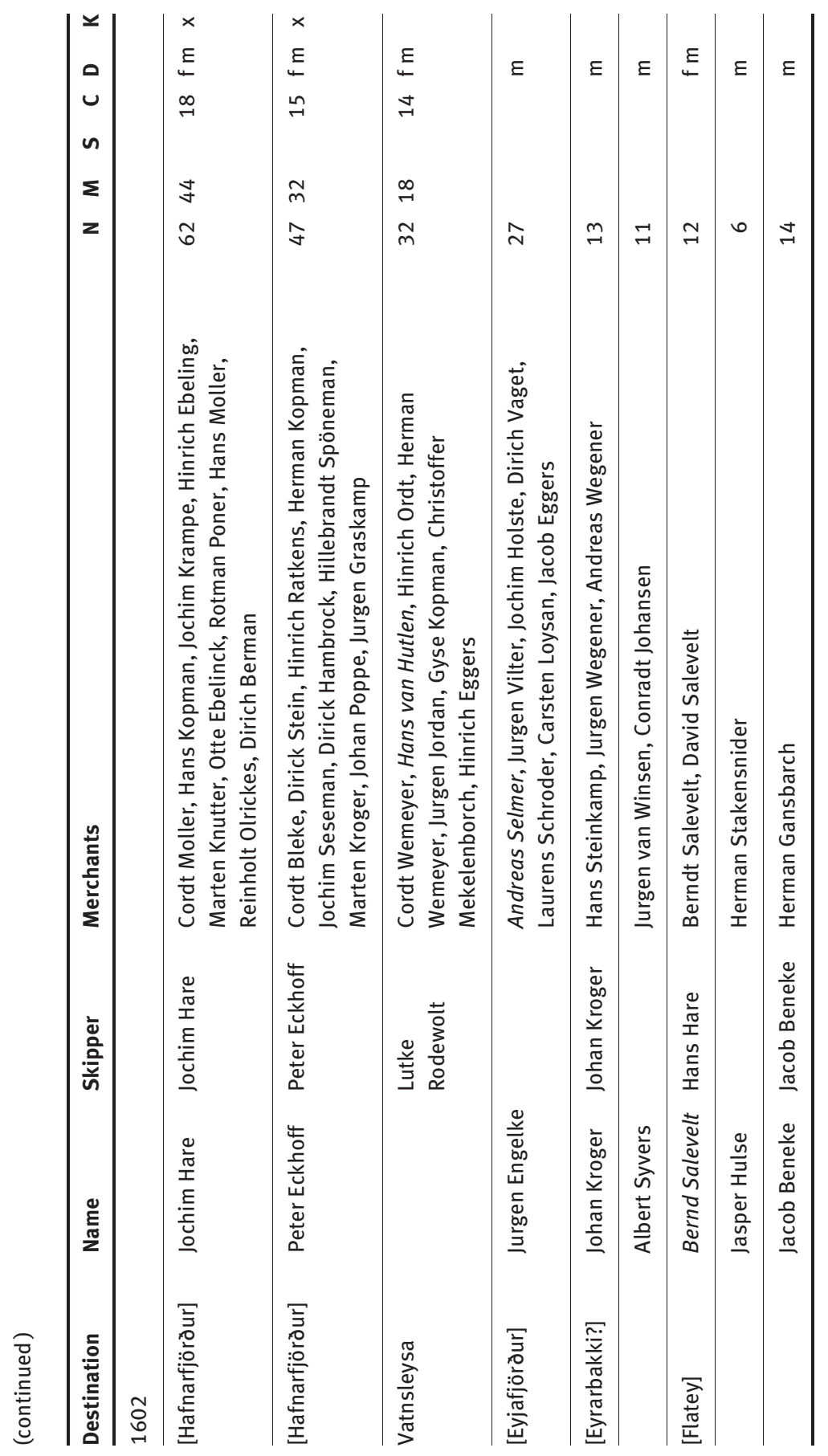




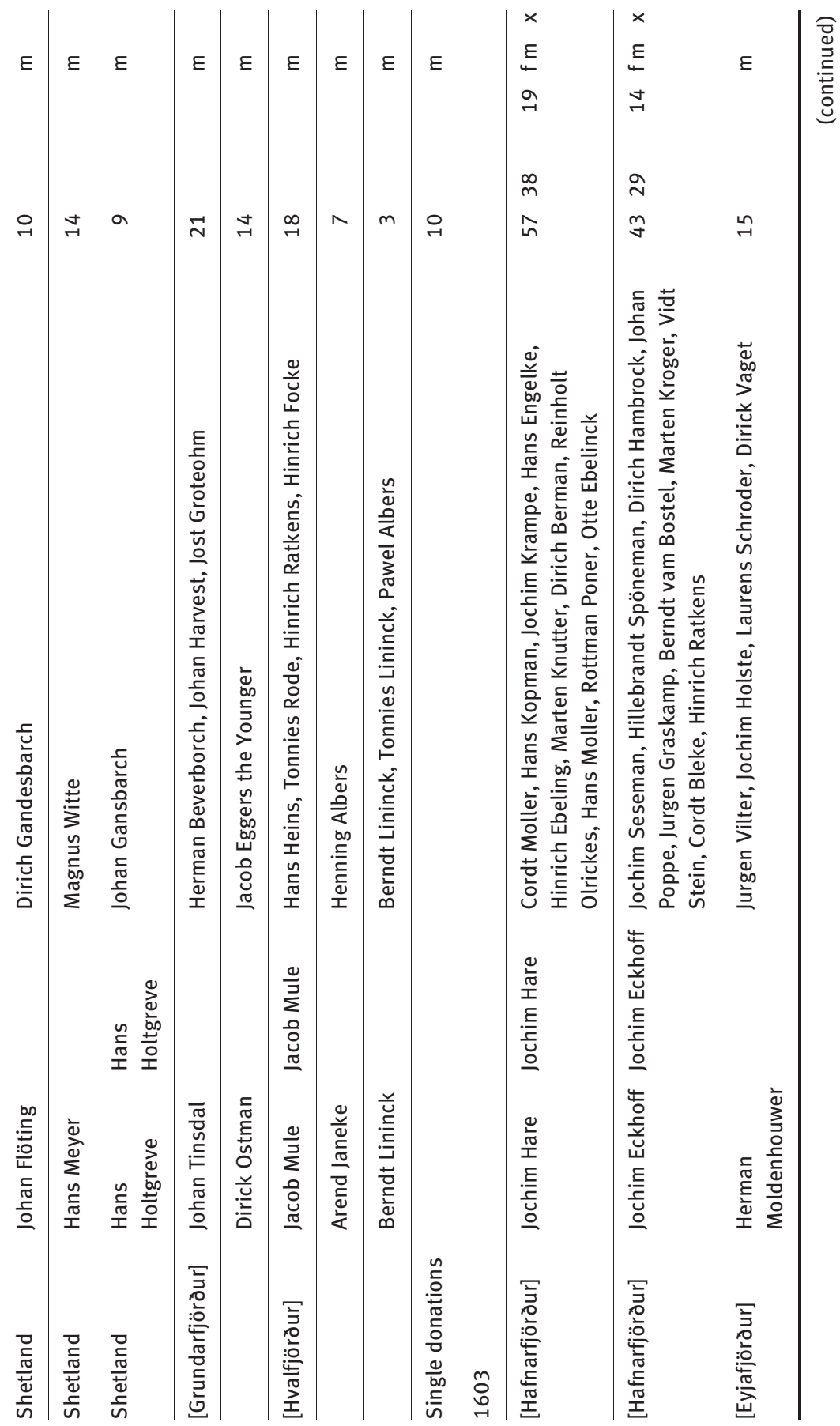




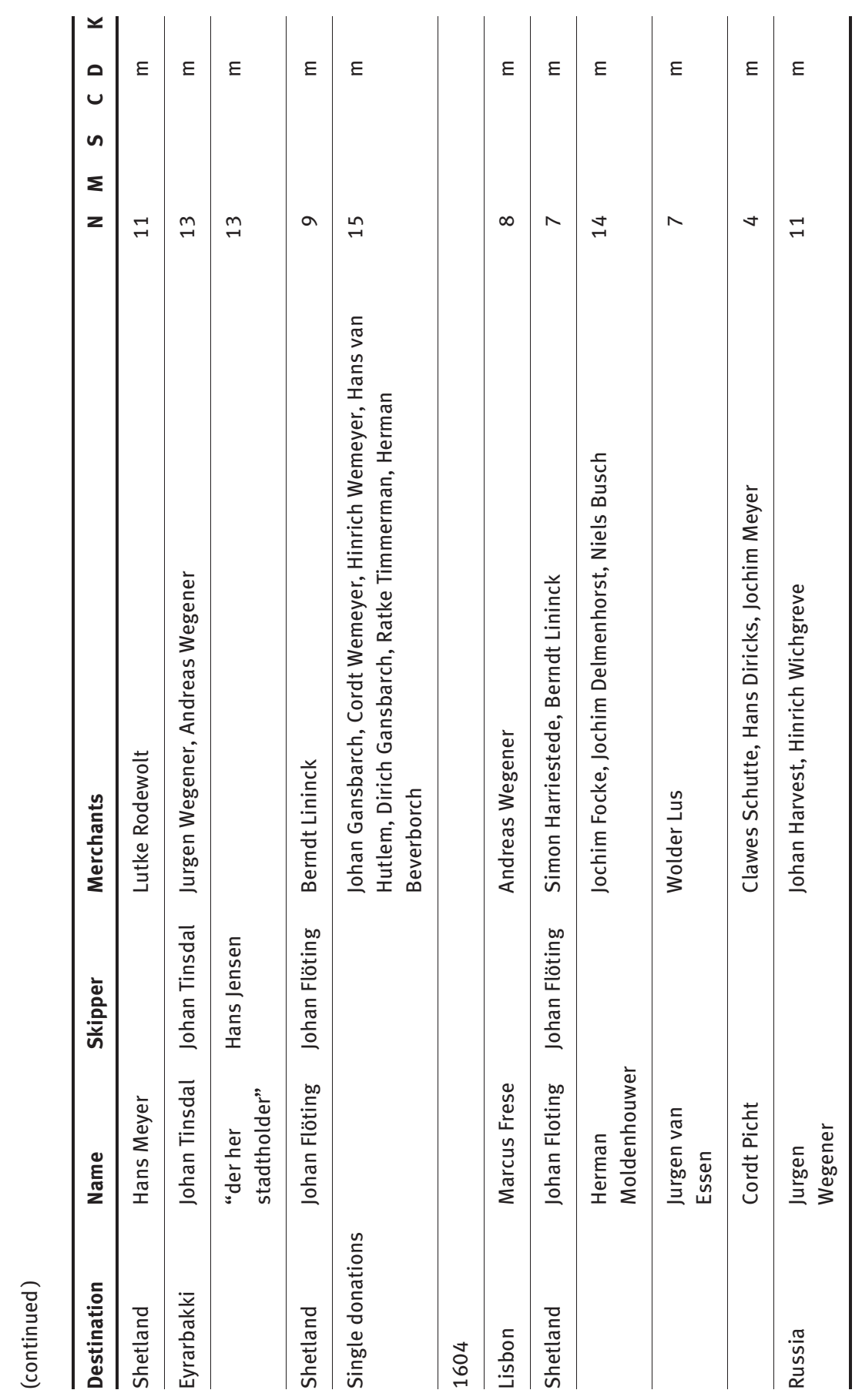




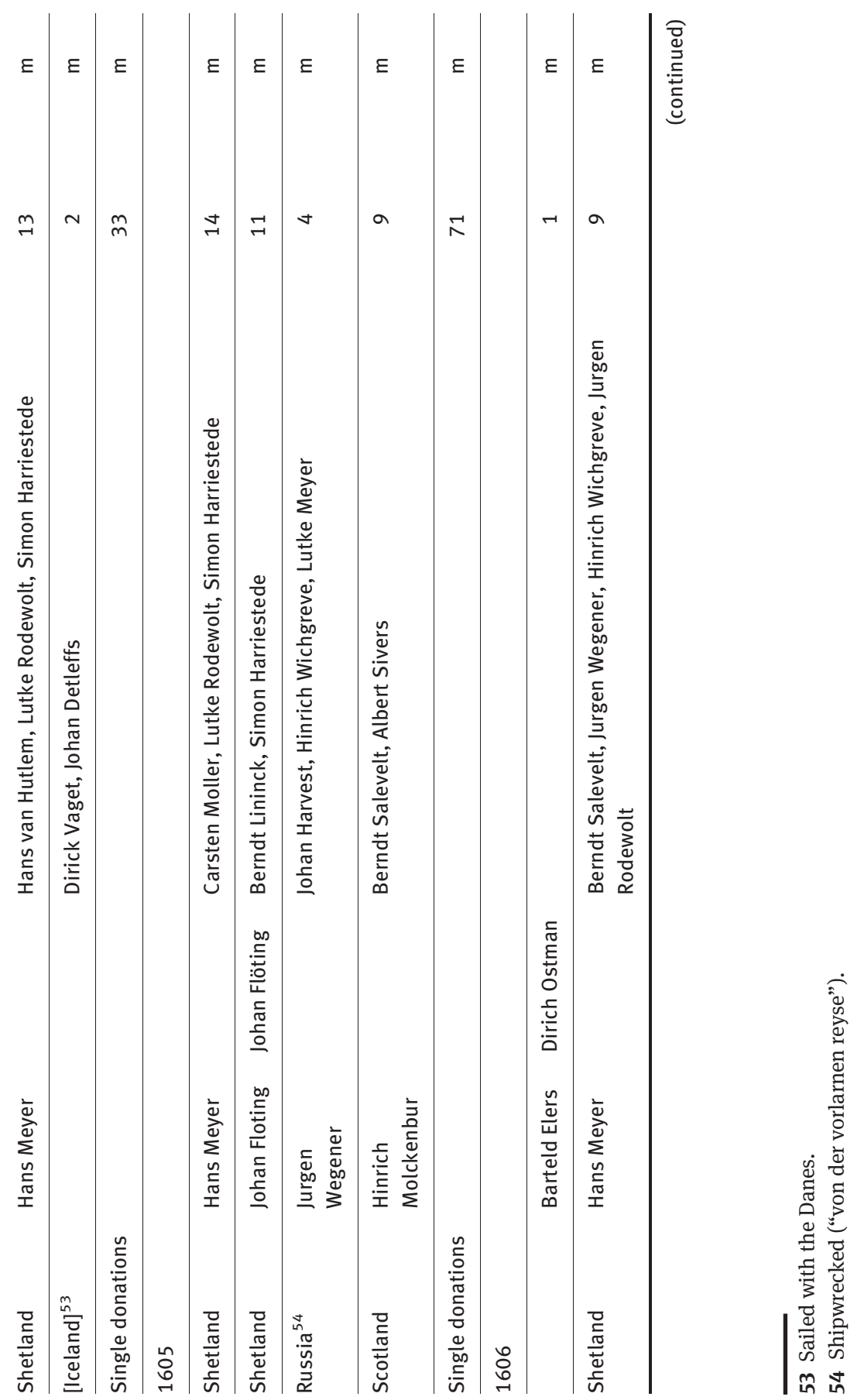




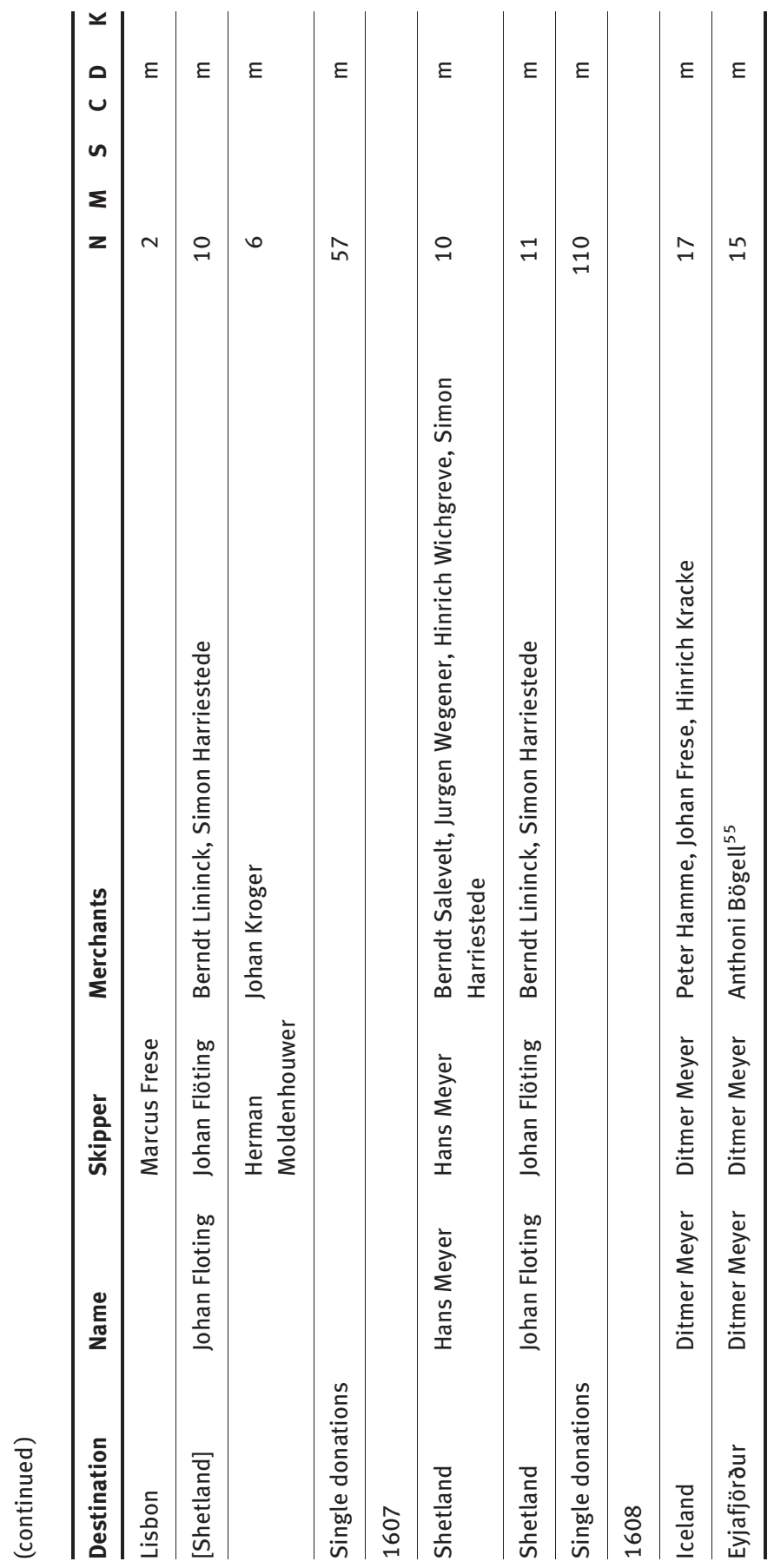

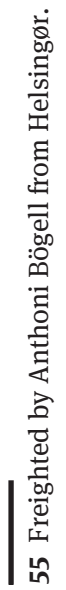




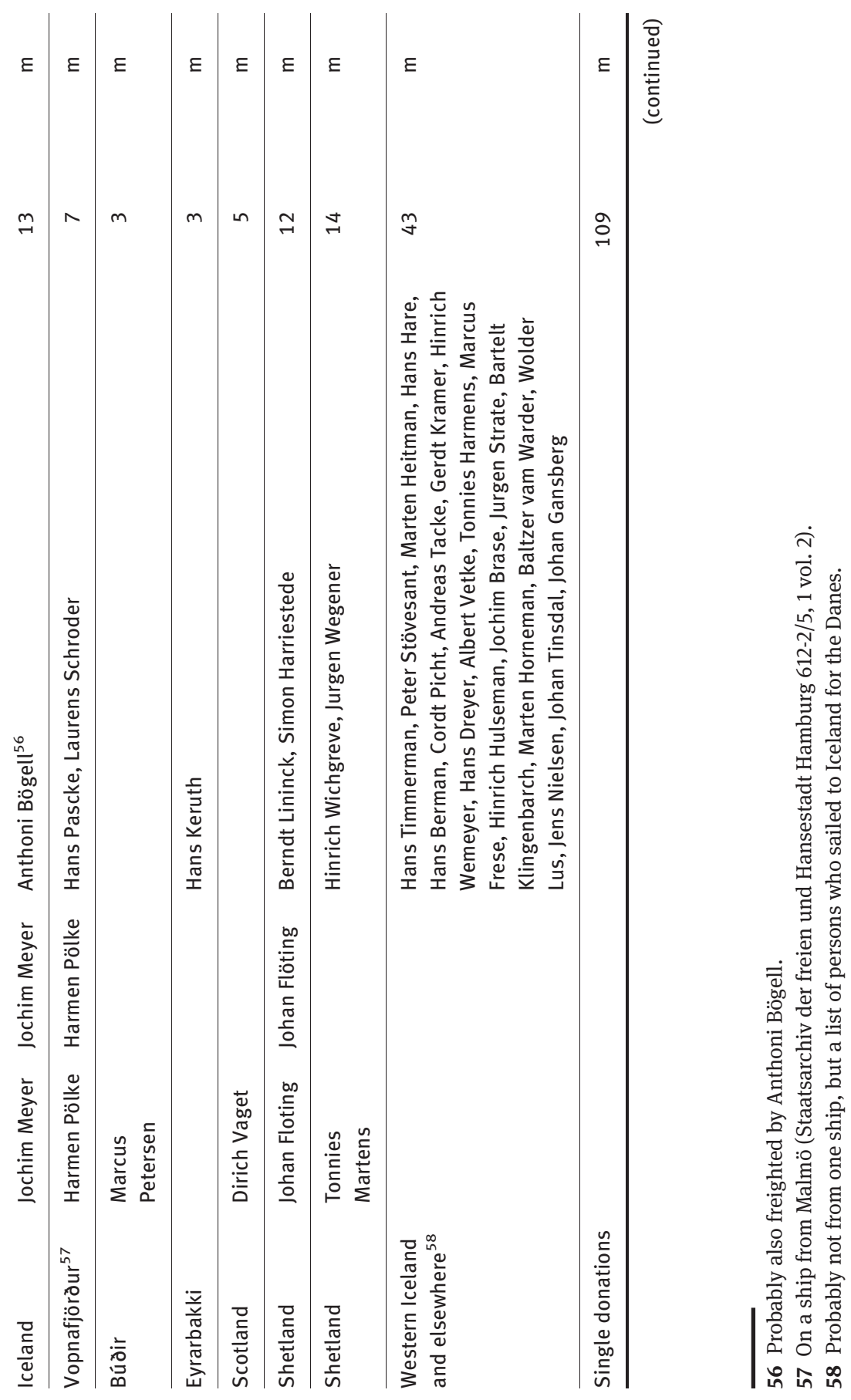




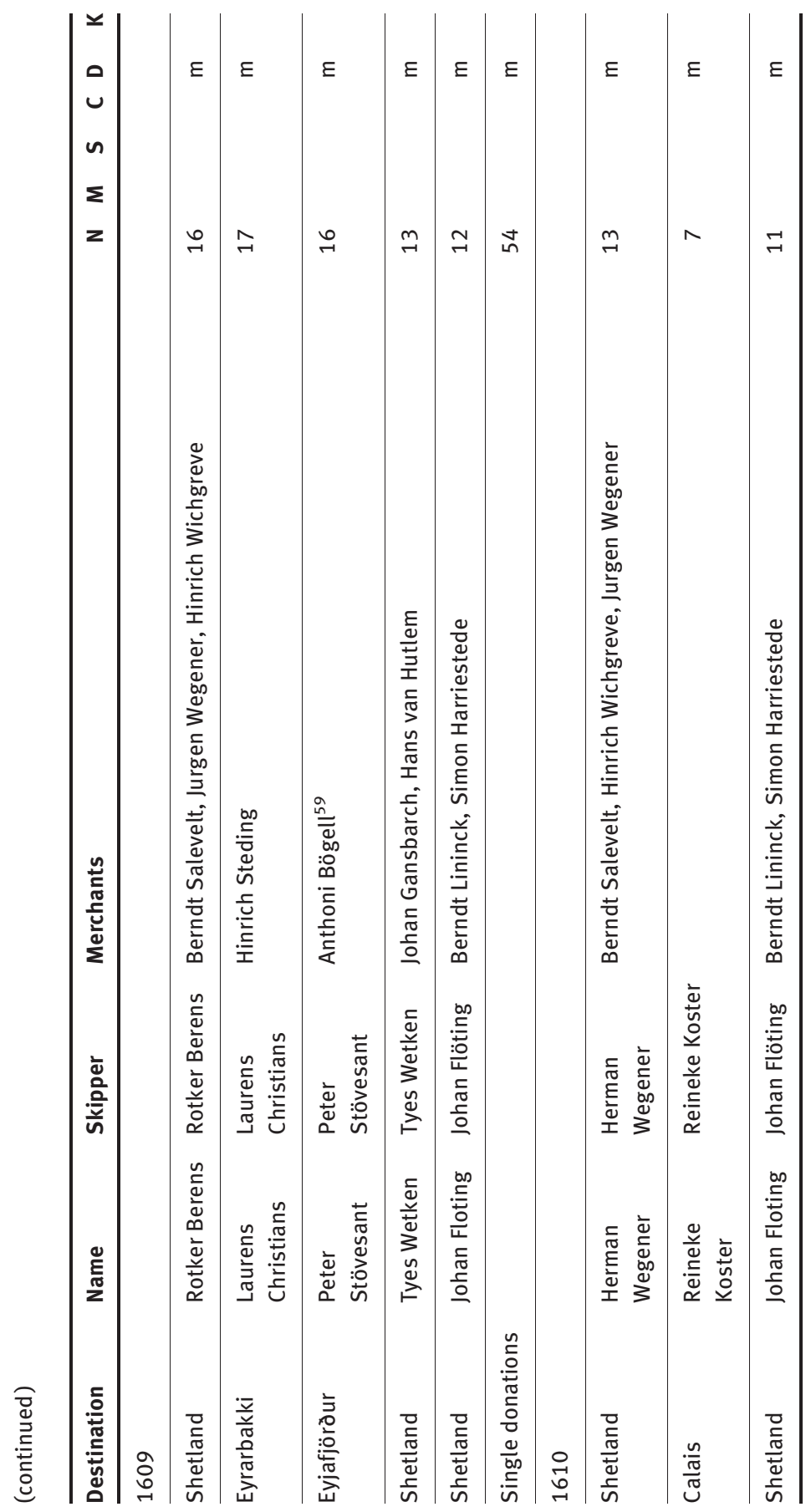

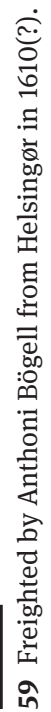




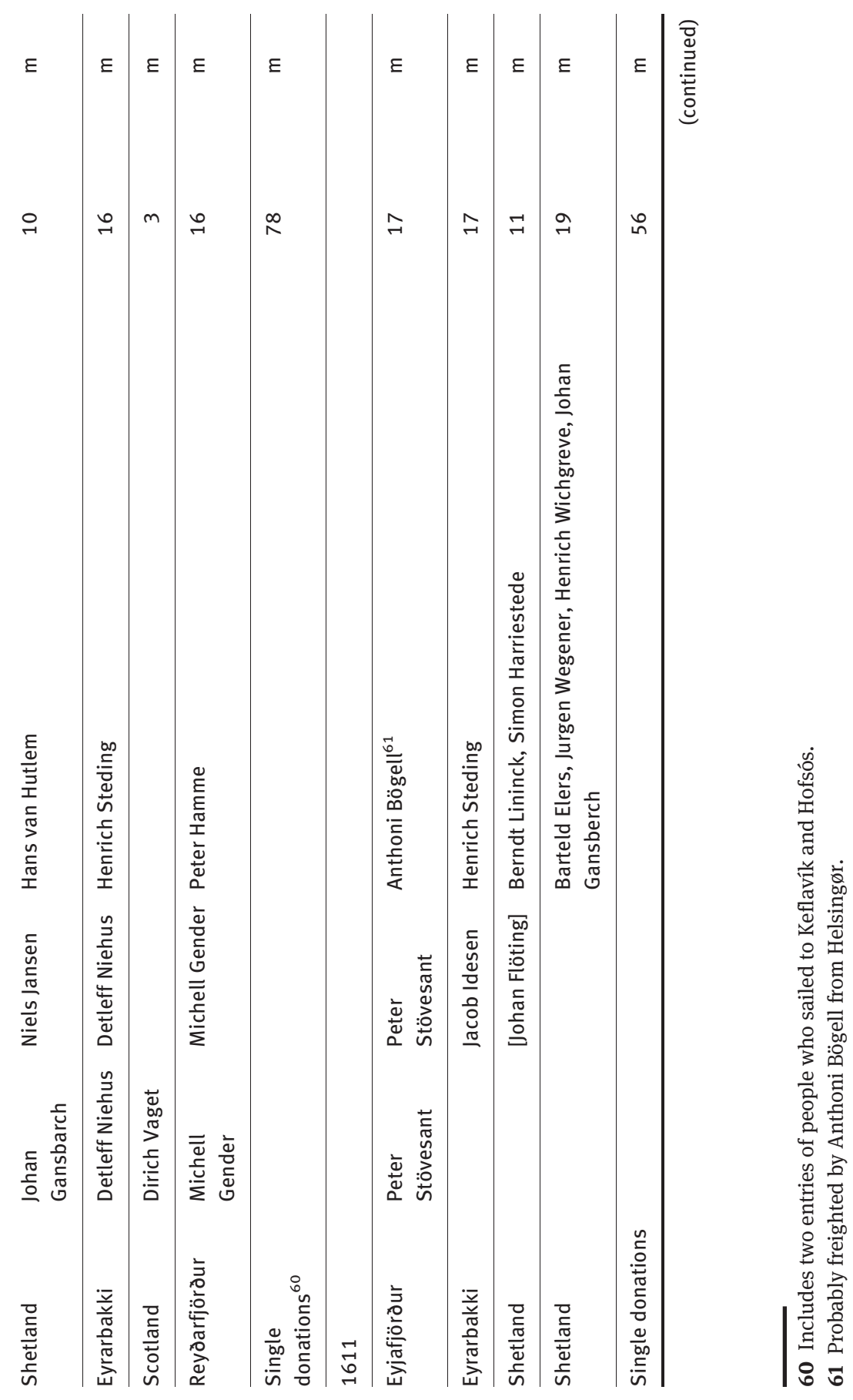




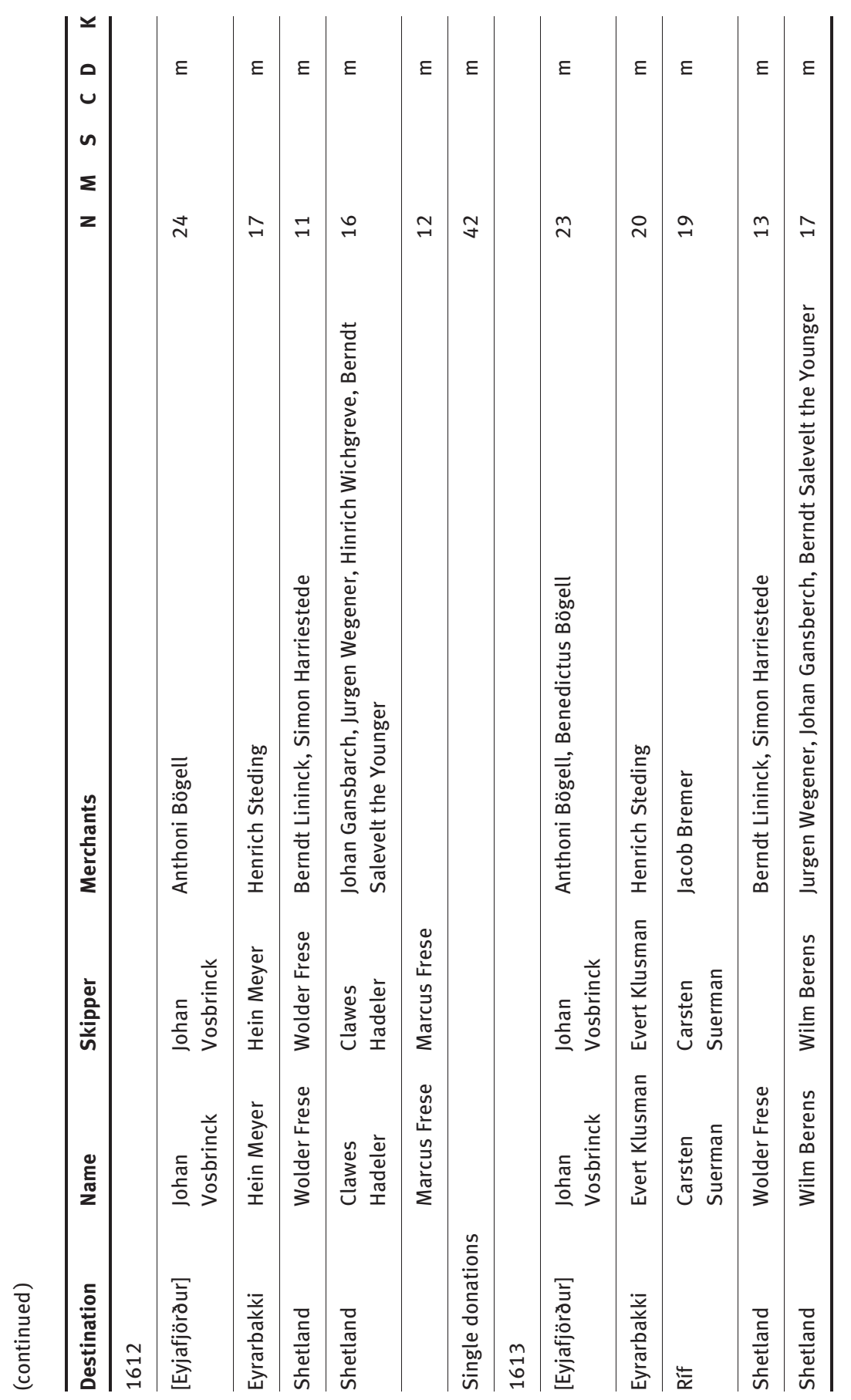




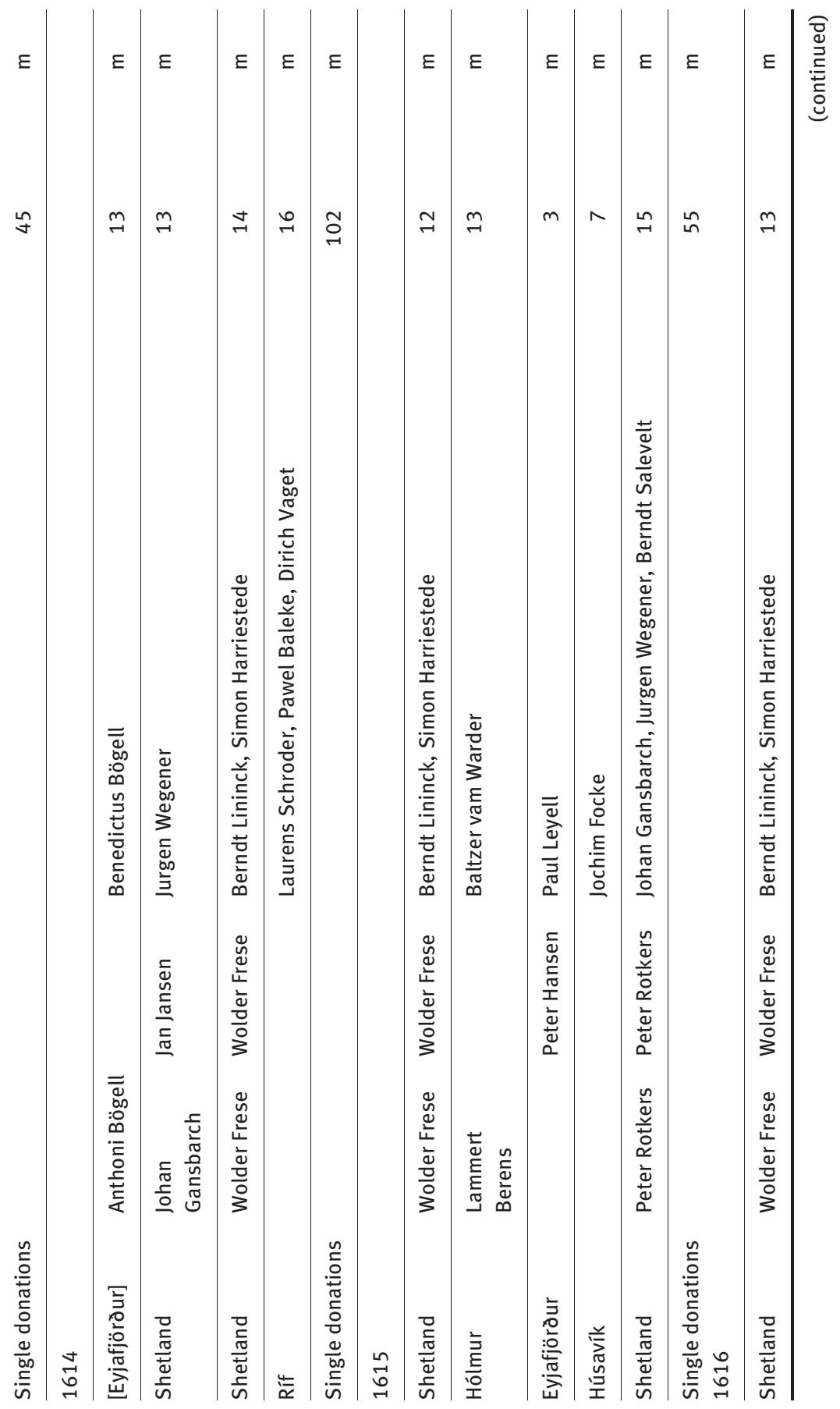




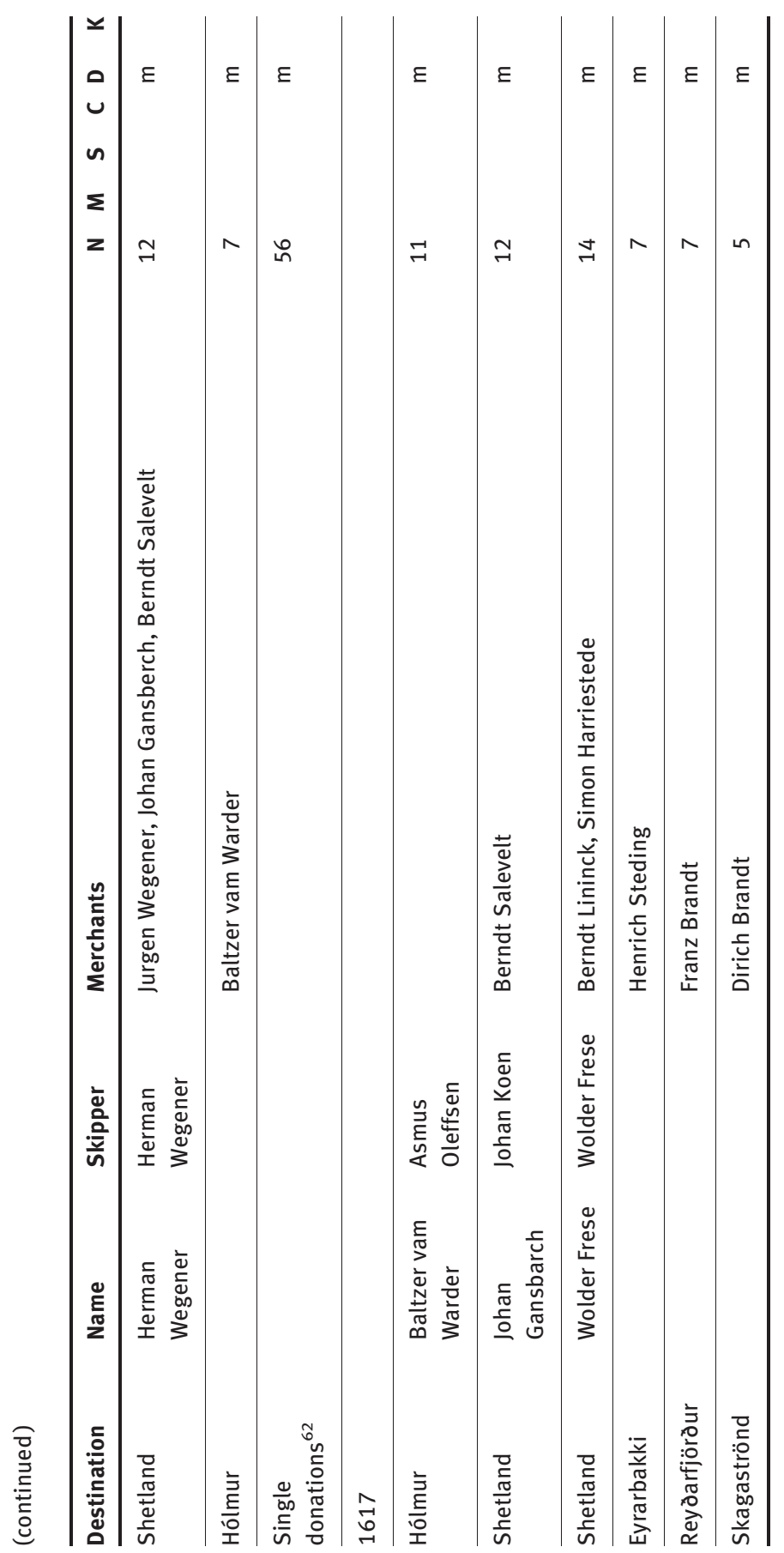

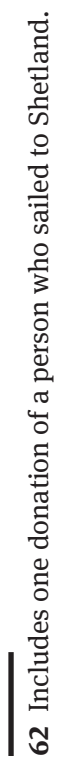




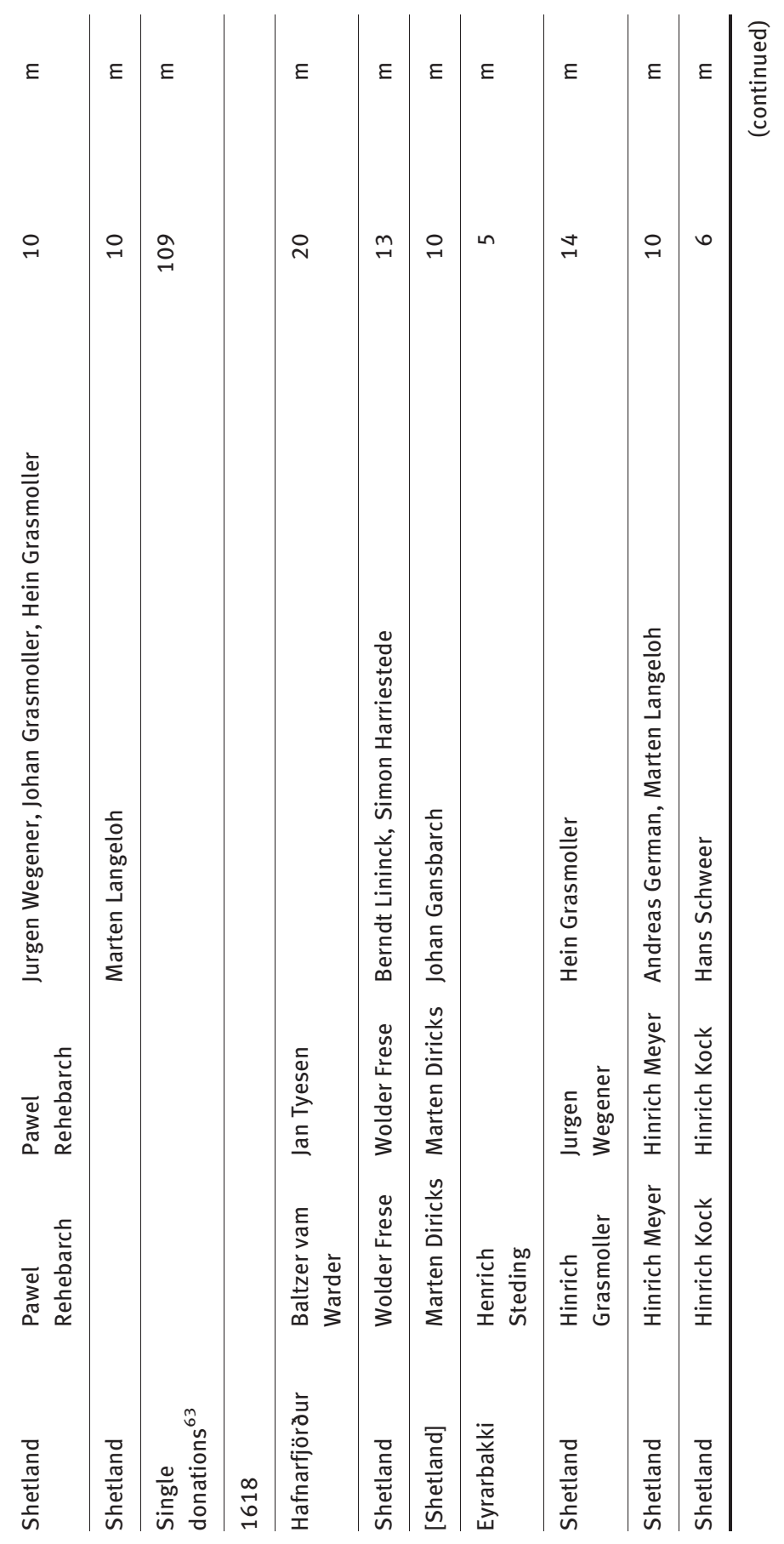

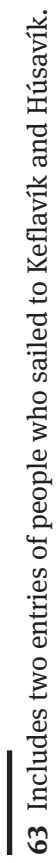




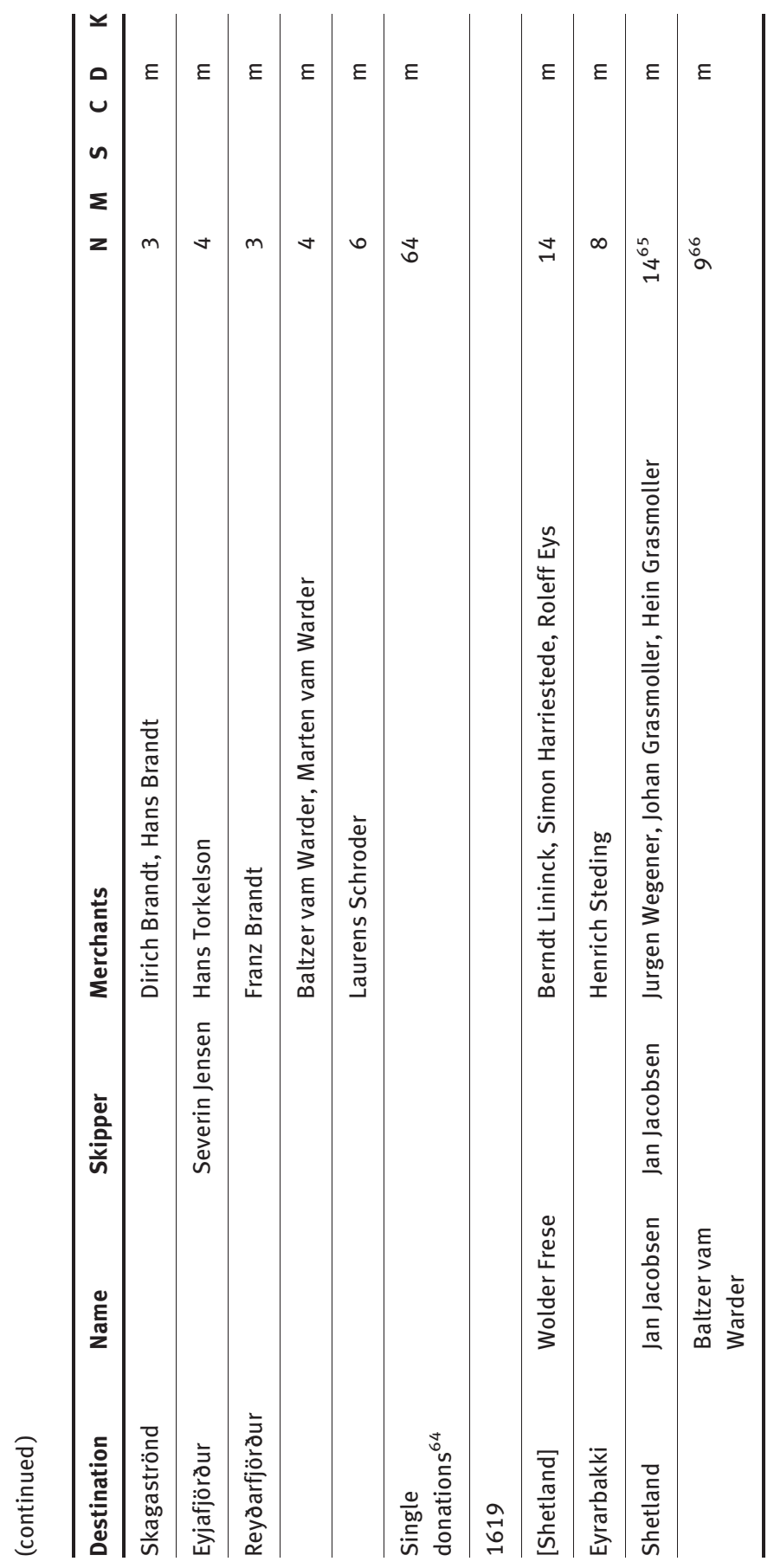

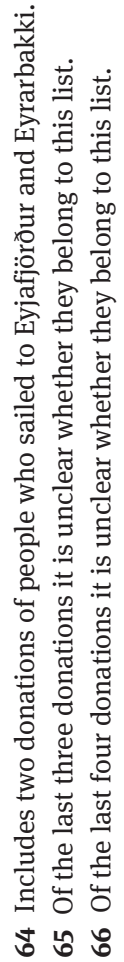




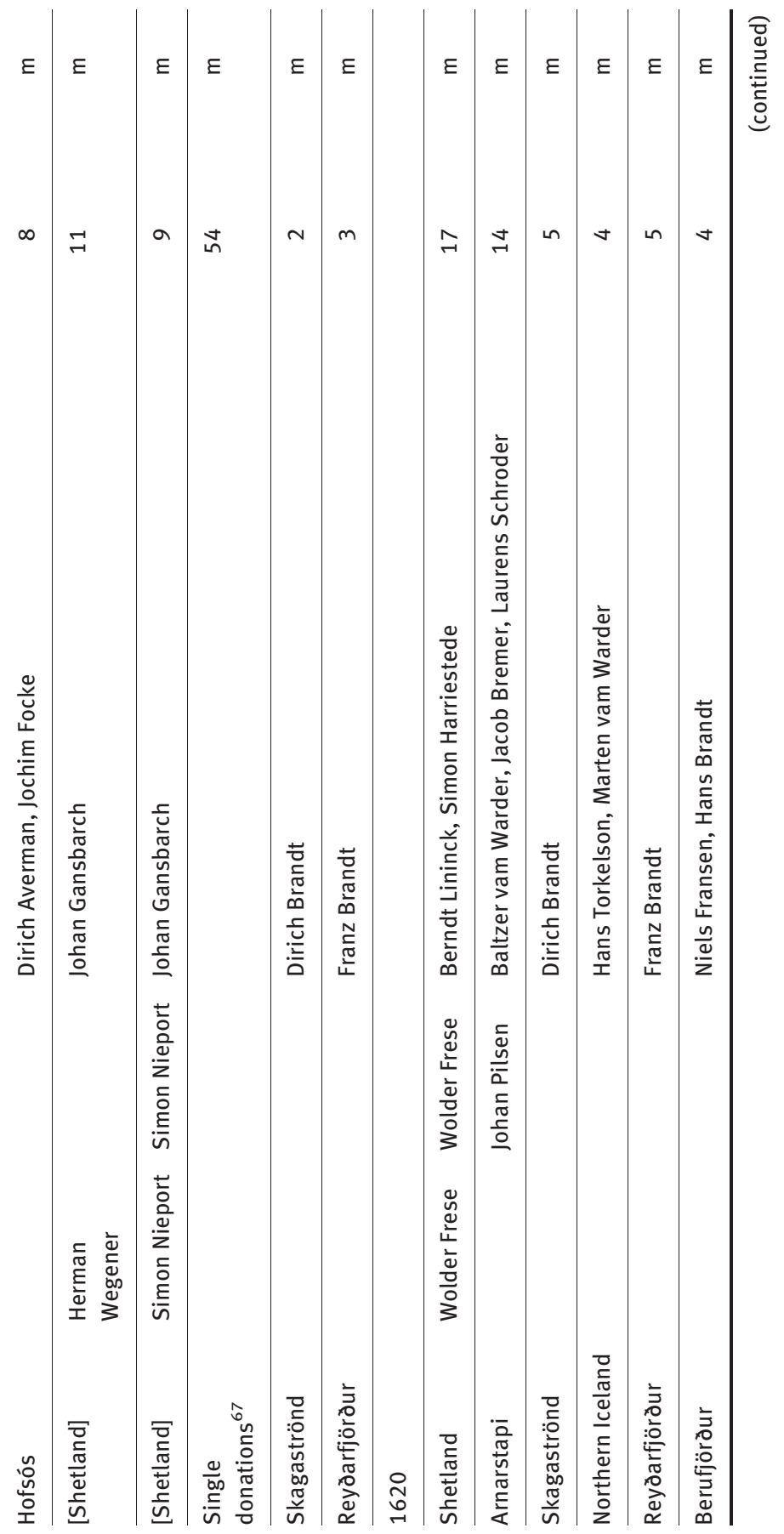

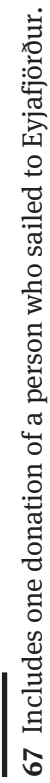




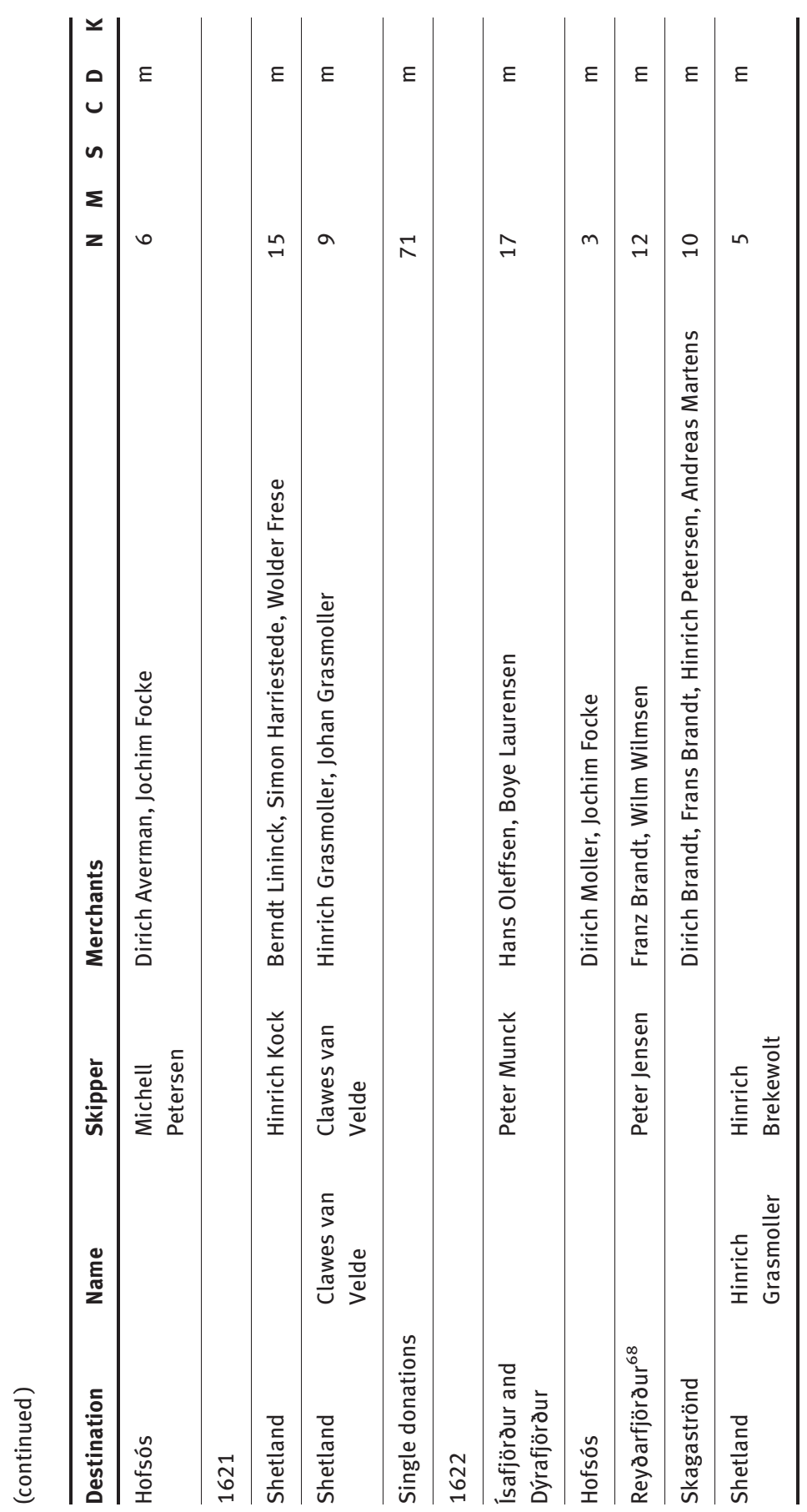

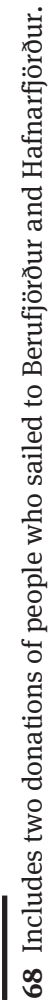




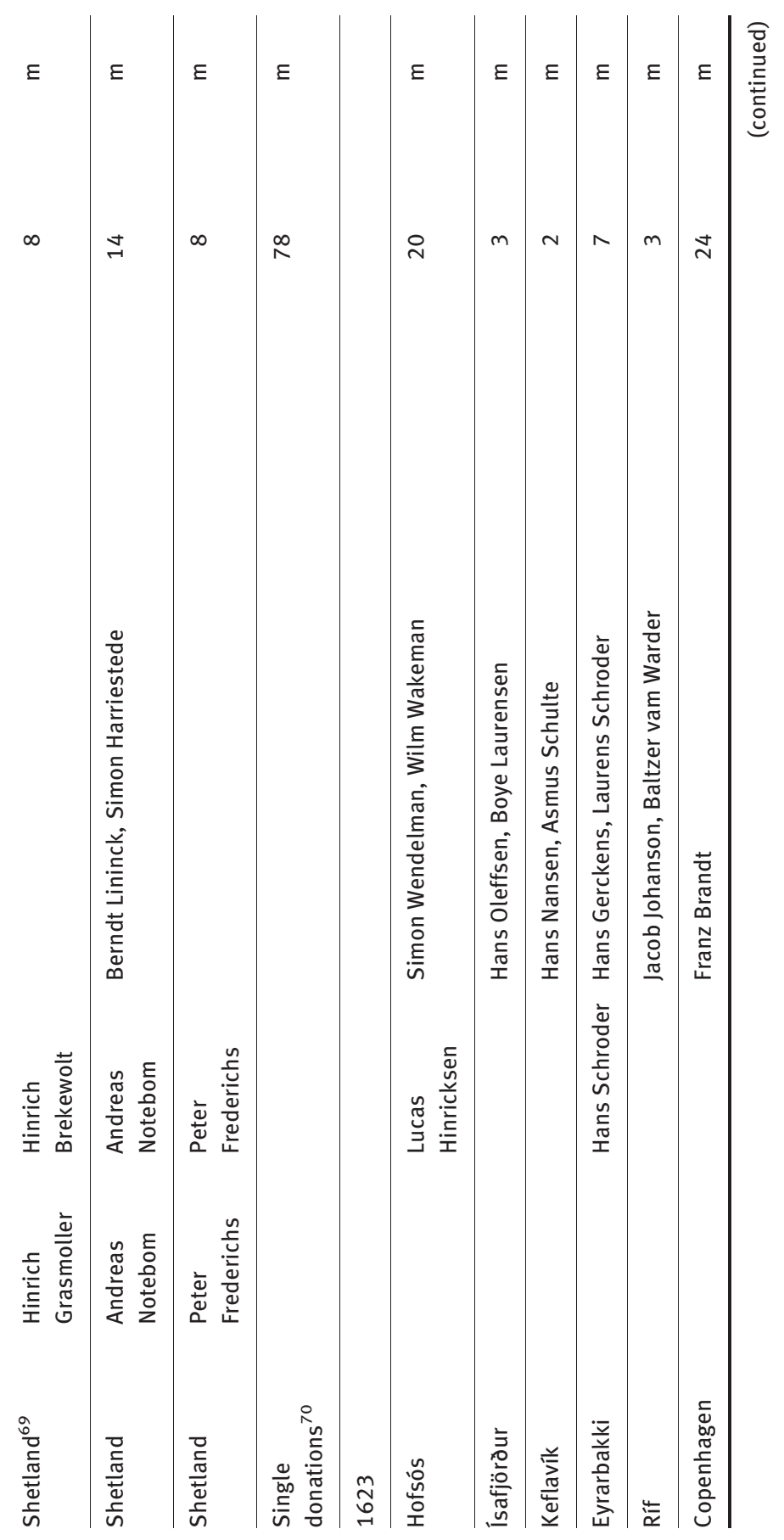

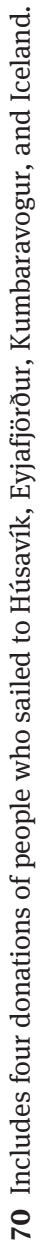




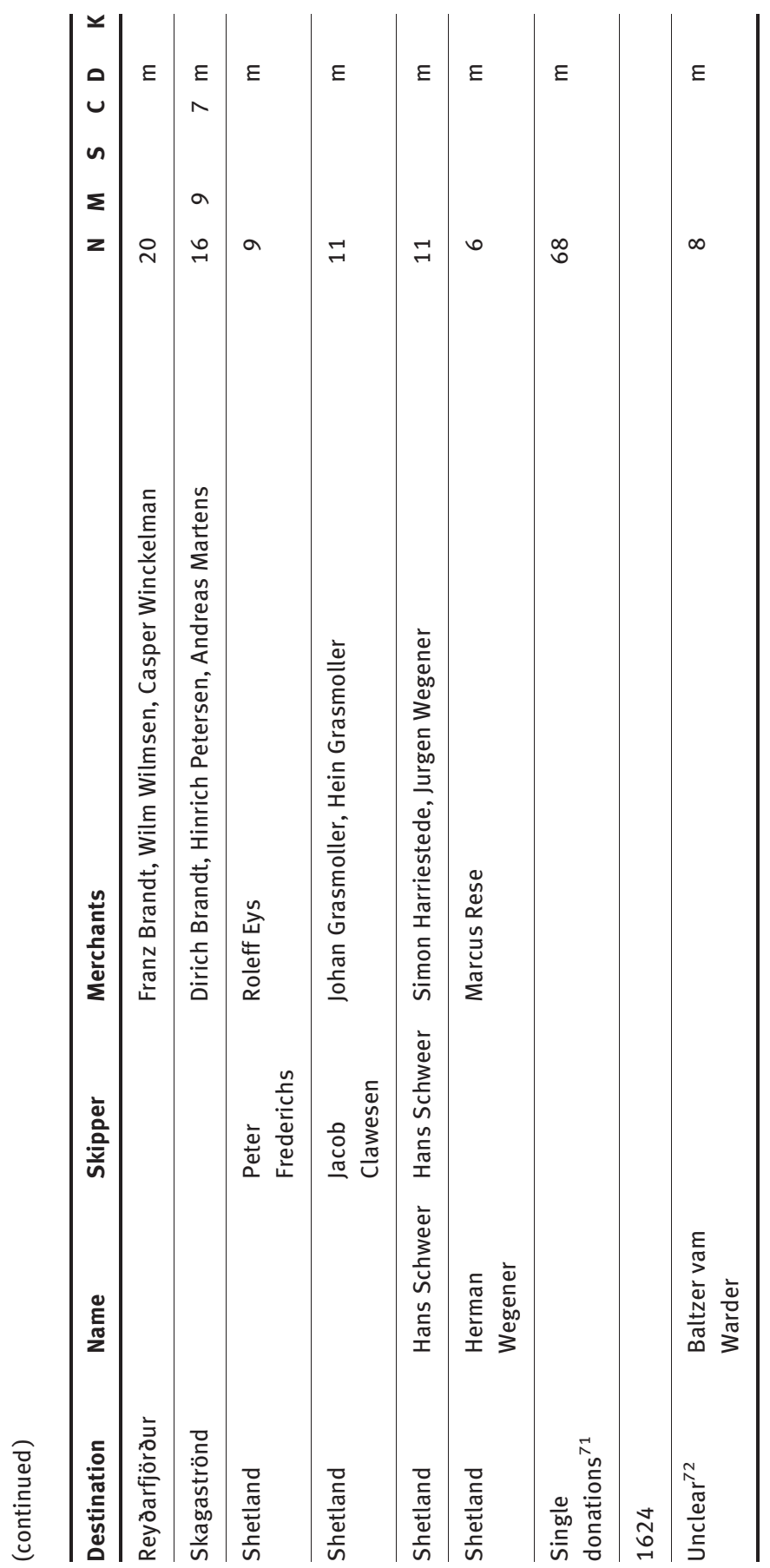

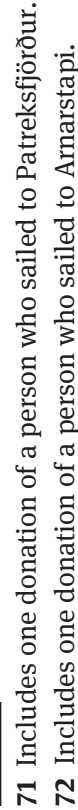




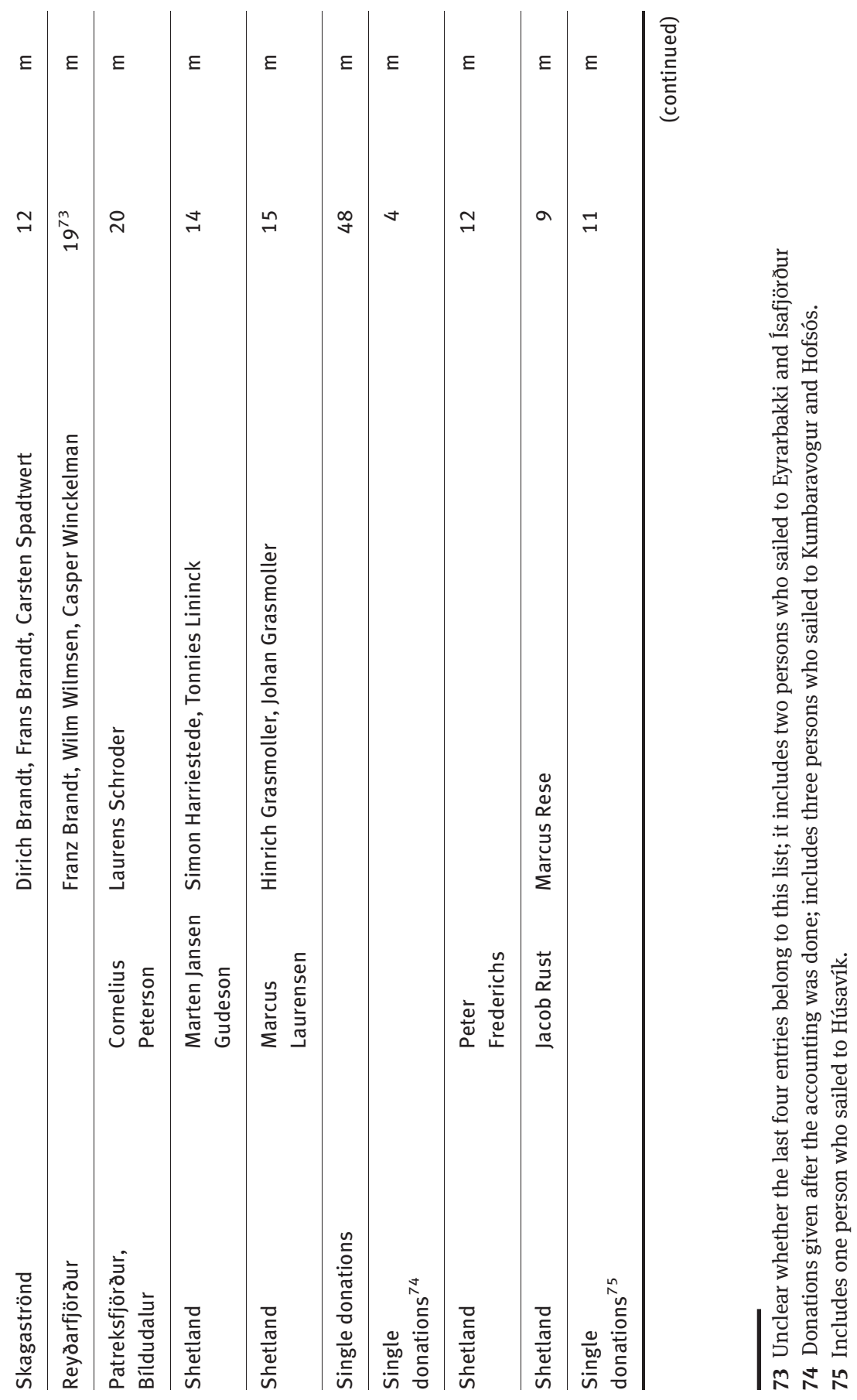




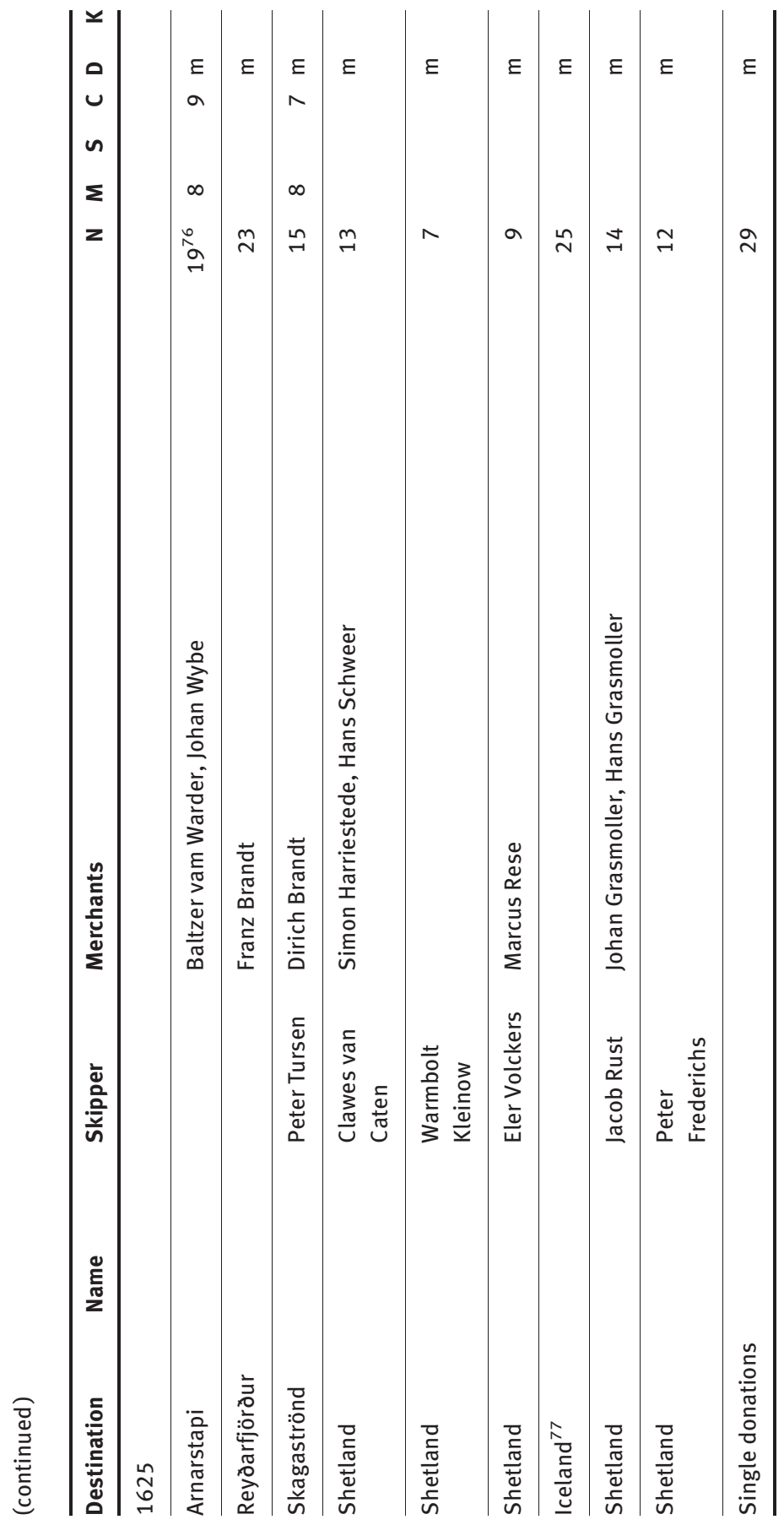

च 


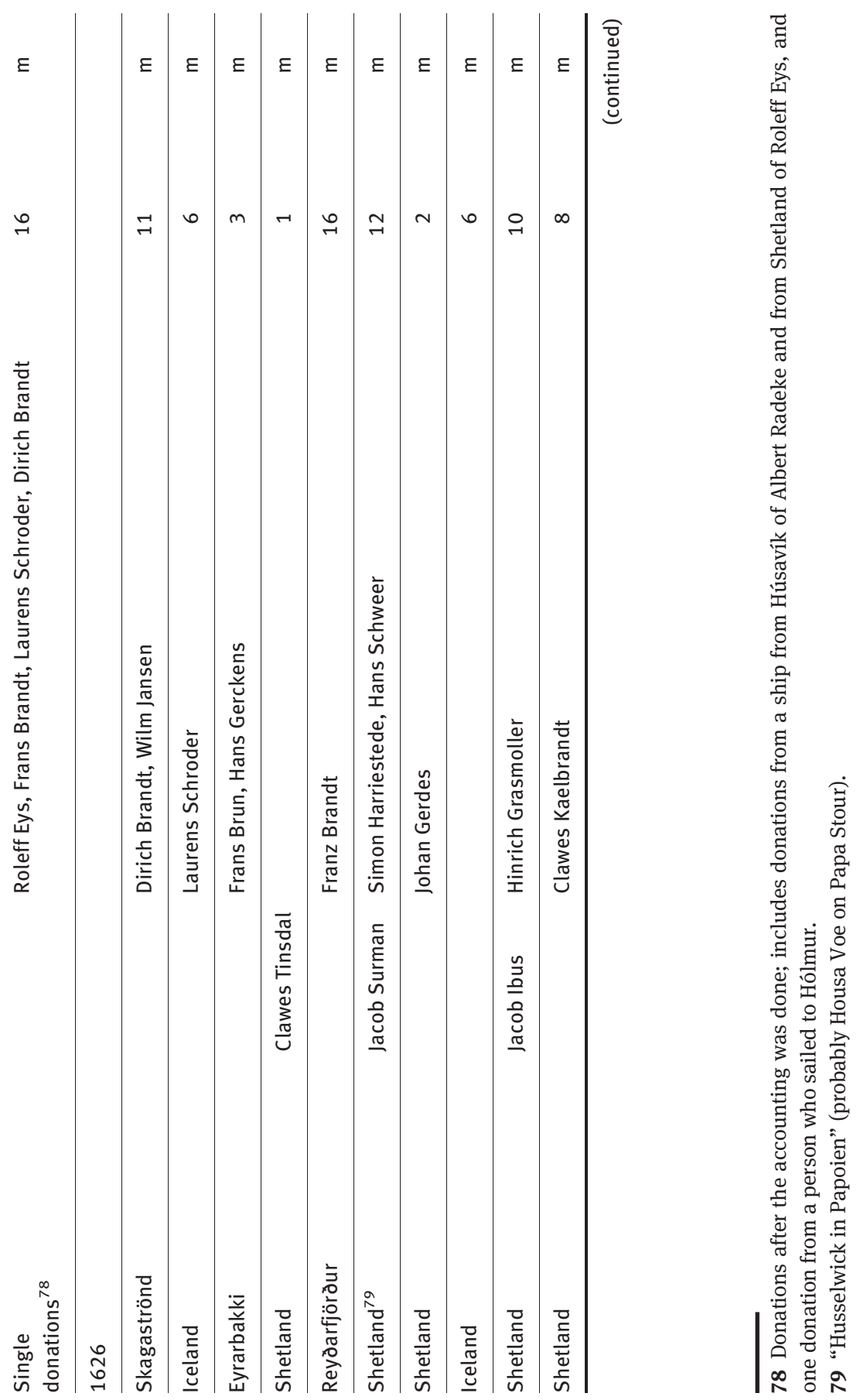




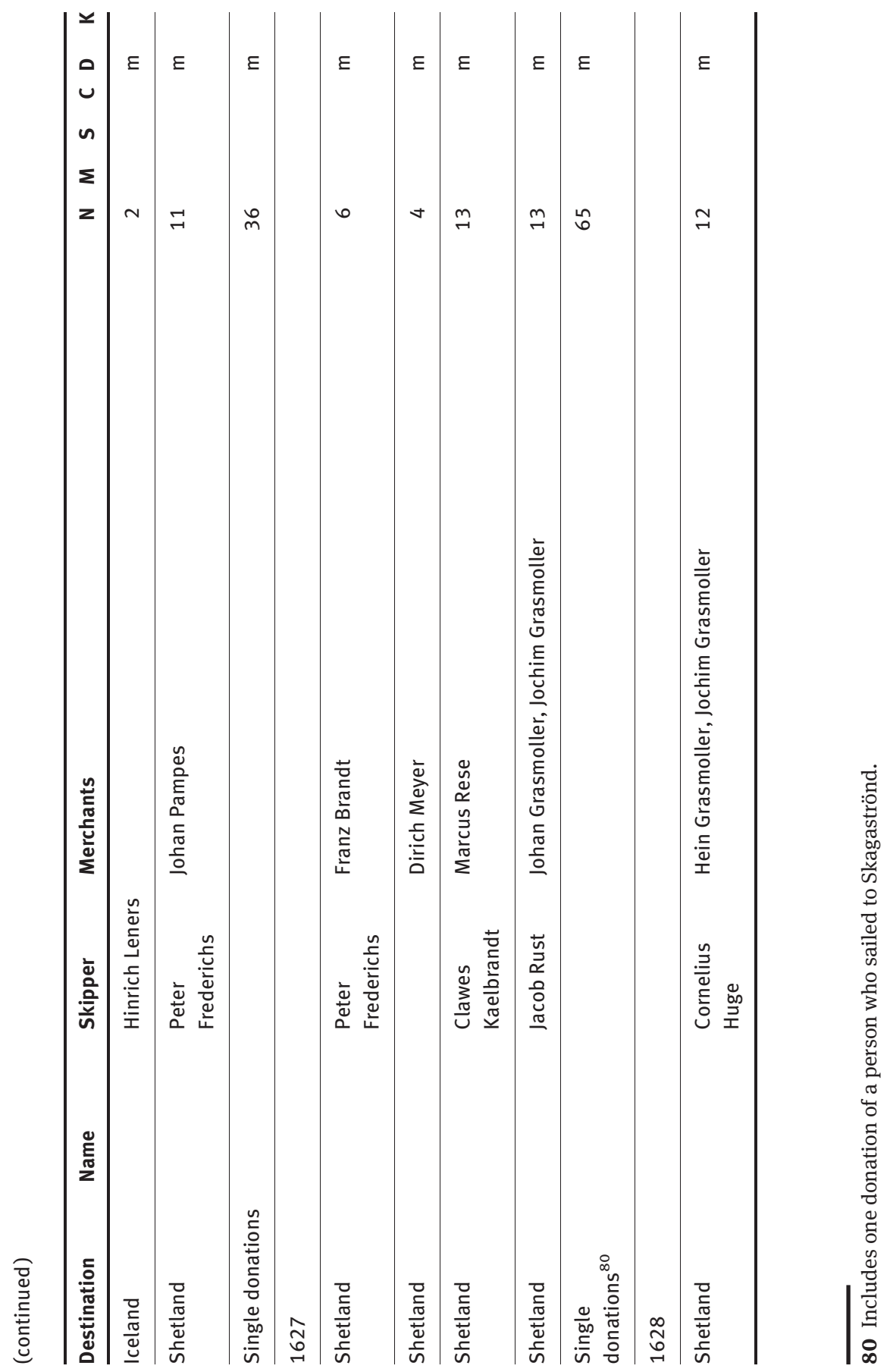




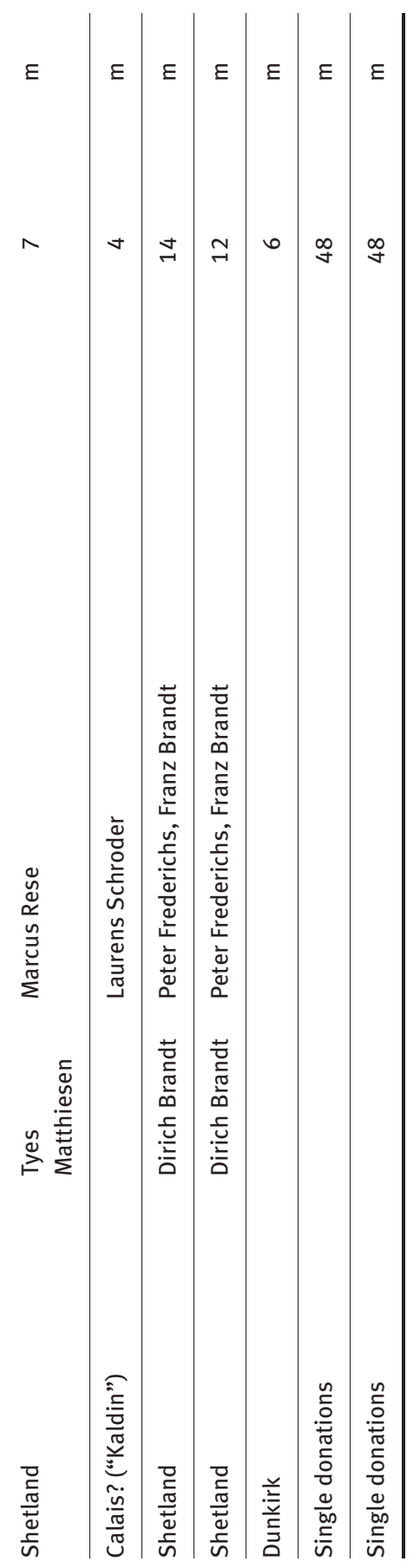




\section{Vol. 2: 1629-1657}

The second volume of the donation register is less clearly structured. Therefore, the following table contains only the lists which clearly refer to actual ships, and the total of other donations per year. All donations are in money.

\begin{tabular}{|c|c|c|c|c|}
\hline Destination & Name & Skipper & Merchant & $\mathbf{N}$ \\
\hline 1629 & & & & 58 \\
\hline Shetland & & Hinrich Suer & Hinrich Ortman & 8 \\
\hline Shetland & & Dirich Brandt & Franz Brandt & 10 \\
\hline Shetland & & $?$ & Hein Grasmoller & 10 \\
\hline 1630 & & & & 48 \\
\hline Shetland & Grasmoller & [Jochim Grasmoller] & Hein Grasmoller & 11 \\
\hline Shetland & Dirich Brandt & & Franz Brandt & 13 \\
\hline Shetland & & Peter Frederichs & & 4 \\
\hline 1631 & & & & 30 \\
\hline Shetland & Grasmoller & Andreas Bohne & & 8 \\
\hline Shetland & Brand & Dirich Brandt & Franz Brandt & 13 \\
\hline 1632 & & & & 73 \\
\hline Shetland & & Dirich Brandt & Franz Brandt & 9 \\
\hline 1633 & & & & 59 \\
\hline [Shetland] & Grasmoller & Andreas Bohne & & 9 \\
\hline Shetland & & Dirich Brandt & & 4 \\
\hline 1634 & & & & 53 \\
\hline Shetland & & Dirich Brandt & Franz Brandt & 13 \\
\hline Shetland & & Andreas Bohne & & 7 \\
\hline 1635 & & & & 44 \\
\hline Shetland & & Dirich Brandt & Franz Brandt & $23 ?^{81}$ \\
\hline
\end{tabular}

81 Unclear where the list ends. 
Shetland

Eheman Cornelis

Hans Basse?

Shetland Jurgen Olufsen

“Tarnö”

Dirich Brandt?

Shetland

Shetland

Hein Grasmoller

Porto

1640

Shetland

Shetland

Grasmoller

Eheman Cornelis

7

\begin{tabular}{lllr} 
& & Dirich Brandt & 6 \\
\hline Shetland & Albert Wipperman & Albert Wipperman & 8 \\
\hline Shetland & Ratgen, Westerman & & 5 \\
\hline
\end{tabular}

Shetland $^{82}$

[Shetland] $^{83}$

Pawel Holste

6

1641

Shetland

Dirich Brandt

Shetland

Eheman Cornelis

Hein Grasmoller

1642

Shetland

Shetland

Albert Wippermann

Otto Make

8

Eheman Cornelis?

1643

\section{Shetland}

Shetland

Albert Wipperman

Dirich Brandt

82 "uth de Pinck".

83 "uth de Schmack". 
(continued)

\begin{tabular}{|c|c|c|c|c|}
\hline Destination & Name & Skipper & Merchant & $\mathbf{N}$ \\
\hline 1644 & & & & 58 \\
\hline Shetland & & Dirich Brandt & & 7 \\
\hline
\end{tabular}

From 1645 onwards, only single donations are listed (1645: 66; 1646: 11; 1647: 49; 1648: 42; 1649: 47; 1650: 30; 1651: 46; 1652: 36; 1653: 33; 1654: 23; 1655: no entries; 1656: 3). 